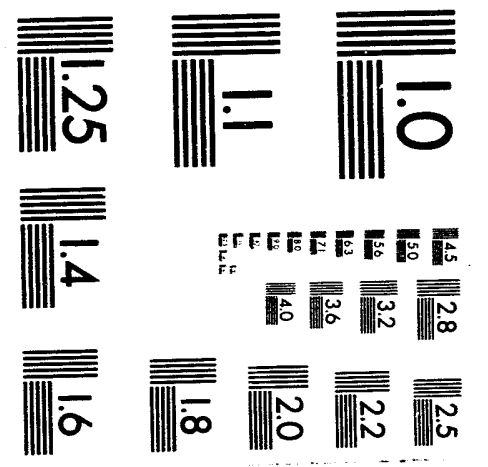



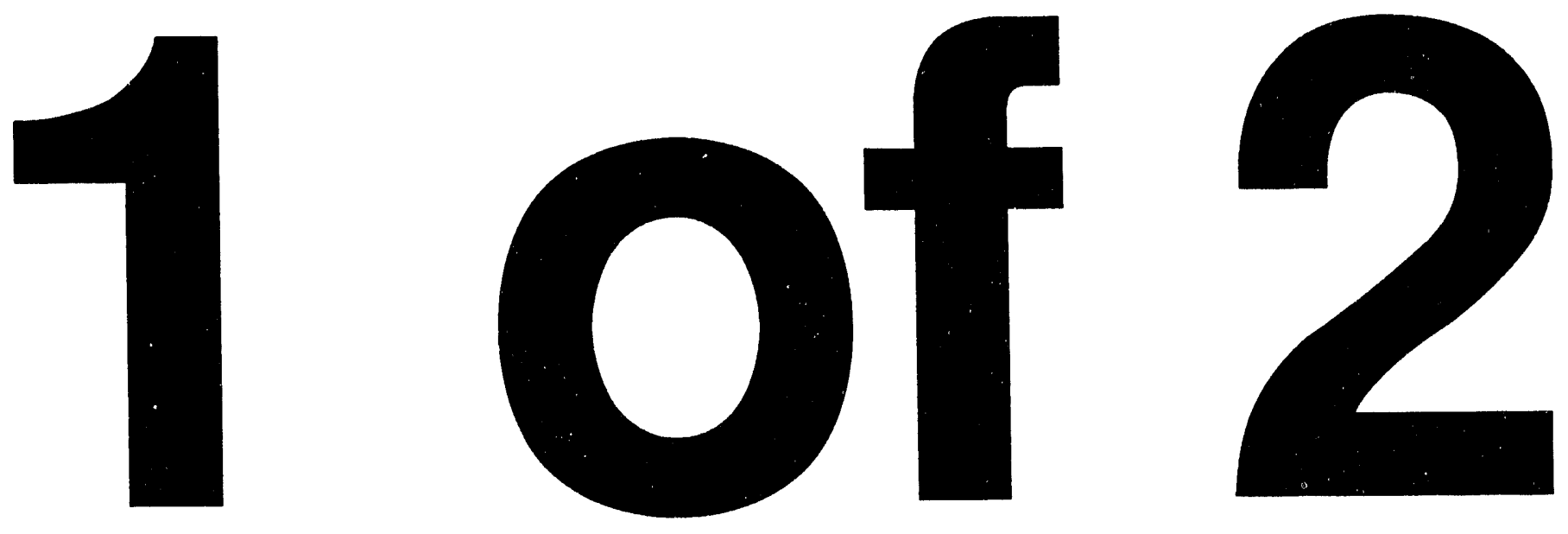


\section{OAK RIDGE NATIONAL LABORATORY}

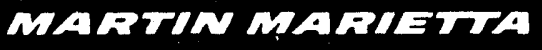

\section{MCNP Analysis of the FOEHN Critical Experiment}

October 1993

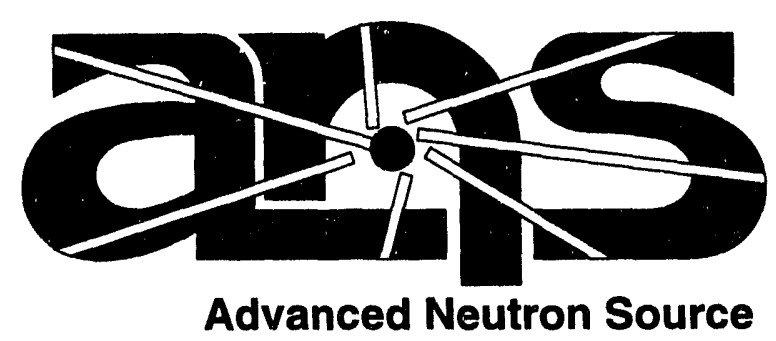

MANAGED BY

MARTIN MARIETTA ENERGY SYSTEMS, INC.

FOR THE UNITEO STATES

DEPARTMENT OF ENERGY 
This report has been reproduced directly from the best available copy.

Available to DOE and DOE contractors from the Office of Scientific and Technical Information, P.O. Box 62, Oak Ridge, TN 37831; prices availabie from (615) 576-8401, FTS 626-8401.

Available to the public from the National Technical Information Service, U.S. Department of Commerce, 5285 Port Royal Rd., Springfield, VA 22161.

This report was prepared as an account of work sponsored by an agency of the United States Government. Neither the United States Government nor any agency thereof, nor any of their employees, makes any warranty, express or implied, or assumes any legal liability or responsibility for the accuracy, completeness, or usefulness of any information, apparatus, product, or process disclosed, or represents that its use would not infringe privately owned rights. Reference herein to any specific commercial product, process, or service by trade name, trademark, manufacturer, or otherwise, does not necessarily constitute or imply its endorsement, recommendation, or favoring by the United States Government or any agency thereof. The views and opinions of authors expressed herein do not necessarily state or reflect those of the United States Government or any agency thereof. 


\title{
MCNP ANALYSIS OF THE FOEHN CRITICAL EXPERIMENT
}

\author{
A. M. Ougouag \\ C. A. Wemple \\ G. A. Rubio \\ J. M. Ryskamp
}

Idaho National Engineering Laboratory

EG\&G IDAHO, Inc., P.O. Box 1625

Idaho Falls, Idaho 83415-3885

October 1993

Prepared by

OAK RIDGE NATIONAL LABORATORY

Oak Ridge, Tennessee 37831-6285

managed by

MARTIN MARIETTA ENERGY SYSTEMS, INC.

for the

U.S. DEPARTMENT OF ENERGY under contract DE-AC05-84OR21400 


\section{CONTENTS}

LIST OF FIGURES $\ldots \ldots \ldots \ldots \ldots \ldots \ldots \ldots \ldots \ldots \ldots \ldots \ldots \ldots \ldots \ldots \ldots$

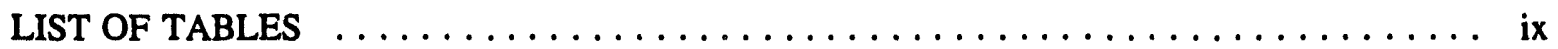

ACKNOWLEDGEMENTS $\ldots \ldots \ldots \ldots \ldots \ldots \ldots \ldots \ldots \ldots \ldots \ldots \ldots \ldots$

EXECUTTVE SUMMARY $\ldots \ldots \ldots \ldots \ldots \ldots \ldots \ldots \ldots \ldots \ldots \ldots \ldots \ldots$

ABSTRACT $\ldots \ldots \ldots \ldots \ldots \ldots \ldots \ldots \ldots \ldots \ldots \ldots \ldots \ldots \ldots \ldots \ldots \ldots \ldots \ldots \ldots \ldots$

1. INTRODUCTION $\ldots \ldots \ldots \ldots \ldots \ldots \ldots \ldots \ldots \ldots \ldots \ldots \ldots \ldots \ldots$

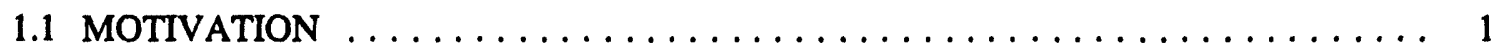

1.2 SCOPE AND LIMITATIONS OF THE STUDY $\ldots \ldots \ldots \ldots \ldots \ldots \ldots \ldots$

1.3 ORGANIZATION OF THE REPORT $\ldots \ldots \ldots \ldots \ldots \ldots \ldots \ldots \ldots \ldots \ldots$

2. THE FOEHN EXPERIMENT $\ldots \ldots \ldots \ldots \ldots \ldots \ldots \ldots \ldots \ldots \ldots \ldots \ldots$

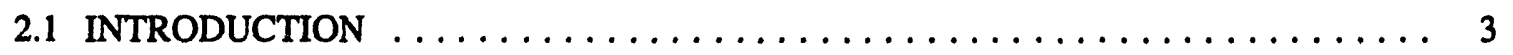

2.2 DESCRIPTION OF THE FOEHN EXPERIMENT $\ldots \ldots \ldots \ldots \ldots \ldots \ldots \ldots \ldots$

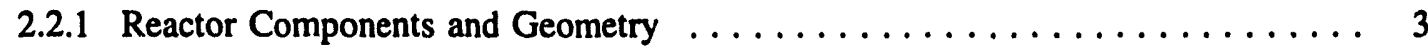

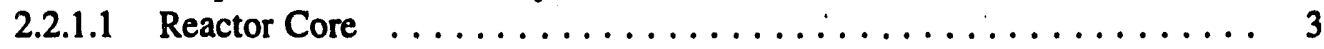

2.2.1.2 Reflector and Internal Stack Geometry ............... 4

2.2.1.3 Control Elements and Safety System ................. 4

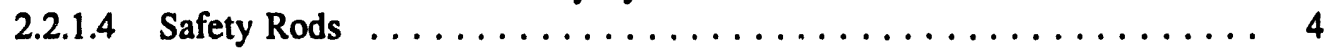

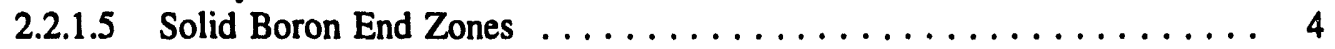

2.2.2 Experimental Facilities $\ldots \ldots \ldots \ldots \ldots \ldots \ldots \ldots \ldots \ldots \ldots \ldots \ldots$

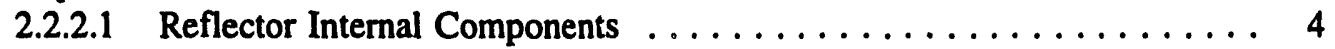

2.2.2.2 Cold Source Facility Mock-up $\ldots \ldots \ldots \ldots \ldots \ldots \ldots \ldots \ldots \ldots$

2.2.2.3 Hot Source Facility Mock-up $\ldots \ldots \ldots \ldots \ldots \ldots \ldots \ldots \ldots \ldots \ldots \ldots \ldots \ldots$

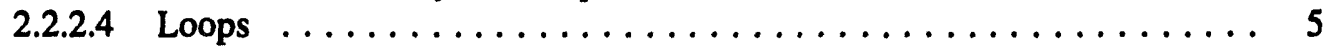

2.2 .3 Materials $\ldots \ldots \ldots \ldots \ldots \ldots \ldots \ldots \ldots \ldots \ldots \ldots \ldots \ldots \ldots \ldots$

2.3 RESULTS OF THE FOEHN EXPERIMENT $\ldots \ldots \ldots \ldots \ldots \ldots \ldots \ldots \ldots$

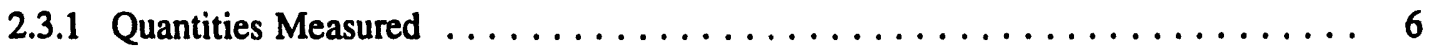

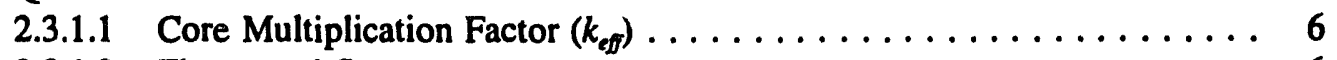

2.3.1.2 Fluxes and Spectrum ...................... 6

2.3.1.3 Flux Efficiency (Rendement) $\ldots \ldots \ldots \ldots \ldots \ldots \ldots \ldots \ldots \ldots$

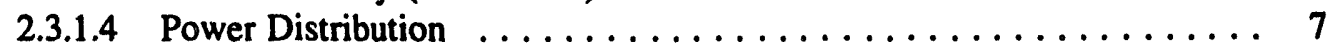

2.3.1.5 Gamma Heating in the Reflector ............... 7

2.3.2 Normalization of Tabulated Results $\ldots \ldots \ldots \ldots \ldots \ldots \ldots \ldots \ldots$

2.3.2.1 FOEHN Experiment Normalization Method ............. 7 
2.3.2.2 Single Table Normalization $\ldots \ldots \ldots \ldots \ldots \ldots \ldots \ldots$

2.3.2.3 Multiple Tables with Missing Data $\ldots \ldots \ldots \ldots \ldots \ldots$

2.3.2.4 Normalization of Fluxes . . . . . . . . . . . . . . . . 9

2.4 ERROR ANALYSIS OF FOEHN RESULTS $\ldots \ldots \ldots \ldots \ldots \ldots \ldots \ldots \ldots \ldots$

2.4.1 Error Reporting in the FOEHN Experiment $\ldots \ldots \ldots \ldots \ldots \ldots \ldots \ldots \ldots$

2.4 .2 Sources of Errors $\ldots \ldots \ldots \ldots \ldots \ldots \ldots \ldots \ldots \ldots \ldots \ldots$

2.4.2.1 Geometric Tolerances $\ldots \ldots \ldots \ldots \ldots \ldots \ldots \ldots \ldots \ldots \ldots \ldots$

2.4.2.2 Materials Data ....................... 11

2.4.2.3 Counting Geometry, Statistics, and Times $\ldots \ldots \ldots \ldots \ldots \ldots 11$

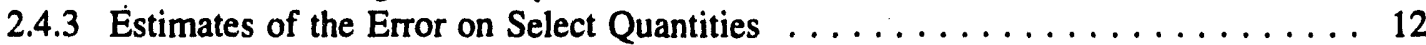

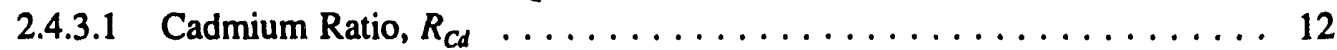

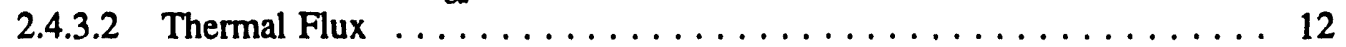

2.4.3.3 Powers ......................... 13

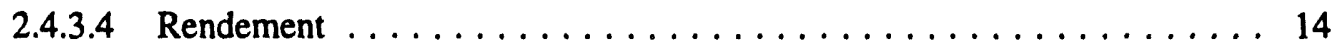

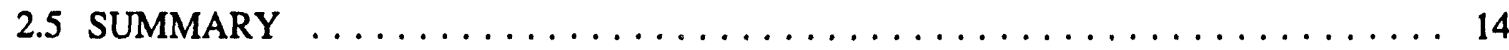

3. MCNP MODEL OF THE FOEHN EXPERIMENT $\ldots \ldots \ldots \ldots \ldots \ldots \ldots \ldots \ldots$

3.1 INTRODUCTION $\ldots \ldots \ldots \ldots \ldots \ldots \ldots \ldots \ldots \ldots \ldots \ldots \ldots \ldots \ldots \ldots$

3.2 MAJOR APPROXIMATIONS AND ASSUMPTIONS $\ldots \ldots \ldots \ldots \ldots \ldots \ldots \ldots$

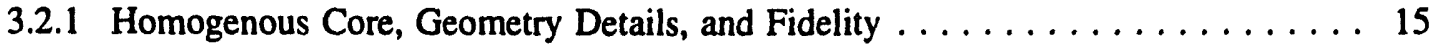

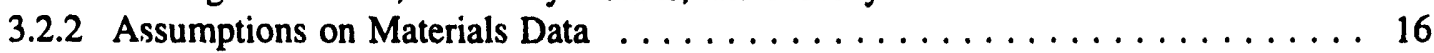

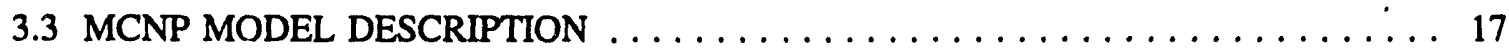

3.3.1 The Core and Surrounding Structures $\ldots \ldots \ldots \ldots \ldots \ldots \ldots \ldots \ldots \ldots$

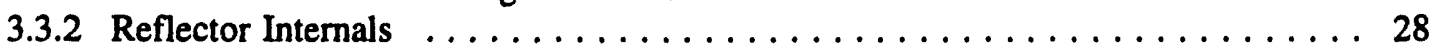

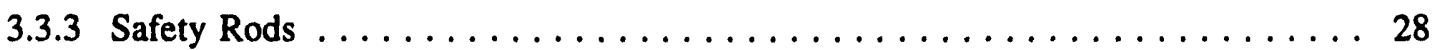

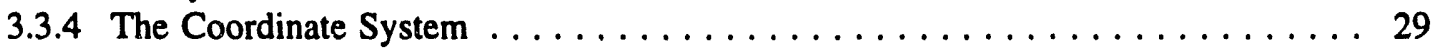

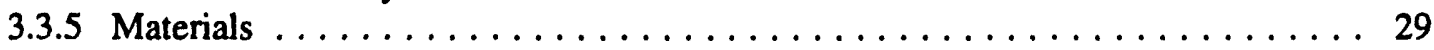

3.4 MCNP TALLIES AND COMPUTATION OF $k_{\text {eff }}$ AND RENDEMENT . . . . . . 29

3.4 .1 Fluxes . . . . . . . . . . . . . . . . . . . . . . . . . . . . 29

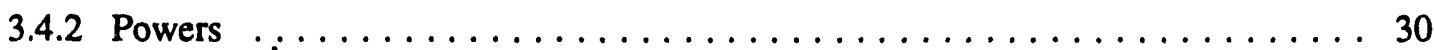

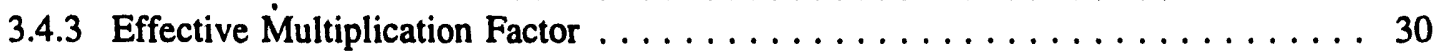

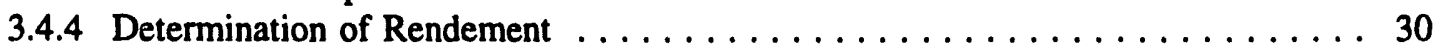

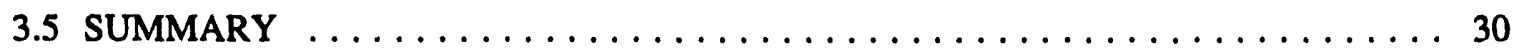

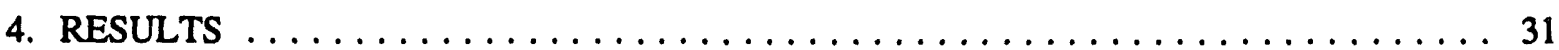

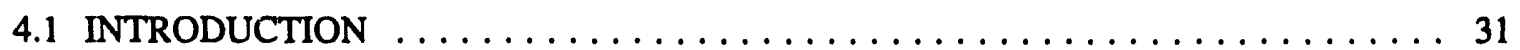

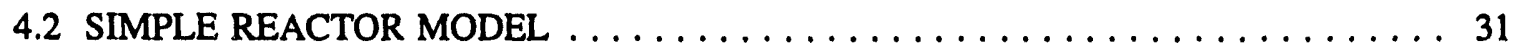

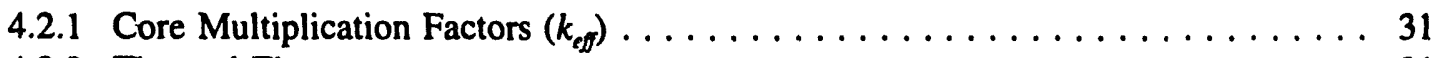

4.2 .2 Thermal Flux $\ldots \ldots \ldots \ldots \ldots \ldots \ldots \ldots \ldots \ldots \ldots \ldots \ldots \ldots$ 


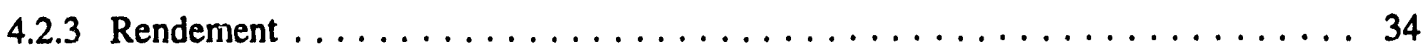

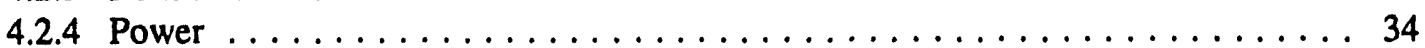

4.3 INTERMEDIATE COMPLEXITY REACTOR MODEL $\ldots \ldots \ldots \ldots \ldots \ldots \ldots \ldots 1$

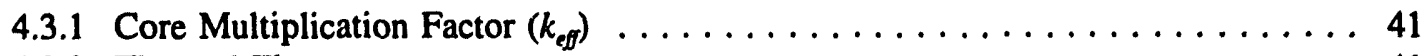

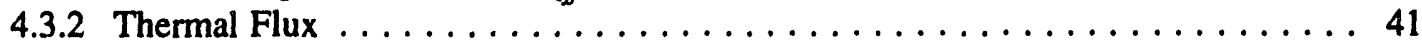

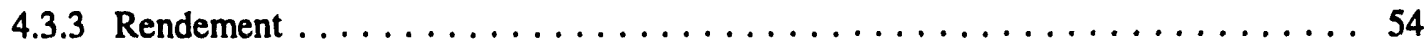

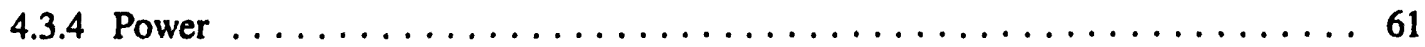

4.4 FULL COMPLEXITY REACTOR MODEL $\ldots \ldots \ldots \ldots \ldots \ldots \ldots \ldots \ldots \ldots \ldots$

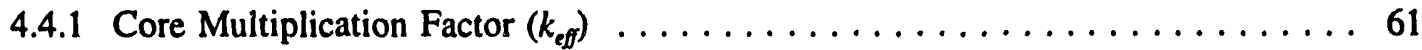

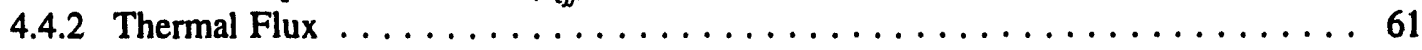

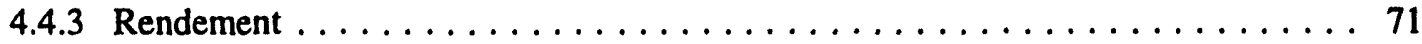

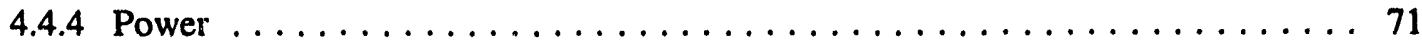

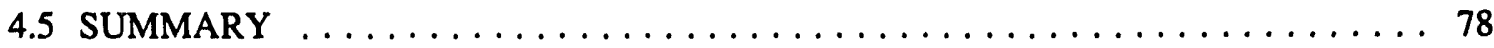

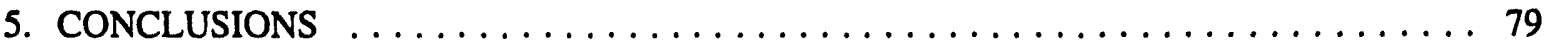

6. REFERENCES $\ldots \ldots \ldots \ldots \ldots \ldots \ldots \ldots \ldots \ldots \ldots \ldots \ldots \ldots \ldots \ldots \ldots$

Appendix A. MCNP MODEL INPUT FILE $\ldots \ldots \ldots \ldots \ldots \ldots \ldots \ldots \ldots \ldots \ldots \ldots$ 


\section{LIST OF FIGURES}

ES-1 Computed vs measured axial power distribution at three radial positions of the FOEHN critical experiment $\ldots \ldots \ldots \ldots \ldots \ldots \ldots \ldots \ldots \ldots \ldots \ldots$

3.1a SABRINA printout of the current ANS reactor design MCNP model $\ldots \ldots \ldots \ldots \ldots 18$

3.1b SABRINA printout of the FOEHN experiment MCNP model (front view) . . . . . . 19

3.2 SABRINA printout of the FOEHN experiment MCNP model (left view) . . . . . . 20

3.3 SABRINA printout of the FOEHN experiment MCNP model (right view) $\ldots \ldots \ldots 21$

3.4 SABRINA printout of the FOEHN experiment MCNP model (top view) $\ldots \ldots \ldots \ldots 22$

3.5 SABRINA printout of the FOEHN experiment MCNP model (lower view) . . . . . . 23

3.6 SABRINA printout of the FOEHN expenrnent MCNP model (back view) . . . . . . 24

3.7 Axial view of the FOEHN core and its surrounding cask $\ldots \ldots \ldots \ldots \ldots \ldots \ldots$

3.7b Radial view of the FOEHN core and its surrounding cask . . . . . . . . . . . 26

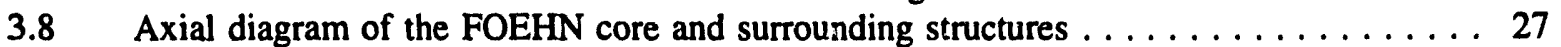

4.1 MCNP prediction of $k_{\text {eff }}$ for a set of critical states of the simple FOEHN reactor configuration $\ldots \ldots \ldots \ldots \ldots \ldots \ldots \ldots \ldots \ldots \ldots \ldots \ldots \ldots$

4.2 Control rod position perturbation effect on $k_{\text {eff }}$ in the simple FOEHN

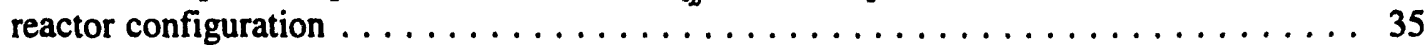

4.3 Comparison of experimental and computed axial flux shapes at $r=235 \mathrm{~mm}$ in the simple FOLHN configuration $\ldots \ldots \ldots \ldots \ldots \ldots \ldots \ldots \ldots \ldots$

4.4 Comparison of experimental and computed axial flux shapes at $r=355 \mathrm{~mm}$ in the simple FOEHN configuration . . . . . . . . . . . . . . . . . 39

4.5 Comparison of experimental and computed axial flux shapes at $r=835 \mathrm{~mm}$ in the simple FOEHN configuration $\ldots \ldots \ldots \ldots \ldots \ldots \ldots \ldots \ldots \ldots \ldots \ldots$

4.6 Comparison of normalized experimental and computed axial power distribution in the simple FOEHN configuration at $r=143.5 \mathrm{~mm} \ldots \ldots \ldots \ldots \ldots \ldots . \ldots 44$

4.7 Comparison of normalized experimental and computed axial power distribution in the simple FOEHN configuration at $r=167.5 \mathrm{~mm} \ldots \ldots \ldots \ldots \ldots \ldots . \ldots 45$

4.8 Comparison of normalized experimental and computed axial power distribution in the simple FOEHN configuration at $r=193.95 \mathrm{~mm} \ldots \ldots \ldots \ldots \ldots \ldots$

4.9 Comparison of normalized experimental and computed axial power distribution in the simple FOEHN configuration at $H=2.5 \mathrm{~mm} \ldots \ldots \ldots \ldots \ldots \ldots \ldots$

4.10 Comparison of normalized experimental and computed radial power distribution in the simple FOEHN configuration at $H=50 \mathrm{~mm} \ldots \ldots \ldots \ldots \ldots \ldots \ldots$

4.11 Comparison of normalized experimental and computed radial power distribution in the simple FOEHN configuration at $H=175 \mathrm{~mm} \ldots \ldots \ldots \ldots \ldots \ldots . \ldots 49$

4.12 Comparison of normalized experimental and computed radial power distribution in the simple FOEHN configuration at $H=400 \mathrm{~mm} \ldots \ldots \ldots \ldots \ldots \ldots$

4.13 Comparison of normalized experimental and computed radial power distribution in the simple FOEHN configuration at $H=625 \mathrm{~mm} \ldots \ldots \ldots \ldots \ldots \ldots \ldots$

4.14 Comparison of normalized experimental and computed radial power distribution in the simple FOEHN configuration at $H=750 \mathrm{~mm} \ldots \ldots \ldots \ldots \ldots \ldots \ldots$

4.15 Comparison of normalized experimental and computed radial power distribution in the simple FOEHN configuration at $H=797.5 \mathrm{~mm} \ldots \ldots \ldots \ldots \ldots \ldots$ 
4.16 MCNP prediction of $k_{\text {eff }}$ for a set of critical states of the intermediate FOEHN reactor configuration $\ldots \ldots \ldots \ldots \ldots \ldots \ldots \ldots \ldots \ldots \ldots$

4.17 Comparison of experimental and computed axial flux shapes at $r=235 \mathrm{~mm}$ in the intermediate FOEHN configuration $\ldots \ldots \ldots \ldots \ldots \ldots \ldots \ldots$

4.18 Comparison of experimental and computed axial flux shapes at $r=355 \mathrm{~mm}$ in the intermediate FOEHN configuration $\ldots \ldots \ldots \ldots \ldots \ldots \ldots \ldots$

4.19 Comparison of experimental and computed axial flux shapes at $r=835 \mathrm{~mm}$

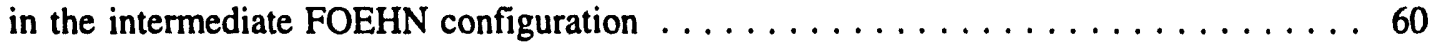

4.20 Comparison of normalized experimental and computed axial power distribution in the intermediate FOEHN configuration at $r=143.5 \mathrm{~mm} \ldots \ldots \ldots \ldots \ldots 6$

4.21 Comparison of normalized experimental and computed axial power distribution in the intermediate FOEHN configuration at $r=167.5 \mathrm{~mm} \ldots \ldots \ldots \ldots \ldots 6$

4.22 Comparison of normalized experimental and computed axial power distribution in the intermediate FOEHN configuration at $r=193.95 \mathrm{~mm} \ldots \ldots \ldots \ldots \ldots 7$

4.23 MCNP prediction of $k_{\text {eff }}$ for a set of critical states of the full-featured

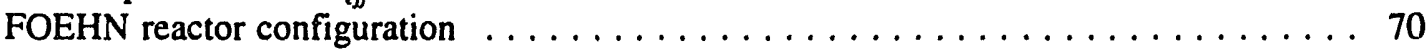

4.24 Comparison of normalized experimental and computed axial power distribution in the full-featured FOEHN configuration at $r=143.5 \mathrm{~mm} \ldots \ldots \ldots \ldots \ldots 74$

4.25 Comparison of normalized experimental and computed axial power distribution in the full-featured FOEHN configuration at $r=167.5 \mathrm{~mm} \ldots \ldots \ldots \ldots \ldots$

4.26 Comparison of normalized experimental and computed axial power distribution in the full-featured FOEHN configuration at $r=193.95 \mathrm{~mm} \ldots \ldots \ldots \ldots \ldots$ 


\section{LIST OF TABLES}

$2.1 \quad$ FOEHN experiment fuel plates characteristics $\ldots \ldots \ldots \ldots \ldots \ldots \ldots \ldots \ldots \ldots$

2.2 Experimental power production distribution in FOEHN $\ldots \ldots \ldots \ldots \ldots \ldots \ldots \ldots$

3.1 Composition of Zircaloy-4 used in the model $\ldots \ldots \ldots \ldots \ldots \ldots \ldots \ldots \ldots$

3.2 Composition of the AG3-NE aluminum alloy $\ldots \ldots \ldots \ldots \ldots \ldots \ldots \ldots$

4.1 MCNP computed core effective multiplication factors $\left(k_{\text {eff }}\right)$ for various critical states of the simple reactor configuration $\ldots \ldots \ldots \ldots \ldots \ldots \ldots \ldots \ldots$

4.2 Effect of control rod perturbations on the core effective multiplication factor for three critical states of the simple reactor configuration $\ldots \ldots \ldots \ldots \ldots \ldots 34$

4.3 Computed thermal fluxes for the simple reactor configuration $\ldots \ldots \ldots \ldots \ldots \ldots$

4.4 MCNP error estimate ( $2 \sigma$, absolute) for the thermal fluxes for the simple

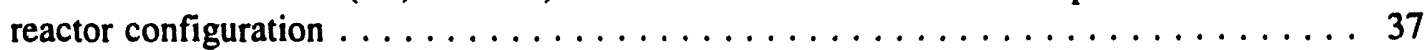

4.5 Normalized MCNP power production (F7:n tallies) for the simple reactor configuration . ............................ 42

4.6 MCNP error estimate ( $2 \sigma$, absolute) for the normalized MCNP power production for the simple reactor configuration $\ldots \ldots \ldots \ldots \ldots \ldots \ldots \ldots$

4.7 MCNP computed core effective multiplication factors $\left(k_{\text {eff }}\right)$ for various critical states of the intermediate complexity reactor configuration .......... 54

4.8 Computed thermal fluxes for the intermediate reactor configuration $\ldots \ldots \ldots \ldots \ldots 56$

4.9 MCNP error estimate ( $2 \sigma$, absolute) for the thermal fluxes for the intermediate reactor configuration $\ldots \ldots \ldots \ldots \ldots \ldots \ldots \ldots \ldots \ldots$

4.10 Normalized MCNP power production (F7:n tallies) for the intermediate

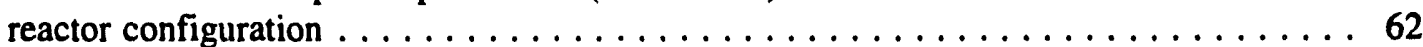

4.11 MCNP error estimate ( $2 \sigma$, absolute) for the normalized MCNP power production for the intermediate reactor configuration $\ldots \ldots \ldots \ldots \ldots \ldots \ldots$

4.12 Experimental power production distribution in the intermediate

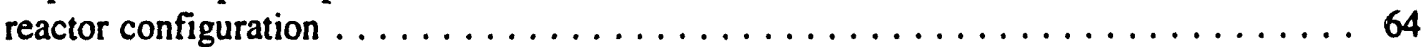

4.13 Points of nonmatching power production density in the intermediate

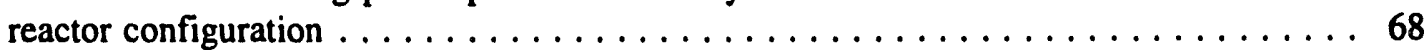

4.14 MCNP-computed core effective multiplication factors $\left(k_{e f f}\right)$ for various critical states of the full complexity reactor configuration . . . . . . . . . . . . . . 69

4.15 Normalized MCNP power production (F7:n tallies) for the full complexity

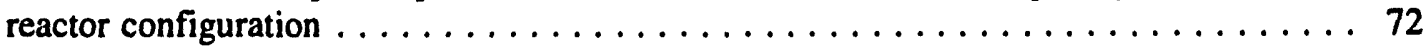

4.16 MCNP error estimate ( $2 \sigma$, absolute) for the normalized MCNP power production for the full complexity reactor configuration $\ldots \ldots \ldots \ldots \ldots \ldots$

4.17 Points of nonmatching power production density in the full complexity

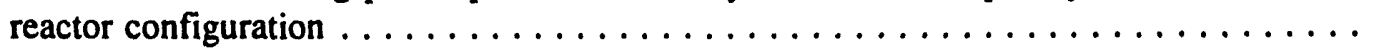




\section{ACKNOWLEDGEMENTS}

We would like to thank Oak Ridge National Laboratory personnel C. D. West, Advanced Neutron Source (ANS) project director, and D. L. Selby, ANS research and development manager, for encouraging this work and providing the necessary funding. We also thank D. L. Selby and

B. A. Worley for reviewing the draft report.

P. Ageron of the Institut Laue-Langevin in Grenoble, France, and K. Böning and A. Rohrmoser of the Technische Universität München, in Munich, Germany, provided J. M. Ryskamp with valuable insights that were not included in the original FOEHN report. In addition, Rohrmoser spent one week in Idaho assisting on the FOEHN model. We sincerely appreciate the help these scientists provided on this project. 


\section{EXECUTIVE SUMMARY}

In the research and development plan of the Advanced Neutron Source (ANS) reactor, the second phase planned for neutronics design methods validation is to compare computational model results and experimental results for a critical facility exhibiting similarities to the ANS reactor.' One such facility is the FOEHN experiment. ${ }^{2}$ In this report, an MCNP model of the FOEHN experiment is developed, and its results are compared to experimental data from the literature. The MCNP ${ }^{3}$ model reproduces measured quantities of interest with a high level of agreement.

FOEHN is a critical experiment performed in the course of the design of the Frarco-German High Flux Reactor [Institut Laue-Langevin (ILL)]. The experiment was conducted at CEN-Cadarache in the French EOLE reactor, which was modified for this purpose. The reactor core is a hollow cylinder made of $90 \%$ enriched uranium-aluminum (U-Al) alloy circular involute fuel plates. The plates have a thickness of $-1.27 \mathrm{~mm}$. The core is heavy water moderated and reflected. Other components in the FOEHN experiment include loops, beam tubes, and boron axial end plates. Many of these features are similar to the currently envisioned design of the ANS reactor. ${ }^{4}$ Design methods capable of properly modeling FOEHN would be well suited for the design and analysis of the ANS reactor.

The core effective multiplication factor $\left(k_{e f f}\right)$, the thermal flux in the reflector, and the core power distribution were measured in FOEHN. In addition, the rendement, a neutron efficiency defined as the ratio of the maximum thermal flux in the reflector to the total power, was evaluated. All of these quantities are compared to their MCNP-computed equivalents. The fluxes and the spectrum were measured using foil activation. They correspond to MCNP F4:n tallies. The power distribution was measured using fission probes of the same material as the reactor fuel plates, yielding a quantity that essentially mirrors the core fission power production shape. This is compared to MCNP F7:n tallies. The effective multiplication factors were measured via the stable period, the continuous run, and the neutron pulse damping methods. ${ }^{2}$ The MCNP KCODE option is used to estimate $k_{\text {eff }}$.

In the FOEHN report ${ }^{2}$ estimates of the errors associated with the measured quantities are given without detailed justification. In the present work, the error estimates are reassessed. Thermal flux measurement errors are believed to range from $3.3 \%$ to as much as $22.8 \%$ vs the $2 \%$ claimed in the FOEHN report. The power istribution measurement error is believed to be $4-8 \%$ vs the $1 \%$ claimed in the FOEHN report. A major omission in the FOEHN report is the nearly $4 \%$ uncertainty on the fission probe volume.

The MCNP model developed here represents the reactor with a very high level of geometric fidelity. Since the thickness of the fuel plates and intervening heavy water channels is very small in terms of neutron mean-free paths, the core is modeled as a homogenous region. This is verified, a posteriori, to be a good approximation. The reflector internals ${ }^{5}$ (loops, beam tubes, hot and cold sources) are modeled explicitly. The material compositions are defined in ref. 5 . The nuclear data are those included in the MCNP ENDF/B-V library.

The effective multiplication factor was computed for all three configurations ${ }^{2}$ of FOEHN for a large number of control rod positions and corresponding experimental critical boron concentrations. In the simplest configuration (no boron end caps, no reflector internals), the agreement between the MCNP-computed $k_{\text {eff }}$ and the experimental value of 1.0 is achieved within two MCNP standard deviations $(2 \sigma)$ for two experimental situations and within three standard deviations $(3 \sigma)$ for five more. In the intermediate configuration (with boron end caps, no reflector internals), four cases agree with the experimental value within $2 \sigma$ and the two other cases within $3 \sigma$. In the most complex configuration (with boron end caps and reflector internals), the agreement is still remarkably good, with three matches within $2 \sigma$ and all the other cases displaying matches within $3 \sigma$. 
The MCNP-computed power distribution was normalized to the same average core power density of 1.0 as the FOEHN data. Typical of the results obtained, the normalized axial power distribution at three radial positions is shown in Fig. ES-1. The experimental error bars of $4 \%$ are based on the discussion presented above. The bars on the computational curve assume errors of $2 \sigma$. Similar curves were generated for radial power distributions. In this way, every experimental data point was plotted at least once. The graphs show that nearly all the computational results coincide with their experimental counterparts within the error bounds established above. In the simple reactor configuration, only two points, $<2 \%$ of the total number (122), do not display any overlap. This is remarkably compatible with the statistical interpretation that $95 \%$ of the points lie within the $\pm 2 \sigma$ "error band." A similar high level of agreement is observed for the thermal fluxes and for the rendement. This work shows that the use of MCNP for the neutronics design of a reactor with features similar to the FOEHN experiment can be achieved successfully. 


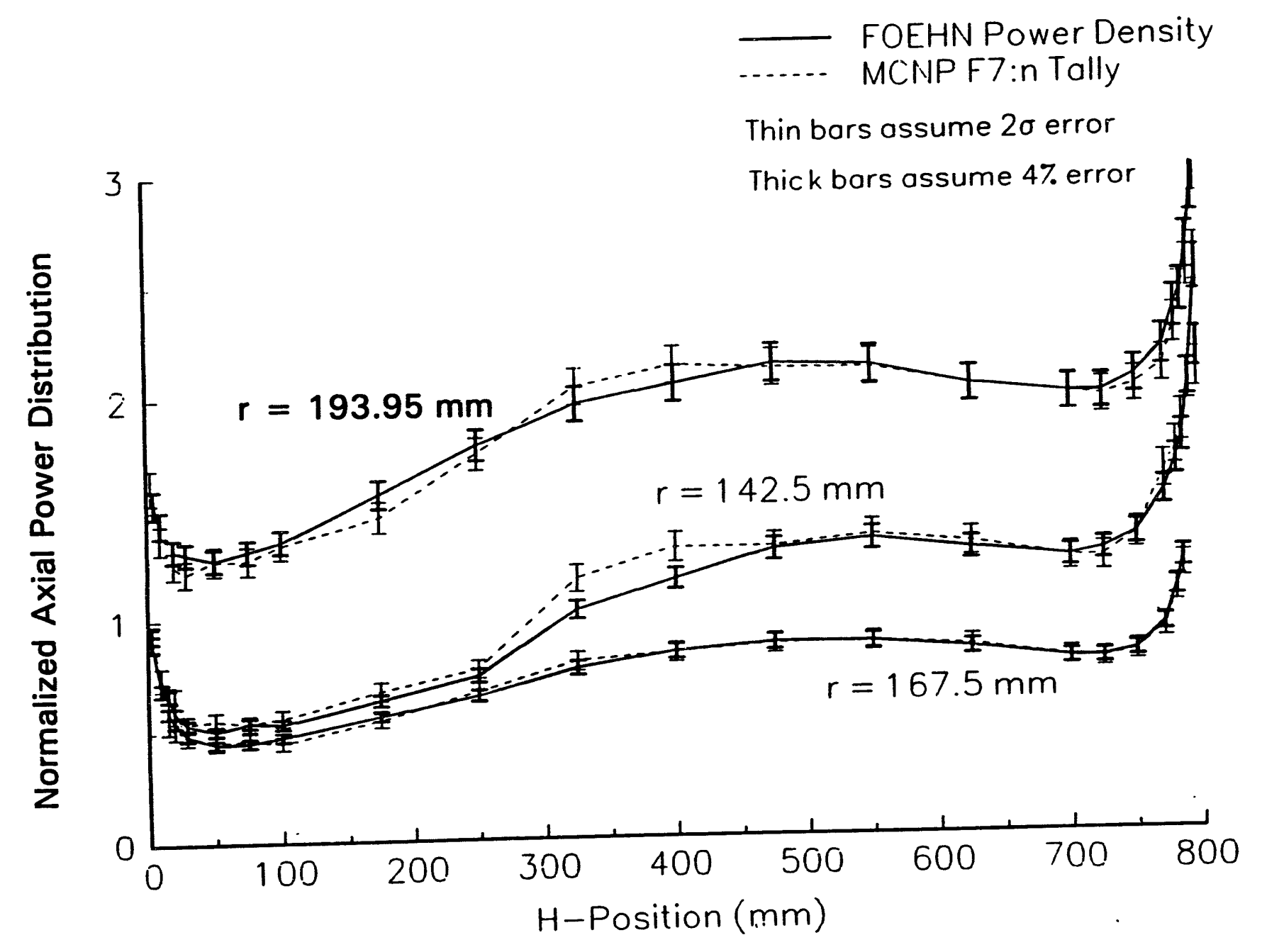

Fig. ES-1. Computed vs measured axial power distribution at three radial positions of the FOEHN critical experiment. 


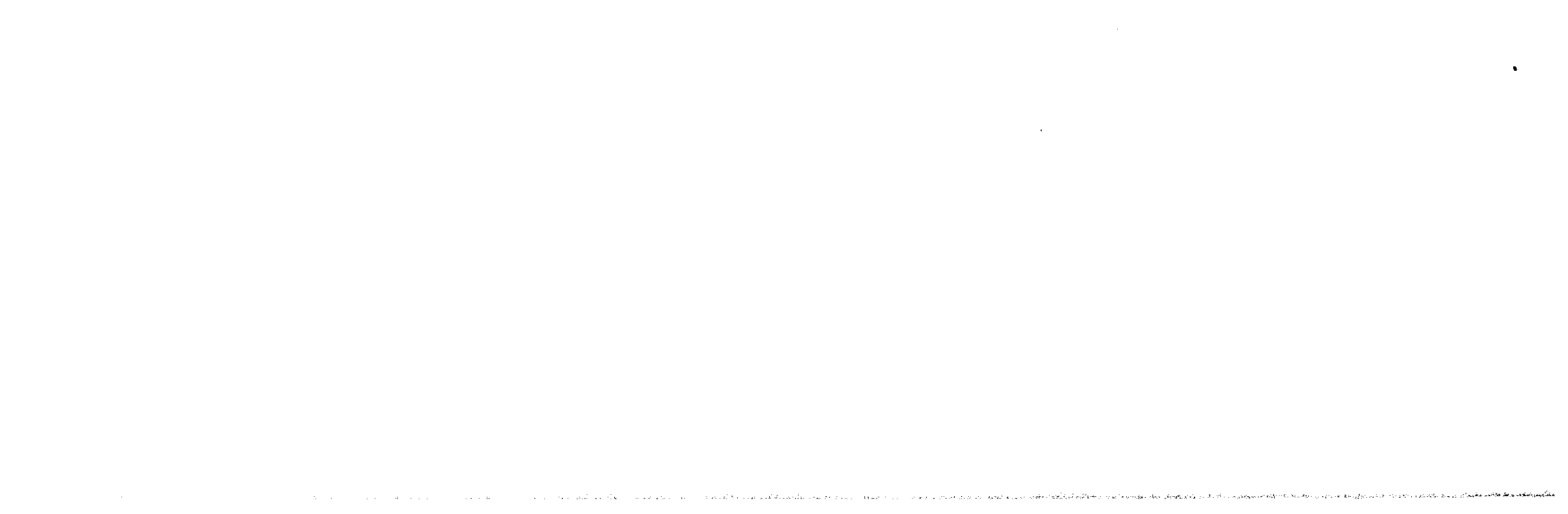




\begin{abstract}
A very high fidelity MCNP model of the Franco-German FOEHN critical experiment has been developed. The results obtained show a high degree of agreement with each of the three configurations of the experiment. In particular, it is shown that the model reproduces the power density production distribution for all but a few of the experimental points internal to the core. Agreement for points of the axial ends at the core is less comprehensive. In the configurations that include boron axial core end covers, the agreement is similar within the core, but a few additional disagreement points arise at the axial ends of the core. The results remain consistent, however, with the statistical interpretation of MCNP tallies. The quantities computed also include the thermal flux in the reflector and the core multiplication factor for various critical configurations. It is found that the fluxes agree with the experiment within the experimental error bounds and two computational standard deviations. Most of the core multiplication results agree within three MCNP standard deviations. The overall conclusion of this study is that MCNP is an appropriate and valid computational tool for the static neutronic design of plate-fueled, heavy-water-moderated reactors, such as FOEHN or the Advanced Neutron Source.
\end{abstract}




\section{INTRODUCTION}

\subsection{MOTIVATION}

In the research and development plan of the Advanced Neutron Source (ANS) reactor, the second phase of validation for the neutronics design methods is to compare model (i.e., computational) results and experimental (i.e., measured) results for a critical facility exhibiting similarities with the ANS reactor. ${ }^{1}$ One such facility is FOEHN, ${ }^{2}$ a critical experiment performed in the course of the design of the Franco-German High Flux Reactor (FGHFR) at the Institut Laue-Langevin (ILL) in Grenoble, France. The experiment was conducted in the French EOLE reactor, which was modified for this purpose. FGHFR is a heavy water reactor with many features similar to those of the proposed ANS reactor. In particular, they both use (or would use) heavy water as moderator and coolant, and they both use (or would use) highly enriched uranium with aluminum plate fuel. The similarity between the two reactors can be seen further from the description of the FOEHN experiment in Chap. 2 and by a graphic rendition of their respective MCNP models in Chap. 3. These similarities in the characteristics of the two reactors suggest that benchmarking $\mathrm{MCNP}^{3}$ calculations against FOEHN experimental results will enhance the current level of confidence in the computational results and will contribute to the validation of the computational approach chosen for the neutronics design of the ANS reactor.

\subsection{SCOPE AND LIMITATIONS OF THE STUDY}

In this work, an MCNP model of the FOEHN experiment is developed and its results are compared to experimental data from the literature. It is found that the MCNP model reproduces measured quantities of interest with a high level of agreement. A validation of the method used for computing power generation in the ANS reactor is inferred from the successful comparison of computational results using this method and experimental results in the case of the FOEHN experiment. The extent to which this validation is achieved is limited only by the lack of availability of comprehensive documentation on the details of the experimental setup and on the experimental results. The main sources of differences between the experiment and the model developed in this work stem from the lack of some geometric data about the reactor and in the lack of more detailed information about the materials used than that supplied in the FOEHN report (e.g., impurities information). The results obtained in the course of this study show that the omission of these data leads to no significant difference from the experimental results.

The MCNP model developed here is extensive. It conforms to a high level of fidelity in the representation of the various features of the reactor. The approximations made, when not dictated by the lack of information on the experiment, are explained and their justifications given in Chap. 3 . The main items of comparison in the current work are (1) the core multiplication factor for several soluble boron concentration/control rod position combinations, (2) the thermal flux, (3) the core power distribution, and (4) the rendement (neutron efficiency).

\subsection{ORGANIZATION OF THE REPORT}

In Chap. 2, a review of the FOEHN experiment is presented. Following a brief description of the experiment, a survey of the measured quantities is given. The method of data normalization used in the FOEHN report is explained, and a compatible one for the MCNP computational results is 
presented. Finally, the error analysis of the FOEHN experiment is reviewed and complemented. In Chap. 3, the MCNP model developed in this work is presented. In Sect. 3.2, the approximations made are discussed. In Sect. 3.3, the modeling of the reactor features is presented. In Sect. 3.4, the choice of tallies and the methods for computing the elements of the comparison with the experiment are given. Chapter 4 documents the results of the comparisons between the experiment and the model. In Chap. 5, the main results and conclusions of this study are summarized. The references cited in this work are listed in Chap. 6. 


\section{THE FOEHN EXPERIMENT}

\subsection{INTRODUCTION}

The FOEHN experiment was conducted with three levels of complexity. The first level involves mock-up of only the core surrounded by a reflector, without boron end caps and without the reflector internal structures (internals). The second includes boron end caps (top and bottom of core) but no reflector internals. The third level includes the boron end caps and mock-ups of the features internal to the reflector. A description of the experimental setup (core, reflector, and experimental facilities of the reactor), the method used in reporting the results, and an analysis of the experimental error estimates are presented in this chapter.

\subsection{DESCRIPTION OF THE FOEHN EXPERIMENT}

\subsubsection{Reactor Components and Geometry}

The components and geometry of the FOEHN experiment are described in the report by Scharmer and Eckert. ${ }^{2}$ A brief review of the elements necessary to the construction of an MCNP model is given in this section.

\subsubsection{Reactor Core}

The fuel zone is a hollow cylinder of height $0.80 \mathrm{~m}$, with outer and inner radii of 0.195 and $0.14 \mathrm{~m}$, respectively. The fuel plates were fabricated out of a uranium-aluminum alloy and shaped as circular involutes with a $134.855-\mathrm{mm}$ generating radius. The fuel plates did not have any cladding along their outer edges. A gap of $1.8 \mathrm{~mm}$ is maintained between the assembled plates. Other characteristics of the fuel plates are summarized in Table 2.1. The core structures were all fabricated from the AG3-NE aluminum alloy described in Sect. 3.2.2.

Table 2.1. FOEHN experiment fuel plates characteristics

\begin{tabular}{ll}
\hline Fuel & $\mathrm{U}-\mathrm{Al}$ alloy $\left(90 \%{ }^{235} \mathrm{U}\right)$ \\
Load $\left(\mathrm{kg}{ }^{235} \mathrm{U} / \mathrm{m}^{2}\right)$ & 0.568 \\
Total ${ }^{235} \mathrm{U}$ mass $(\mathrm{kg})$ & 8.556 \\
Number of plates in core & 276 \\
Plate length $(\mathrm{mm})$ & $800.0 \pm 0.5$ \\
Plate width (mm) & $68.3 \pm 0.2$ \\
Plate thickness (mm) & $1.27 \pm 0.05$ \\
Thickness of lateral Al cladding $(\mathrm{mm})$ & 0.1 \\
\hline
\end{tabular}


The coolant channel volume in the fuel zone was determined in ref. 2 on the basis of the dimensions of the fuel plates and the core structures as measured after fabrication. The borated heavy water volume thus contained in the core was $0.027 \mathrm{~m}^{3}$ (ref. 2). The total free column volume in the core barrel, including the gaps around the fuel zone, was reported as $0.02885 \mathrm{~m}^{3}$ (ref. 2).

\subsubsection{Reflector and Internal Stack Geometry}

The core is located in the center of a cylindrical tank of $2.30-\mathrm{m}$ diam and $2.21-\mathrm{m}$ height. The tank is filled with $\mathrm{D}_{2} \mathrm{O}$. A stack passes through the tank axially. The stack extends to the upper rotating plug and has the function of isolating the core and preventing the entire heavy water inventory in the reflector from being contaminated by boron in the event of a leak in the core barrel.

\subsubsection{Control Elements and Safety System}

The excess reactivity of the reactor is compensated for partly by the boron dissolved in the moderator and partly by a control rod that is inserted from below into the central flux trap. The absorber section of this control rod is a nickel tube $5-\mathrm{mm}$ thick, $1.0-\mathrm{m}$ long, and of outer radius $0.126 \mathrm{~m}$.

\subsubsection{Safety Rodis}

Six dummy safety rods were used. They were supported by upright aluminum guide tubes of 0.04-m diam and a wall thickness of $4 \mathrm{~mm}$. The safety rods consisted of 2-mm thick cadmium tubes of $90-\mathrm{mm}$ OD and $1.50-\mathrm{m}$ length, clad in $0.5-\mathrm{mm}$ stainless steel.

\subsubsection{Solid Boron End Zones}

A portion of the excess reactivity is compensated for by boron plates above and below the fuel zone. The boron end zones consist of horizontal, 1-mm thick, borated aluminum plates and pure aluminum plates.

\subsubsection{Experimental Facilities}

A variety of experimental components are included in the reflector of the FOEHN critical facility. These include 16 beam tubes, a hot source, a cold source, and pneumatic tubes for material irradiations. These assemblies closely resemble the facilities originally designed for the FGHFR and are described more fully in the FOEHN report and in ref. 6. A brief description of the main reflector components is given below.

\subsubsection{Reflector Internal Components}

Sixteen beam tubes comprise the bulk of the reflector components. These are used for functions ranging from isotope production and neutron extraction for scattering experiments to conversion electron and/or photon extraction. The beam tubes in FOEHN are of three main shapes: cylindrical, rectangular, and truncated conical. Beam tube orientations range from horizontal to vertical. All beam tube walls are composed of the AG3-NE aluminum alloy and are evacuated within. Two pneumatic tubes for material irradiations are also present in the reflector. These vertical cylindrical tubes are 0.04-m diam and made of the AG3-NE aluminum alloy. One tube nose is located at the core midplane, 
and the other is $0.2-\mathrm{m}$ above the midplane. The beta spectrometry vertical channel has an ID of $0.20 \mathrm{~m}$ and a wall thickness of $2 \mathrm{~mm}$. It passes through the full height of the reflector. The pneumatic transport systems are simulated by vertical aluminum tubes with $0.04-\mathrm{m}$ ID and 2-mm wall thickness.

\subsubsection{Cold Source Facility Mock-up}

The cold source is simulated by an aluminum vessel of $0.40-\mathrm{m}$ ID and $0.50-\mathrm{m}$ height. The wall thickness is $5 \mathrm{~mm}$. The effect of the cold moderator on neutron absorption in the wall is simulated via an increase in the wall thickness. In the experiment, this was achieved using an aluminum bell 3-mm thick that fit over the cold source.

\subsubsection{Hot Source Facility Mock-up}

The FOEHN hot source mock-up consisted of a cylindrical block of graphite inside a Zircaloy-4 vessel, surrounded by an AG3-NE tube. Two probe holes, one horizontal and one vertical, extend through the center of the graphite block to provide access for measurements within the hot source. The hot source mock-up was located at a radius of $0.496 \mathrm{~m}$ from the core centerline, and its centerline was 0.1- $\mathrm{m}$ below the core midplane.

\subsubsection{Loops}

The FOEHN critical facility contains three separate loops. The core loop serves to isolate the core region and allows for addition of borated heavy water to the core for reactivity control. The stack loop seals off the primary coolant loop from the reflector. The reflector loop provides cooling for the reflector components. Both the stack and reflector loops can be independently heated and cooled.

\subsubsection{Materials}

The materials used in the FOEHN experiment are described in great detail in ref. 2, and some of their properties are summarized in Sect. 2.2.1.1 above. The description of the materials does not include quantification of any impurity content. In Sect. 3.2.2, the differences between experiment and model materials are enumerated.

\subsection{RESULTS OF THE FOEHN EXPERIMENT}

The FOEHN experiment is summarized in a report by Scharmer and Eckert. ${ }^{2}$ The main results of interest to the current study are those related to benchmarking an MCNP simulation against the experiment. These results are the spatial distribution of power production, the fluxes, the effective core multiplication factor $\left(k_{e f f}\right)$, and the rendement. The quantities of interest (limited to the static parameters) are reviewed below, and their actual meanings in the FOEHN experiment are clarified. The actual results of the FOEHN experiment are reviewed in Chap. 4 in conjunction with their comparison to the model. 


\subsubsection{Quantities Measured}

\subsubsection{Core Multiplication Factor $\left(k_{\text {ads }}\right)$}

The reactivity was measured in the FOEHN experiment via three methods: (1) the stable period method for slightly supercritical states, (2) the continuous reactivity measurement method for cases with large reactivity, and (3) the pulsed neutron source method for subcritical states. The experimental results reported include both critical and off-critical states.

\subsubsection{Fluxes and Spectrum}

The fluxes and the spectrum were measured in the FOEHN experiment using the well known method of foil activation. For the thermal flux measurements, the cadmium ratio, $R_{c d}$, was evaluated using a manganese $(\mathrm{Mn})$ probe irradiated at the same location in the experiment and at the same power, once without a cover $(\mathrm{Mn})$ and once under a thick cadmium $(\mathrm{Cd})$ cover $(\mathrm{Mn} / \mathrm{Cd})$. From $\boldsymbol{R}_{C d}$ and the total activity (Mn case), the thermal flux can be computed. The epithermal flux was measured using gold ( $\mathrm{Au}$ ) and indium (In) resonance probes under $\mathrm{Cd}$ covers. The fast flux was measured using the threshold reactions of sulfur $(S)$ and phosphorus $(P)$ probes.

The flux spectrum in the FOEHN experiment was measured using paired probes of uraniumplutonium $(\mathrm{U} / \mathrm{Pu})$ and lutetium-manganese $(\mathrm{Lu} / \mathrm{Mn})$ in addition to the manganese and $\mathrm{Mn} / \mathrm{Cd}$ probes used for $\boldsymbol{R}_{C \boldsymbol{c}}$. The activation ratios obtained from these pairs were then used to obtain a discrete neutron spectrum (thermal, epithermal, and fast neutron energy groups).

\subsubsection{Flux Efriciency (Rendement)}

The rendement is defined in the FOEHN report as the ratio of the maximum thermal flux in the reflector to the total power produced in the core,

$$
r=\frac{\phi_{\omega}^{m x}}{P_{m a x}}
$$

For experimental determination, this expression is rewritten in terms of experimentally available quantities,

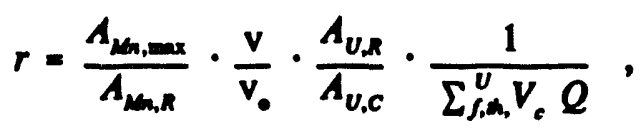

where $A_{\max }, A_{M_{n, S}}, A_{U_{\Omega},}$, and $A_{U, C}$ are measured activations, respectively, of manganese at the maximum of the flux, of manganese in the reflector, of uranium in the reflector, and of uranium in the core. $V_{c}$ is the core volume, $v$ is the mean neutron velocity at the location of the maximum of the flux, and $v_{0}$ is

$$
v_{0}=\frac{2}{(\pi)^{1 / 2}} \cdot 2200 \mathrm{~m} / \mathrm{s} \text {. }
$$


The ratio $v / \mathrm{v}_{0}$ and the effective microscopic fission cross section $\sigma_{f, e f f}(503$ barns at the point of the measurement located at a radius of $0.50 \mathrm{~m}$ from the centerline of the reactor) were evaluated using the code THERMOS. The evaluation of $r$ in the FOEHN report also assumes that the recoverable energy released per fission event, $Q$, is $199.73 \mathrm{MeV}$.

\subsubsection{Power Distribution}

In the FOEHN report, it is claimed that the power distribution is measured. In reality, the fission power production density (understood to include all the recoverable energy, then normalized to a unit average power density throughout the core) is measured and reported. The fission power production is measured using fission probes of composition similar to that of the reactor material (fuel plates) and cut right into the plates. This choice has the advantage of not significantly disturbing the system studied. The fission foils are irradiated; then the gamma activity above $511 \mathrm{keV}$ is measured. The measured activity is deemed proportional to the power released in the probe during irradiation. The measurements necessarily include all gammas above $511 \mathrm{keV}$ and, hence, may include activity contributed by nonfission events. The results reported do not describe the power distribution as it would result from the combined effects of power production, transport, and deposition. Gamma heating is also reported and is discussed in the next subsection.

\subsubsection{Gamma Heating in the Reflector}

Gamma heating of structural and other materials is the result of the transfer of energy via gamma radiation and the subsequent deposition of the gamma radiation. It is measured in the FOEHN experiment using glass dosimeters and an ionization chamber. The glass dosimetry technique relies on the measurement of the fluorescence induced by the formation of optical centers (i.e., defects) in the glass as a consequence of irradiation by the gamma rays. The effect of the neutron-induced centers is subtracted by comparison to activation measurements. The method is suitable for the measurement of the photon flux and of the energy deposition in the glass probe. A prediction for the energy deposition in other materials (e.g., reflector materials) can be inferred from their respective energy absorption coefficients. The ionization chamber method is fully described in classical references, such as The Atomic Nucleus by R. D. Evans. ${ }^{7}$ The chamber used in the FOEHN experiment has a sensitivity to gammas of $1200 \mathrm{~W} / \mathrm{g}-\mathrm{A}$. The FOEHN report does not give a sensitivity to gammas for the glass probes.

\subsubsection{Normalization of Tabulated Results}

The flux and power data obtained in the FOEHN experiment were reported normalized to an average power density (or flux density) of 1.0 over the core of the reactor. The report did not describe the normalization method in sufficient detail to make it easily reproducible. In this section, the normalization method used in the FOEHN report is explained. A simple and more practical alternative, which is shown to be compatible with that of the experimental report, yet easier to implement, is proposed and describud.

\subsubsection{FOEHN Experiment Normalization Method}

The powers reported for the FOEHN experiment are normalized to an average density of 1.0 over the whole reactor core. The procedure followed by the FOEHN experiment authors is described in Sect. 5.1.4 of their report. They used both a "mechanical" (i.e., semigraphical) and a "mathematical" 
(i.e., semi-analytical numerical) integration approach to evaluate the total core power for use in normalization. In the mechanical approach, the measured radial power distribution is plotted at each value of the axial variable. then graphically integrated. An axial power distribution results that is then integrated to yield a total core power. The normalized power is then determined by multiplying each experimental value by the: volume of the core and dividing it by the total power. The resulting distribution has the advantage of consisting of numbers close to 1.0 when the power density measurements are close to the core average power density. The second normalization method used by the authors of the FOEHN experiment differs only in the way the total power integral is obtained. In this second method, the entire set of measurements is fitted by polynomials, and the resulting twodimensional curve is used in a computational integration procedure. In the next two subsections, an alternative method is introduced that works well when a sufficient number of data points are available.

\subsubsection{Single Table Normalization}

The integration and normalization methods used in the FOEHN experiment should be expected to work well, but they are not fully rigorous from a mathematical point of view. Indeed, the measurements were made with probes of finite dimensions $(3 \mathrm{~mm} \times 5 \mathrm{~mm} \times 1.27 \mathrm{~mm})$ that are not negligible with respect to the distance over which the flux changes significantly (in some regions at a rate of $3 \% / \mathrm{mm}$ ). The reported measurement values are actually average values over the probe and not point values. The correct curve fitting procedure taking this fact into account is a complicated one, involving considerations of functional analysis. ${ }^{8}$ This method is beyond the scope of this study. A procedure that errs in the opposite direction may be as legitimate as the one used by the authors of the FOEHN experiment, especially when dealing with a large number of experimental points. This procedure is outlined below.

The normalization procedure proposed here differs from those of the FOEHN report only in the use of an $r, H$ trapezoidal integration procedure. In this approach, it is assumed that the data from a given probe applies to the domain surrounding it up to the middle of the distance separating it from the center of the closest adjacent probes in the $r$ and $H$ directions (or up to the edge of the fuel plate if applicable). The integration is then carried out by multiplying the power (or power density) by the volume of the region and summing over all probes. This integration procedure was applied to the data of Table 5.1.5 of the FOEHN report. The average power density is found to be 1.014 . The difference of $1.4 \%$ between our computations and the expected value of 1.0 shows that the two normalization procedures (FOEHN report and ours) are compatible and confirms the fact that the table in the FOEHN report is normalized to an average density of 1.0 .

\subsubsection{Multiple Tables with Missing Data}

It is desirable to obtain an average from multiple tables of similar data (such as Tables 5.3.6, 5.3.7, 5.3.8, and 5.3.9 of the FOEHN report). It is in fact necessary to combine the data from these tables because they cannot be reproduced computationally without precise data on the azimuthal position of the experimental fuel plates that carry the probes. In addition, for the sake of better statistics, the tally cells are actually annuli. The computational results, therefore, correspond to an average of a large number of probes distributed around the core. The averaging of the data from the four experimental plates is the best option available for a comparison. 
The construction of a proper average of the experimental data could be achieved in two ways: (1) renormalize the experimental data to 1.0; then form a point-to-point average according to

$$
\left(T_{1}\right)_{a v}=\frac{1}{N_{1}} \sum_{p}\left(T_{1}\right)_{p}
$$

or (2) perform a point-to-point average according to the formula shown above without first renormalizing the data. In the equation, $\left(T_{1}\right)_{a v}$ stands for the average tally for the $\mathrm{i}$-th position (defined by its radial and axial coordinates). $\left(T_{1}\right)_{p}$ is the $\mathrm{i}$-th position tally in the p-th experimental plate, and $N_{1}$ is the number of (nonmissing) entries for tallies in the $\mathrm{i}$-th position. These two options should both work well if the number of data points is large in each table (i.e., there are enough data points for the integration procedure to be accurate), and the initial tables are found to be normalized to 1.0 (or very close to 1.0) following the method proposed in Sect. 2.3.2.2. If there are many missing data points, or if the tables are not found to be normalized to an average density close enough to 1.0, then the second procedure must be used. The rationale for this choice is that the reported data are already normalized to an average power density of 1.0 according to the method used in the FOEHN experiment. Such data can then be averaged without further transformation. The resulting combined table should be expected to be more closely approximated by the tallies over annuli that are used in this study. The combined table, having a larger number of points than any of its constituent tables, should also be expected to be normalized to a value closer to 1.0 than (at least some of) the individual tables. The combined data from Tables 5.3.6-5.3.9 of the FOEHN report are shown in Table 2.2. It was verified that the entries of this new table are normalized to an average core power density of -1.006 according to the procedure in Sect. 2.3.2.2.

\subsubsection{Normalization of Fluxes}

The fluxes in the FOEHN experiment are reported normalized to a total core power of $1.0 \mathrm{~W}$. The MCNP tallies are normalized "per fission neutron." The MCNP tallies must be renormalized to make a direct comparison with experimental values possible. The fluxes are renormalized by multiplying the MCNP tallies by the power normalization factor PN given by ${ }^{9}$

$$
P N=P \cdot v \cdot \frac{1}{Q} \cdot \frac{1}{k_{e t}} \text {, }
$$

where $P$ is the reactor power, $v$ is the average number of neutrons per fission, $Q$ is the fission energy, and $k_{e f f}$ is the effective multiplication factor from the MCNP run that yielded the flux tallies to be renormalized. The normalization to $1.0 \mathrm{~W}$ is achieved by setting $P$ equal to 1.0 . In this work, $v$ is computed within MCNP for each reactor configuration and is reported along with the results that use it. When a value for $v$ is not reported, the value 2.44175 is assumed. The energy per fission used in this work, $Q$, is $202.47 \mathrm{MeV} / \mathrm{fission}$, except in the evaluation of the rendement where the value 199.73 $\mathrm{MeV}$ was used in order to conform with the practice adopted in the FOEHN report. 
Table 2.2. Experimental power production distribution in FOEHN ${ }^{e}$

\begin{tabular}{|c|c|c|c|c|c|c|c|c|c|c|c|}
\hline $\begin{array}{c}H / r \\
(\mathrm{~mm})\end{array}$ & 143.5 & 146.5 & 149.5 & 152.5 & 159.0 & 167.5 & 176.0 & 182.5 & 185.5 & 188.5 & 193.95 \\
\hline 2.5 & 0.5033 & 0.4701 & 0.4529 & 0.4492 & 0.4462 & 0.4908 & 0.5958 & 0.7363 & 0.8162 & 0.9236 & 1.2140 \\
\hline 5.0 & & & & & & & & & & & 1.1739 \\
\hline 9.4 & 0.6978 & & & & & & & & & & 1.1654 \\
\hline 14.5 & 0.4629 & & & & & 0.4437 & & & & & 1.1657 \\
\hline 19.4 & 0.4880 & & & & & 0.4295 & & & & & 1.1697 \\
\hline 28.5 & 0.4920 & & & & & 0.4270 & & & & & 1.1787 \\
\hline 50.0 & 0.5061 & 0.4655 & 0.4540 & 0.4359 & 0.4214 & 0.4560 & 0.5526 & 0.6827 & 0.7796 & 0.8979 & 1.2395 \\
\hline 75.0 & 0.5441 & & & & & 0.4965 & & & & & 1.3249 \\
\hline 100.0 & 0.6163 & & & & & 0.5283 & & & & & 1.4047 \\
\hline 175.0 & 0.7386 & 0.6832 & 0.6508 & 0.6328 & 0.6002 & 0.6410 & 0.7650 & 0.9542 & 1.0744 & 1.2272 & 1.6764 \\
\hline 250.0 & 0.8609 & & & & & 0.7408 & & & & & 1.8965 \\
\hline 325.0 & 0.9626 & & & & & 0.8191 & & & & & 2.0636 \\
\hline 400.0 & 1.0555 & 0.9788 & 0.9144 & 0.8984 & 0.8473 & 0.8850 & 1.0357 & 1.2898 & 1.4189 & 1.6113 & 2.2120 \\
\hline 475.0 & 1.3656 & & & & & 0.9684 & & & & & 2.2314 \\
\hline 550.0 & 1.4596 & & & & & 0.9621 & & & & & 2.1906 \\
\hline 625.0 & 1.3661 & 1.2192 & 1.0878 & 1.0273 & 0.9211 & 0.9003 & 1.0106 & 1.2300 & 1.3538 & 1.5147 & 2.0550 \\
\hline 700.0 & 1.2275 & & & & & 0.8055 & & & & & 1.8327 \\
\hline 725.0 & 1.1729 & & & & & 0.7442 & & & & & 1.7600 \\
\hline 750.0 & 1.1257 & 0.9867 & 0.8775 & 0.8289 & 0.7265 & 0.7100 & 0.7993 & 1.0039 & 1.0851 & 1.2325 & 1.7150 \\
\hline 771.5 & 1.1000 & & & & & 0.6721 & & & & & 1.6685 \\
\hline 780.6 & 1.1352 & & & & & 0.7285 & & & & & 1.6806 \\
\hline 785.5 & 1.1344 & & & & & 0.7188 & & & & & 1.6985 \\
\hline 790.6 & 1.1528 & & & & & & & & & & 1.7021 \\
\hline 795.0 & & & & & & & & & & & 1.7183 \\
\hline 797.5 & 1.2958 & 1.1534 & 1.0572 & 1.0238 & 0.9171 & 0.8625 & 0.9632 & 1.1537 & 1.2353 & 1.3559 & 1.8193 \\
\hline
\end{tabular}

${ }^{a}$ Combines Tables 5.3.6-5.3.9 of ref. 2. 


\subsection{ERROR ANALYSIS OF FOEHN RESULTS}

\subsubsection{Error Reporting in the FOEHN Experiment}

The measurement errors on the ratios related to the flux spectrum are reported as $1 \%$ for $R_{C d}$ and $R_{P u N}$, and $2 \%$ for $R_{L W M n}$ respectively. ${ }^{2}$ The errors claimed by the authors of the FOEHN experiment are $2 \%$ for the relative thermal flux measurements, $3 \%$ for the absolute thermal flux measurements, $4-15 \%$ for the relative epithermal fluxes, and $13 \%$ for fast flux measurements near the core. They attributed most of the experimental error in the thermal flux measurements to the error in positioning the probes. They claim that the flux varies by $30 \% / \mathrm{cm}$ on the tank surface at the reactor midplane. The error on the powers is reported to be $<1 \%{ }^{2}$ In the critical states experiments, the error on the positioning of the control rod is reported as $<1 \mathrm{~mm}$, whereas the error on the corresponding boron concentration is not reported. With very little analysis, the errors on the determinations of the rendement are reported in the FOEHN report as $\pm 2, \pm 2$, and $\pm 3 \%$, respectively, for the simple, the intermediate, and the full complexity reactor configurations.

\subsubsection{Sources of Errors}

\subsubsection{Geometric Tolerances}

The occurrence of geometric inaccuracies leads to errors in the experimentally measured data. Some of the geometric sources of error are the positioning error of foils and probes in the experiment, the error on the dimension of plates and other structures during fabrication, and the tolerance in the positioning of rods. Other geometric sources of error may include the effect of accidental deformation of the fuel plates as well as deformation caused by the actual operation of the reactor.

\subsubsection{Materials Data}

The composition of the various materials used in the FOEHN experiment are not known unequivocally. In particular, no infornation on the impurity contents was given in the FOEHN report. Another possible (though very likely small) source of error is the undocumented uncertainty on the boron concentration used for criticality experiments. The FOEHN report is ambiguous in its description of the material used for fabrication of the reflector internals. Whereas it is stated that the standard beam tube is made of the AG3-NE aluminum alloy referred to simply as aluminum in the report, the material of other structures is not explicitly described as AG3-NE, but rather only as aluminum.

\subsubsection{Counting Geometry, Statistics, and Times}

The counting statistics and consequent errors of the various measurements were not explicitly reported by the authors of the FOEHN experiment. It is unclear whether the errors they quote relate only to the counting or to the entire experiment. For example, the error of $<1 \%$ reported for the power measurements is not assigned to any particular aspect of the experimental procedure. It is reasonable to assume that it is related solely to the counting time, geometry, and statistics. 


\subsubsection{Estimates of the Error on Select Quantities}

The errors discussed in the previous section may be viewed as having two types of sources: statistical and systematic. In combining and propagating the two types of errors, care must be taken to use the proper applicable rules. The uncertainty in the measurements of activation associated with the probe positioning constitutes an unknown error of unknown sign. It was estimated by the authors of the experiment at approximately $\pm 3 \%$. This error is random, but since this error is associated to fewer than three measurements for each sample, confidence bounds in the statistical sense cannot be defined for it, and the error cannot be treated like a statistical error. This error also affects all the measurements equally, so it is treated like a systematic error in this work, except that its sign is not known. It is therefore not combined statistically with the other errors. Instead, the corresponding uncertainties are combined conservatively, as if they were known errors. In contrast, the counting errors are of statistical nature. The activities of two probes irradiated at the same location, although under modified conditions, are correlated. It follows that the combination of errors should ideally take the correlation into account. Since the precise way in which the activations are correlated is not known, limiting situations have to be identified. The actual errors would then fall within the range thus determined. Such limiting ranges are defined below for the cadmium ratio, the thermal flux, and the powers. The resulting estimates for the statistical and systematic errors are then combined conservatively in $:$ nonstatistical way.

\subsubsection{Cadmium Ratio, $\boldsymbol{R}_{C d}$}

The cadmium ratio, $R_{C d}$, is obtained as the ratio of two activities. If a foil is positioned with an error of the order of $1 \mathrm{~mm}$, as claimed in the FOEHN report, the systematic error on its activation would be of the order of $3 \%$. It follows that the error on $R_{C d}$ would be $-6 \%$ from the compounding of the errors on two foils. The contribution of the counting error to the total relative error ranges from 0 to $\sqrt{2}$. These two figures assume the activities to be fully positively correlated and uncorrelated, respectively. The assumption of positive correlation is plausible for activations of foils at the same location in the reactor. If the correlation was negative, the contribution would have been bound by a maximum value of $2 \%$. Other errors, such as the sample-size error, may also be present but are ignored in this analysis. The total error for the cadmium ratio ranges, therefore, between 6 and $7.4 \%$.

\subsubsection{Thermal Flux}

The thermal flux is computed in the FOEHN experiment according to

$$
\phi_{t h}=B \cdot\left(v / v_{0}\right) \cdot A \cdot\left(1-1 / R_{C d}\right)
$$

where $B$ is a normalization constant and $A$ is the activation of the thermal probe. It is not clear from the FOEHN report how the cadmium ratio was determined for a given thermal flux measurement. Specifically, it is not clear whether $R_{C d}$ was measured once at some location in the reflector and used for all thermal flux determinations at that and other locations or if $R_{C d}$ was reevaluated separately for each location. From the report, it seems that the former approach was adopted. If this is the case, the error on the thermal flux would follow from the error on $B$, the error on $A$ (comprising at least $-3 \%$ for positioning and $1 \%$ for counting), and the error on $R_{C d}$ (comprising the combined errors on two activity measurements, about $6-7.4 \%$ ). In the present analysis, it is assumed that $R_{C d}$ was determined 
only once, and hence the logic stated at the beginning of Sect. 2.4 .3 applies. In the converse, the error on the flux would entail only the errors on the two correlated measurements of the activities under cadmium cover and without cadmium cover.

Contributions to the error on $\phi_{t h}$ arise from each of the factors in the right side of Eq. (6). The first term is the normalization constant $B$. In the FOEHN report, it is claimed that this normalization is performed using the measured value of the rendement. Such an approach would imply that the factor $B$ would be either proportional or inversely proportional to the rendement and, consequently, that the corresponding relative error would have to be added to the above estimates. In Sect. 2.4.3.4, it is shown that the error on the rendement ranges from $2.2 \%$, when only the error on the ratio $\mathrm{v} / \mathrm{v}_{\mathrm{o}}$ is accounted for, to $16.2 \%$, when the positioning errors, the counting errors, and the error on $v / v_{0}$ are taken into consideration. The second factor, $v / v_{0}$, was shown by Rohrmoser ${ }^{10}$ to entail an error of about $2.2 \%$. The last two factors, $A$ and $\left(1-1 / R_{C d}\right)$, contain errors resulting from positioning and counting. If it is assumed that all the statistical errors (i.e., counting errors) and the error on $v / v_{0}$ from $B$ and from its explicit occurrence in Eq. (6) cancel out, then the error on $\phi_{t h}$ would be of the order of $15.3 \%$ for a value of $R_{C d}$ of 20 . This would decrease toward $15 \%$ as $R_{C d}$ increases and would be reduced to $3.3 \%$ if the positioning errors are assumed to cancel out in the evaluation of the rendement. If the errors on $v / v_{0}$ do not cancel out, and the cancellation of statistical error is minimal, then the error would be of the order of $22.8 \%$, $(10.8 \%$ if positioning error is ignored in determination of the rendement). If it is assumed that the error of $2 \%$ (to $3 \%$ ) on the measured rendement claimed in the FOEHN report is correct, then the error on the thermal flux would be between 8.5 and $8.6 \%$ (to between 9.5 and $9.6 \%$ ), depending on the extent of statistical error cancellation.

From the above, it can be seen that estimates of the error on the thermal flux can range from $3.3-22.8 \%$, with a more plausible minimum of the order of $9.6 \%$. If no other sources of error are present, then the error on the thermal flux measurements should be taken to be at least $10 \%$. Since this is unlikely, error bars resulting from the lower estimate based on the claims of the FOEHN experiment report should be regarded as a minimum width for the error, that is, a nonconservative estimate.

\subsubsection{Powers}

In the FOEHN report, the claimed error of $1 \%$ on the powers is attributed mainly to the uncertainty in positioning the plates with respect to one another (i.e., distance between adjacent plates). In another part of the report, it is claimed that a positioning error of $1 \mathrm{~mm}$ induces an error of up to $3 \%$ in the activation (i.e., the flux or the power). It can be expected that the positioning of the fuel plates is known to be about $0.1 \mathrm{~mm}$ (the distance between plates is given as $1.8 \mathrm{~mm}$ ) and hence that the corresponding error would be only as high as $0.3 \%$. To this, the error related to the dimensions of the fission probes proper and the counting must also be accounted for in the calculation. If the counting error (i.e., measurement error) is the same as that for the flux measurements, then it should be taken to be $-1 \%$. The error on the dimensions of the probes cannot be known with any degree of certainty since they are not documented in the report. It can be guessed, however, that they can be related to the errors made on measurements of some of the features of the EOLE reactor. For example, the error on the thickness of the fuel plate is $0.05 \mathrm{~mm}$. If a similar error is made for each of the dimensions of the fission probes, the resulting relative error on the area of a given probe would be $-2.7 \%$. The implied error on the power measurement resulting from this would be the same (i.e., 2.7\%). In addition, the error on the dimension of $0.05 \mathrm{~mm}$ for each side of the rectangular shapes would induce a positioning error on the flux (or power) similar to that caused by four positioning errors by distances half the dimension error and hence add up to $0.3 \%$ for the two sides of the rectangle (or to $0.45 \%$ if a thickness positioning error is assumed). The sum of all the errors discussed here ranges from $1-4.15 \%$. The relative error on the thickness of the probes $(0.05 \mathrm{~mm}$ for a $1.27-\mathrm{mm}$ 
thickness) would affect the counting and hence would contribute an additional 3.94\% to the power error estimate. A grand total of up to $8 \%$ is therefore plausible. Other possible errors resulting from the actual location (i.e., positioning error) of the probes and from deformation (resulting from cutting and use) are not accounted for in this scenario. The upper bound of $4 \%$ chosen in the remainder of this work as the error on the power (for use in comparisons to MCNP results) is a lowest estimate and is similar to the estimate of the error on the flux arrived at in Sect. 2.4.3.2 by reanalyzing the FOEHN report data and claims.

\subsubsection{Rendement}

The computation of the rendement in the FOEHN experiment uses four measured activations, an estimate of the energy and core volume averaged fission cross section, an estimate of the ratio $v / v_{0}$, and an estimate of the energy released per fission event. Each of these can be known only approximately and, hence, is a source of error. Assuming a relative error on each constituent term in the equation for $r$, the nonstatistical component of the relative error on $r$ is

$$
\begin{aligned}
\frac{\Delta r}{r}= & \frac{\Delta A_{M n, \max }}{A_{M n, \max }}+\frac{\Delta A_{M n, R}}{A_{M n, R}}+\frac{\Delta\left(\mathrm{v} / \mathrm{v}_{\mathrm{o}}\right)}{\mathrm{v} / \mathrm{v}_{\mathrm{o}}}+ \\
& \frac{\Delta A_{U, R}}{A_{U, R}}+\frac{\Delta A_{U, c}}{U_{U, c}}+\frac{\Delta \Sigma_{f, h}^{U}}{\Sigma_{f, t h}^{U}}+\frac{\Delta V_{c}}{V_{c}}+\frac{\Delta p}{p} .
\end{aligned}
$$

The statistical error on the activities has to be added. The error on the ratio $v / v_{0}$ was shown by Rohrmoser to be $2.2 \%$. If the errors on the fission cross section and on the core volume $V_{c}$ are ignored, and if the error on the activations is taken to be $1 \%$ (following the claims in the FOEHN report) to $4 \%$ (3\% positioning and $1 \%$ counting), then the error on $r$ should be between $2.2 \%$ (assuming positioning error cancellation, hence ignoring all but the error on $v / v_{0}$, and with the counting error contributing $0 \%$ for full positive correlation, when maximum cancellation occurs) and $16.2 \%$ (positioning errors taken into account and with statistical error contributing $2 \%$ in the uncorrelated case). The error sources omitted here may or may not be negligible and might have to be accounted for in the analysis.

\subsection{SUMMARY}

The FOEHN experiment has been reviewed and its salient features described. The quantities that were measured have been identified. A method for normalizing model data that is compatible with the normalization method used in the FOEHN report has been proposed. The reported estimates of the experimental errors were discussed. It is concluded here that, as given in ref. 2 , the error estimates of the FOEHN experiment are significantly underestimated. It is shown, in particular, that the errors on the fluxes should be taken to be at least of the order of $10 \%$, while the errors on the powers should be taken to be at least $4 \%$ of the reported values. 


\section{MCNP MODEL OF THE FOEHN EXPERIMENT}

\subsection{INTRODUCTION}

MCNP models that correspond to the three configurations of the FOEHN experiment have been developed and are described in this chapter. The assumptions and approximations made are outlined in Sect. 3.2. In Sect. 3.3, the geometry and modeled features of the reactor are described. The choice of MCNP tallies and methods for computation of nontally quantities are described in Sect. 3.4. The full MCNP model (i.e., input file) is included as Appendix A.

\subsection{MAJOR APPROXIMATIONS AND ASSUMPTIONS}

The highest possible degree of geometric fidelity was systematically sought in the modeling of the FOEHN critical experiment. Whenever possible, the exact geometry of the component was used. The reactor core was modeled with some approximations justified in the next section. The reflector internal components were modeled explicitly and in full accordance with the specifications of the FOEHN experiment report. The next two subsections describe geometry and materials approximations made in the development of the MCNP model, respectively.

\subsubsection{Homogenous Core, Geometry Details, and Fidelity}

The FOEHN core, described in Sect. 2.2.1.1, was modeled as a homogenous hollow cylinder of fuel, cladding and structural materials, and borated heavy water. The dimensions are those specified in the FOEHN report. In the experiment, the power measurements were conducted on individual fuel plates. The highest fidelity description would hence require the explicit modeling of the plates and of the individual fission probes. This is an unpractical option, however, since the fuel plates are shaped as circular involutes, a shape not available in the MCNP geometry modules. In addition, since the fuel plates are much smaller than the mean free path of neutrons in the fuel material, the fuel can be homogenized with no significant loss of accuracy." Another major reason for avoiding explicit treatment of the fission probes is the fact that computing tallies over such small volumes would make obtaining satisfactory statistics prohibitively expensive.

The only other geometric approximations made involve some structural and control materials of the axial end zones separating the core region from the heavy water moderator. In the actual experimental facility, in the simplest reactor configuration, an AG3-NE alloy "plug" plate isolates the borated heavy water in the core region from the surrounding unborated heavy water. It is followed (on the outside) by unborated $\mathrm{D}_{2} \mathrm{O}$ and, much farther, by the axial portion of the reactor core barrel. In the intermediate and full complexity configurations, the boron end caps follow the inner AG3-NE alloy plug, replacing some of the $\mathrm{D}_{2} \mathrm{O}$ between the axial plug and the axial portion of the core barrel. These boron end caps are constructed as altemate layers of borated and unborated AG3-NE plates in a B/U/B pattern repeated four times (for a total of eight Borated layers and four Unborated ones). In the MCNP model, only the inner AG3-NE seal (plug) is modeled explicitly. The boron end caps are modeled as homogenous regions $30-\mathrm{mm}$ thick. The axial portion of the core barrel (exact location and thickness undocumented), having little neutronic impact, is simply ignored. The modeling of the borated end caps as homogenous regions allows the use of the boron end zone homogenized material description from the FOEHN report. Little effect on global core parameters is anticipated, and only minor perturbations in the core power distribution are expected. 
The MCNP model of the radial description of the reactor follows closely the information provided in the FOEHN report. Such information is, however, not complete, and assumptions have to be made. A summary of the description of the core region starting at the reactor centerline and moving outward is given in Sect. 3.3.1.

In some critical states, the control rod top was at a height $<1.0 \mathrm{~m}$ position in the MCNP coordinate system. In these cases, a portion of the rod was below the bottom of the reflector tank, which is the lower boundary of the MCNP model. In the model, the portion of the rod protruding below the tank floor was neglected. This should not produce any significant problem since the distance of this portion of the rod from the active core is large. In these states, dissolved boron is the primary source of reactivity control, and, hence, the protruding section of the control rod has negligible worth. Further discussion of this phenomenon is included in Sect. 4.2.1.

\subsubsection{Assumptions on Materials Data}

The materials used in the MCNP model of the FOEHN critical facility mirror as closely as possible the actual materials used in the facility. This was accomplished by using the material compositions given in Table 3.1 of the FOEHN report for the fueled region of the core and for the boron end plates. The atomic contents of all other material compositions (e.g., borated and unborated $\mathrm{D}_{2} \mathrm{O}, \mathrm{AG} 3-\mathrm{NE}$, etc.) were calculated in this work. Where gaps appear in the table, approximations and best guesses had to be used. These are explained below.

Table 3.1. Composition of Zircaloy-4 used in the model ${ }^{a}$

\begin{tabular}{cc}
\hline Element & Weight percent \\
\hline $\mathrm{Zr}$ & Balance \\
$\mathrm{Sn}$ & 1.5 \\
$\mathrm{Fe}$ & 0.20 \\
$\mathrm{Cr}$ & 0.10 \\
$\mathrm{Ni}$ & 0.007 \\
\hline
\end{tabular}

'From S. Glasstone and A. Sesonske, Nuclear Reactor Engineering, 3rd Ed., p. 460, Van Nostrand Reinhold, 1981.

The hot source graphite and the cadmium in the safety rods were modeled as elemental graphite and cadmium at full theoretical density with no impurities. This produces an overestimate of the atomic densities for these materials and is expected to produce some local effects, especially in the hot source flux calculations. However, since the safety rods were not included in any of the FOEHN experiments used in these calculations, the cadmium density had no effect on the results.

In several reflector internal components, the zirconium alloy Zircaloy-4 and stainless steel type 304 (SS-304) were used. Compositions for these alloys were not available, so the material composition for SS-304 was taken from a standard handbook, ${ }^{12}$ and that of Zircaloy-4 was assumed to be the same as the one used in the MCNP model of the ANS reactor. The composition used for Zircaloy-4 is shown in Table 3.1. Since there is a large range of possible nuclide contents for these alloys, there ensues a consequent degree of uncertainty about the fidelity of the model. This will again produce mainly local effects, with insignificant global consequences. The composition data used for the 
AG3-NE aluminum alloy are given in Table 3.2. All heavy water is assumed to be contaminated by 0.25 at. \% light water. This value is very close to the values quoted in the FOEHN report.

Table 3.2. Composition of the AG3-NE aluminum alloy

\begin{tabular}{cccc}
\hline Element & $10^{30}$ atoms $/ \mathrm{m}^{3}$ & Element & $10^{30}$ atoms $/ \mathrm{m}^{3}$ \\
\hline $\mathrm{Al}$ & 0.031673 & $\mathrm{FE}$ & $6.9681 \times 10^{-5}$ \\
$\mathrm{Co}$ & $2.1221 \times 10^{-8}$ & $\mathrm{Ni}$ & $6.6513 \times 10^{-7}$ \\
$\mathrm{Cr}$ & $6.493 \times 10^{-5}$ & $\mathrm{Cu}$ & $6.3346 \times 10^{-7}$ \\
$\mathrm{Mn}$ & $1.1323 \times 10^{-4}$ & $\mathrm{Ga}$ & $4.4342 \times 10^{-6}$ \\
$\mathrm{Th}$ & $4.751 \times 10^{-9}$ & $\mathrm{Ta}$ & $3.1673 \times 10^{-6}$ \\
\hline
\end{tabular}

\subsection{MCNP MODEL DESCRIPTION}

The FOEHN experiment incorporates many of the features found in the current design of the ANS reactor. The comparison is illustrated by SABRINA ${ }^{13}$ printouts of the MCNP models for the ANS reactor and FOEHN in Figs. 3.1a and 3.1b, respectively. As can be seen from Fig. 3.1b, the MCNP model of the FOEHN critical experiment incorporates a full description of the entire experiment, including all reflector internals and the boron end zones. The cases that did not require either the reflector internals or boron end zones are modeled by substituting heavy water for the actual material in the appropriate zones. The approximations used in developing the model are described in the previous section. The complete model is described below. Additional details of the model can be seen in Figs. 3.1b-3.6. These are SABRINA printouts of six views of the experiment as modeled in MCNP. The views are front, left, right, top, bottom, and rear, respectively.

\subsubsection{The Core and Surrounding Structures}

The core is modeled as a hollow cylinder $0.8-\mathrm{m}$ tall, with inner and outer radii of 0.14 and $0.195 \mathrm{~m}$, respectively. Figures $3.7 \mathrm{a}$ and $3.7 \mathrm{~b}$ show, respectively, a diagram of an axial and a radial (top view) of the core and the surrounding barrel. The core region is modeled as a homogenous mixture of the uranium fuel, borated heavy water, and aluminum cladding material. The choice of a homogenous core model was justified in Sect. 3.2.1. An additional reason for using a homogenous core model is the fact that the actual plate locations are not documented in the FOEHN report, and their spacings could vary since the fuel plates were not welded to the inner and outer core barrel walls. The core material properties are those of Table 3.1 of the FOEHN report. Dissolved boron in the heavy water was added to the mixture as required for each case, with the appropriate corrections made to the material description and overall atom density. The boron end zones were modeled as homogenous regions at the top and bottom of the core, 30-mm thick, with the same radius as the core.

Figure 3.8 shows an axial diagram of the core region and its surrounding structures. The control rod was modeled as a nickel annulus $5-\mathrm{mm}$ thick and $1-\mathrm{m}$ long. The dimensions for the heavy water regions and surrounding core barrel and isolation cask were derived from detailed figures of these regions (ref. 6). The structures above and below the core were modeled according to Fig. 3.3 in the FOEHN report. Since no exact dimensions were provided, best estimates from the diagram were used. 


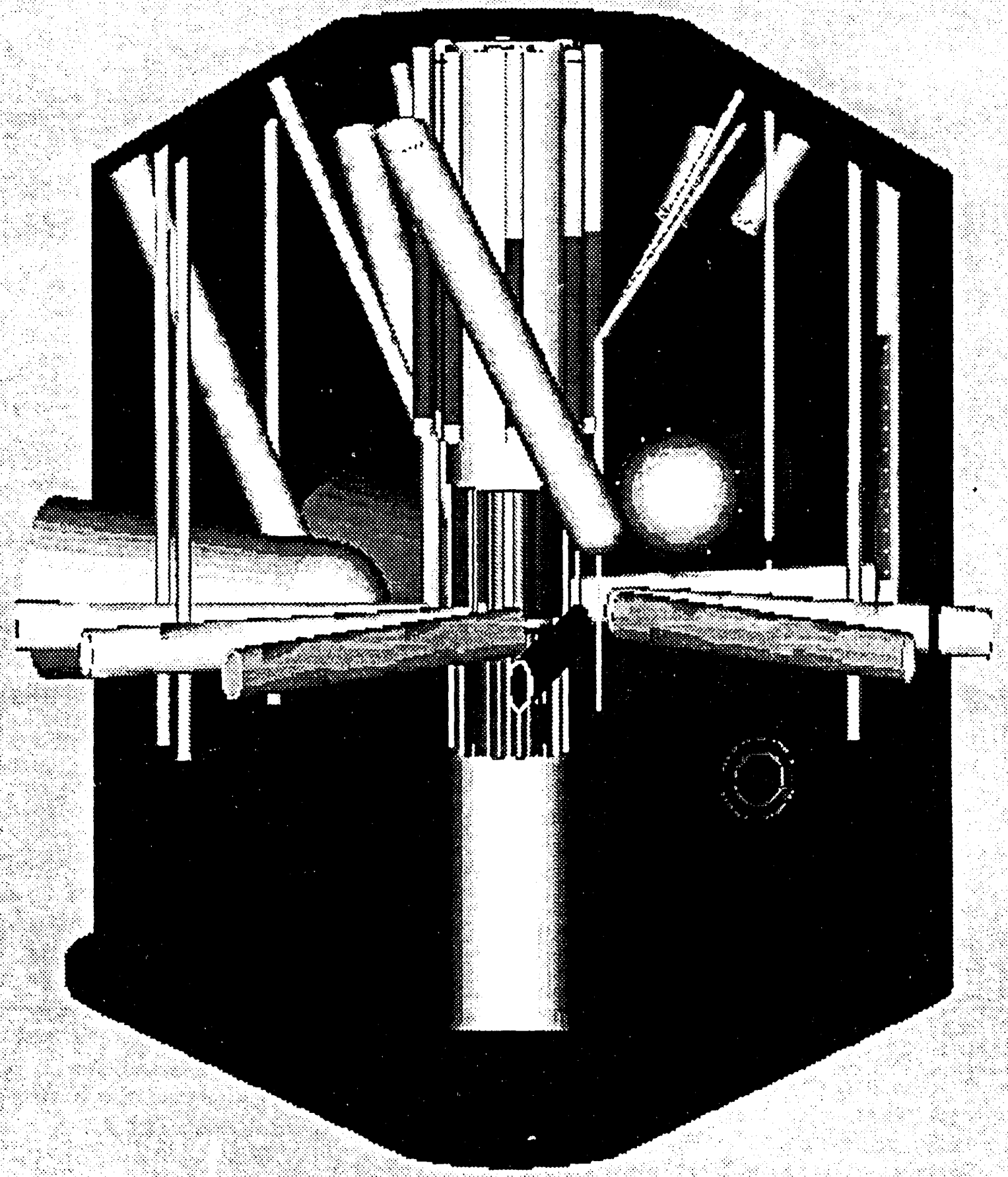

Fig. 3.1a. SABRINA printout of the current ANS reactor design MCNP model. 


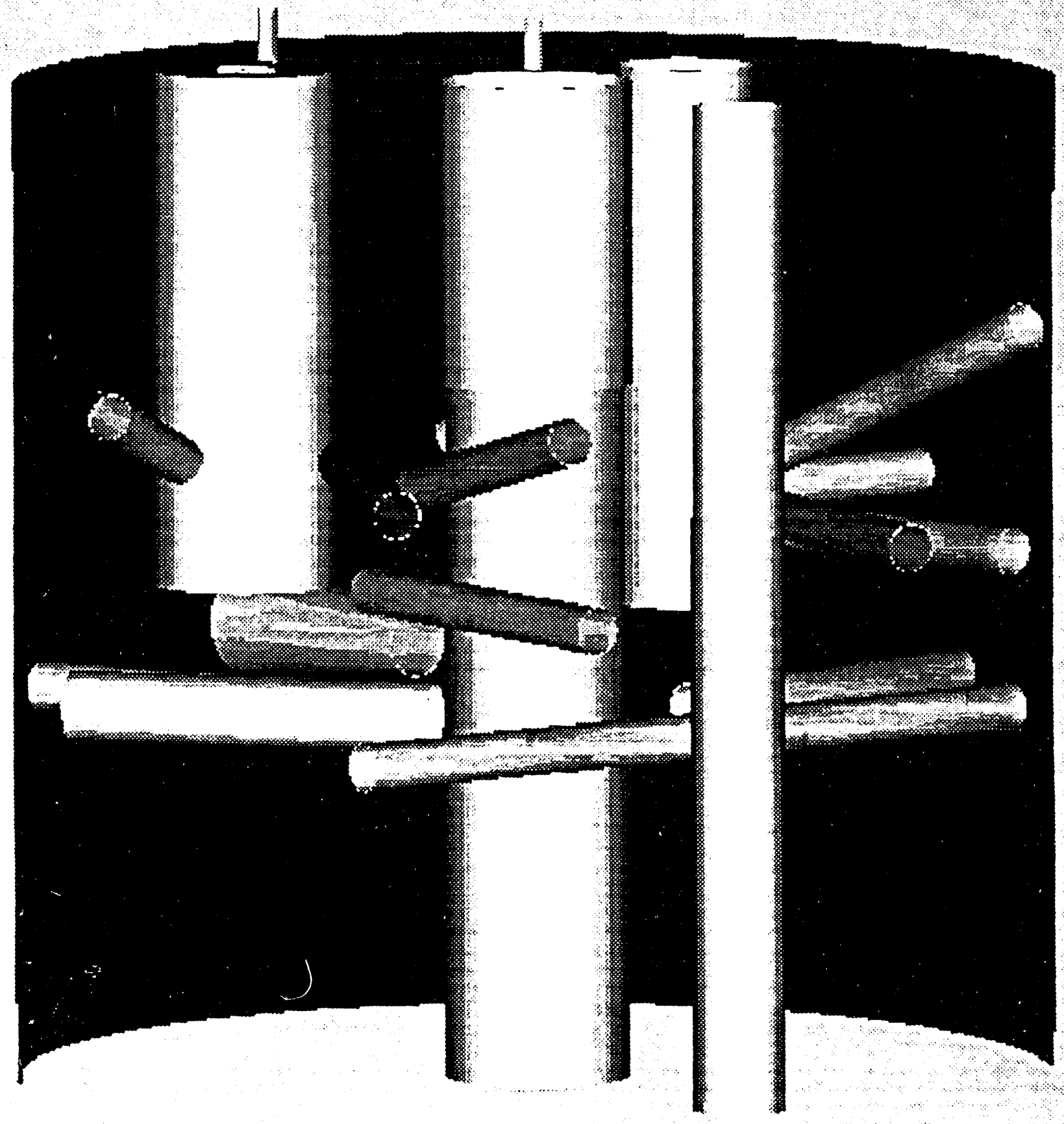

Fig. 3,1h. SABRISA printuut of the FOEHN experiment MCNP model (front view). 


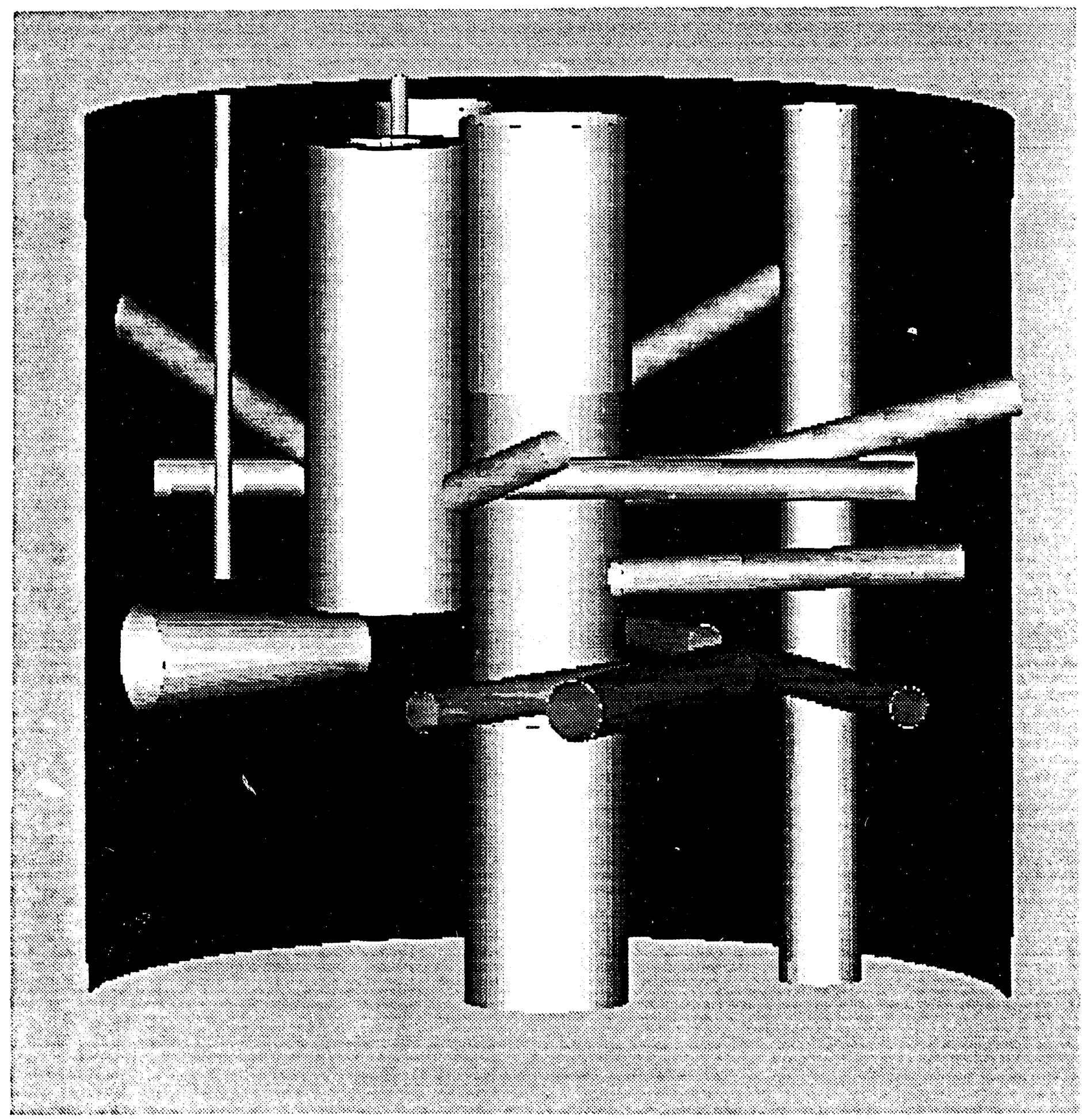

Fig. 3.2. SABRINA printout of the FOEHN experiment MCNP model (left view). 


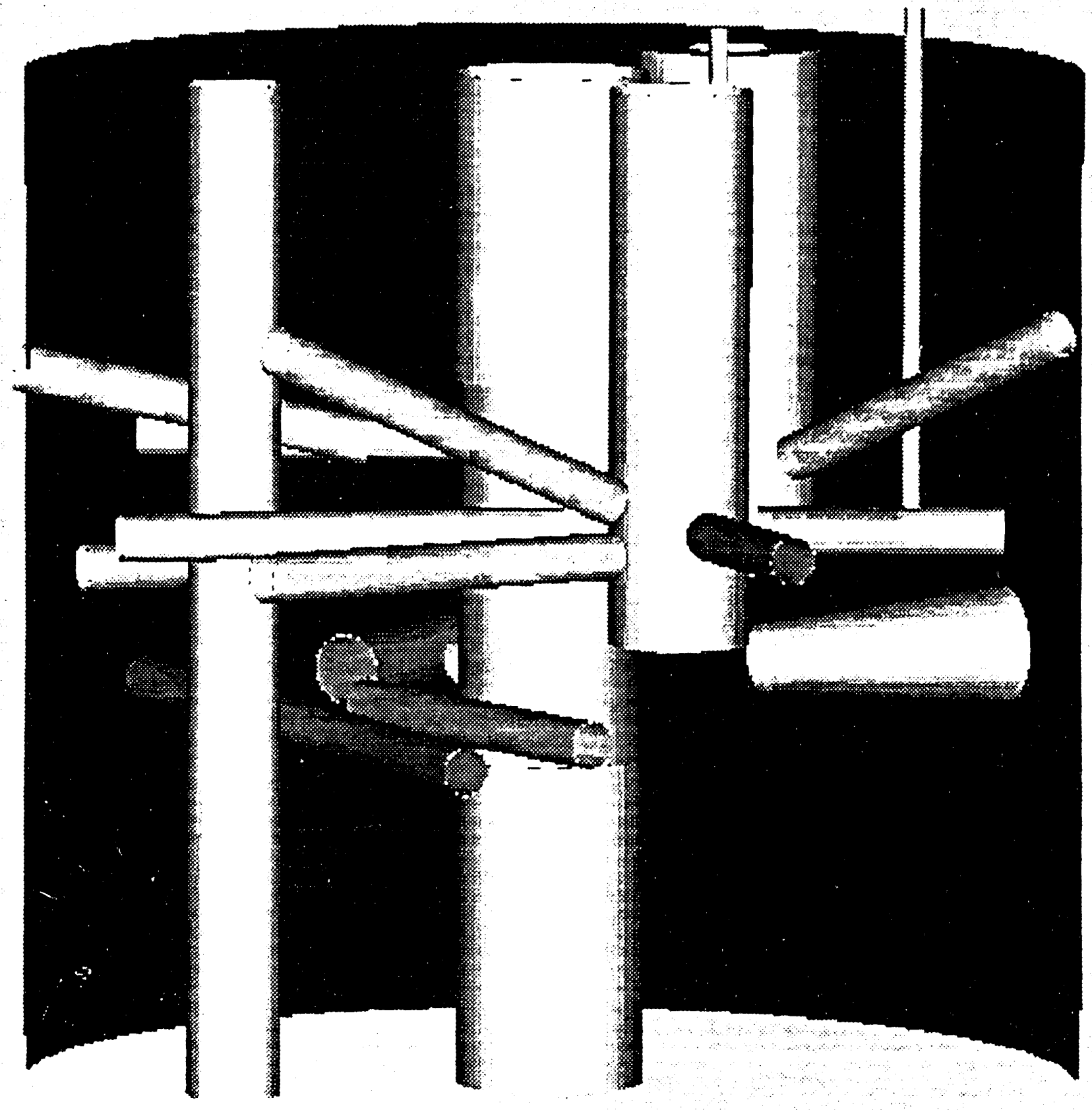

Fig. 3.3. SABRINA printout of the FOBHN experiment MI NP model (right view). 


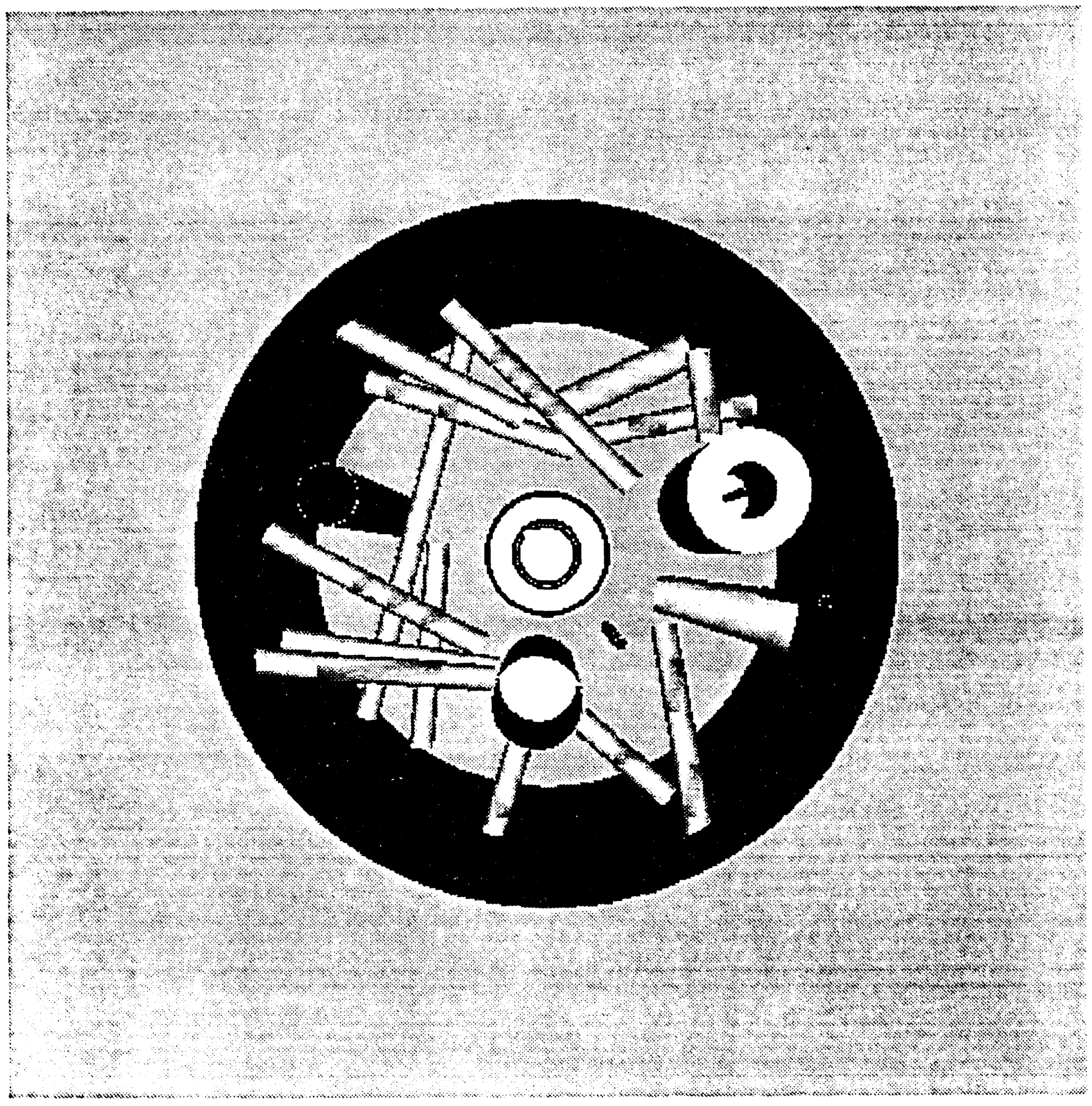

Fig. 3.4. SABRINA printout of the FOEHN experiment MCNP model (top view). 


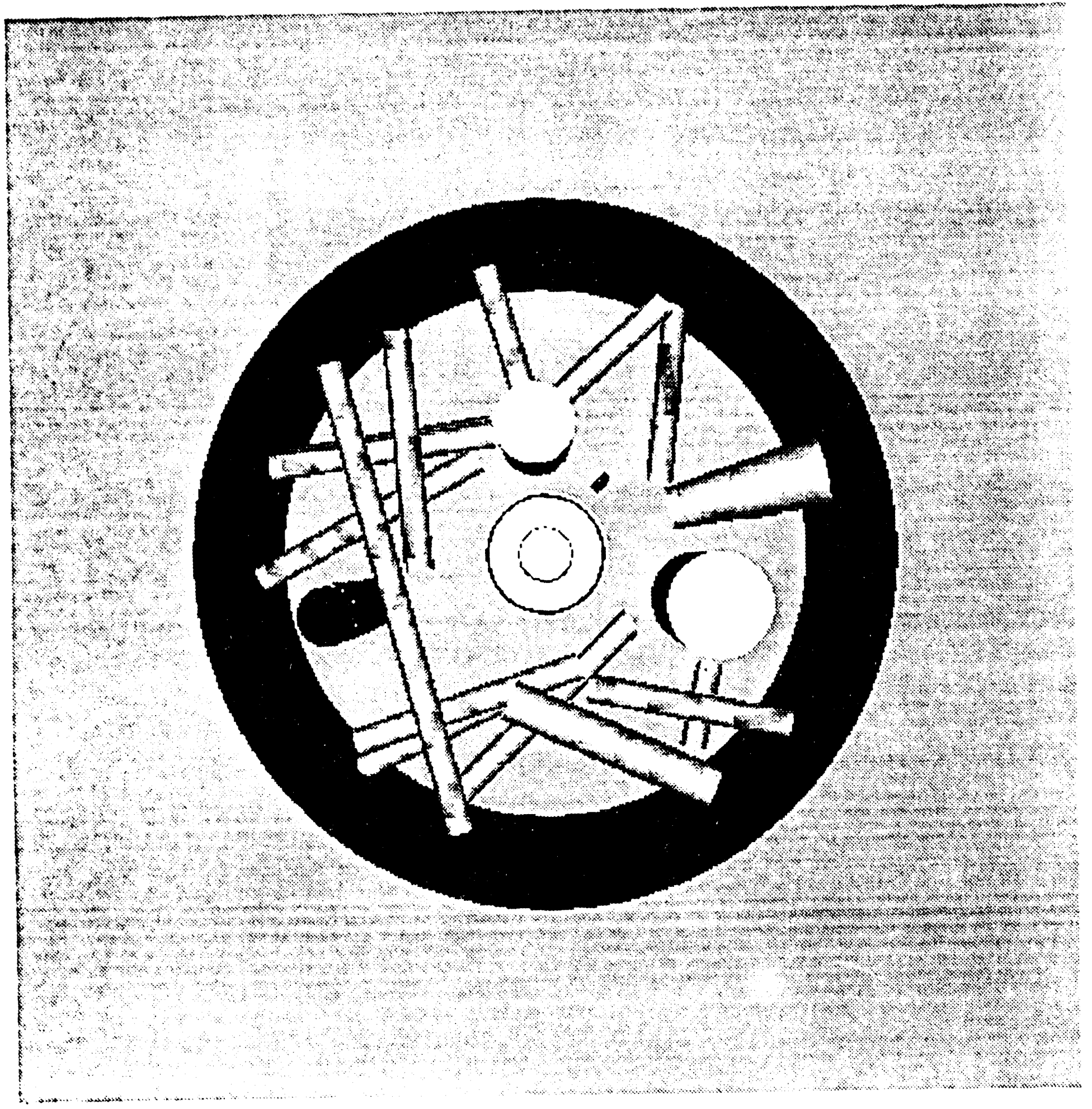

Fig. 3.5. SABRINA printout of the FOEHN experiment MCNP model (lower view). 


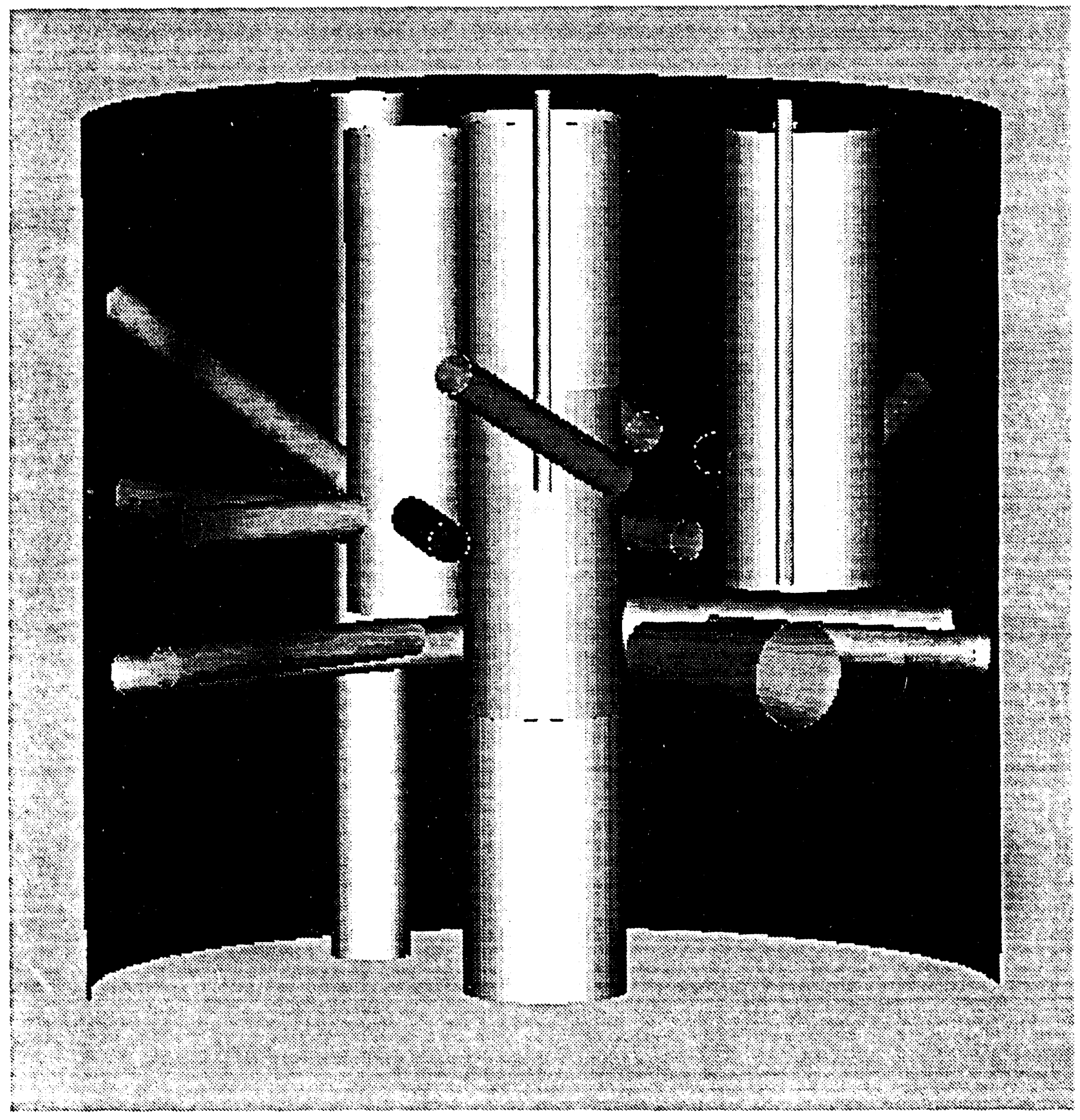

Fig. 3.6. SABRINA printout of the FOEHN experiment MCNP model (back view). 


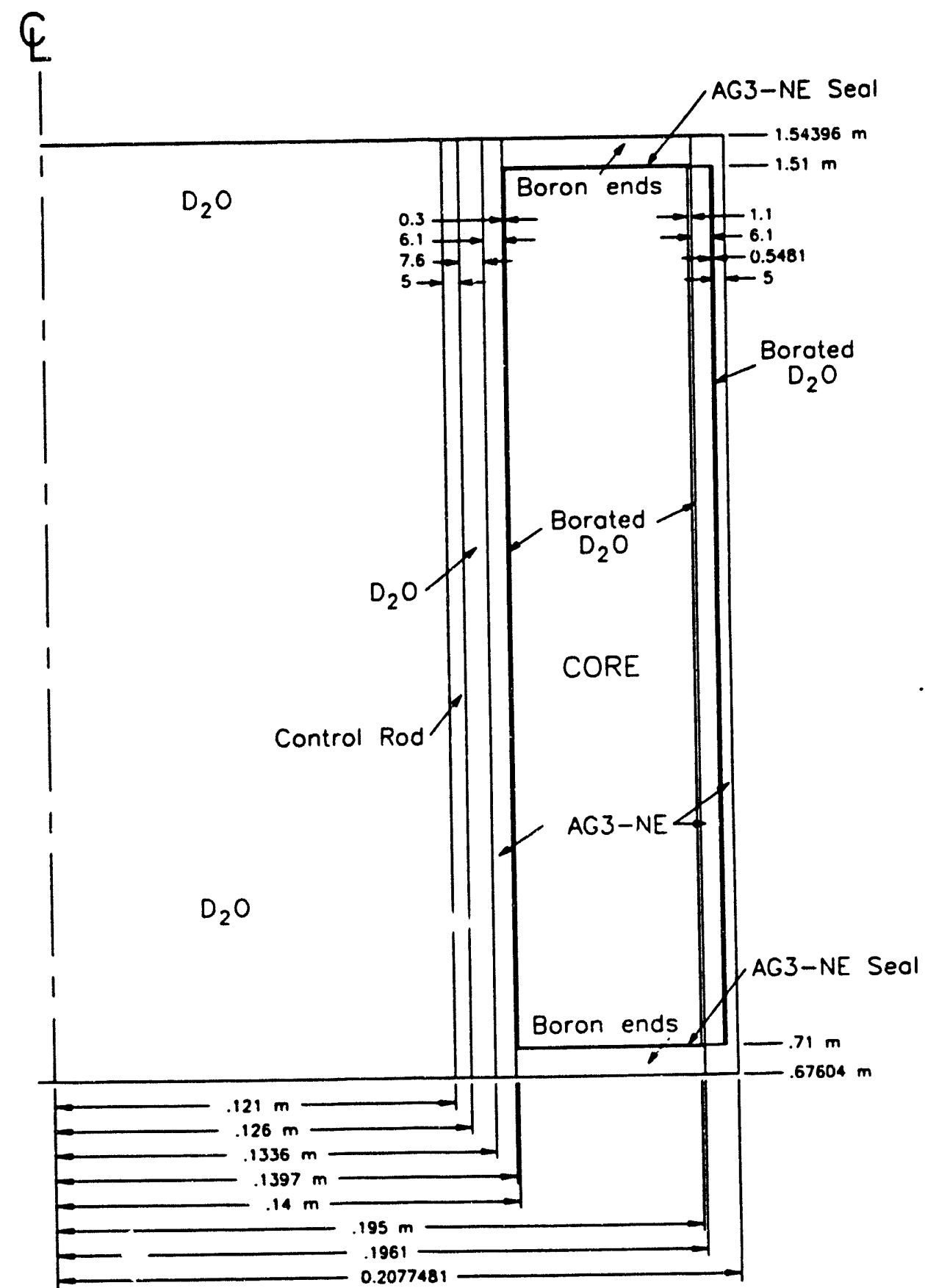

Not to Scale

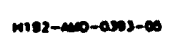

Fig. 3.7a. Axial view of the FOEHN core and its surrounding cask. 


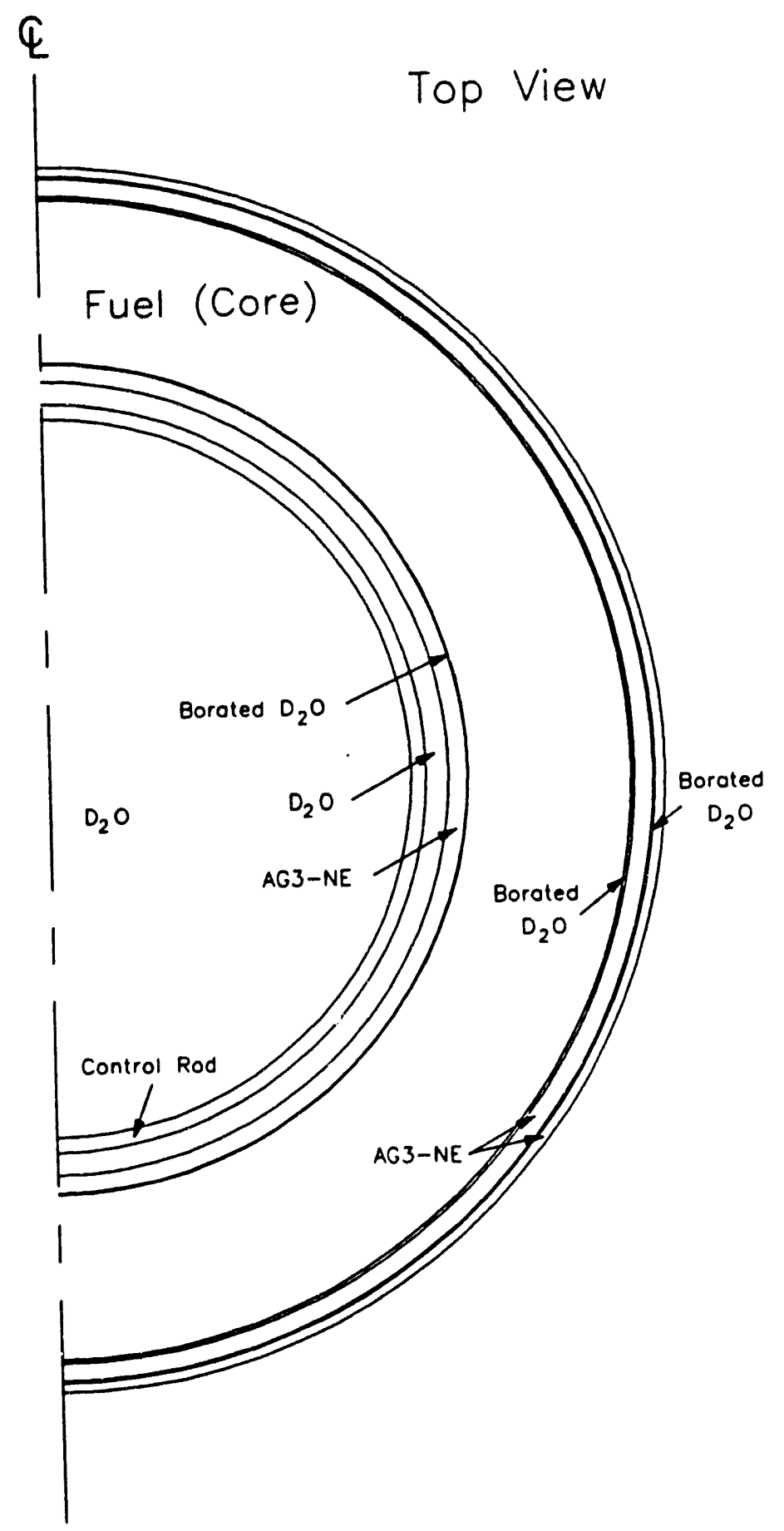

M192- - $10-0303-04$

Fig. 3.7b. Radial view of the FOEHN core and its surrounding cask. 


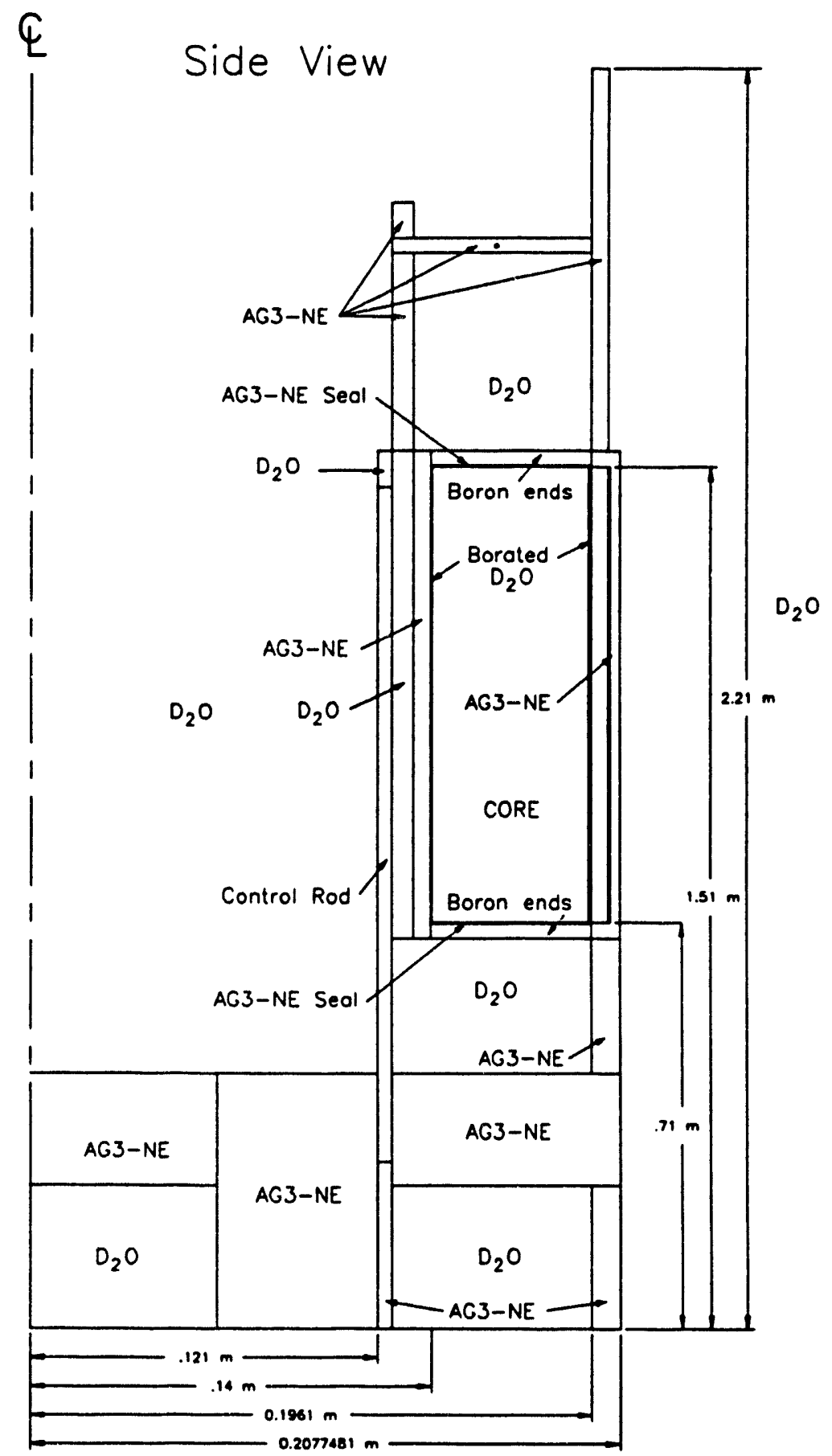

M192-A0No-0203-05

Fig. 3.8. Axial diagram of the FOEHN core and surrounding structures. 
In modeling the core, the control cylinder, and the core barrel, a number of assumptions had to be made. Referring to Figs. 3.7a and 3.7b, the core is now described starting from the centerline and moving outward. The central region is occupied by unborated heavy water up to a radius of $121 \mathrm{~mm}$. The following cylindrical shell is the control rod (5-mm thick). Following the control rod is a layer of unborated heavy water extending $7.6 \mathrm{~mm}$. After this heavy water comes the inner wall of the core barrel. The outside surface of this wall, facing the inner reflector and control shell, is smooth. The inside surface, facing the core, is grooved (comb teeth) to hold the fuel plates in place. It is not clear from the FOEHN report whether the inner side combs cover the entire length of the core. In that report, pictures of the external combs show that they do not fully cover the core. The comb region may have gaps containing borated $\mathrm{D}_{2} \mathrm{O}$. In the model, the geometric details of the gaps are ignored; the entire shell (solid portion and comb region) is modeled as a single, solid, 6.1-mm thick AG3-NE shell followed by a $0.3-\mathrm{mm}$ layer of borated $\mathrm{D}_{2} \mathrm{O}$. The fuel lies immediately after this heavy water layer. The thickness of the fuel region is $55.0 \mathrm{~mm}$. This region is assumed to contain a homogenous mixture of borated $\mathrm{D}_{2} \mathrm{O}$, aluminum, and ${ }^{235} \mathrm{U}$. A borated $\mathrm{D}_{2} \mathrm{O}$-filled gap of $1.1 \mathrm{~mm}$ separates the fuel region from the external comb region (also used to hold the fuel plates in place). The remarks made about the inside comb region are applicable to the outside one. The region is also modeled as a solid AG3-NE shell $6.1-\mathrm{mm}$ thick. The water contained in the comb region is modeled as a separate layer of borated $\mathrm{D}_{2} \mathrm{O}$ located between the comb shell and the outer wall of the core barrel. This layer also accounts for the fact that the fit between the comb shell and the core barrel wall cannot be exact, and that some tolerance is to be expected. The thickness of the borated $\mathrm{D}_{2} \mathrm{O}$ layer is chosen to be $0.5481 \mathrm{~mm}$. This choice accommodates the balance of borated $\mathrm{D}_{2} \mathrm{O}$ contained within the core barrel and otherwise not accounted for in the "free" (nonfuel) volume within the core. The outside wall of the core barrel is $5-\mathrm{mm}$ thick. The core barrel is surrounded by the external nonborated $\mathrm{D}_{2} \mathrm{O}$ reflector.

The above description contains an assumption pertaining to the distribution of borated heavy water within the core/core barrel region. It is assumed that some of the borated heavy water is not located in the fuel region and instead constitutes a shell within the outer core barrel region. A similar assumption is not made, however, for the inner core barrel region. With these assumptions, the core and core barrel regions are modeled to contain $28.85 \mathrm{~L}$ of borated $\mathrm{D}_{2} \mathrm{O}$. This is the measured borated $\mathrm{D}_{2} \mathrm{O}$ content of the core/core barrel in FOEHN, and it is different from the design content of $27.0 \mathrm{~L}$.

\subsubsection{Reflector Internals}

The description and placement of the reflector internals were done according to Fig. 2 and Table 2 of ref. 5. The beam tubes and other assorted channels were modeled as evacuated AG3-NE tubes using material 40 from Table 3.1 of the FOEHN report. The hot and cold sources geometry and materials were modeled exactly as described in Figs. 3 and 4 of ref. 8 . The beam tubes were modeled as AG3-NE alloy tubes. The interior of the beam tubes was modeled as a vacuum.

\subsubsection{Safety Rods}

The safety rods were modeled as described in Sect. 2.2.1.4. Locations for the safety rods were based on Sect. 5.5.2.2 of the FOEHN report with the rod centers located $0.33 \mathrm{~m}$ from the core center. The safety rods were not included in any of the experiments modeled. They were replaced, therefore, with heavy water in all model cases. 


\subsubsection{The Coordinate System}

The coordinate system used in the FOEHN model was the same as that used to describe most of the structures in the experiment. The origin was at the core centerline and at the bottom of the reflector tank. The use of this coordinate system allowed direct translation of the core structures and reflector internals to the MCNP geometry model. Figure 3.8 shows the origin and coordinate system used. A different coordinate system was used for the control rod, and, thus, some translation to the MCNP geometry model was required. In the FOEHN report, the origin for the control rod system was $0.1-\mathrm{m}$ above the top of the core, wit.i the positive direction being downward. The top of the control rod was considered to be the zero point on the rod. Thus, when the top of the control rod was $0.1-\mathrm{m}$ above the top of the core, the control rod was said to be inserted to $0.0 \mathrm{~m}$, and downward motion was positive insertion. This system was translated to the MCNP geometry model, which put the zero point at $1.61 \mathrm{~m}$. This created some minor problems when the control rod was at a height of $<1.0 \mathrm{~m}$, as the bottom of the rod was then outside the MCNP model. In these cases, the portion of the rod below the tank bottom was neglected.

\subsubsection{Materials}

The materials used in the model are described in Sect. 3.2.2 of this report. The core and the boron end caps were taken from Table 3.1 of the FOEHN report. The data for graphite, cadmium, Zircaloy-4, and stainless steel 304 (SS-304) were not included in the FOEHN report. The assumptions used in selecting data for these materials are also discussed in Sect. 3.2.2. The actual nuclide concentrations used can be found in Appendix A, which lists the entire input file for the MCNP model. The compositions used for Zircaloy-4 and SS-304 are the same as those previously used in a model of the ANS reactor and a model of the High Flux Reactor of ILL. Figures 3.7 and 3.8 show the MCNP materials used to model the individual core regions. The beam tubes were modeled using the AG3-NE alloy. The core, borated heavy water, and aluminum core structural material compositions were altered as needed to reflect changes in the dissolved boron concentration in the core.

\subsection{MCNP TALLIES AND COMPUTATION OF $\boldsymbol{k}_{\text {eff }}$ AND RENDEMENT}

The choices of MCNP tallies to be used in the comparison between the FOEHN experiment and the computational model are shown, and the reasons for their selection are summarized in this section. In addition, the methods used to compute $k_{\text {eff }}$ and the rendement are discussed.

\subsubsection{Fluxes}

The thermal fluxes reported in the FOEHN experiments are obtained by estimating the activation due to thermal neutrons (the activation is proportional to the flux). They are, therefore, best approximated by a track length estimate of the flux (i.e., a F4:n MCNP tally). The upper energy boundary of the thermal energy group should be chosen as $0.625 \mathrm{eV}$ to conform with the definition of thermal flux chosen in the FOEHN experiment based on the cadmium effective cutoff energy. 


\subsubsection{Powers}

The fission power density or fission power production density is described as power distribution in the FOEHN report. It is measured by evaluating the number of fission events that occurred in a given fission probe. The measurements yield a quantity proportional to the power released in the probe during irradiation. The MCNP tally that most closely represents this physical quantity is a F7:n tally.

\subsubsection{Effective Multiplication Factor}

The multiplication factor $\left(k_{e}\right)$ is measured via three different methods in the FOEHN experiment (see Sect. 2.3.1.1). In the present work, $k_{e f}$ is computed via the KCODE option of MCNP.

\subsubsection{Determination of Rendement}

A measure of the neutron efficiency, the rendement, is defined as the ratio of the maximum thermal flux in the reflector to the total recoverable power produced in the reactor. In the MCNP model, the rendement is computed from the maximum value of F4:n tallies in the reflector renormalized using the multiplying factor

$$
R N=v \cdot \frac{1}{Q} \cdot \frac{1}{k_{\alpha}}
$$

where $v$ is the average number of neutrons per fission, $Q$ is the fission energy, and $k_{e f}$ is the effective multiplication factor from the MCNP run that yielded the flux tally to be renormalized. In this work, $v$ is computed as the ratio of two separate MCNP tallies, and its value is reported whenever pertinent. When a value is not computed for $v$, and one is required, the number 2.44175 is used. The energy released per fission event, $Q$, is taken to be $202.47 \mathrm{MeV} /$ fission unless otherwise specified. In order to obtain a meaningful comparison in the computational determination of the rendement, the same value of $Q(199.73 \mathrm{MeV})$ as that of the FOEHN report is used in this work, but only for "rendement" computations.

\subsection{SUMMARY}

In this chapter, the MCNP model developed in this work has been presented. The main approximation made was the use of a homogenized fuel region and of homogenized boron axial end covers above and below the core. These appruximations were justified by the fact that the neutron mean free path in these regions is much larger than any of the dimensions of the constituting components. The materials used in the model accurately represent the compositions used in the experiment. The only exceptions are the use of full theoretical density graphite (C) and cadmium (Cd) data. When Zircaloy -4 and stainless steel 304 were required, data developed for models of the ANS reactor and of the FGHFR were used. The fluxes and the power production distribution are modeled as F4:n and F7:n tallies, respectively. The rendement is computed as a particular case of a renormalized F4:n tally. The core multiplication factors are obtained via the KCODE option of MCNP. 


\section{RESULTS}

\subsection{INTRODUCTION}

The results obtained in the course of this study are detailed in this chapter. The FOEHN report is consistently referred to for comparisons. The results are reported by reactor configuration. The core multiplication factor, thermal flux, rendement, and power distribution are addressed in turn. It is shown that the model and the experimental results coincide very well within the computational statistical error and experimental error bounds. The model results are reported normalized as described in the text. The MCNP error estimates (standard deviations $\sigma$ ) are reported as fractions of the tallies they qualify unless otherwise noted to be absolute values.

\subsection{SIMPLE REACTOR MODEL}

\subsubsection{Core Multiplication Factors $\left(\boldsymbol{k}_{\mathrm{eff}}\right)$}

The multiplication factor has been evaluated for 11 critical control rod positions and corresponding boron concentrations for the simple FOEHN configuration (no boron end caps and no reflector internals). These computations used the KCODE option of MCNP with 40 cycles and 3000 histories per cycle. The results are given in Table 4.1 and shown in Fig. 4.1. The cases in Fig. 4.1 are defined in the table as particular combinations of control rod positions and soluble boron concentrations for which the reactor is critical. The case definitions for all reactor configurations are taken from Table 5.1.1 of ref. 2. It can be seen from Fig. 4.1 that the computational results coincide with 1.0 within a tolerance of $2 \sigma$ for two cases and are very close for five other cases. The miss rate is $9 / 11$ (i.e., nearly $82 \%$ ). This rate is far greater than the theoretically expected average miss rate of about $5 \%$ for $2 \sigma$ error bars. If the error bars are increased to $3 \sigma$, the miss rate drops to five, of which two would be very close misses.

An estimate of the effect of small perturbations in control rod position on the calculated critical states was obtained by moving the control rod up or down $20 \mathrm{~mm}$ from the critical position. This was done for each of three different critical states: rod at $1.438 \mathrm{~m}$ and $0.2477 \mathrm{~g} / \mathrm{L}$ of boron in the core; rod at $1.009 \mathrm{~m}$ and $0.4509 \mathrm{~g} / \mathrm{L}$ of boron in the core; and rod at $0.714 \mathrm{~m}$ and $0.5386 \mathrm{~g} / \mathrm{L}$ of boron in the core. The results of these runs are presented in Table 4.2 and Fig. 4.2. These show that for the first critical state (rod initially at $1.438 \mathrm{~m}$ and $0.2477 \mathrm{~g} / \mathrm{L}$ of boron), the rod position perturbation produces the expected behavior-rod withdrawal increases the core multiplication factor, whereas rod insertion reduced it. For the intermediate boron concentration $(0.4509 \mathrm{~g} / \mathrm{L})$, the same behavior is observed. In the last case, the core multiplication factors of the initial critical state and of the perturbed states are within the $2 \sigma$ error bars defined by the computational statistics and, thus, are not distinguishable. This can be attributed to the reduced worth of the control rod caused by the high concentration of boron in the core. For this critical state, the boron concentration in the core provides the bulk of the reactivity control, and hence small perturbations in the control rod positions have small effects, and the observed fluctuations have no statistical significance.

\subsubsection{Thermal Flux}

Calculated MCNP thermal fluxes (F4:n tallies, KCODE, 40 cycles, 10000 histories/cycle) were compared to the results given in Table 5.1.4 of ref. 2. The thermal flux for this comparison was 
Table 4.1. MCNP computed core effective multiplication factors $\left(k_{e, f}\right)$ for various critical states of the simple reactor configuration

\begin{tabular}{cccccc}
\hline & \multicolumn{2}{c}{$\begin{array}{c}\text { Control rod } \\
\text { position }(\mathrm{m})\end{array}$} & & & \\
Case & MCNP & FOEHN & $\begin{array}{c}\text { Boron conc. } \\
(\mathrm{g} / \mathrm{L})\end{array}$ & $\begin{array}{c}\text { MCNP } \\
k_{\text {ef }}\end{array}$ & $\begin{array}{c}\text { MCNP error } \\
\text { estimate }(\sigma)\end{array}$ \\
\cline { 2 - 6 } 1 & 1.438 & 0.172 & 0.2477 & 1.0003 & 0.0019 \\
2 & 1.253 & 0.357 & 0.3349 & 1.0076 & 0.0029 \\
3 & 1.155 & 0.455 & 0.3863 & 1.0092 & 0.0021 \\
4 & 1.142 & 0.4673 & 0.3855 & 1.0093 & 0.0030 \\
5 & 1.014 & 0.596 & 0.4501 & 1.0127 & 0.0023 \\
6 & 1.009 & 0.601 & 0.4509 & 1.0080 & 0.0031 \\
7 & 1.008 & 0.602 & 0.4536 & 1.0095 & 0.0026 \\
8 & 0.949 & 0.661 & 0.4791 & 1.0069 & 0.0029 \\
9 & 0.753 & 0.857 & 0.5268 & 1.0034 & 0.0033 \\
10 & 0.720 & 0.89 & 0.5386 & 1.0104 & 0.0021 \\
11 & 0.714 & 0.896 & 0.5386 & 1.0069 & 0.0028 \\
\hline
\end{tabular}

defined as the flux below $0.625 \mathrm{eV}$. This cutoff energy was chosen to match the cutoff energy used in the FOEHN experiment. The F4:n tally gives the neutron flux averaged over a cell in units of particles $/ \mathrm{cm}^{2}$. Measured thermal fluxes in ref. 2 were reported at specific radii ( $r$ ) and heights (z), but no specific azimuthal location was given in the report. To model these locations in MCNP, annuli of $0.01-\mathrm{m}$ width and $0.01-\mathrm{m}$ height were used. The center of the annuli were located at the coordinates $(r, z)$ of the detector foils. The control rod height for this case was set at $1.01 \mathrm{~m}$ in the MCNP model. The boron-10 $\left({ }^{10} \mathrm{~B}\right)$ concentration was $0.450 \mathrm{~g} / \mathrm{L}$.

The MCNP F4:n tallies were normalized to $1 \mathrm{~W}$ total reactor power for a direct comparison with the experimental results. Table 4.3 shows the MCNP-calculated thermal fluxes, and Table 4.4 shows the corresponding computed error estimate $(2 \sigma)$. The entries in these two tables are in units of $10^{11} \mathrm{~m}^{-2} \cdot \mathrm{s}^{-1}$. The results in both of these tables use 2.43862 for $v$ and $202.47 \mathrm{MeV}$ for $Q$. These results can be directly compared to the thermal fluxes in Table 5.1 .4 of ref. 2 . In Figs. 4.3, 4.4, and 4.5, experimental and computational axial flux shapes are shown at radii of $0.235 \mathrm{~m}, 0.355 \mathrm{~m}$, and $0.835 \mathrm{~m}$, respectively, from the center of the reactor. As discussed in Sect. 2.4.3.2, the error bars for the experimental data points are taken as $\pm 12 \%$, a much more realistic figure than the $\pm 2 \%$ claim in the FOEHN report. The error bars on the MCNP points are based on a $\pm 2 \sigma$ error estimate. These figures show that MCNP-calculated thermal fluxes agree, within statistics and experimental error estimates, with the experimental results. Not seen from the three figures is the total number of points for which the experimental and computational results do not coincide (in the sense that their respective error bars overlap). This total number of misses is six. If the experimental bars are assumed to be 


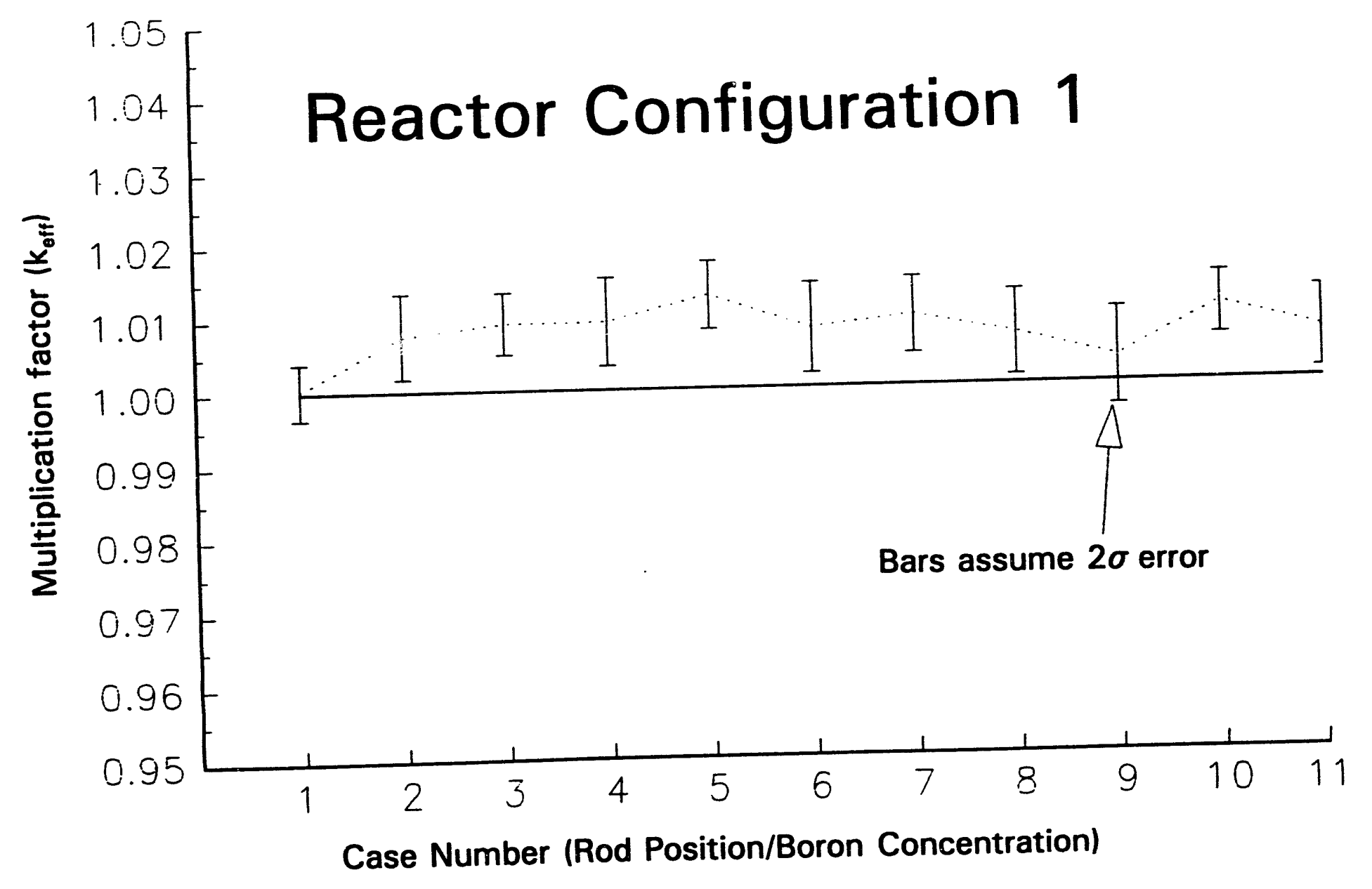

Fig. 4.1. MCNP prediction of $\boldsymbol{k}_{\text {eff }}$ for a set of critical states of the simple FOEHN reactor configuration. 
Table 4.2. Effect of control rod perturbations on the core effective multiplication factor for three critical states of the simple reactor configuration

\begin{tabular}{lccc}
\hline & & \multicolumn{2}{c}{ Core multiplication } \\
\cline { 3 - 4 } $\begin{array}{c}\text { Control rod } \\
\text { position }(\mathrm{m})\end{array}$ & $\begin{array}{c}\text { Core boron } \\
\text { concentration }(\mathrm{g} / \mathrm{L})\end{array}$ & $k_{\text {eft }}$ & $\sigma$ \\
\hline 1.478 & 0.2477 & 0.9937 & 0.0029 \\
1.438 (base) & 0.2477 & 1.0003 & 0.0019 \\
1.398 & 0.2477 & 1.0068 & 0.0030 \\
1.049 & 0.4509 & 1.0016 & 0.0025 \\
1.009 (base) & 0.4509 & 1.0080 & 0.0031 \\
0.969 & 0.4509 & 1.0165 & 0.0029 \\
0.760 & 0.5386 & 1.0030 & 0.0031 \\
0.720 (base) & 0.5386 & 1.0104 & 0.0021 \\
0.680 & 0.5386 & 1.0054 & 0.0027 \\
\hline
\end{tabular}

more narrow, the number of misses increases to 15 for $10 \%$ experimental error and to 38 for $8 \%$ experimental error. Since there are 158 experimental points, these misses represent miss rates of 3.8, 9.5 , and $24 \%$ respectively. The $12 \%$ experimental error assumption yields results that are compatible with the statistical interpretation of the $2 \sigma$ computational bars.

\subsubsection{Rendement}

For the simple reactor configuration, the measured rendement $\left(r_{\text {meas }}\right)$ is $2.480 \times 10^{11}$ neutrons/ $\mathrm{m}^{2} \cdot \mathrm{s} \cdot \mathrm{W}$. The error on this quantity ranges from at least $\pm 2.2 \%$ to possibly as much as $16.2 \%$ as estimated in Sect. 2.4.3.4 (vs the FOEHN report claim of $\pm 2 \%$ ). In the remainder, it is assumed that the error is the same as that on the flux-about $12 \%$.

The MCNP computed rendement, $r_{\text {calc }}$, is found to be $2.777 \times 10^{11}$ neutrons $/ \mathrm{m}^{2} \cdot \mathrm{s} \cdot \mathrm{W}$, with a standard deviation $(\sigma)$ of $0.94 \%$ (assuming $Q$ is $199.73 \mathrm{MeV}$, the same as the one used in the FOEHN report, and $v$ is 2.43862). The computed value of the rendement is $-12 \%$ higher than the experimental one. A similar result ( $14 \%$ higher) was found independently by Rohrmoser. ${ }^{10}$ The two error bands (experimental and computational-2 $\sigma$ ) overlap significantly. They would overlap slightly even if the experimental error was taken to be as low as $-10 \%$. The two estimates of the rendement can be considered to be coinciding.

\subsubsection{Power}

The MCNP model of the FOEHN critical experiment has been used to obtain F7:n tallies. The tallies have been normalized to the same constant (1.014239) as the data of the corresponding Table 5.1.5 of the FOEHN report, according to the procedure summarized in Sect. 2.3.2.2. The 


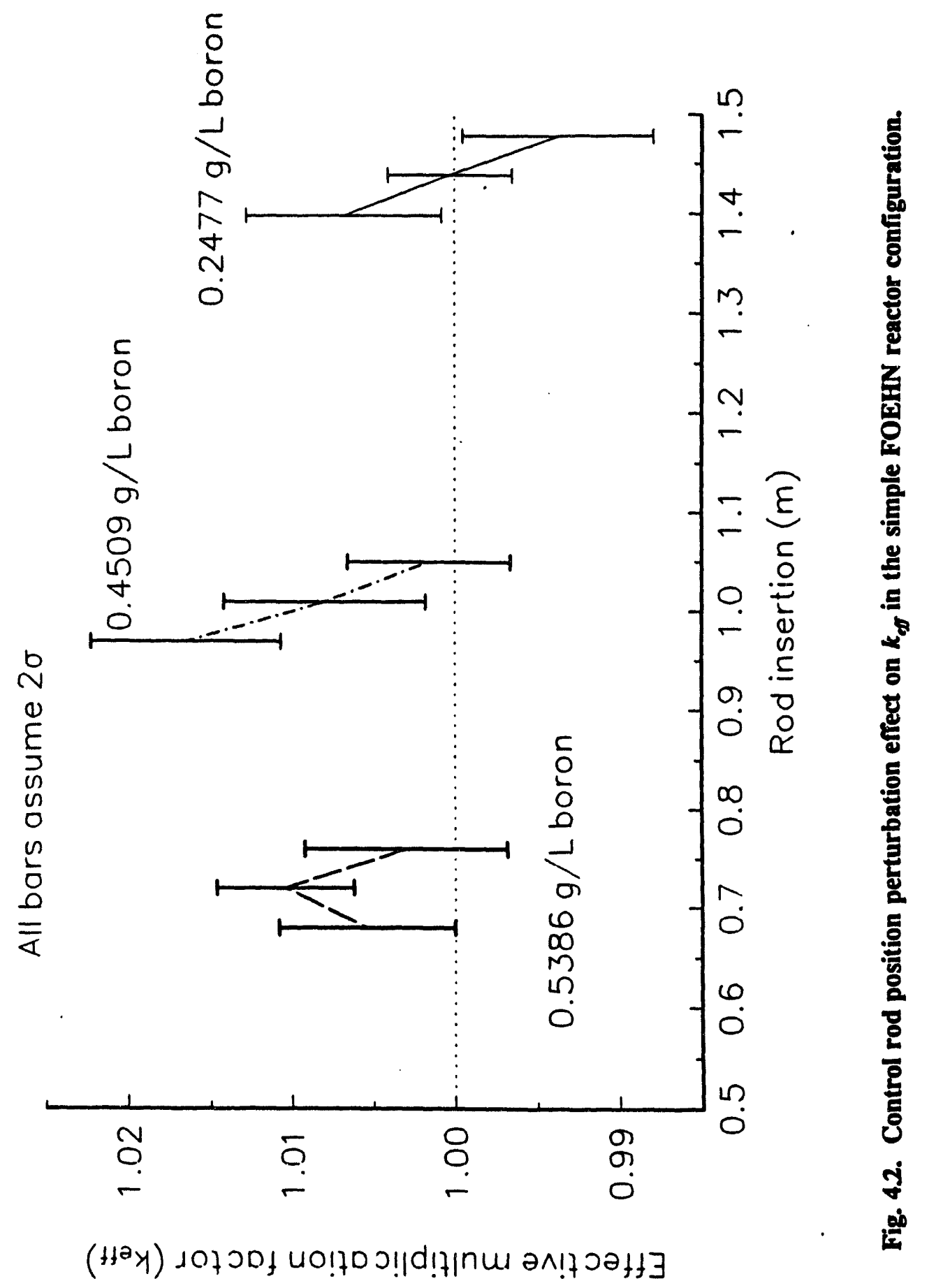


Table 4.3. Computed thermal fluxes for the simple reactor configuration

(MCNP F4:n tallies; $0.625 \mathrm{eV}$ cutoff; $1 \mathrm{~W}$ reactor power; units: $10^{11} \mathrm{~m}^{-2} \cdot \mathrm{s}^{-1}$ )

\begin{tabular}{cccccccccccccc}
\hline $\begin{array}{c}H / r \\
(\mathrm{~mm})\end{array}$ & 235 & 255 & 275 & 295 & 315 & 335 & 355 & 395 & 435 & 515 & 635 & 755 & 835 \\
\hline 525 & 0.6062 & 0.6828 & 0.7652 & 0.7298 & 0.7819 & 0.7997 & 0.8147 & 0.7878 & 0.7916 & 0.6971 & 0.5548 & 0.4008 & 0.3043 \\
625 & 0.9433 & 1.0015 & 1.0857 & 1.0532 & 1.1355 & 1.1259 & 1.1325 & 1.0841 & 1.0632 & 0.9136 & 0.7038 & 0.4942 & 0.3714 \\
725 & 0.9636 & 1.1321 & 1.3528 & 1.3327 & 1.4048 & 1.4777 & 1.4824 & 1.4568 & 1.3779 & 1.1713 & 0.8622 & 0.5972 & 0.4579 \\
825 & 1.1441 & 1.4061 & 1.7076 & 1.5790 & 1.7676 & 1.8411 & 1.8447 & 1.8072 & 1.6965 & 1.4314 & 1.0106 & 0.7069 & 0.5353 \\
925 & 1.3566 & 1.6437 & 2.0492 & 1.8655 & 2.1158 & 2.1648 & 2.1489 & 2.1101 & 1.9917 & 1.6737 & 1.1570 & 0.8019 & 0.6018 \\
975 & 1.4740 & 1.7678 & 2.1728 & 2.0135 & 2.2842 & 2.3366 & 2.3357 & 2.2271 & 2.1308 & 1.7431 & 1.2169 & 0.8280 & 0.6295 \\
1075 & 1.6401 & 1.9841 & 2.3830 & 2.2314 & 2.5320 & 2.5096 & 2.5115 & 2.4646 & 2.2986 & 1.8900 & 1.3199 & 0.8768 & 0.6564 \\
1125 & 1.7087 & 2.0244 & 2.5312 & 2.2904 & 2.5933 & 2.6569 & 2.6205 & 2.5339 & 2.3806 & 1.9510 & 1.3422 & 0.9029 & 0.6707 \\
1225 & 1.7296 & 2.1213 & 2.5841 & 2.3716 & 2.6410 & 2.6807 & 2.6773 & 2.5733 & 2.4249 & 1.9489 & 1.3576 & 0.9011 & 0.6574 \\
1275 & 1.6828 & 2.1096 & 2.5514 & 2.3458 & 2.6393 & 2.6709 & 2.7046 & 2.5457 & 2.3463 & 1.8856 & 1.3205 & 0.8724 & 0.6429 \\
1325 & 1.6915 & 2.0312 & 2.4320 & 2.3055 & 2.5459 & 2.5847 & 2.5897 & 2.4973 & 2.3164 & 1.8541 & 1.2858 & 0.8580 & 0.6446 \\
1375 & 1.5896 & 1.9342 & 2.3635 & 2.2044 & 2.4702 & 2.4866 & 2.4523 & 2.3535 & 2.1798 & 1.7959 & 1.2447 & 0.8239 & 0.6251 \\
1425 & 1.5401 & 1.8585 & 2.2559 & 2.1000 & 2.2881 & 2.3401 & 2.3536 & 2.3021 & 2.0707 & 1.7082 & 1.1965 & 0.8102 & 0.5820 \\
1525 & 1.6926 & 1.8797 & 2.0065 & 1.9877 & 2.0685 & 2.0725 & 2.0369 & 1.9349 & 1.8237 & 1.5049 & 1.0570 & 0.7181 & 0.5280 \\
1675 & 1.6369 & 1.6406 & 1.6205 & 1.6262 & 1.5828 & 1.5827 & 1.5395 & 1.4569 & 1.3349 & 1.1077 & 0.8017 & 0.5635 & 0.4370 \\
1825 & 1.0853 & 1.0584 & 1.0410 & 1.0707 & 1.0461 & 1.0075 & 0.9953 & 0.9314 & 0.8624 & 0.7334 & 0.5652 & 0.4316 & 0.3054 \\
\hline
\end{tabular}


Table 4.4. MCNP error estimate ( $2 \sigma$, absolute) for the thermal fluxes for the simple reactor configuration (units: $10^{11} \mathrm{~m}^{-2} \cdot \mathrm{s}^{-1}$ )

\begin{tabular}{|c|c|c|c|c|c|c|c|c|c|c|c|c|c|}
\hline $\begin{array}{c}H / r \\
(\mathrm{~mm})\end{array}$ & 235 & 255 & 275 & 295 & 315 & 335 & 355 & 395 & 435 & 515 & 635 & 755 & 835 \\
\hline 525 & 0.0258 & 0.0270 & 0.0282 & 0.0279 & 0.0281 & 0.0277 & 0.0272 & 0.0255 & 0.0249 & 0.0215 & 0.0173 & 0.0135 & 0.0180 \\
\hline 625 & 0.0341 & 0.0341 & 0.0337 & 0.0345 & 0.0341 & 0.0331 & 0.0324 & 0.0301 & 0.0293 & 0.0249 & 0.0194 & 0.0147 & 0.0121 \\
\hline 725 & 0.0335 & 0.0355 & 0.0376 & 0.0384 & 0.0374 & 0.0384 & 0.0371 & 0.0358 & 0.0331 & 0.0281 & 0.0216 & 0.0164 & 0.0136 \\
\hline 825 & 0.0368 & 0.0405 & 0.0423 & 0.0417 & 0.0428 & 0.0427 & 0.0417 & 0.0394 & 0.0370 & 0.0312 & 0.0234 & 0.0180 & 0.0145 \\
\hline 925 & 0.0404 & 0.0434 & 0.0467 & 0.0451 & 0.0461 & 0.0463 & 0.0447 & 0.0426 & 0.0398 & 0.0338 & 0.0250 & 0.0192 & 0.0155 \\
\hline 975 & 0.0419 & 0.0449 & 0.0482 & 0.0471 & 0.0484 & 0.0477 & 0.0467 & 0.0441 & 0.0409 & 0.0345 & 0.0258 & 0.0194 & 0.0161 \\
\hline 1075 & 0.0440 & 0.0476 & 0.0500 & 0.0495 & 0.0511 & 0.0497 & 0.0482 & 0.0458 & 0.0428 & 0.0355 & 0.0267 & 0.0198 & 0.0163 \\
\hline 1125 & 0.0444 & 0.0478 & 0.0521 & 0.0499 & 0.0513 & 0.0510 & 0.0493 & 0.0466 & 0.0438 & 0.0363 & 0.0274 & 0.0202 & 0.0165 \\
\hline 1225 & 0.0453 & 0.0496 & 0.0527 & 0.0512 & 0.0518 & 0.0509 & 0.0503 & 0.0473 & 0.0441 & 0.0366 & 0.0272 & 0.0204 & 0.0162 \\
\hline 1275 & 0.0441 & 0.0494 & 0.0520 & 0.0511 & 0.0523 & 0.0507 & 0.0508 & 0.0468 & 0.0427 & 0.0354 & 0.0267 & 0.0197 & 0.0161 \\
\hline 1325 & 0.0450 & 0.0483 & 0.0506 & 0.0507 & 0.0509 & 0.0501 & 0.0492 & 0.0464 & 0.0431 & 0.0352 & 0.0265 & 0.0196 & 0.0162 \\
\hline 1375 & 0.0436 & 0.0468 & 0.0501 & 0.0498 & 0.0509 & 0.0497 & 0.0481 & 0.0447 & 0.0414 & 0.0352 & 0.0259 & 0.0190 & 0.0158 \\
\hline 1425 & 0.0422 & 0.0461 & 0.0496 & 0.0483 & 0.0485 & 0.0482 & 0.0471 & 0.0447 & 0.0402 & 0.0342 & 0.0256 & 0.0190 & 0.0150 \\
\hline 1525 & 0.0454 & 0.0481 & 0.0466 & 0.0473 & 0.0459 & 0.0456 & 0.0436 & 0.0410 & 0.0383 & 0.0319 & 0.0241 & 0.0181 & 0.0144 \\
\hline 1675 & 0.0465 & 0.0453 & 0.0418 & 0.0436 & 0.0405 & 0.0399 & 0.0382 & 0.0358 & 0.0326 & 0.0272 & 0.0205 & 0.0159 & 0.0133 \\
\hline 1825 & 0.0380 & 0.0354 & 0.0335 & 0.0351 & 0.0333 & 0.0316 & 0.0307 & 0.0279 & 0.0257 & 0.0219 & 0.0172 & 0.0035 & 0.0109 \\
\hline
\end{tabular}




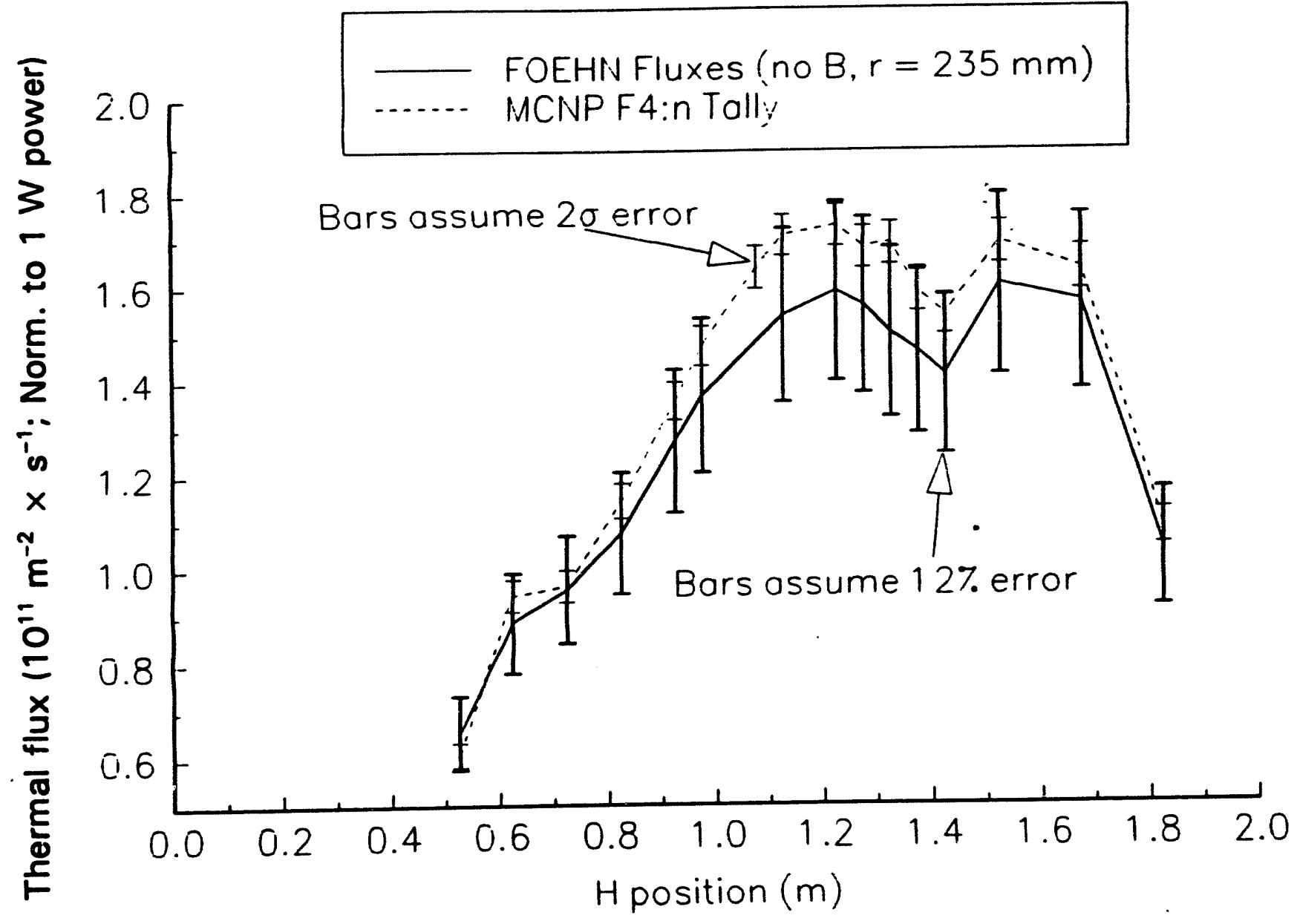

$\ddot{\infty}$

Fig. 4.3. Comparison of experimental and computed axial nux shapes at $r=235 \mathrm{~mm}$ in the simple FOEHN configuration. 


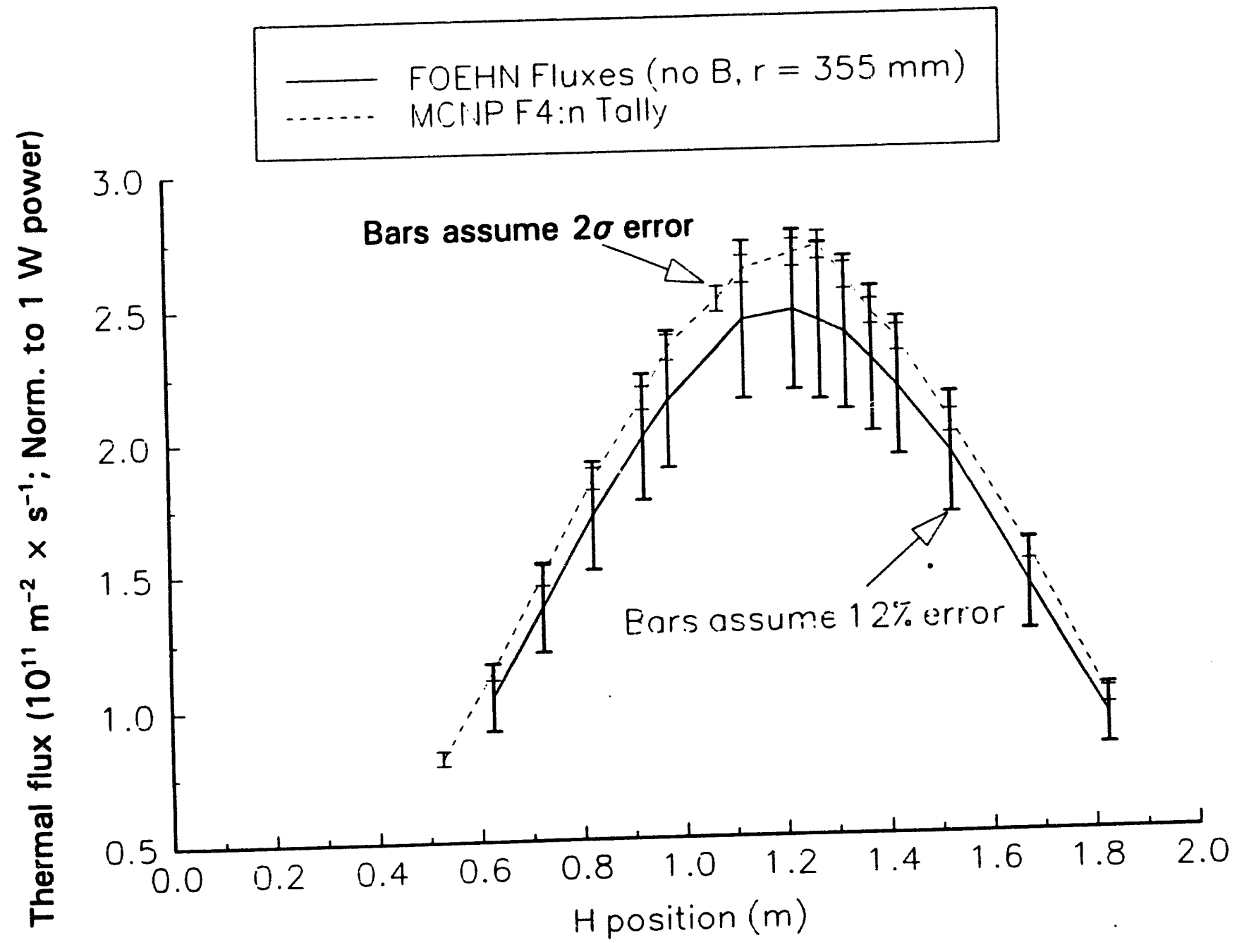

Fig. 4.4. Comparison of experimental and computed axial flux shapes at $r=355 \mathrm{~mm}$ in the simple FOEHN configuration. 


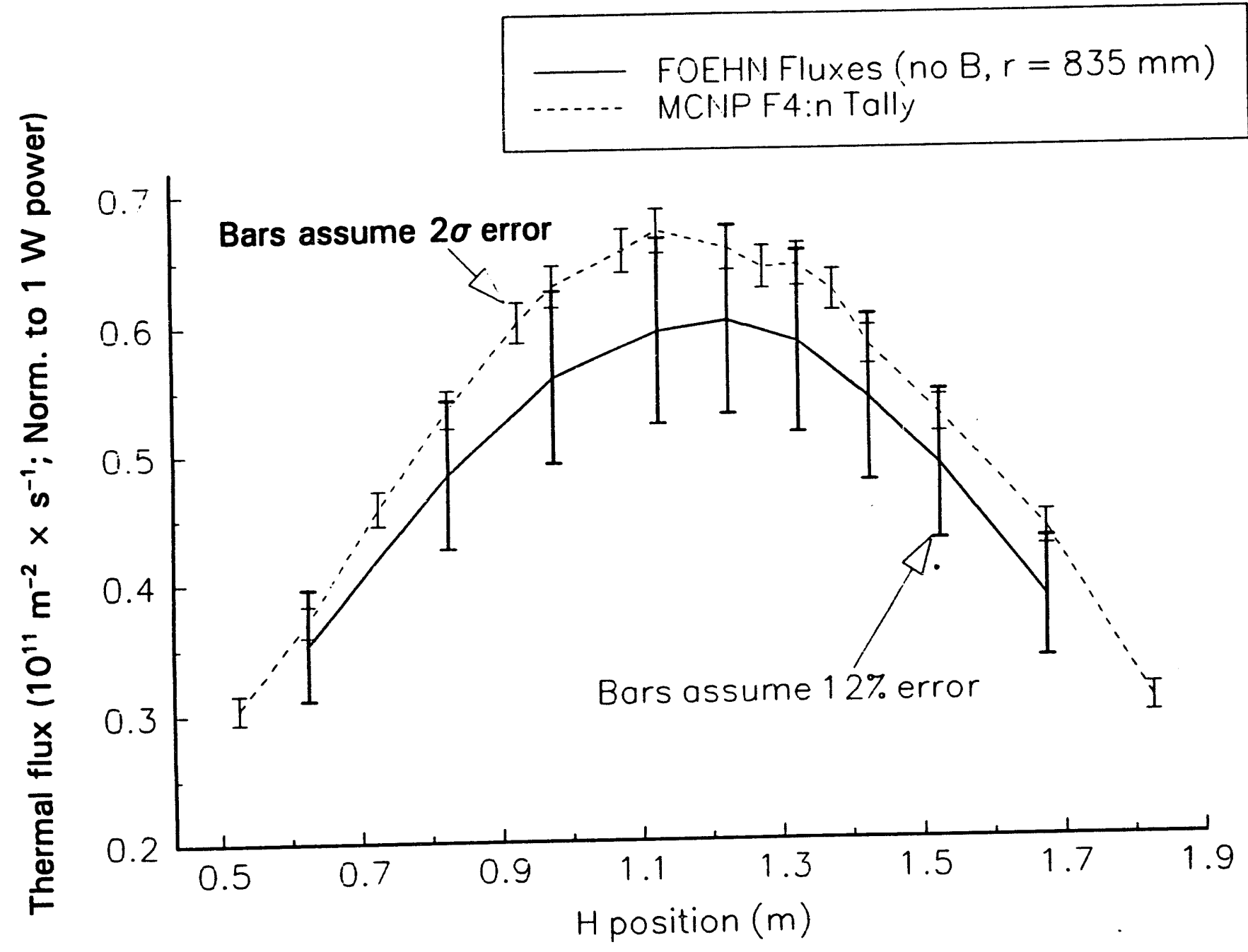

Fig. 45. Comparison of experimental and computed axial nux shapes at $r=835 \mathrm{~mm}$ in the simple FOEHN configuration. 
normalized results are shown in Table 4.5. In Table 4.6, the corresponding MCNP error estimates ( $2 \sigma$, i.e., two times the standard deviation from the normalized entries of Table 4.5) are shown.

The tallies (from Table 4.5) and the experimental data from Table 5.1.5 of the FOEHN report are compared in Figs. 4.5-4.15. The error bars shown for the computed results correspond to the $2 \sigma$ values tabulated in Table 4.6. The error bars for the experimental points correspond to the $4 \%$ estimate for the error discussed in Chap. 2.

In Figs. 4.6, 4.7, and 4.8, the power distribution is plotted as a function of the axial coordinate $H$ for the radii of $143.5 \mathrm{~mm}, 167.5 \mathrm{~mm}$, and $193.95 \mathrm{~mm}$, respectively. In Figs. 4.9-4.15, the power density is plotted as a function of the radius, $r$, for the axial planes at $2.5,50,175,400,625,750$, and $797.5 \mathrm{~mm}$, respectively. In this way, every data point featured in Table 5.1.5 of the FOEHN report is plotted at least once. It can be seen from the figures that, for most points, there is at least partial overlap of the error bars from the computational predictions and the experiment. In most cases, the overlap is significant, with the experimental point actually falling within the computational error bar (or vice versa). The only points that do not show any overlap are those given by the $r, H$ coordinate pairs in $\mathrm{mm}(143.5,325.0)$ and $(143.5,400.0)$.

These two points correspond to slightly $<1.64 \%$ of the total number (122) of experimental points. This result is in remarkably high agreement with the statistical interpretation of the computational error bars. The bars are $2 \sigma$ in width. It follows that there is a $95 \%$ probability that the physically correct value of the computed quantity lie within the band defined by such error bars. The $1.64 \%$ of the points lying outside the error band is compatible with the corresponding 5\% probability that points lie outside the band. In an independent study, using the discrete ordinate transport code DOT, Rohrmoser ${ }^{10}$ obtained similar results-the same two experimental points were not reproduced by his model. The difference between models and experiment are in the same direction. The agreement between the two independent modeling efforts suggests that the experimental points might be incorrect. The difference $(-3 \%)$ is not significant. The use of a homogenized representation for the fuel is known to be capable of producing local power variations as high as $5 \%$ in MCNP computations. "This effect appears not to be significant in the present case.

\subsection{INTERMEDIATE COMPLEXITY REACTOR MODEL}

\subsubsection{Core Multiplication Factor $\left(k_{e f}\right)$}

The results of KCODE calculations (40 cycles, 3000 histories/cycle) for the intermediate complexity reactor configuration are tabulated in Table 4.7 and shown in Fig. 4.16. The cases referred to in the figure are defined in Table 4.7. For this reactor configuration, the $k_{\text {eff }}$ predictions coincide (within $2 \sigma$ ) with the expected experimental value of 1.0 in four cases out of six. The two misses are within the $3 \sigma$ band. These results can be interpreted as $0-33 \%$ misses.

\subsubsection{Thermal Flux}

Calculated MCNP thermal fluxes were compared to the results given in Table 5.2.5 of ref. 2. As stated previously, thermal fluxes for this benchmarking analysis were computed as F4:n tallies for neutron energies below $0.625 \mathrm{eV}$ in a KCODE calculation using 40 cycles of 10000 particles each. Modeling of the detectors was done in the same way as described in Sect. 4.2.2. The control rod height for this case was set at $1.163 \mathrm{~m}$ in MCNP (corresponding to the experimental control rod height of $0.447 \mathrm{~m}$ given in ref. 2 ). The boron $\left({ }^{10} \mathrm{~B}\right)$ concentration was set to $0.258 \mathrm{~g} / \mathrm{L}$. 
Table 4.5. Normalized MCNP power production (F7:n tallies) for the simple reactor configuration

\begin{tabular}{|c|c|c|c|c|c|c|c|c|c|c|c|}
\hline $\begin{array}{c}H / r \\
(\mathrm{~mm})\end{array}$ & 143.5 & 146.5 & 149.5 & 152.5 & 159.0 & 167.5 & 176.0 & 182.5 & 185.5 & 188.5 & 193.95 \\
\hline 02.5 & 0.9140 & 0.9214 & 0.8688 & 0.8321 & 0.8763 & 0.9120 & 1.0486 & 1.1412 & 1.1877 & 1.3026 & 1.6102 \\
\hline 09.4 & 0.7367 & & & & & & & & & & 1.3728 \\
\hline 14.5 & 0.6567 & & & & & 0.5302 & & & & & \\
\hline 19.4 & 0.6551 & & & & & 0.5064 & & & & & 1.2527 \\
\hline 28.5 & 0.5374 & & & & & 0.4774 & & & & & 1.2152 \\
\hline 50.0 & 0.5492 & 0.4938 & 0.4541 & 0.4255 & 0.3944 & 0.4528 & 0.5227 & 0.6585 & 0.7909 & 0.8983 & 1.2714 \\
\hline 75.0 & 0.5344 & & & & & 0.4611 & & & & & 1.2705 \\
\hline 100.0 & 0.5565 & & & & & 0.4441 & & & & & 1.3406 \\
\hline 175.0 & 0.6676 & 0.6066 & 0.5734 & 0.5360 & 0.4921 & 0.5390 & 0.6686 & 0.7855 & 0.8908 & 1.0792 & 1.4619 \\
\hline 250.0 & 0.7621 & & & & & 0.6617 & & & & & 1.7424 \\
\hline 325.0 & 1.1703 & & & & & 0.7913 & & & & & 2.0383 \\
\hline 400.0 & 1.3068 & 1.1060 & 0.9866 & 0.9477 & 0.8592 & 0.8242 & 0.9336 & 1.1980 & 1.3518 & 1.5135 & 2.1311 \\
\hline 475.0 & 1.3052 & & & & & 0.8577 & & & & & 2.1121 \\
\hline 550.0 & 1.3527 & & & & & 0.8606 & & & & & 2.1074 \\
\hline 625.0 & 1.3112 & 1.2016 & 1.0356 & 0.9174 & 0.8360 & 0.8374 & 0.9156 & 1.0927 & 1.2429 & 1.4430 & 2.0251 \\
\hline 700.0 & 1.2340 & & & & & 0.7771 & & & & & 1.9788 \\
\hline 725.0 & 1.2306 & & & & & 0.7680 & & & & & 1.9595 \\
\hline 750.0 & 1.3354 & 1.1567 & 1.0637 & 0.9207 & 0.8023 & 0.7971 & 0.9368 & 1.1539 & 1.2480 & 1.4645 & 2.0040 \\
\hline 771.5 & 1.6154 & & & & & 0.9039 & & & & & 2.0945 \\
\hline 780.6 & 1.7211 & & & & & 1.0737 & & & & & 2.2735 \\
\hline 785.5 & 1.8351 & & & & & 1.1864 & & & & & 2.4136 \\
\hline 790.6 & 2.0209 & & & & & & & & & & 2.5324 \\
\hline 797.5 & 2.5715 & 2.3638 & 2.2892 & 2.2125 & 2.0568 & 2.0743 & 2.1973 & 2.2845 & 2.4287 & 2.5611 & 2.9713 \\
\hline
\end{tabular}


Table 4.6. MCNP error estimate ( $2 \sigma$, absolute) for the normalized MCNP power production for the simple reactor configuration

\begin{tabular}{|c|c|c|c|c|c|c|c|c|c|c|c|}
\hline $\begin{array}{c}H / r \\
(\mathrm{~mm})\end{array}$ & 143.5 & 146.5 & 149.5 & 152.5 & 159.0 & 167.5 & 176.0 & 182.5 & 185.5 & 188.5 & 193.95 \\
\hline 02.5 & 0.0590 & 0.0617 & 0.0553 & 0.0536 & 0.0535 & 0.0529 & 0.0581 & 0.0600 & 0.0615 & 0.0659 & 0.0776 \\
\hline 09.4 & 0.0497 & & & & & 0.0346 & & & & & \\
\hline 14.5 & 0.0475 & & & & & $\begin{array}{l}0.0340 \\
0.0351\end{array}$ & & & & & 0.0609 \\
\hline 19.4 & 0.0455 & & & & & 0.0334 & & & & & 0.0593 \\
\hline 28.5 & 0.0361 & 0.0337 & 0.0330 & 0.0328 & 0.0280 & 0.0353 & 0.0343 & 0.0412 & 0.0478 & 0.0512 & 0.0651 \\
\hline 50.0 & 0.0379 & & & & & 0.0319 & & & & & 0.0653 \\
\hline 75.0 & 0.0340 & & & & & 0.0283 & & & & & 0.0660 \\
\hline 100.0 & 0.0365 & 0.0385 & 0.0346 & 0.0331 & 0.0312 & 0.0320 & 0.0397 & 0.0426 & 0.0499 & 0.0546 & 0.0699 \\
\hline 175.0 & 0.0403 & & & & & 0.0379 & & & & & 0.0725 \\
\hline 250.0 & $\begin{array}{l}0.0407 \\
0.0620\end{array}$ & & & & & 0.0416 & & & & & 0.0828 \\
\hline 325.0 & $\begin{array}{l}0.0620 \\
0.0674\end{array}$ & 0.0551 & 0.0493 & 0.0476 & 0.0450 & 0.0425 & 0.0463 & 0.0568 & 0.0611 & 0.0657 & 0.0831 \\
\hline 400.0 & $\begin{array}{l}0.0674 \\
0.0637\end{array}$ & & & & & 0.0444 & & & & & 0.0828 \\
\hline 475.0 & $\begin{array}{l}0.0637 \\
0.0666\end{array}$ & & & & & 0.0432 & & & & & 0.0830 \\
\hline 550.0 & $\begin{array}{l}0.0666 \\
0.0645\end{array}$ & 0.0627 & 0.0551 & 0.0490 & 0.0426 & 0.0467 & 0.0449 & 0.0538 & 0.0562 & 0.0638 & 0.0814 \\
\hline 625.0 & $\begin{array}{l}0.0645 \\
0.0647\end{array}$ & & & & & 0.0401 & & & & & 0.0815 \\
\hline 700.0 & $\begin{array}{l}0.0647 \\
0.0655\end{array}$ & & & & & 0.0424 & & & & & 0.0815 \\
\hline 725.0 & $\begin{array}{l}0.0655 \\
0.0686\end{array}$ & 0.0620 & 0.0589 & 0.0516 & 0.0440 & 0.0454 & 0.0482 & 0.0554 & 0.0569 & 0.0624 & 0.0814 \\
\hline 750.0 & $\begin{array}{l}0.0686 \\
0.0821\end{array}$ & & & & & 0.0483 & & & & & 0.0825 \\
\hline 771.5 & 0.0821 & & & & & 0.0543 & & & & & 0.0873 \\
\hline 780.5 & 0.0840 & & & & & 0.0603 & & & & & 0.0932 \\
\hline 785.5 & $\begin{array}{l}0.0921 \\
0.0922\end{array}$ & & & & & & & & & & 0.0942 \\
\hline 790.6 & $\begin{array}{l}0.0922 \\
0.1080\end{array}$ & 0.1040 & 0.1016 & 0.0938 & 0.0872 & 0.0888 & 0.0875 & 0.0896 & 0.0923 & 0.0942 & 0.1046 \\
\hline
\end{tabular}




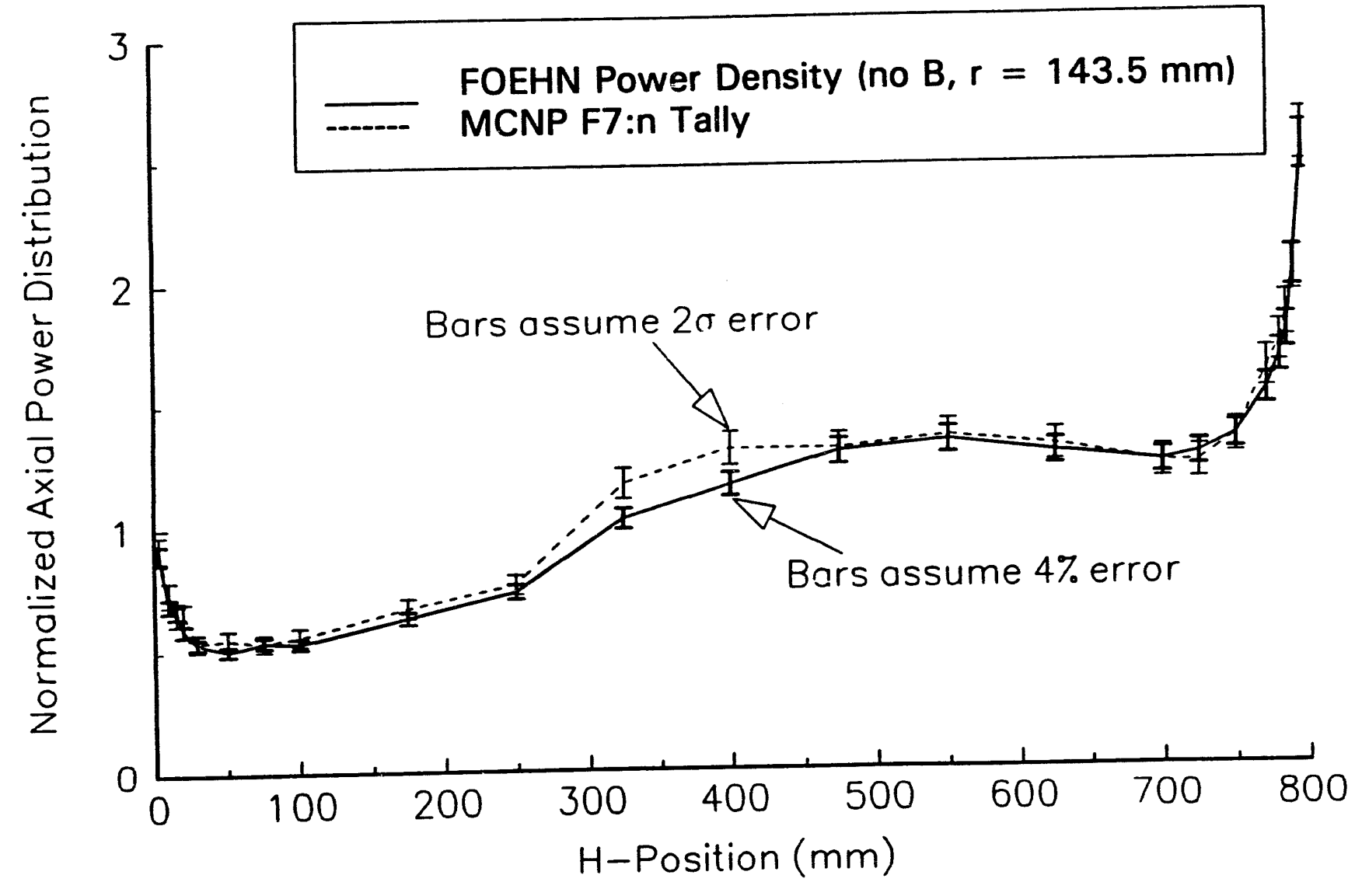




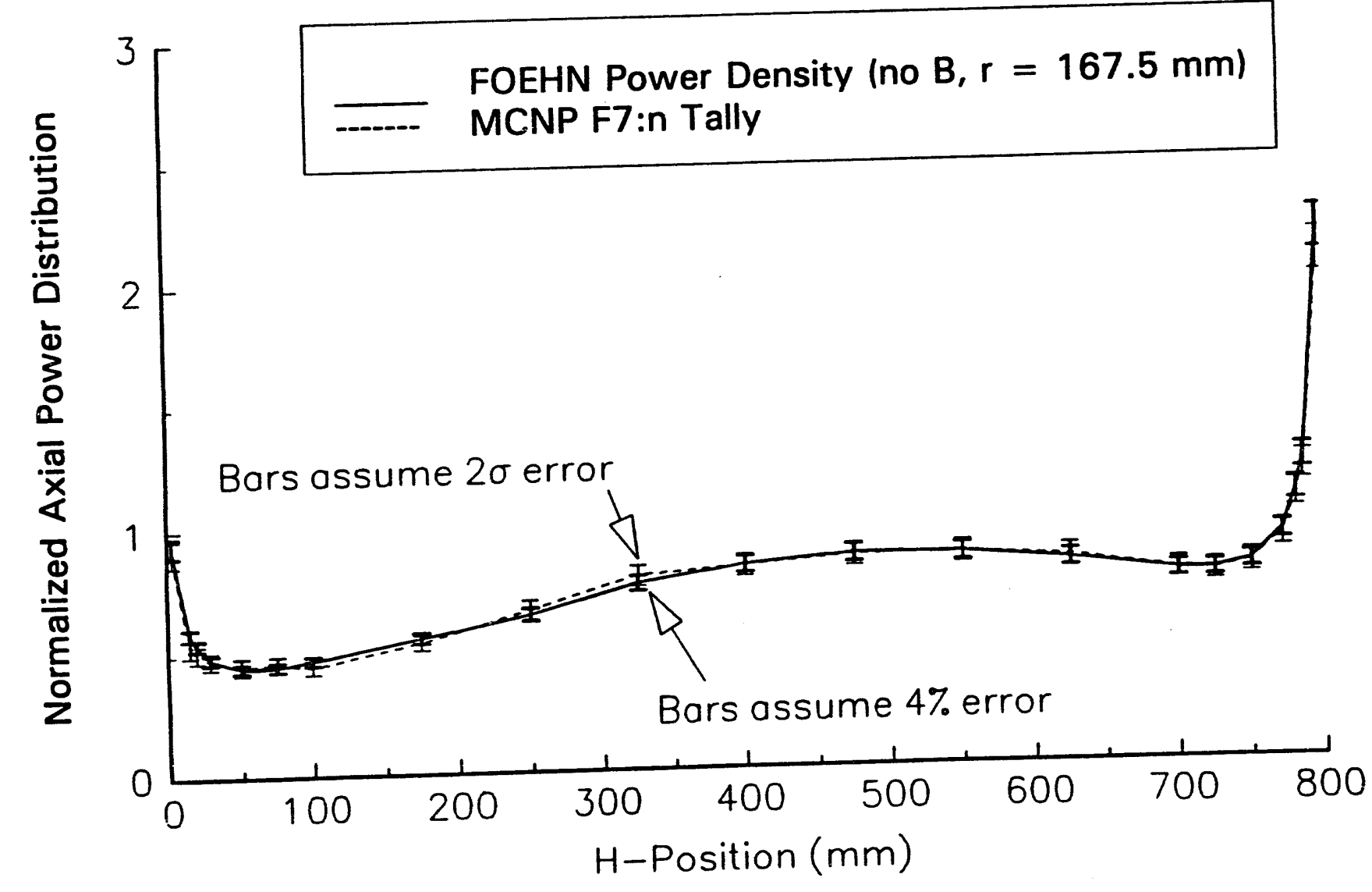

Fig. 4.7. Comparison of normalized experimental and computed axial power distribution in the simple FOEHN configuration at $r=167.5 \mathrm{~mm}$. 


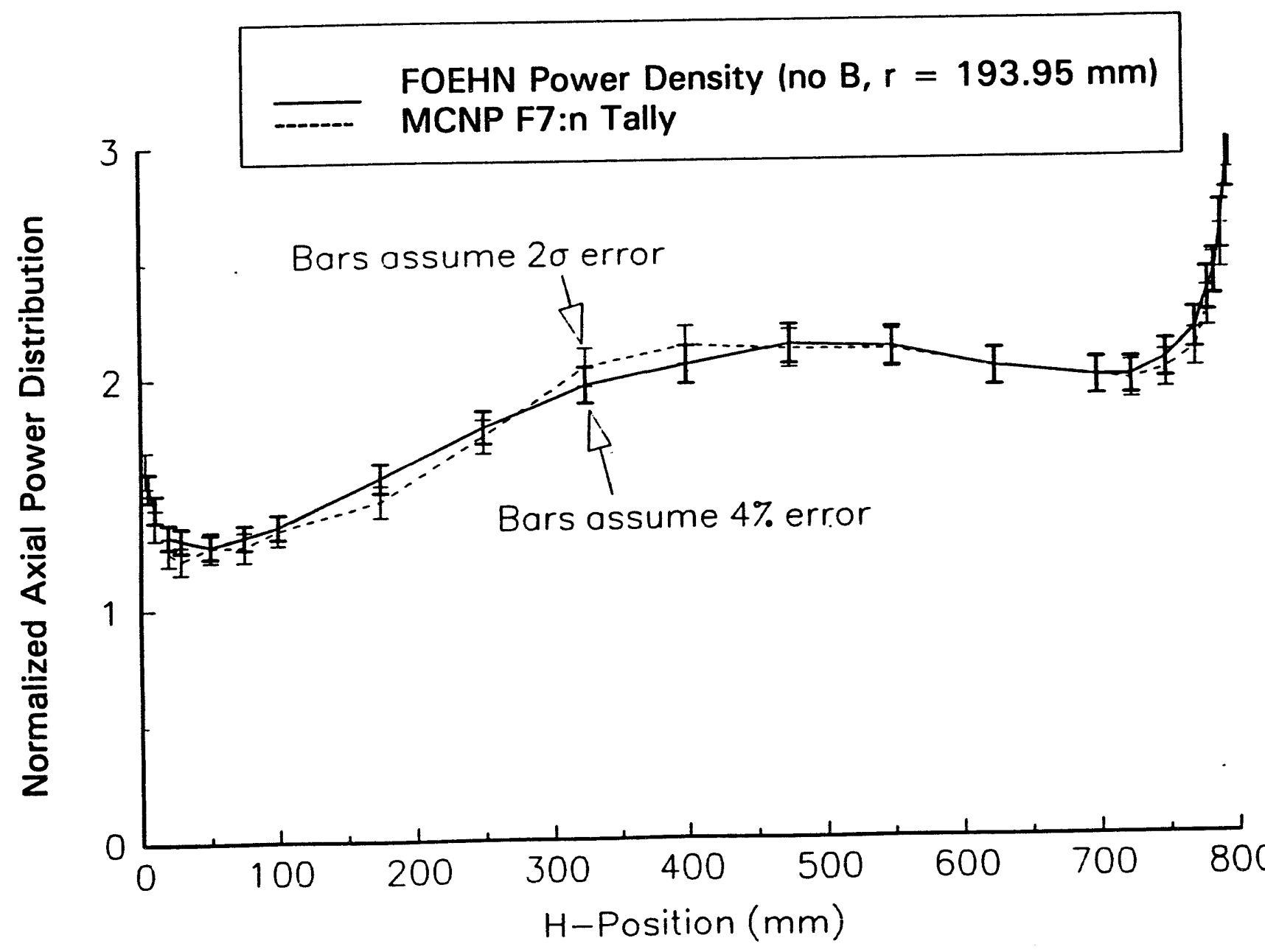

Fig. 4.8. Comparison of normalized experimental and computed axial power distribution in the simple FOEHN configuration at $r=193.95 \mathrm{~mm}$. 


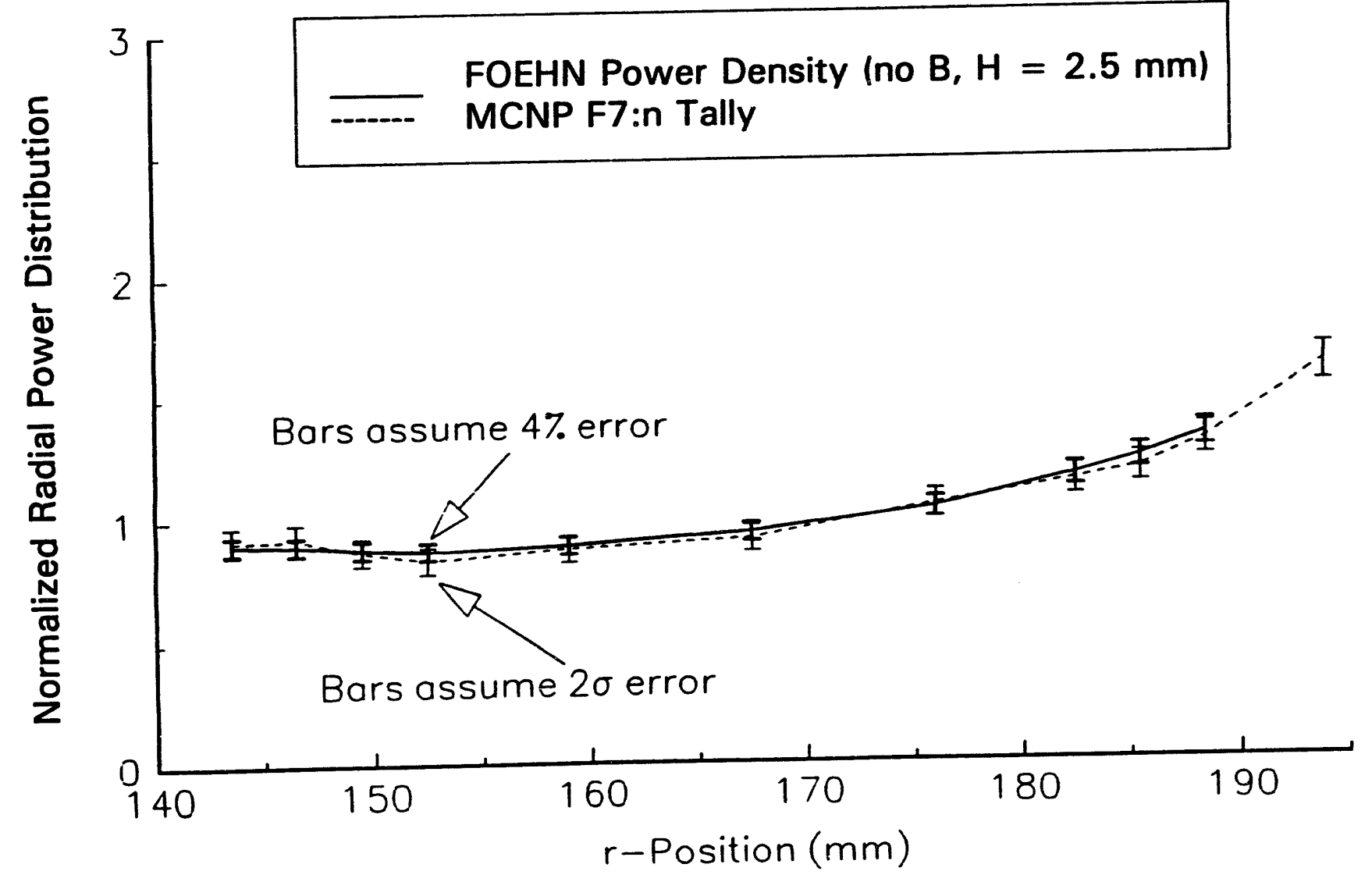

Fig. 49. Comparison of normalized experimental and computed axial power distribution in the simple FOEHN configuration at $H=2.5 \mathrm{~mm}$. 


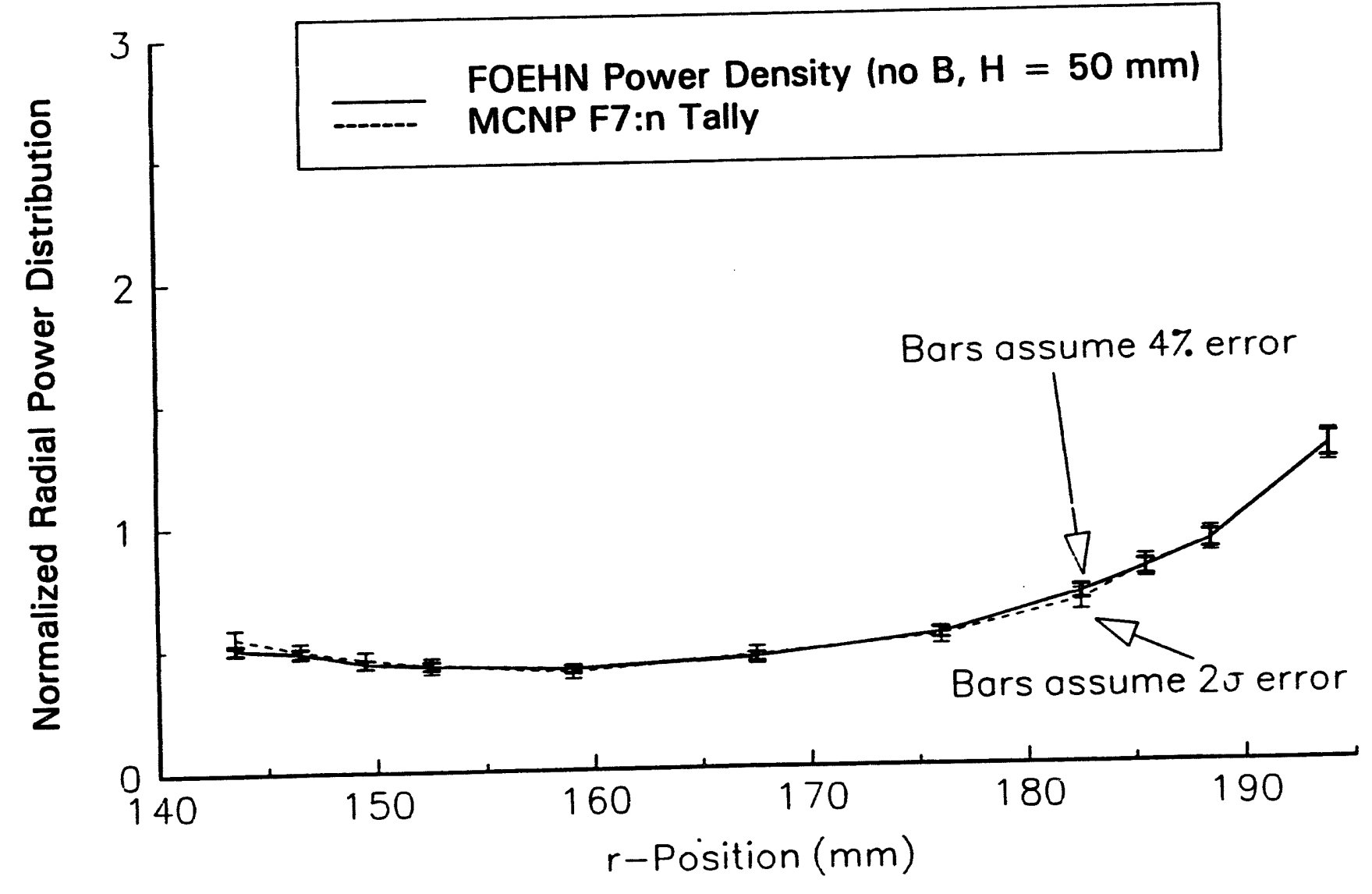

Fig. 4.10. Comparison of normalized experimental and computed radial power distribution in the simple FOEHN configuration at $H=50 \mathrm{~mm}$. 


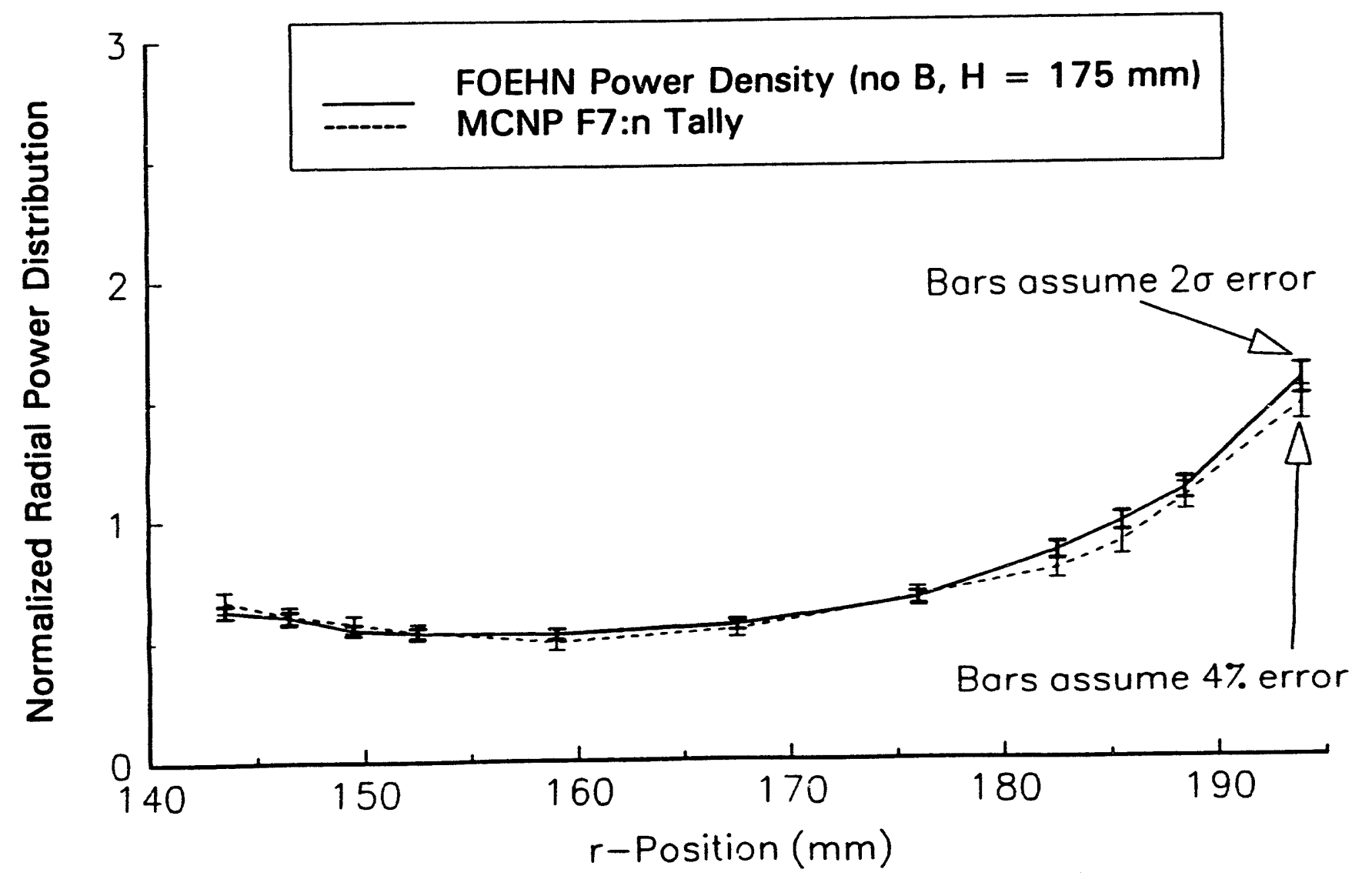

Fig. 4.11. Comparison of normalized experimental and computed radial power distribution in the simple FOEHN configuration at $H=175 \mathrm{~mm}$. 


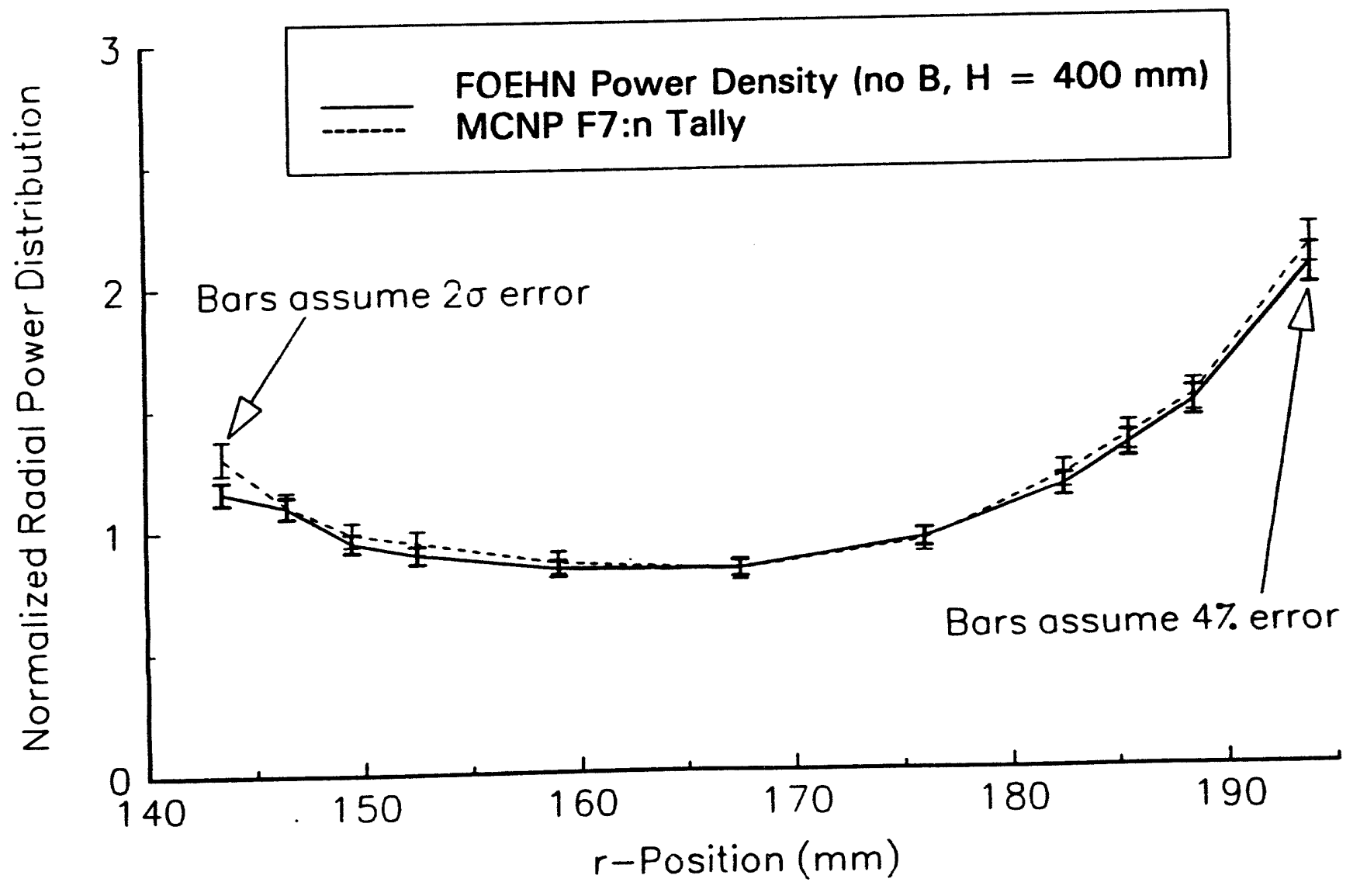

Fig. 4.12. Comparison of normalized experimental and computed radial power distribution in the simple FOEHN configuration at $H=400 \mathrm{~mm}$. 


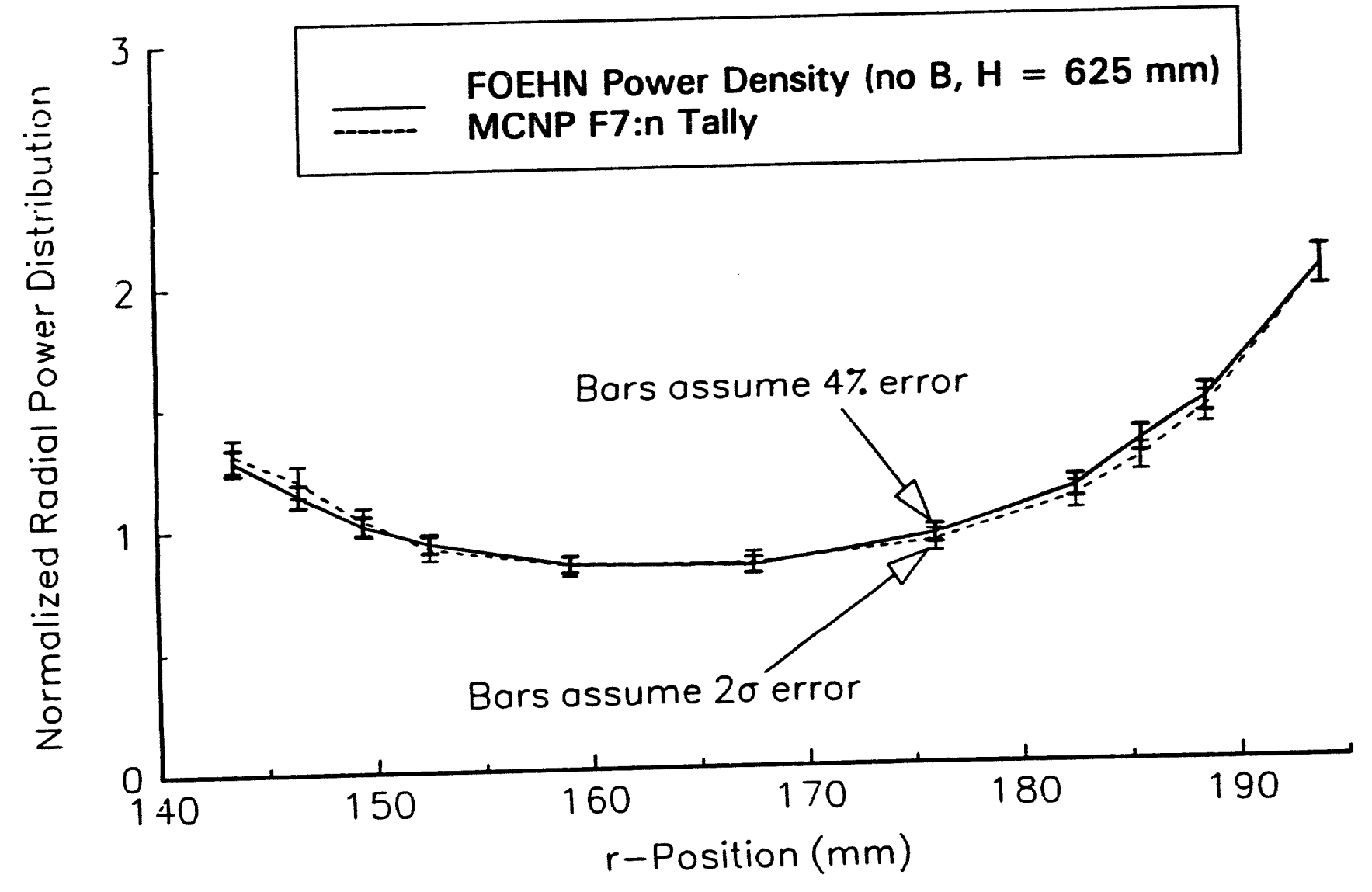

Fig. 4.13. Comparison of normalized experimental and computed radial power distribution in the simple FOEHN configuration at $H=625 \mathrm{~mm}$. 


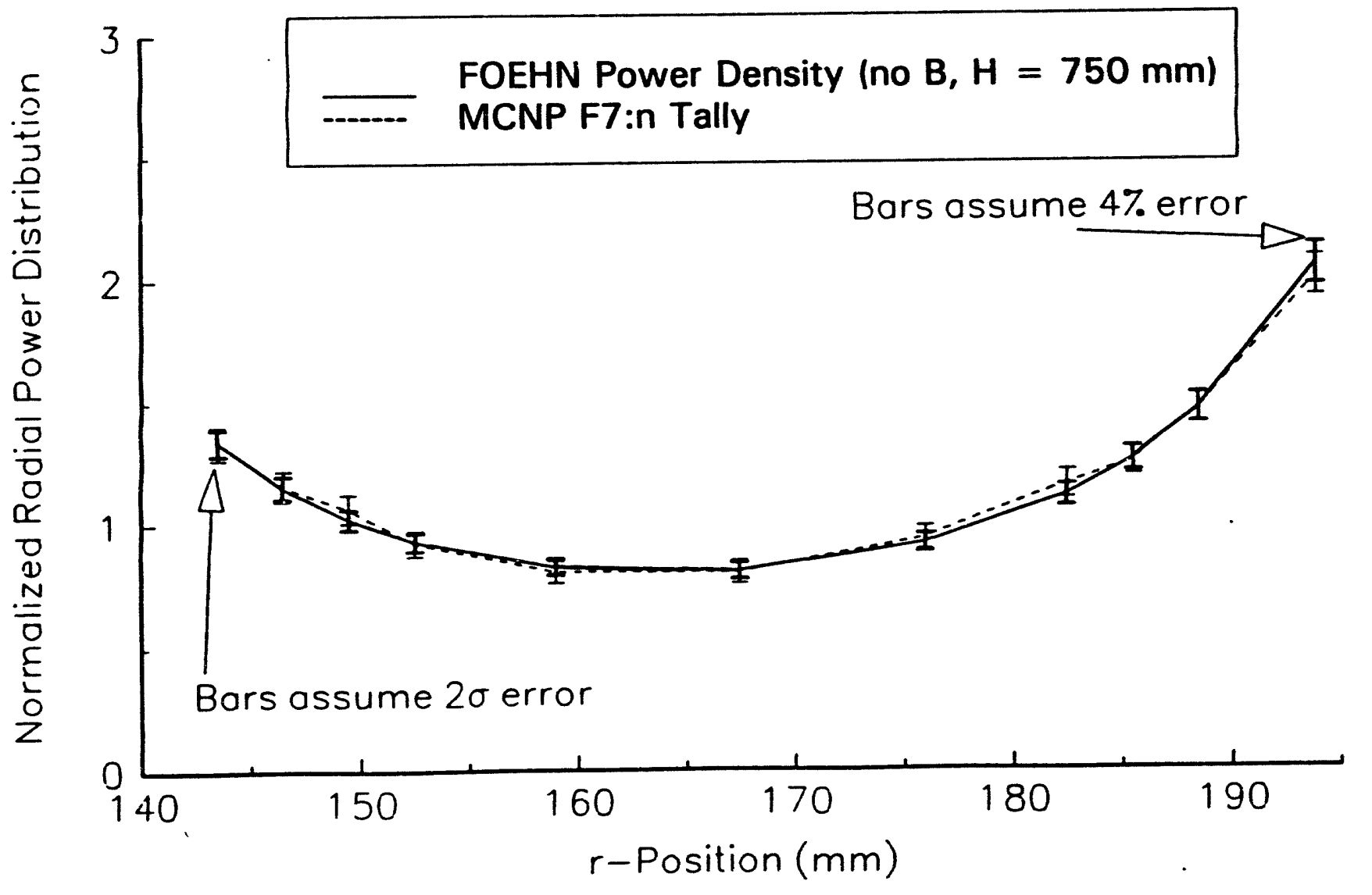

Fig. 4.14. Comparison of normalized experimental and computed radial power distribution in the simple FOEHN configuration at $H=750 \mathrm{~mm}$. 


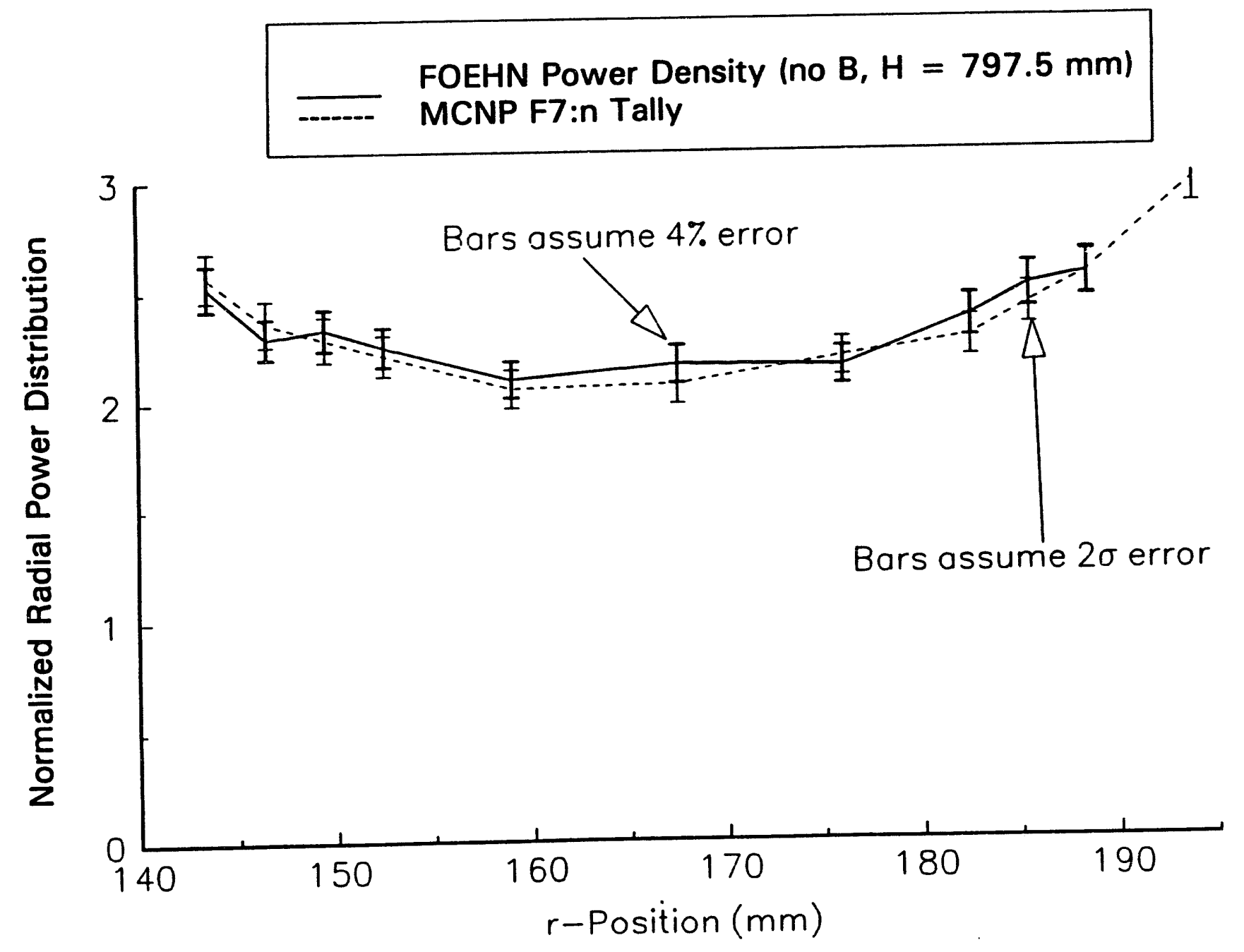

Fig. 4.15. Comparison of normalized experimental and computed radial power distribution in the simple FOEHN configuration at $H=797.5 \mathrm{~mm}$. 
Table 4.7. MCNP computed core effective multiplication factors $\left(k_{e f f}\right)$ for various critical states of the intermediate complexity reactor configuration

\begin{tabular}{cccccc}
\hline & \multicolumn{2}{c}{$\begin{array}{c}\text { Control rod } \\
\text { position }(\mathrm{m})\end{array}$} & $\begin{array}{c}\text { Boron } \\
\text { conc. } \\
(\mathrm{g} / \mathrm{L})\end{array}$ & $\begin{array}{c}\text { MCNP } \\
k_{\text {eff }}\end{array}$ & $\begin{array}{c}\text { MCNP error } \\
\text { estimate } \\
(\sigma)\end{array}$ \\
\cline { 2 - 6 } & MCNP & FOEHN & 0.210 & 1.0017 & 0.0028 \\
\hline 1 & 1.2578 & 0.3522 & 0.258 & 1.0090 & 0.0030 \\
3 & 1.163 & 0.447 & 0.270 & 1.0004 & 0.0026 \\
4 & 1.153 & 0.457 & 0.350 & 1.0025 & 0.0036 \\
5 & 1.001 & 0.609 & 0.371 & $: .0081$ & 0.0025 \\
6 & 0.946 & 0.664 & 0.419 & 1.0054 & 0.0026 \\
\hline
\end{tabular}

The MCNP F4:n tallies were normalized to $1 \mathrm{~W}$ total reactor power to allow a direct comparison to the experimental thermal fluxes of Table 5.2.5 in ref. 2. Table 4.8 shows the MCNP-calculated thermal fluxes, and Table 4.9 shows their respective relative errors $(2 \sigma)$. The entries in these two tables are in units of $10^{11} \mathrm{~m}^{-2} \cdot \mathrm{s}^{-1}$. In this case, the computed value of 2.43871 was used for $\mathrm{v}$. The value of $Q$ was $202.47 \mathrm{MeV}$, except for the estimate of the rendement for which the value 199.73 $\mathrm{MeV}$ was used. Figures $4.17,4.18$, and 4.19 show a comparison of the MCNP-calculated and the experimental results at the radii of $0.235 \mathrm{~m}, 0.355 \mathrm{~m}$, and $0.835 \mathrm{~m}$. The error bars assume $\pm 2 \sigma$ for the computational points and $\pm 4, \pm 8, \pm 8 \%$ for the experimental points in the three figures, respectively (vs the $\pm 2 \%$ claimed in the FOEHN report). These figures show that MCNP-calculated thermal fluxes and the experimental fluxes are in agreement within the bands defined by the experimental error and the statistical limits.

\subsubsection{Rendement}

The rendement calculated by MCNP, $r_{\text {calc }}$, is $2.8529 \times 10^{11}$ neutrons $/ \mathrm{m}^{2} \cdot \mathrm{s} \cdot \mathrm{W}$ with a standard deviation, $\sigma$, of $0.94 \%$. The measured rendement, reported in ref. $2, r_{\text {meas }}$ is $2.56 \times 10^{11}$ neutrons $/ \mathrm{m}^{2}$. $\mathrm{s} \cdot \mathrm{W}$. As discussed in Sect. 2.4.3.4, an error of between 2.2 and $16.2 \%$ should be associated with the measured value (vs the $\pm 2 \%$ claimed in ref. 2 ). In the following, it is assumed that the experimental error is of the order of $12 \%$ (same as for the fluxes). The aifference between the computational and the experimental results is approximately $+11.5 \%$. Rohrmoser independently computed a value $13 \%$ larger than the experimental one. As in the previous case (simplest reactor configuration), the two estimates of the rendement can be considered to be coinciding since the error bands associated with them $( \pm 12 \%$ and $\pm \sigma)$ overlap significantly. It is noteworthy that the two estimates overlap even if the experimental error band is decreased to $-10 \%$. 


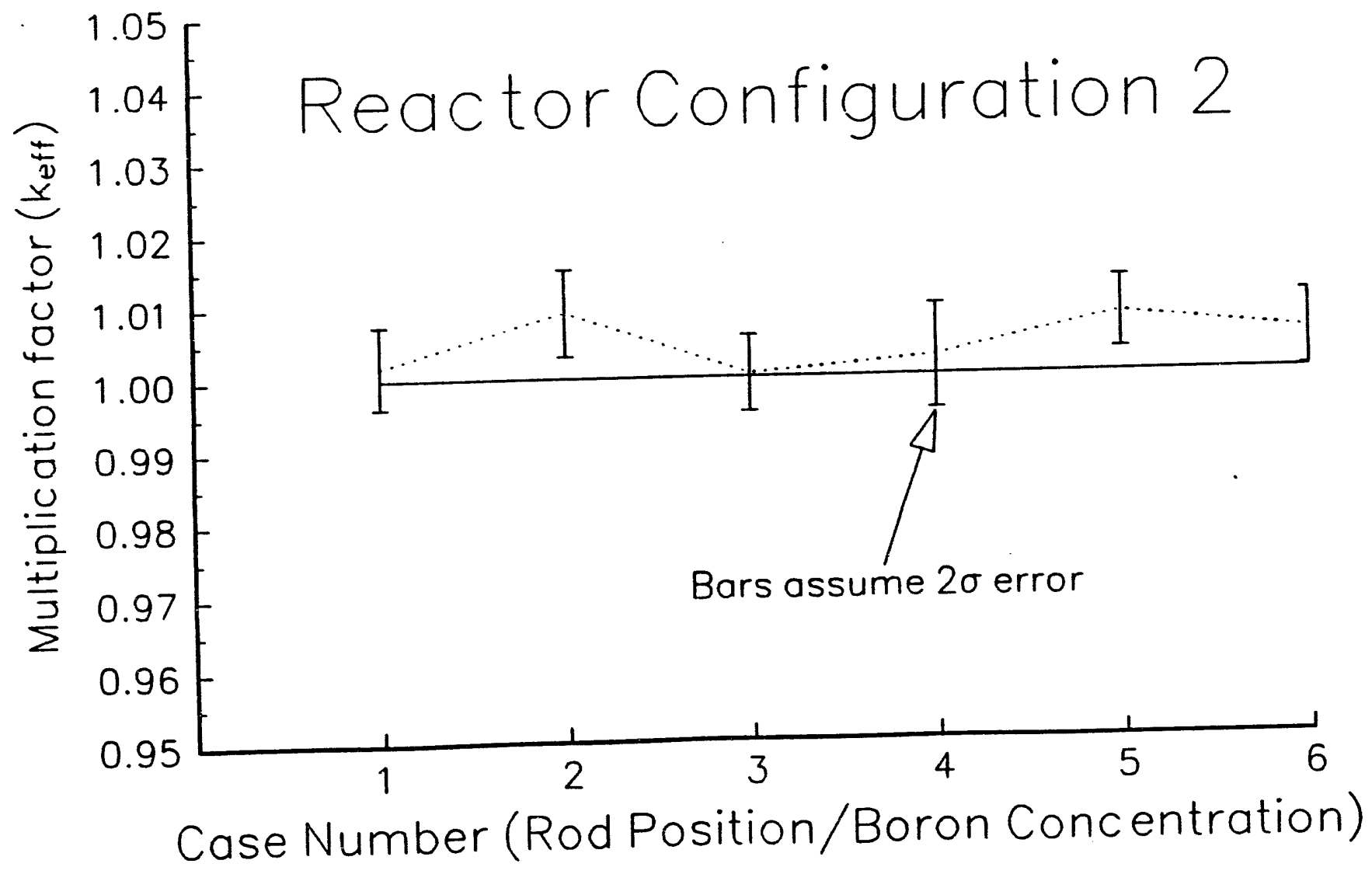

Fig. 4.16. MCNP prediction of $k_{\text {eff }}$ for a set of critical states of the intermediate FOEHN reactor configuration. 
Table 4.8. Computed thermal fluxes for the intermediate reactor configuration"

\begin{tabular}{|c|c|c|c|c|c|c|c|c|c|c|c|c|c|c|}
\hline $\begin{array}{c}H / r \\
(\mathrm{~mm})\end{array}$ & 235 & 275 & 315 & 335 & 355 & 375 & 395 & 435 & 515 & 675 & 755 & 835 & 915 & 955 \\
\hline 510 & 0.5603 & 0.6461 & 0.7398 & 0.7621 & 0.7548 & 0.7485 & 0.7479 & 0.7136 & 0.6620 & 0.4824 & 0.3943 & 0.3082 & 0.2156 & 0.1813 \\
\hline 610 & 0.8278 & 0.9498 & 1.0481 & 1.0725 & 1.0791 & 1.0900 & 1.0517 & 1.0041 & 0.9047 & 0.6014 & 0.4917 & 0.3746 & 0.2696 & 0.2242 \\
\hline 710 & 0.8786 & 1.1951 & 1.3845 & 1.4176 & 1.4361 & 1.4378 & 1.3973 & 1.3660 & 1.1741 & 0.7774 & 0.5935 & 0.4518 & 0.3303 & 0.2672 \\
\hline 810 & 1.1505 & 1.5598 & 1.7764 & 1.8310 & 1.8264 & 1.8080 & 1.7878 & 1.6916 & 1.4122 & 0.9175 & 0.7098 & 0.5300 & 0.3712 & 0.3052 \\
\hline 910 & 1.4072 & 1.9431 & 2.2152 & 2.2280 & 2.2166 & 2.1946 & 2.1763 & 2.0602 & 1.6964 & 1.0593 & 0.8042 & 0.5922 & 0.4212 & 0.3498 \\
\hline 1010 & 1.6225 & 2.2402 & 2.4869 & 2.5653 & 2.5538 & 2.4961 & 2.4833 & 2.2784 & 1.8769 & 1.1445 & 0.8766 & 0.6404 & 0.4602 & 0.3673 \\
\hline 1060 & 1.7193 & 2.3355 & 2.6097 & 2.6120 & 2.6530 & 2.6175 & 2.5585 & 2.3745 & 1.9351 & 1.1672 & 0.8880 & 0.6599 & 0.4614 & 0.3788 \\
\hline 1110 & 1.7867 & 2.4579 & 2.6938 & 2.7880 & 2.7620 & 2.7043 & 2.6319 & 2.4422 & 2.0041 & 1.1935 & 0.8841 & 0.6701 & 0.4598 & 0.3818 \\
\hline 1160 & 1.7484 & 2.4750 & 2.7342 & 2.7930 & 2.7921 & 2.7693 & 2.6698 & 2.4847 & 1.9970 & 1.1929 & 0.9148 & 0.6738 & 0.4719 & 0.3804 \\
\hline 1210 & 1.8122 & 2.4653 & 2.7421 & 2.8143 & 2.8009 & 2.7308 & 2.7065 & 2.4567 & 2.0027 & 1.2021 & 0.9094 & 0.6711 & 0.4709 & 0.3825 \\
\hline 1260 & 1.7670 & 2.4378 & 2.6935 & 2.7644 & 2.7510 & 2.6683 & 2.6162 & 2.4439 & 1.9291 & 1.1699 & 0.8877 & 0.6622 & 0.4621 & 0.3773 \\
\hline 1310 & 1.7220 & 2.3228 & 2.6046 & 2.6796 & 2.6408 & 2.5680 & 2.5494 & 2.3327 & 1.8961 & 1.1377 & 0.8500 & 0.6453 & 0.4491 & 0.3651 \\
\hline 1410 & 1.5132 & 2.0385 & 2.2988 & 2.3106 & 2.3220 & 2.2738 & 2.2254 & 2.0807 & 1.7147 & 1.0423 & 0.8020 & 0.5976 & 0.4177 & 0.3389 \\
\hline 1510 & 1.3235 & 1.7094 & 1.8858 & 1.9349 & 1.9423 & 1.8933 & 1.8538 & 1.7593 & 1.4920 & 0.9171 & 0.7079 & 0.5392 & 0.3868 & 0.3139 \\
\hline 1610 & 1.4131 & 1.5393 & 1.5722 & 1.5757 & 1.5798 & 1.5135 & 1.4815 & 1.4285 & 1.2118 & 0.7973 & 0.6172 & 0.4595 & 0.3239 & 0.2781 \\
\hline 1710 & 1.2452 & 1.2212 & 1.2136 & 1.2185 & 1.2026 & 1.1993 & 1.1537 & 1.0896 & 0.9507 & 0.6216 & 0.4965 & 0.3804 & 0.2812 & 0.2232 \\
\hline 1810 & 0.9437 & 0.9385 & 0.9127 & 0.8981 & 0.8985 & 0.8724 & 0.8627 & 0.8218 & 0.7003 & 0.4915 & 0.4290 & 0.2994 & 0.2212 & 0.1867 \\
\hline
\end{tabular}

TMCNP F4:n tallies; $0.625 \mathrm{eV}$ cutoff; $1 \mathrm{~W}$ reactor power; units: $10^{11} \mathrm{~m}^{-2} \cdot \mathrm{s}^{-1}$. 
Table 4.9. MCNP error estimate ( $2 \sigma$, absolute) for the thermal fluxes for the intermediate reactor configuration (units: $10^{11} \mathrm{~m}^{-2} \cdot \mathrm{s}^{-1}$ )

\begin{tabular}{|c|c|c|c|c|c|c|c|c|c|c|c|c|c|c|}
\hline $\begin{array}{c}H / r \\
(\mathrm{~mm})\end{array}$ & 235 & 275 & 315 & 335 & 355 & 375 & 395 & 435 & 515 & 675 & 755 & 835 & 915 & 955 \\
\hline 510 & 0.0252 & 0.0264 & 0.0275 & 0.0271 & 0.0261 & 0.0254 & 0.0250 & 0.0233 & 0.0211 & 0.0157 & 0.0133 & 0.0111 & 0.0087 & 0.0077 \\
\hline 610 & 0.0320 & 0.0325 & 0.0329 & 0.0326 & 0.0319 & 0.0314 & 0.0297 & 0.0277 & 0.0246 & 0.0173 & 0.0148 & 0.0121 & 0.0097 & 0.0087 \\
\hline 710 & 0.0320 & 0.0366 & 0.0377 & 0.0371 & 0.0365 & 0.0362 & 0.0347 & 0.0333 & 0.0282 & 0.0199 & 0.0164 & 0.0134 & 0.0109 & 0.0092 \\
\hline 810 & 0.0364 & 0.0415 & 0.0426 & 0.0425 & 0.0413 & 0.0401 & 0.0390 & 0.0365 & 0.0308 & 0.0217 & 0.0179 & 0.0146 & 0.0115 & 0.0101 \\
\hline 910 & 0.0405 & 0.0466 & 0.0478 & 0.0468 & 0.0457 & 0.0448 & 0.0435 & 0.0408 & 0.0343 & 0.0235 & 0.0193 & 0.0154 & 0.0123 & 0.0109 \\
\hline 1010 & 0.0438 & $0.049 ?$ & 0.0502 & 0.0503 & 0.0490 & 0.0474 & 0.0467 & 0.0428 & 0.0360 & 0.0245 & 0.0200 & 0.0163 & 0.0130 & 0.0111 \\
\hline 1060 & 0.0454 & 0.0514 & 0.0517 & 0.0502 & 0.0499 & 0.0487 & 0.0471 & 0.0473 & 0.0364 & 0.0245 & 0.0202 & 0.0165 & 0.0128 & 0.0114 \\
\hline 1110 & 0.0457 & 0.0526 & 0.0523 & 0.0524 & 0.0508 & 0.0498 & 0.0474 & 0.0440 & 0.0373 & 0.0251 & 0.0200 & 0.0166 & 0.0129 & 0.0113 \\
\hline 1160 & 0.0451 & 0.0525 & 0.0530 & 0.0520 & 0.0508 & 0.0498 & 0.0481 & 0.0447 & 0.0367 & 0.0246 & 0.0203 & 0.0166 & 0.0130 & 0.0113 \\
\hline 1210 & 0.0464 & 0.0523 & 0.0532 & 0.0529 & 0.0510 & 0.0497 & 0.0482 & 0.0442 & 0.0368 & 0.0252 & 0.0206 & 0.0166 & 0.0131 & 0.0115 \\
\hline 1260 & 0.0456 & 0.0531 & 0.0528 & 0.0525 & 0.0506 & 0.0486 & 0.0471 & 0.0445 & 0.0363 & 0.0246 & 0.0202 & 0.0164 & 0.0130 & 0.0113 \\
\hline 1310 & 0.0451 & 0.0506 & 0.0516 & 0.0514 & 0.0496 & 0.0478 & 0.0474 & 0.0429 & 0.0360 & 0.0241 & 0.0196 & 0.0163 & 0.0127 & 0.0110 \\
\hline 1410 & 0.0430 & 0.0473 & 0.0487 & 0.0481 & 0.0474 & 0.0450 & 0.0436 & 0.0408 & 0.0343 & 0.0231 & 0.0191 & 0.0155 & 0.0123 & 0.0107 \\
\hline 1510 & 0.0400 & 0.0438 & 0.0445 & 0.0441 & 0.0435 & 0.0417 & 0.0404 & 0.0376 & 0.0319 & 0.0216 & 0.0177 & 0.0149 & 0.0118 & 0.0102 \\
\hline 1610 & 0.0421 & 0.0428 & 0.409 & 0.0400 & 0.0392 & 0.0369 & 0.0359 & 0.0343 & 0.0288 & 0.0204 & 0.0169 & 0.0136 & 0.0106 & 0.0098 \\
\hline 1710 & 0.0408 & 0.0379 & 0.0357 & 0.0351 & 0.0339 & 0.0336 & 0.0316 & 0.0292 & 0.0255 & 0.0177 & 0.0150 & 0.0122 & 0.0101 & 0.0086 \\
\hline 1810 & 0.0347 & 0.0332 & 0.0307 & 0.0300 & 0.0291 & 0.0279 & 0.0274 & 0.0253 & 0.0214 & 0.0157 & 0.0034 & 0.0108 & 0.0089 & 0.0079 \\
\hline
\end{tabular}




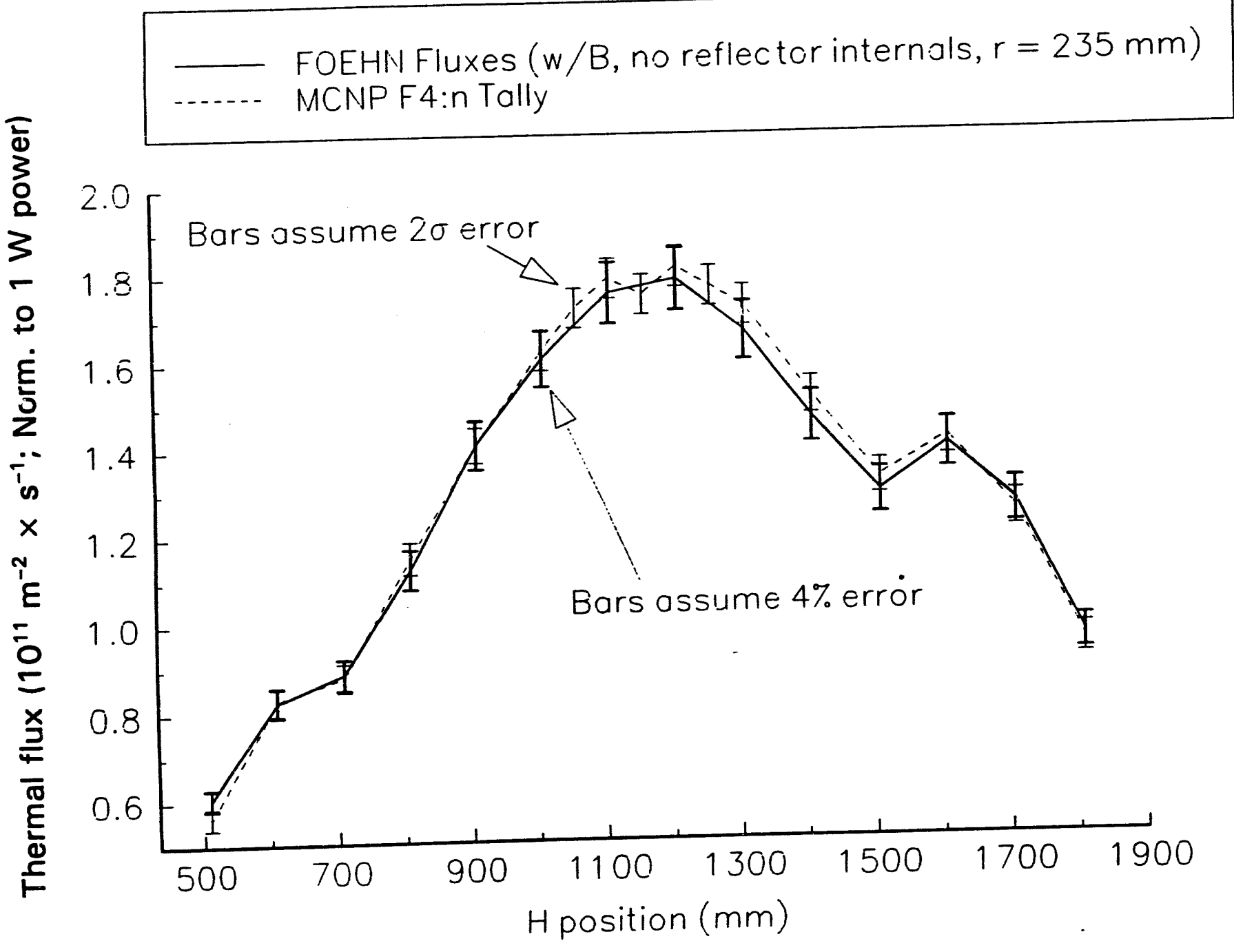

Fig. 4.17. Comparison of experimental and computed axial nux shapes at $r=235 \mathrm{~mm}$ in the intermediate FOEHN configuration. 


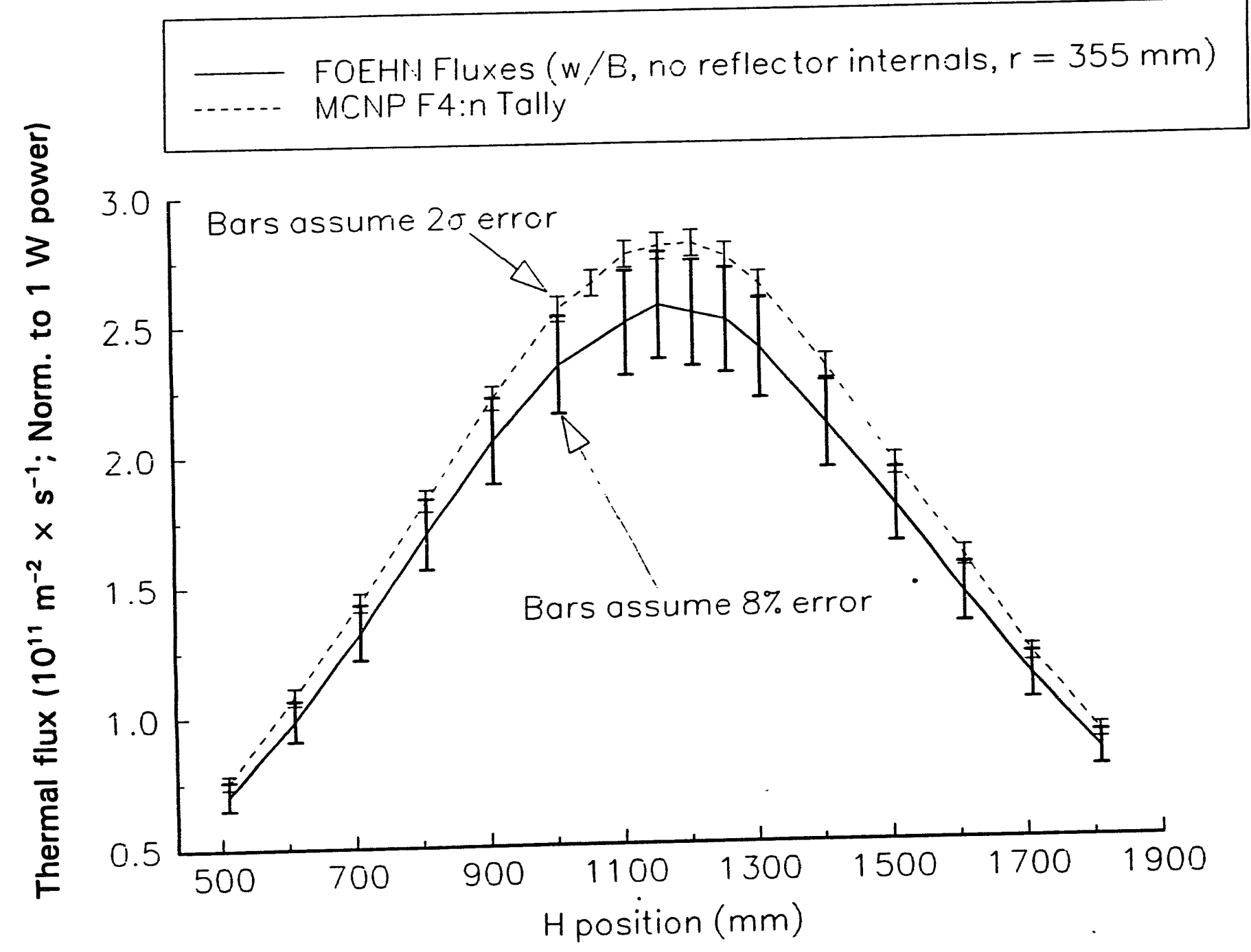

Fig. 4.18. Comparison of experimental and computed axial nux shapes at $r=355 \mathrm{~mm}$ in the intermediate FOEHN configuration. 


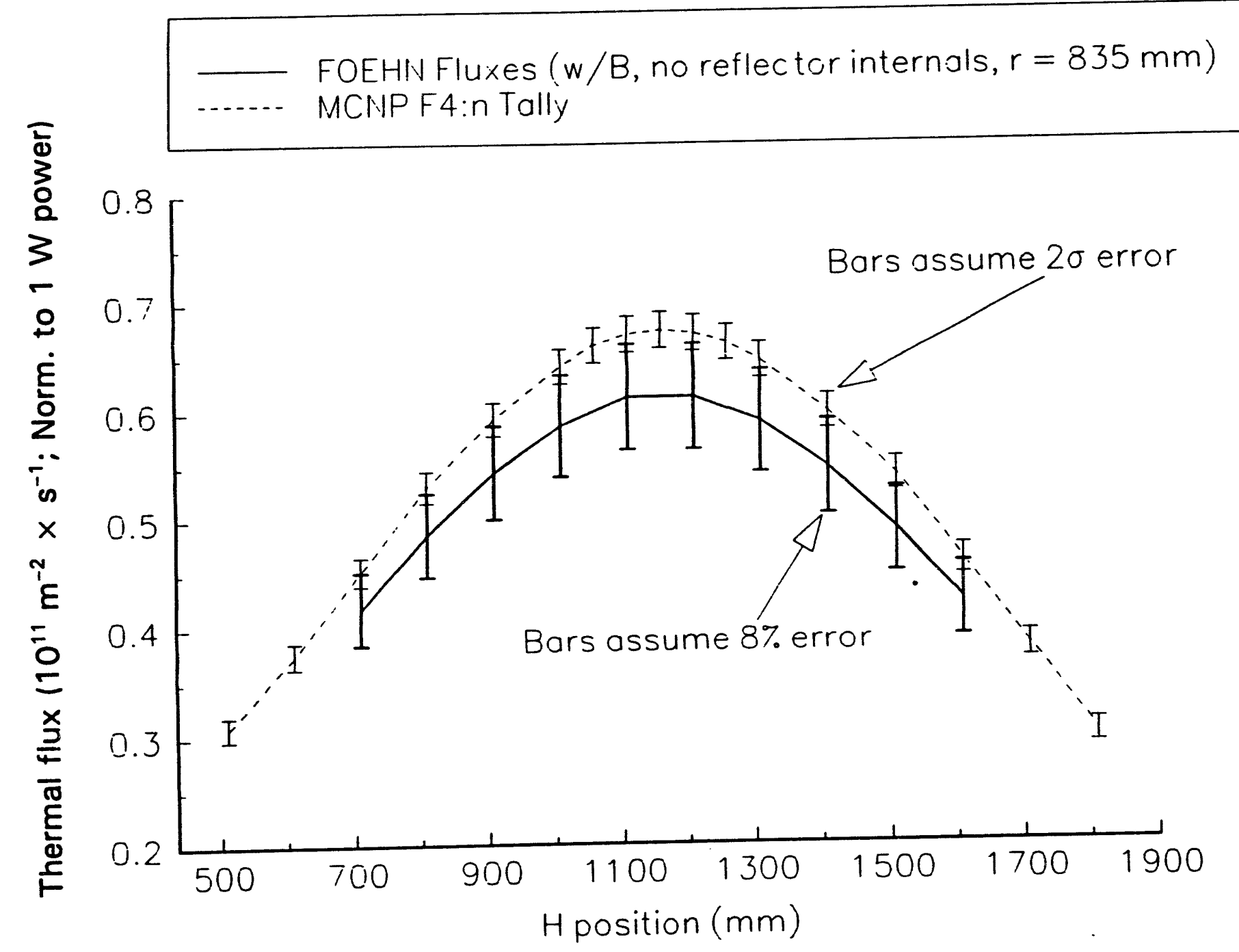

Fig. 4.19. Comparison of experimental and computed axial nux shapes at $r=835 \mathrm{~mm}$ in the intermediate FOEHN configuration. 


\subsubsection{Power}

The intermediate complexity MCNP model of the FOEHN critical experiment has been used to obtain F7:n tallies (KCODE option, 80 cycles, 10000 particles/cycle). The tallies have been normalized to the same constant $(0.99781)$ as the data of the corresponding table of the FOEHN report (Table 5.2.6), according to the procedure summarized in Sect. 2.3.2.2. The normalized MCNP results are shown in Table 4.10. In Table 4.11, the corresponding MCNP error estimates (2 $\sigma$ ) are shown. For the sake of completeness, the experimental data (Table 5.2.6 of ref. 2) are shown in Table 4.12.

The tallies from Table 4.10 and the experimental data from Table 5.2.6 of the FOEHN report are compared in Figs. 4.20-4.22. The error bars shown for the computed results correspond to the $2 \sigma$ values tabulated in Table 4.11. The error bars for the experimental points correspond to the $4 \%$ estimate for the error discussed in Chap. 2.

In Figs. 4.20-4.22, the power distribution is plotted as a function of the axial coordinate $H$ for the radii of $143.5,167.5$, and $193.95 \mathrm{~mm}$, respectively. It can be seen from the figures that for most points in the reactor interior, there is at least partial (and most of the time significant) overlap of the error bars from the computational predictions and the experiment. In Table 4.13, all the experimental and computational results are compared in the sense of overlap of their respective error bands. In the table, an entry of 0 indicates overlap, whereas an entry of 1 indicates no overlap. There are 12 nonoverlapping points out of a total of 123 data points. This implies a nonmatching rate of $9.76 \%$. The table shows that overlap occurs for most points internal to the reactor and that nearly all points at the top and bottom of the core show no overlap. This can be attributed to a lack of precise information about the location of the boron end caps and their modeling as homogenous rather than heterogenous regions. In addition, a possible, though probably negligible, effect might be the impact of the absence of an external AG3-NE end cover. These external covers (axial portion of the reactor tank, beyond the inner AG3-NE seals and the boron end caps) were not modeled because their size is not known, and they are expected to have little neutronic relevance, if any. If the nommatching end points ( 9 points-2 at top and 7 at bottom of core) are excluded from the nonmatching count, the nonmatching rate drops to $2.44 \%$, well within the expected nonoverlap rate of $5 \%$ predictable from the use of the $\pm 2 \sigma$ error bands.

\subsection{FULL COMPLEXITY REACTOR MODEL}

\subsubsection{Core Multiplication Factor $\left(k_{e f f}\right)$}

The multiplication factor for the FOEHN experiment in the full complexity reactor configuration has been computed for several control rod positions and corresponding critical soluble boron concentrations (defined in Table 5.3.2 of ref. 2). The KCODE estimates (40 cycles, 3000 histories/cycle) of $k_{\text {eff }}$ for the full-featured reactor configuration are tabulated in Table 4.14 and are shown in Fig. 4.23. They display three close misses and one miss by about 10 . In three cases, the estimate of $k_{\text {eff }}$ overlaps with the expected value of 1.0 (within $2 \sigma$ ). In these three cases, however, the overlap is by a very small margin. As in the previous two configurations, the small number of cases limits the statistical significance of the results.

\subsubsection{Thermal Flux}

For the full-complexity FOEHN configuration, the thermal flux was measured at the noses of several beam tubes, radially and axially through the hot source, axially through the cold source, and 
Table 4.10. Normalized MCNP power production (F7:n tallies) for the intermediate reactor configuration

\begin{tabular}{cccccccccccc}
\hline $\begin{array}{c}H / r \\
(\mathrm{~mm})\end{array}$ & 143.5 & 146.5 & 149.5 & 152.5 & 159.0 & 167.5 & 176.0 & 182.5 & 185.5 & 188.5 & 193.95 \\
\hline 2.5 & 0.4918 & 0.4541 & 0.4300 & 0.4241 & 0.3590 & 0.4224 & 0.5387 & 0.6491 & 0.7339 & 0.8520 & 1.1667 \\
9.4 & 0.4905 & & & & & & & & & & \\
1.1733 \\
14.5 & 0.4708 & & & & & 0.4285 & & & & 1.1304 \\
19.4 & 0.4607 & & & & & 0.4342 & & & & 1.2063 \\
28.5 & 0.4858 & & & & & 0.4325 & & & & 1.1563 \\
50.0 & 0.5447 & 0.4788 & 0.4491 & 0.4717 & 0.4044 & 0.4271 & 0.5349 & 0.6463 & 0.7655 & 0.8724 & 1.2390 \\
75.0 & 0.5334 & & & & & 0.4732 & & & & 1.3318 \\
100.0 & 0.6005 & & & & & 0.5259 & & & & 1.4222 \\
175.0 & 0.7687 & 0.7013 & 0.6651 & 0.6403 & 0.5809 & 0.6249 & 0.7231 & 0.9331 & 1.0298 & 1.1228 & 1.5690 \\
250.0 & 0.8994 & & & & & 0.7783 & & & & & 1.9762 \\
325.0 & 0.9600 & & & & & 0.8230 & & & & 2.0875 \\
400.0 & 1.0411 & 0.9761 & 0.9307 & 0.8933 & 0.8266 & 0.8588 & 1.0681 & 1.2665 & 1.4233 & 1.6231 & 2.2295 \\
475.0 & 1.4025 & & & & & 0.9759 & & & & & 2.2987 \\
550.0 & 1.4749 & & & & & 0.9592 & & & & 2.2911 \\
625.0 & 1.3238 & 1.2077 & 1.0794 & 1.0092 & 0.8876 & 0.8658 & 0.9922 & 1.1805 & 1.3557 & 1.6413 & 2.1978 \\
700.0 & 1.1736 & & & & & 0.7781 & & & & 1.8758 \\
725.0 & 1.1740 & & & & & 0.7317 & & & 1.7848 \\
750.0 & 1.1131 & 0.9953 & 0.8451 & 0.7881 & 0.7397 & 0.6913 & 0.7818 & 1.0226 & 1.1521 & 1.2781 & 1.7095 \\
771.5 & 1.0583 & & & & & 0.6549 & & & & 1.7299 \\
780.6 & 1.1249 & & & & & 0.6785 & & & & 1.7121 \\
785.5 & 1.0787 & & & & & 0.6380 & & & & & 1.7523 \\
790.6 & 1.1233 & & & & & & & & & & 1.7326 \\
797.5 & 1.1574 & 1.0260 & 0.9053 & 0.8431 & 0.7667 & 0.7043 & 0.8371 & 1.0455 & 1.1916 & 1.2919 & 1.7957 \\
\hline
\end{tabular}


Table 4.11. MCNP error estimate ( $2 \sigma$, absolute) for the normalized MCNP power production for the intermediate reactor configuration

\begin{tabular}{|c|c|c|c|c|c|c|c|c|c|c|c|}
\hline $\begin{array}{c}H / r \\
(\mathrm{~mm})\end{array}$ & 143.5 & 146.5 & 149.5 & 152.5 & 159.0 & 167.5 & 176.0 & 182.5 & 185.5 & 188.5 & 193.95 \\
\hline 2.5 & 0.0409 & 0.0343 & 0.0315 & 0.0327 & 0.0279 & 0.0307 & 0.0373 & 0.0439 & 0.0483 & 0.0491 & 0.0653 \\
\hline 9.4 & 0.0344 & & & & & & & & & & 0.0615 \\
\hline 14.5 & 0.0347 & & & & & 0.0308 & & & & & 0.0619 \\
\hline 19.4 & 0.0334 & & & & & 0.0309 & & & & & 0.0644 \\
\hline 28.5 & 0.0345 & & & & & 0.0309 & & & & & 0.0624 \\
\hline 50.0 & 0.0395 & 0.0338 & 0.0322 & 0.0362 & 0.0289 & 0.0296 & 0.0342 & 0.0401 & 0.0452 & 0.0508 & 0.0619 \\
\hline 75.0 & 0.0366 & & & & & 0.0311 & & & & & 0.0666 \\
\hline 100.0 & 0.0364 & & & & & 0.0351 & & & & & 0.0697 \\
\hline 175.0 & 0.0423 & 0.0390 & 0.0372 & 0.0365 & 0.0345 & 0.0376 & 0.0419 & 0.0504 & 0.0505 & 0.0546 & 0.0715 \\
\hline 250.0 & 0.0455 & & & & & 0.0405 & & & & & 0.0806 \\
\hline 325.0 & 0.0511 & & & & & 0.0430 & & & & & 0.0843 \\
\hline 400.0 & 0.0498 & 0.0472 & 0.0477 & 0.0481 & 0.0428 & 0.0419 & 0.0536 & 0.0580 & 0.0615 & 0.0665 & $\begin{array}{l}0.0843 \\
00910\end{array}$ \\
\hline 475.0 & 0.0679 & & & & & 0.0472 & & & & & $\begin{array}{l}0.0910 \\
0.0894\end{array}$ \\
\hline 550.0 & 0.0711 & & & & & 0.0468 & & & & & $\begin{array}{l}0.0894 \\
0.0870\end{array}$ \\
\hline 625.0 & 0.0675 & 0.0623 & 0.0555 & 0.0557 & 0.0447 & 0.0448 & 0.0488 & 0.0548 & 0.0594 & $0.0 / 02$ & $\begin{array}{l}0.0870 \\
0.0773\end{array}$ \\
\hline 700.0 & 0.0638 & & & & & $\begin{array}{l}0.0426 \\
0.0414\end{array}$ & & & & & 0.0778 \\
\hline 725.0 & 0.0664 & 0.0569 & & & & $\begin{array}{l}0.0414 \\
0.0411\end{array}$ & 0.0439 & 0.0515 & 0.0583 & 0.0649 & 0.0773 \\
\hline 750.0 & 0.0634 & & 0.0507 & 0.0476 & 0.0493 & & & & & & 0.0758 \\
\hline 771.5 & 0.0622 & & & & & $\begin{array}{l}0.0411 \\
0.0419\end{array}$ & & & & & 0.0774 \\
\hline 780.6 & 0.0637 & & & & & 0.0389 & & & & & 0.0785 \\
\hline 785.5 & $\begin{array}{l}0.0613 \\
0.0660\end{array}$ & & & & & 0.0000 & & & & & 0.0807 \\
\hline $\begin{array}{l}790.6 \\
797.5\end{array}$ & $\begin{array}{l}0.0660 \\
0.0681\end{array}$ & 0.0630 & 0.0581 & 0.0528 & 0.0486 & 0.0421 & 0.0487 & 0.0533 & 0.0617 & 0.0641 & 0.0787 \\
\hline
\end{tabular}


Table 4.12. Experimental power production distribution in the intermediate reactor configuratione

\begin{tabular}{|c|c|c|c|c|c|c|c|c|c|c|c|}
\hline $\begin{array}{c}H / r \\
(\mathrm{~mm})\end{array}$ & 143.5 & 146.5 & 149.5 & 152.5 & 159.0 & 167.5 & 176.0 & 182.5 & 185.5 & 188.5 & 193.95 \\
\hline 2.5 & 0.5018 & 0.4759 & 0.4512 & 0.4397 & 0.4338 & 0.4766 & 0.5805 & 0.7211 & 0.8090 & 0.9171 & \\
\hline 4.5 & & & & & & & & & & & $\begin{array}{l}1.1850 \\
1.1990\end{array}$ \\
\hline 9.4 & 0.4839 & & & & & & & & & & 1.2000 \\
\hline 14.5 & 0.4794 & & & & & $\begin{array}{l}0.4238 \\
0.4167\end{array}$ & & & & & 1.1911 \\
\hline 19.4 & 0.4794 & & & & & $\begin{array}{l}0.4101 \\
0.4245\end{array}$ & & & & & 1.2224 \\
\hline 28.5 & 0.4847 & 0.4742 & 0.4459 & 0.4239 & 0.4093 & 0.4420 & 0.5392 & 0.6769 & 0.7785 & 0.8976 & 1.2601 \\
\hline 50.0 & 0.5110 & & 0.4459 & & & 0.4770 & & & & & 1.3421 \\
\hline 75.0 & $\begin{array}{l}0.5567 \\
0.5930\end{array}$ & & & & & 0.5121 & & & & & 1.4317 \\
\hline iO0.0 & $\begin{array}{l}0.5930 \\
0.7313\end{array}$ & 0.6753 & 0.6400 & 0.6051 & 0.5872 & 0.6257 & 0.7491 & 0.9407 & 1.0623 & 1.2310 & 1.7123 \\
\hline 175.0 & $\begin{array}{l}0.7313 \\
0.8502\end{array}$ & & & & & 0.7224 & & & & & 1.9383 \\
\hline 250.0 & $\begin{array}{l}0.8502 \\
0.9511\end{array}$ & & & & & 0.8000 & & & & & 2.1266 \\
\hline 325.0 & $\begin{array}{l}0.9511 \\
1.0142\end{array}$ & 0.9537 & 0.8855 & 0.8438 & 0.8084 & 0.8560 & 1.1200 & 1.2612 & 1.4062 & 1.6161 & 2.2504 \\
\hline 400.0 & $\begin{array}{l}1.0142 \\
1.3118\end{array}$ & & & & & 0.9275 & & & & & 2.3172 \\
\hline $\begin{array}{l}475.0 \\
5500\end{array}$ & 1.3564 & & & & & 0.9315 & & & & & 2.2620 \\
\hline $\begin{array}{l}550.0 \\
625.0\end{array}$ & 1.3150 & 1.1794 & 1.0616 & 0.9743 & 0.8880 & 0.8800 & 0.9931 & 1.2161 & 1.3458 & 1.5414 & 2.1313 \\
\hline 700.0 & 1.1813 & & & & & 0.7740 & & & & & 1.9097 \\
\hline 725.0 & 1.1423 & & & & & 0.7301 & & & & & 1.8183 \\
\hline 750.0 & 1.0947 & 0.9687 & 0.8770 & 0.7968 & 0.7082 & 0.6966 & 0.8015 & 0.9889 & 1.1146 & 1.2653 & 1.7799 \\
\hline 771.5 & 1.0978 & & & & & 0.6885 & & & & & 1.7620 \\
\hline 780.6 & 1.0300 & & & & & 0.7054 & & & & & 1.7518 \\
\hline 785.5 & 1.1152 & & & & & 0.7138 & & & & & 1.7609 \\
\hline 790.6 & 1.1577 & & & & & & & & & & 1.7956 \\
\hline 797.5 & 1.2617 & 1.1367 & 1.0807 & 0.9924 & 0.9023 & 0.8946 & 0.9708 & 1.1586 & 1.2664 & 1.4038 & 1.8400 \\
\hline
\end{tabular}

Table 5.2 .6 of ref. 2. 


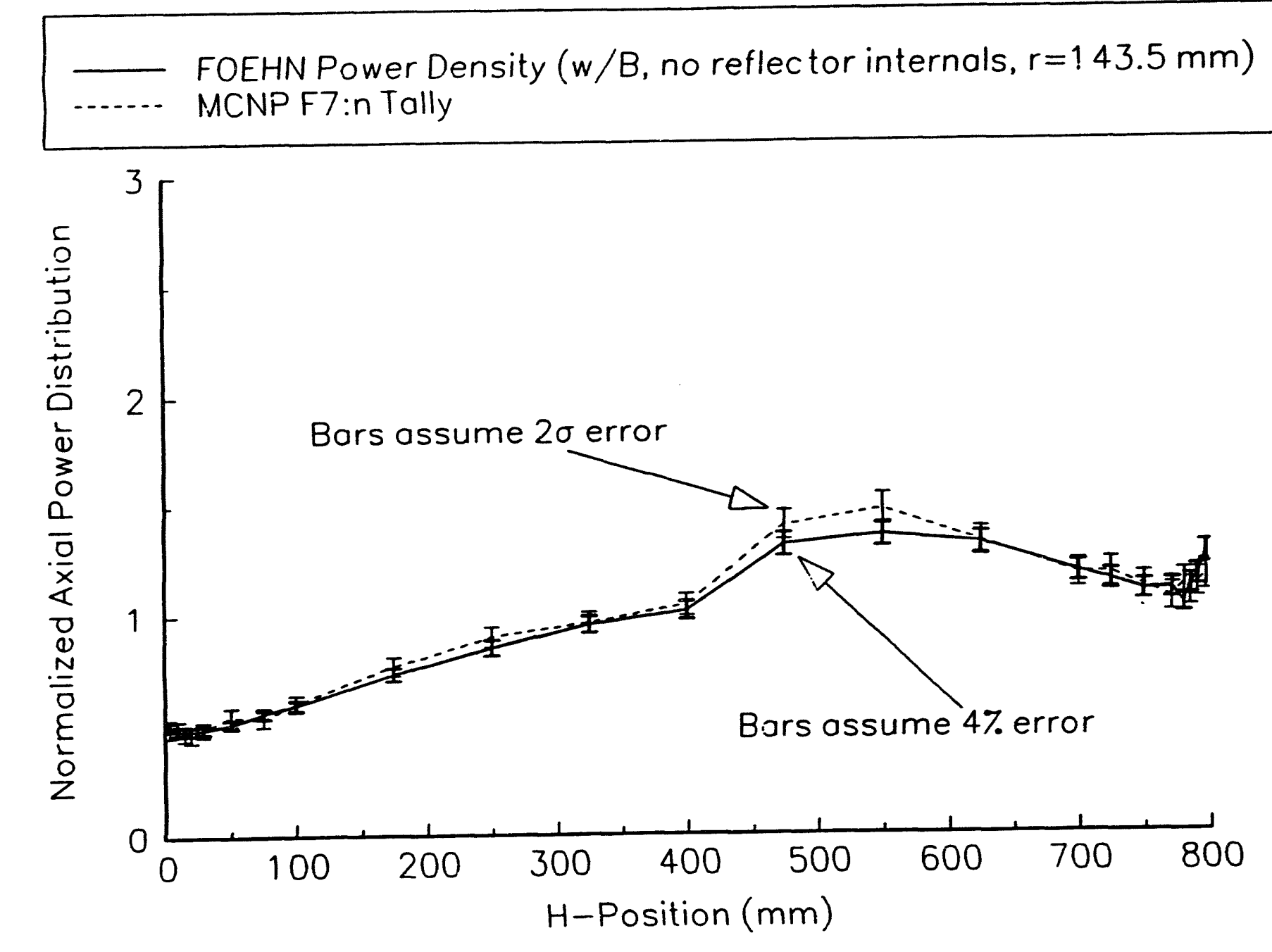

용

Fig. 4.20. Comparison of normalized experimental and computed axial power distribution in the intermediate FOEHN configuration at $r=143.5 \mathrm{~mm}$. 


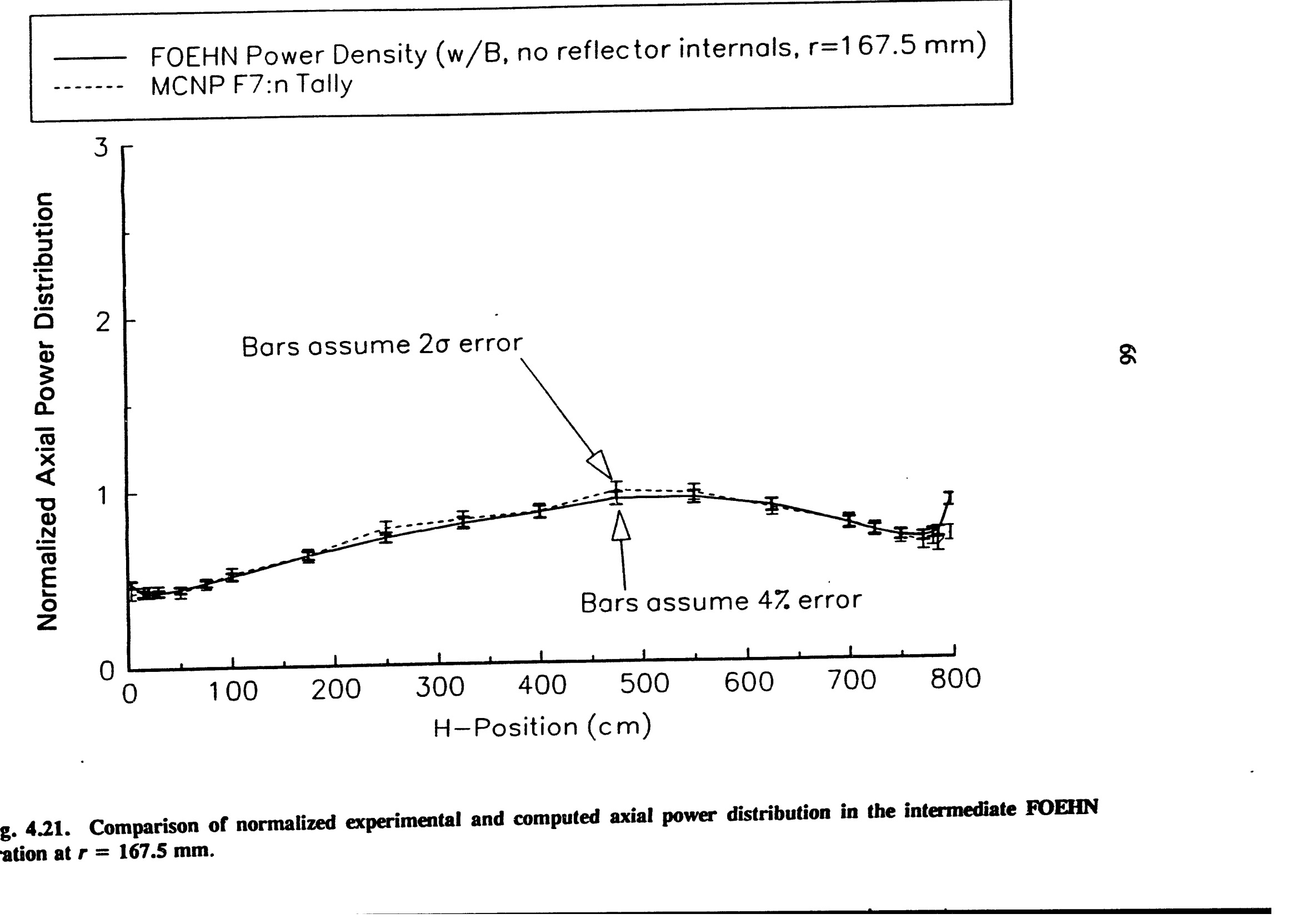




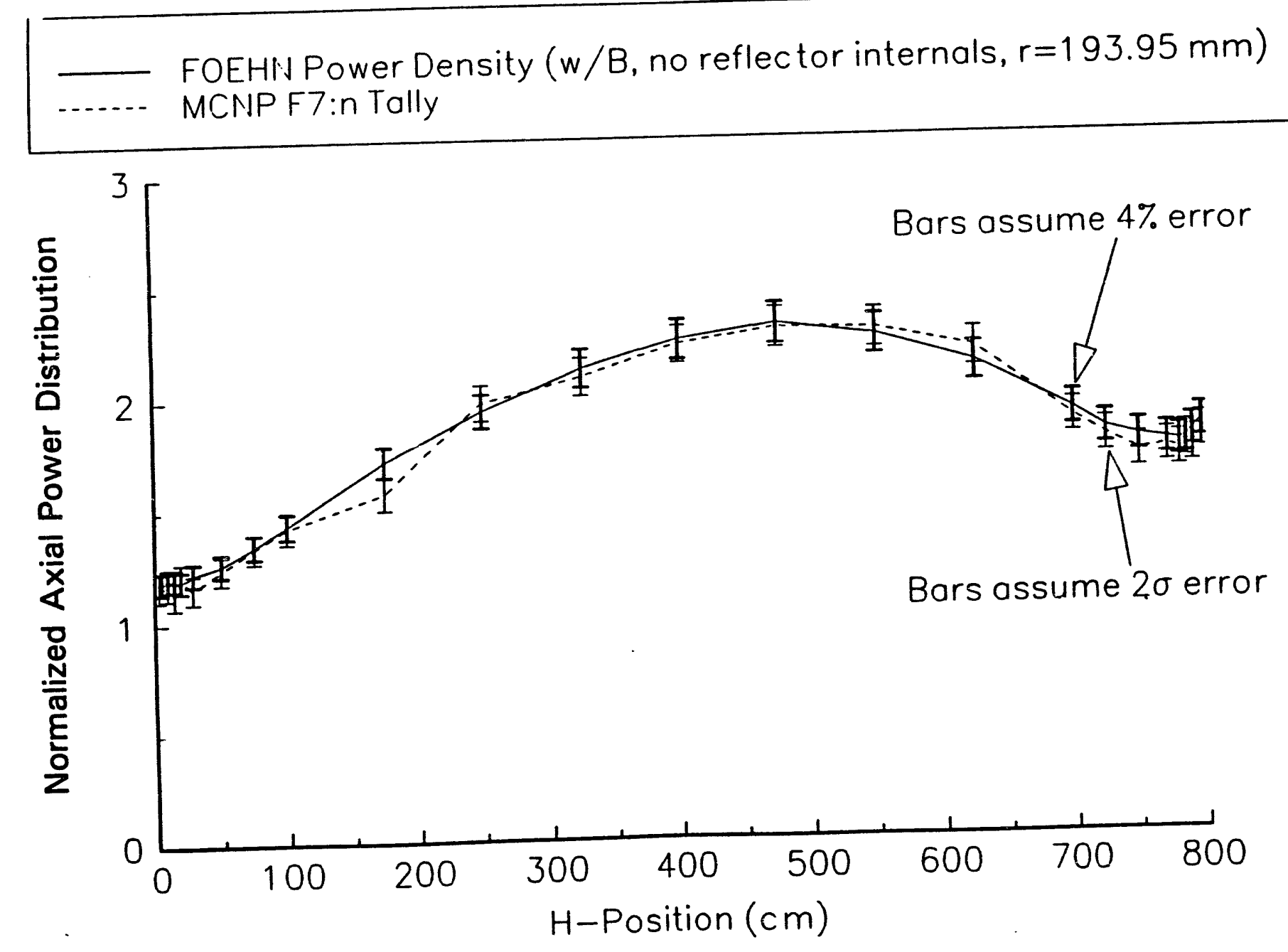

Fig. 4.22. Comparison of normalized experimental and computed axial power distribution in the interme configuration at $r=193.95 \mathrm{~mm}$. 
Table 4.13. Points of nonmatching power production density in the intermediate reactor configuration

\begin{tabular}{|c|c|c|c|c|c|c|c|c|c|c|c|}
\hline $\begin{array}{c}H / r \\
(\mathrm{~mm})\end{array}$ & 143.5 & 146.5 & 149.5 & 152.5 & 159.0 & 167.5 & 176.0 & 182.5 & 185.5 & 188.5 & 193.95 \\
\hline $\begin{array}{l}2.5 \\
4.5\end{array}$ & 0 & 0 & 0 & 0 & 1 & 1 & 0 & 0 & 0 & 0 & 0 \\
\hline 9.4 & 0 & & & & & & & & & & 0 \\
\hline 14.5 & 0 & & & & & 0 & & & & & 0 \\
\hline 19.4 & 0 & & & & & 0 & & & & & 0 \\
\hline 28.5 & 0 & & & & & 0 & & & & & 0 \\
\hline 50.0 & 0 & 0 & 0 & 0 & 0 & 0 & 0 & 0 & 0 & 0 & 0 \\
\hline 75.0 & 0 & & & & & 0 & & & & & 0 \\
\hline 100.0 & 0 & & & & & 0 & & & & & 0 \\
\hline 175.0 & 0 & 0 & 0 & 0 & 0 & 0 & 0 & 0 & 0 & 1 & 1 \\
\hline 250.0 & 0 & & & & & 0 & & & & & 0 \\
\hline 325.0 & 0 & & & & & 0 & & & & & 0 \\
\hline 400.0 & 0 & 0 & 0 & 0 & 0 & 0 & 0 & 0 & 0 & 0 & 0 \\
\hline 475.0 & 0 & & & & & 0 & & & & & 0 \\
\hline 550.0 & 0 & & & & & 0 & & & & & 0 \\
\hline 625.0 & 0 & 0 & 0 & 0 & 0 & 0 & 0 & 0 & 0 & 0 & 0 \\
\hline 700.0 & 0 & & & & & 0 & & & & & 0 \\
\hline 725.0 & 0 & & & & & 0 & & & & & 0 \\
\hline 750.0 & 0 & 0 & 0 & 0 & 0 & 0 & 0 & 0 & 0 & 0 & 0 \\
\hline 771.5 & 0 & & & & & 0 & & & & & 0 \\
\hline 780.6 & 0 & & & & & 0 & & & & & 0 \\
\hline 785.5 & 0 & & & & & 1 & & & & & 0 \\
\hline 790.6 & 0 & & & & & & & & & & 0 \\
\hline 797.5 & 0 & 1 & 1 & 1 & 1 & 1 & 1 & 1 & 0 & 0 & 0 \\
\hline
\end{tabular}


Table 4.14. MCNP-computed core effective multiplication factors $\left(k_{\mathrm{eff}}\right)$ for various critical states of the full complexity reactor configuration

\begin{tabular}{|c|c|c|c|c|c|}
\hline \multirow[b]{2}{*}{ Case } & \multicolumn{2}{|c|}{$\begin{array}{c}\text { Control rod } \\
\text { position }(\mathrm{mm})\end{array}$} & \multirow{2}{*}{$\begin{array}{l}\text { Boron } \\
\text { conc. } \\
(\mathrm{g} / \mathrm{L})\end{array}$} & \multirow{2}{*}{$\begin{array}{c}\mathrm{MCNP} \\
k_{\text {eff }}\end{array}$} & \multirow{2}{*}{$\begin{array}{l}\text { MCNP error } \\
\text { estimate } \\
(\sigma)\end{array}$} \\
\hline & MCNP & FOEHN & & & \\
\hline 1 & 0.806 & 0.804 & 0.347 & 0.9935 & 0.0027 \\
\hline 2 & 0.899 & 0.711 & 0.311 & 0.9981 & 0.0024 \\
\hline 3 & 1.014 & 0.596 & 0.260 & 0.9973 & 0.0027 \\
\hline 4 & 1.031 & 0.579 & 0.248 & 0.9935 & 0.0027 \\
\hline 5 & 1.107 & 0.503 & 0.210 & 0.9931 & 0.0027 \\
\hline 6 & 1.225 & 0.385 & 0.143 & 0.9943 & 0.0028 \\
\hline 7 & 1.361 & 0.249 & 0.078 & 0.9890 & 0.0028 \\
\hline
\end{tabular}

axially on the surface of Channel 17. In an attempt to accurately model these measurements, point detector tallies (i.e., next collision estimator, MCNP F5 tallies) were used. These allowed the flux at exact locations to be calculated with better statistics than the track length tallies (F4 tally) with small volume elements. The beam tube fluxes were calculated with the control rod position set to $1.139 \mathrm{~m}$ and a core boron concentration of $0.177 \mathrm{~g} / \mathrm{L}$. The other flux calculations were performed with the control rod set at $1.016 \mathrm{~m}$ and a core boron concentration of $0.255 \mathrm{~g} / \mathrm{L}$. The results obtained displayed a very large number of significant discrepancies between the experimental and the MCNP-computed fluxes, with many points showing no overlap between the computational and experimental error bands by a large margin. These large discrepancies result mainly from the inability of MCNP point detector tallies to incorporate histories involving $S(\alpha, \beta)$ interactions with moderating materials. The computational results have no value from a benchmarking point of view and, hence, are omitted from this report. The $S(\alpha, \beta)$ effect is explained below.

The $S(\alpha, \beta)$ cross-section data correspond to the coherent and incoherent elastic and incoherent inelastic scattering cross sections for materials with significant crystalline or other lattice-dependent scattering effects. These cross-section data, incorporated in the MCNP cross-section libraries and utilized in the FOEHN MCNP models, have a large effect on the behavior of heavy-water-moderated reactors and also influence the performance of other materials, such as liquid deuterium in cold sources and graphite in hot sources.

The large quantity of heavy water in the FOEHN experiment induces nearly all thermal neutrons to undergo at least one lattice-influenced thermal interaction before reaching the reflector components. These $S(\alpha, \beta)$ interactions are not accounted for by MCNP point detector tallies. This can result in a significant discrepancy between the computed tallies and the measured values. This was made very apparent in the initial analysis of the reflector thermal fluxes for the full complexity configuration, when inclusion of the $S(\alpha, \beta)$ data produced flux results that were a factor of two to four below the experimental values. The alternative to this method is to compute the fluxes without using the $S(\alpha, \beta)$ cross-section data. This would produce global inaccuracies in the flux energy distribution since fewer 


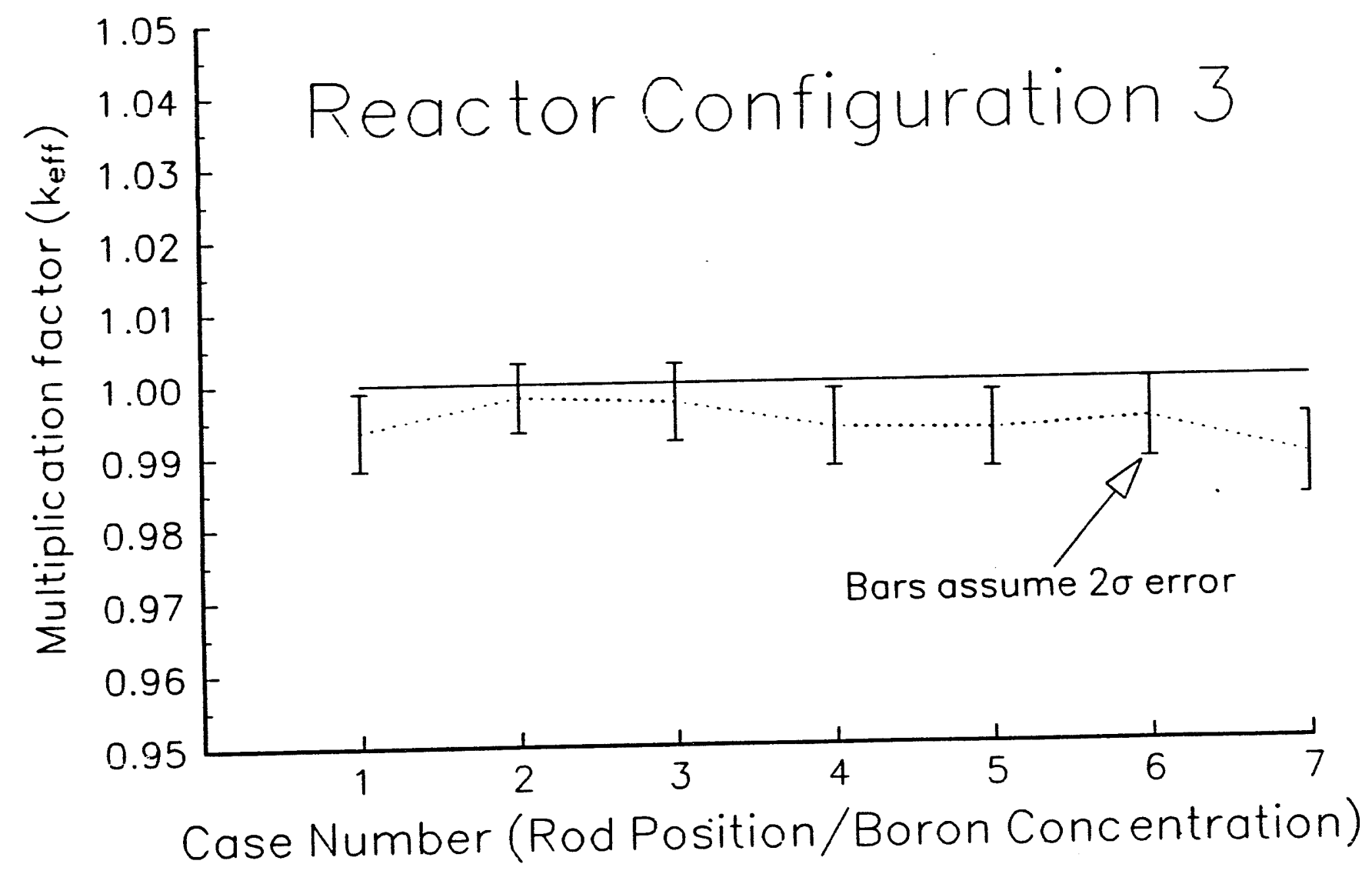

Fig. 4.23. MCNP prediction of $k_{\text {eff }}$ for a set of critical states of the full-featured FOEHN reactor configuration. 
neutrons would be scattered into the lower thermal energy ranges $(<0.625 \mathrm{eV})$. However, this would allow all neutron histories to interact with the point detector tallies. This method was tried and produced a systematic underestimation of the thermal fluxes calculated. These results are also omitted from this report.

An additional effect of the lack of $S(\alpha, \beta)$ cross-section data is seen in the results for the hot source. The presence of hot $(-2000 \mathrm{~K})$ graphite in the hot source introduces another set of $S(\alpha, \beta)$ cross-section data into the calculation. These have a different effect on the flux energy distribution, as there is significantly more upscattering from interactions with hot graphite than from interactions with room-temperature heavy water. The result is a tendency to lower the thermal flux $(<0.625 \mathrm{eV})$ with increasing penetration into the hot source. Since the $S(\alpha, \beta)$ treatment is absent from the simulation, there ensues a large overestimation of the radial and axial thermal flux distributions in the hot source.

4.4.3 $\mathrm{r}$ nent

The MCNP computed rendement, $r_{\text {alc }}$, is $2.4114 \times 10^{11}$ neutrons $/ \mathrm{m}^{2} \cdot \mathrm{s} \cdot \mathrm{W}$. The error estimate on this, $2 \sigma$, is $4.968 \times 10^{9}$ neutrons $/ \mathrm{m}^{2} \cdot \mathrm{s} \cdot \mathrm{W}$. The measured rendement reported in ref. $2, r_{\text {mom }}$ is $2.30 \times 10^{11}$ neutrons $/ \mathrm{m}^{2} \cdot \mathrm{s} \cdot \mathrm{W}$. The error reported in ref. 2 is $\sim 0.05 \times 10^{11}$ neutrons $/ \mathrm{m}^{2} \cdot \mathrm{s} \cdot \mathrm{W}$ (i.e., $\sim 3 \%$ ). This error may be underestimated and could be as large as $\sim 16.2 \%$ (see Sect. 2.4.3.4). With a difference of only $4.84 \%$ between the center values, the two estimates of the rendement agree within statistics (even with the lowest error estimates).

\subsubsection{Power}

The full complexity MCNP model of the FOEHN critical experiment has been used to obtain F7:n tallies (KCODE option, 80 cycles, 10000 particles/cycle). The tallies have been normalized to the same value (1.006) as the data of Table 2.2 obtained in Sect. 2.3.2.3 by combining the results of Tables 5.3.6-5.3.9 of the FOEHN report. The normalized MCNP results are shown in Table 4.15 of this report. In Table 4.16, the corresponding MCNP error estimates $(2 \sigma)$ are shown. The tallies from Table 4.15 and the combined experimental data from Table 2.2 are compared in Figs. 4.24-4.26. The error bars shown for the computed results are the $2 \sigma$ values tabulated in Table 4.16. The error bars for the experimental points correspond to the $4 \%$ estimate for the error discussed in Chap. 2.

In Figs. 4.24-4.26 the power distribution is plotted as a function of the axial coordinate $H$ for the radii of $143.5,167.5$, and $193.95 \mathrm{~mm}$, respectively. As in the intermediate complexity case, it can be seen from the figures that for most points in the reactor interior, there is at least partial (and, in most instances, significant) overlap of the error bars from the computational predictions and the experiment. In Table 4.17, all the experimental and computational results are compared in the sense of overlap of their respective error bands. In the table, an entry of 0 indicates overlap, whereas an entry of 1 indicates no overlap. There are 18 nonoverlapping points out of a total of 125 data points. This implies a nonmatching rate of $14.4 \%$. The table shows that overlap occurs for most points internal to the reactor and that nearly all points at the bottom and almost half the points at the top of the core show no overlap. As in the previous configuration, this can be attributed to the lack of precise information about the location of the borated end caps, the omission of the AG3-NE end covers in the model, and possibly to the modeling of the boron end caps as homogenous rather than heterogenous regions. If the end points (14 points, top and bottom of core) are excluded from the nonmatching count, the nonmatching rate drops to $3.20 \%$, well within the expected nonoverlap rate of $5 \%$ predictable from the use of the $\pm 2 \sigma$ error bands. Aside from the axial end points, two of the remaining four nonoverlap points occur at the inner radius of the core near the tip of the inserted control rod, where flux gradients are sharp and the discrepancy between MCNP F7:n tallies and the measured power 
Table 4.15. Normalized MCNP power production (F7:n tallies) for the full complexity reactor configuration

\begin{tabular}{|c|c|c|c|c|c|c|c|c|c|c|c|}
\hline $\begin{array}{c}H / r \\
(\mathrm{~mm})\end{array}$ & 143.5 & 146.5 & 149.5 & 152.5 & 159.0 & 167.5 & 176.0 & 182.5 & 185.5 & 188.5 & 193.95 \\
\hline 2.5 & $\begin{array}{l}0.5044 \\
0.4881\end{array}$ & 0.4600 & 0.4189 & 0.4090 & 0.4294 & 0.4340 & 0.5167 & 0.6771 & 0.7065 & 0.7916 & $\begin{array}{l}1.1002 \\
1.1871\end{array}$ \\
\hline $\begin{array}{c}9.4 \\
14.5\end{array}$ & $\begin{array}{l}0.4881 \\
0.4829\end{array}$ & & & & & 0.4092 & & & & & \\
\hline 19.4 & 0.4854 & & & & & 0.4351 & & & & & 1.2219 \\
\hline 28.5 & 0.5392 & & & & & 0.4283 & & & & & 1.1927 \\
\hline 50.0 & 0.5305 & 0.4931 & 0.4392 & 0.4430 & 0.4566 & 0.4293 & 0.5406 & 0.6496 & 0.7680 & 0.9189 & 1.2167 \\
\hline 75.0 & 0.5806 & & & & & 0.5034 & & & & & 1.3222 \\
\hline 100.0 & 0.6347 & & & & & 0.5593 & & & & & 1.3701 \\
\hline 175.0 & 0.7294 & 0.6678 & 0.6653 & 0.6339 & 0.6275 & 0.6528 & 0.7472 & 0.9301 & 1.0398 & 1.2076 & 1.5916 \\
\hline 250.0 & 0.9000 & & & & & 0.7454 & & & & & 1.9029 \\
\hline 325.0 & 0.9773 & & & & & 0.8130 & & & & & 2.0977 \\
\hline 400.0 & 1.0904 & 1.0323 & 0.9687 & 0.9121 & 0.8414 & 0.8904 & 1.0201 & 1.2561 & 1.4289 & 1.6747 & 2.2091 \\
\hline 475.0 & 1.5061 & & & & & 1.0533 & & & & & 2.2745 \\
\hline 550.0 & 1.6064 & & & & & 0.9873 & & & & & 2.1995 \\
\hline 625.0 & 1.3510 & 1.2273 & 1.1075 & 1.0047 & 0.8925 & 0.9016 & 1.0031 & 1.2251 & 1.3244 & 1.5141 & 2.0027 \\
\hline 700.0 & 1.3155 & & & & & 0.8339 & & & & & 1.8211 \\
\hline 725.0 & 1.1976 & & & & & 0.7740 & & & & & 1.7019 \\
\hline 750.0 & 1.1100 & 0.9172 & 0.8365 & 0.7941 & 0.7155 & 0.7349 & 0.8652 & 1.0136 & 1.1565 & 1.2903 & 1.7236 \\
\hline 771.5 & 1.0874 & & & & & 0.6835 & & & & & 1.6379 \\
\hline 780.6 & 1.1191 & & & & & 0.7063 & & & & & 1.6754 \\
\hline 785.5 & 1.1037 & & & & & 0.6727 & & & & & 1.5936 \\
\hline 790.6 & 1.1370 & & & & & & & & & & 1.6444 \\
\hline 797.5 & 1.2027 & 1.0695 & 0.9411 & 0.8474 & 0.7471 & 0.7574 & 0.8243 & 0.0116 & 1.0783 & 1.2262 & 1.6124 \\
\hline
\end{tabular}


Table 4.16. MCNP error estimate (2 $\sigma$, absolute) for the normalized MCNP power production for the full complexity reactor configuration

\begin{tabular}{|c|c|c|c|c|c|c|c|c|c|c|c|}
\hline $\begin{array}{c}H / r \\
(\mathrm{~mm})\end{array}$ & 143.5 & 146.5 & 149.5 & 152.5 & 159.0 & 167.5 & 176.0 & 182.5 & 185.5 & 188.5 & 193.95 \\
\hline 2.5 & 0.0377 & 0.0353 & 0.0318 & 0.0316 & 0.0327 & 0.0317 & 0.0372 & 0.0437 & 0.0455 & 0.0477 & 0.0607 \\
\hline 9.4 & 0.0344 & & & & & & & & & & 0.0651 \\
\hline 14.5 & $\begin{array}{l}0.0356 \\
0.0335\end{array}$ & & & & & $\begin{array}{l}0.0300 \\
0.0329\end{array}$ & & & & & 0.0689 \\
\hline 19.4 & $\begin{array}{l}0.0335 \\
0.0418\end{array}$ & & & & & $\begin{array}{l}0.0329 \\
0.0322\end{array}$ & & & & & 0.0656 \\
\hline 28.5 & $\begin{array}{l}0.0418 \\
0.0383\end{array}$ & 0.0346 & 0.0299 & & & $\begin{array}{l}0.0322 \\
0.0288\end{array}$ & 0.0375 & 0.0433 & 0.0501 & 0.0535 & 0.0638 \\
\hline 50.0 & $\begin{array}{l}0.0383 \\
0.0383\end{array}$ & & & 0.0327 & 0.0383 & $\begin{array}{l}0.0288 \\
0.0342\end{array}$ & & & & & 0.0677 \\
\hline 75.0 & $\begin{array}{l}0.0383 \\
0.0410\end{array}$ & & & & & $\begin{array}{l}0.0342 \\
0.0366\end{array}$ & & & & & 0.0680 \\
\hline 100.0 & $\begin{array}{l}0.0410 \\
0.0398\end{array}$ & 0.0369 & 0.0379 & 0.0350 & & $\begin{array}{l}0.0360 \\
0.0377\end{array}$ & 0.0427 & 0.0484 & 0.0526 & 0.0599 & 0.0754 \\
\hline 175.0 & $\begin{array}{l}0.0398 \\
0.0468\end{array}$ & & & & 0.0438 & 0.0404 & & & & & 0.0784 \\
\hline 250.0 & $\begin{array}{l}0.0468 \\
0.0481\end{array}$ & & & & & 0.0429 & & & & & 0.0856 \\
\hline 325.0 & $\begin{array}{l}0.0481 \\
0.0497\end{array}$ & & 0.0469 & 0.0440 & 0.0406 & 0.0459 & 0.0492 & 0.0575 & 0.0634 & 0.0693 & 0.0844 \\
\hline 400.0 & $\begin{array}{l}0.0497 \\
0.0723\end{array}$ & 0.0508 & & & & 0.0518 & & & & & 0.0873 \\
\hline 475.0 & $\begin{array}{l}0.0723 \\
0.0774\end{array}$ & & & & & 0.0486 & & & & & 0.0845 \\
\hline 550.0 & $\begin{array}{l}0.0774 \\
0.0676\end{array}$ & 0.0631 & 0.0571 & $0.050 \varepsilon$ & 0.0469 & 0.0445 & 0.0488 & 0.0590 & 0.0615 & 0.0669 & 0.0793 \\
\hline 625.0 & $\begin{array}{l}0.0676 \\
0.0687\end{array}$ & & & & & 0.0484 & & & & & 0.0772 \\
\hline 700.0 & $\begin{array}{l}0.0687 \\
0.0651\end{array}$ & & & & & 0.0430 & & & & & 0.0735 \\
\hline 725.0 & $\begin{array}{l}0.0651 \\
0.0666\end{array}$ & 0.0532 & 0.0478 & 0.0483 & 0.0454 & 0.0428 & 0.0495 & 0.0545 & 0.0601 & 0.0614 & 0.0782 \\
\hline 750.0 & 0.0666 & & & & & 0.0421 & & & & & 0.0737 \\
\hline 771.5 & 0.0642 & & & & & 0.0436 & & & & & 0.0754 \\
\hline 780.6 & 0.0642 & & & & & 0.0398 & & & & & 0.0739 \\
\hline 785.5 & $\begin{array}{l}0.0640 \\
0.0664\end{array}$ & & & & & & & & & & 0.0779 \\
\hline 790.6 & $\begin{array}{l}0.0664 \\
0.0702\end{array}$ & 0.0640 & 0.0574 & 0.0534 & 0.0466 & 0.0457 & 0.0465 & 0.0542 & 0.0552 & 0.0601 & 0.0735 \\
\hline
\end{tabular}



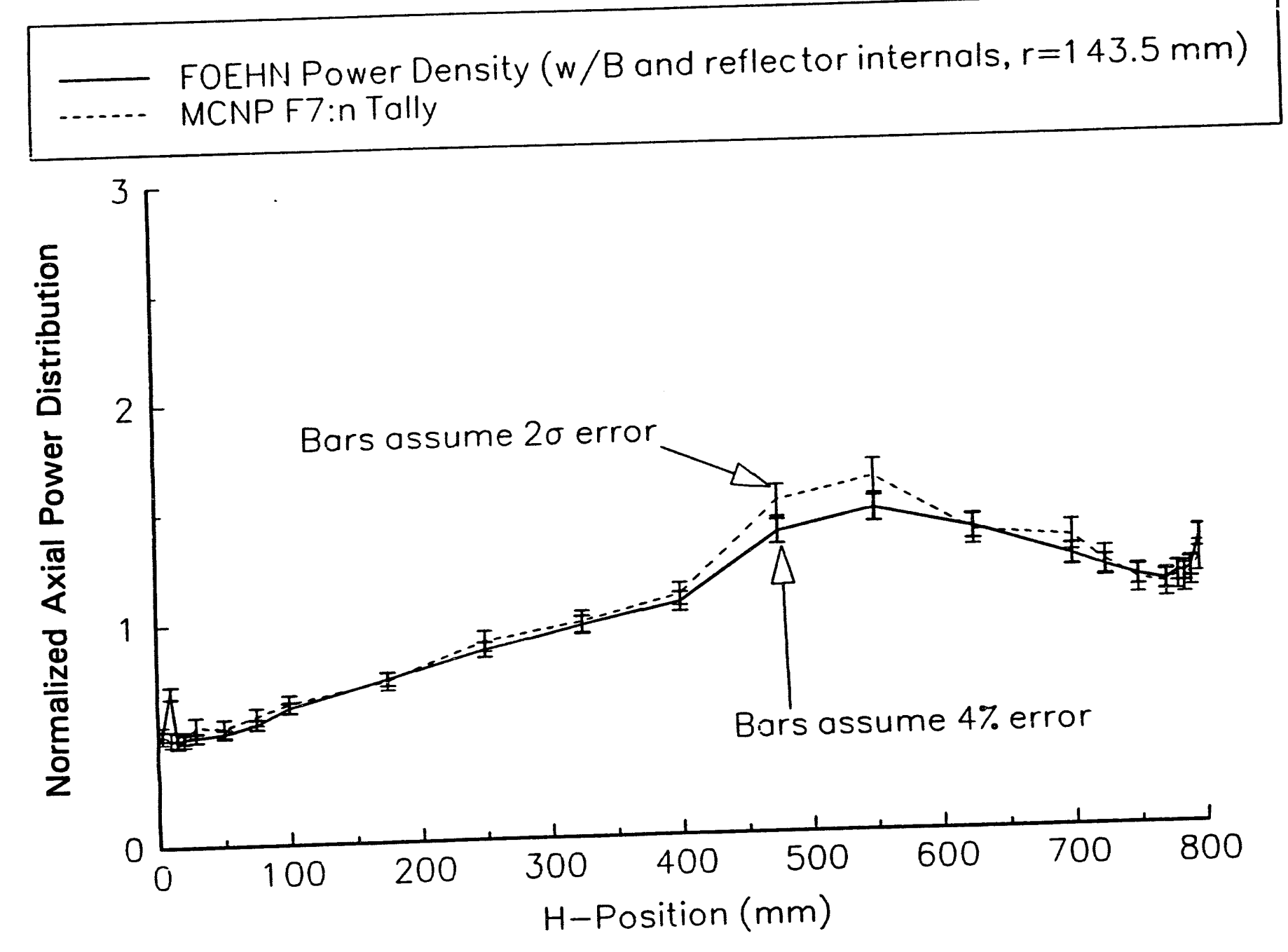

Fig. 4.24. Comparison of normalized experimental and computed axial power distribution in the full-featured FOEHN configuration at $r=143.5 \mathrm{~mm}$. 


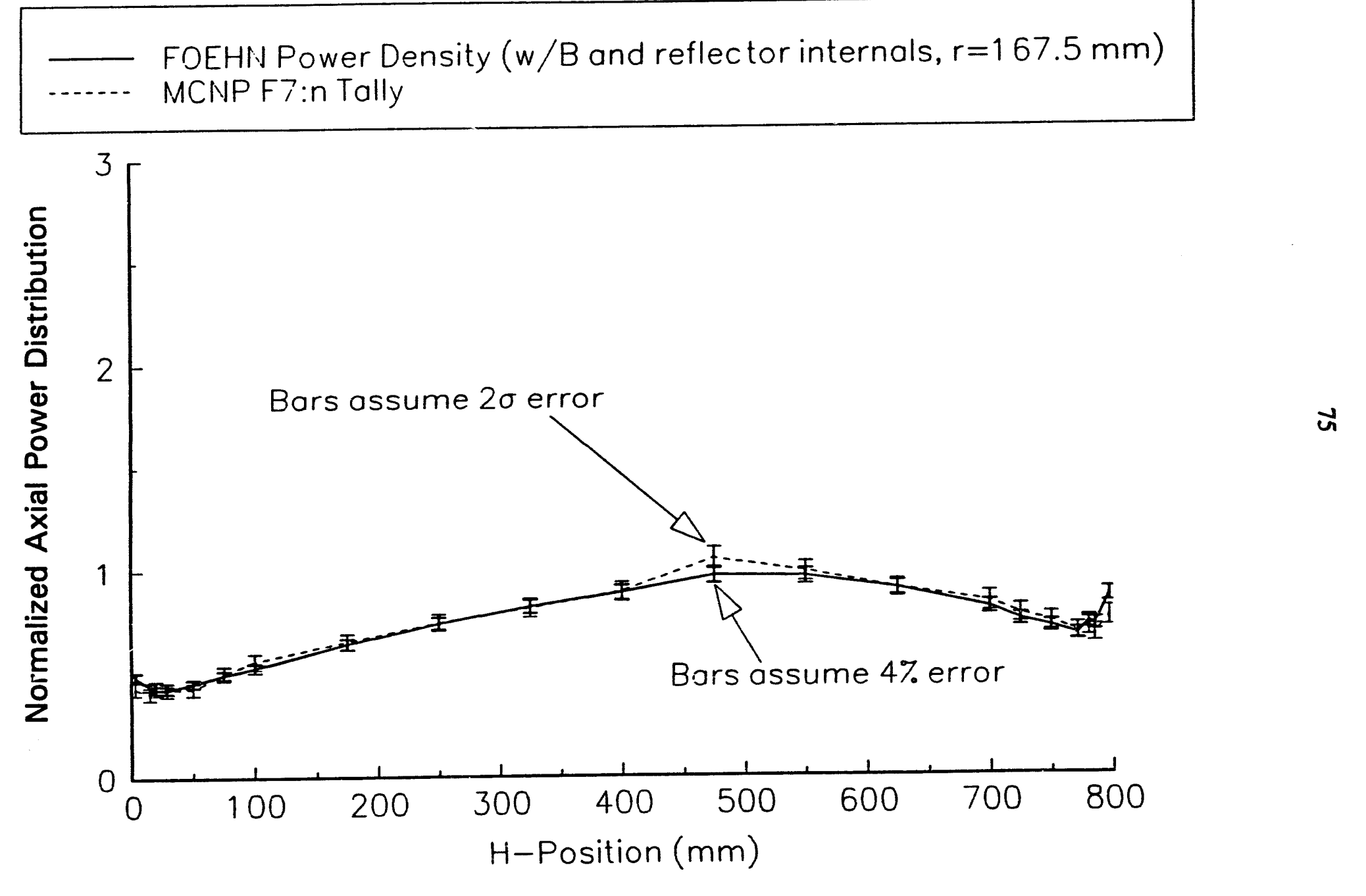

Fig. 4.25. Comparison of normalized experimental and computed axial power distribution in the full-featured FOEHN configuration at $r=167.5 \mathrm{~mm}$. 


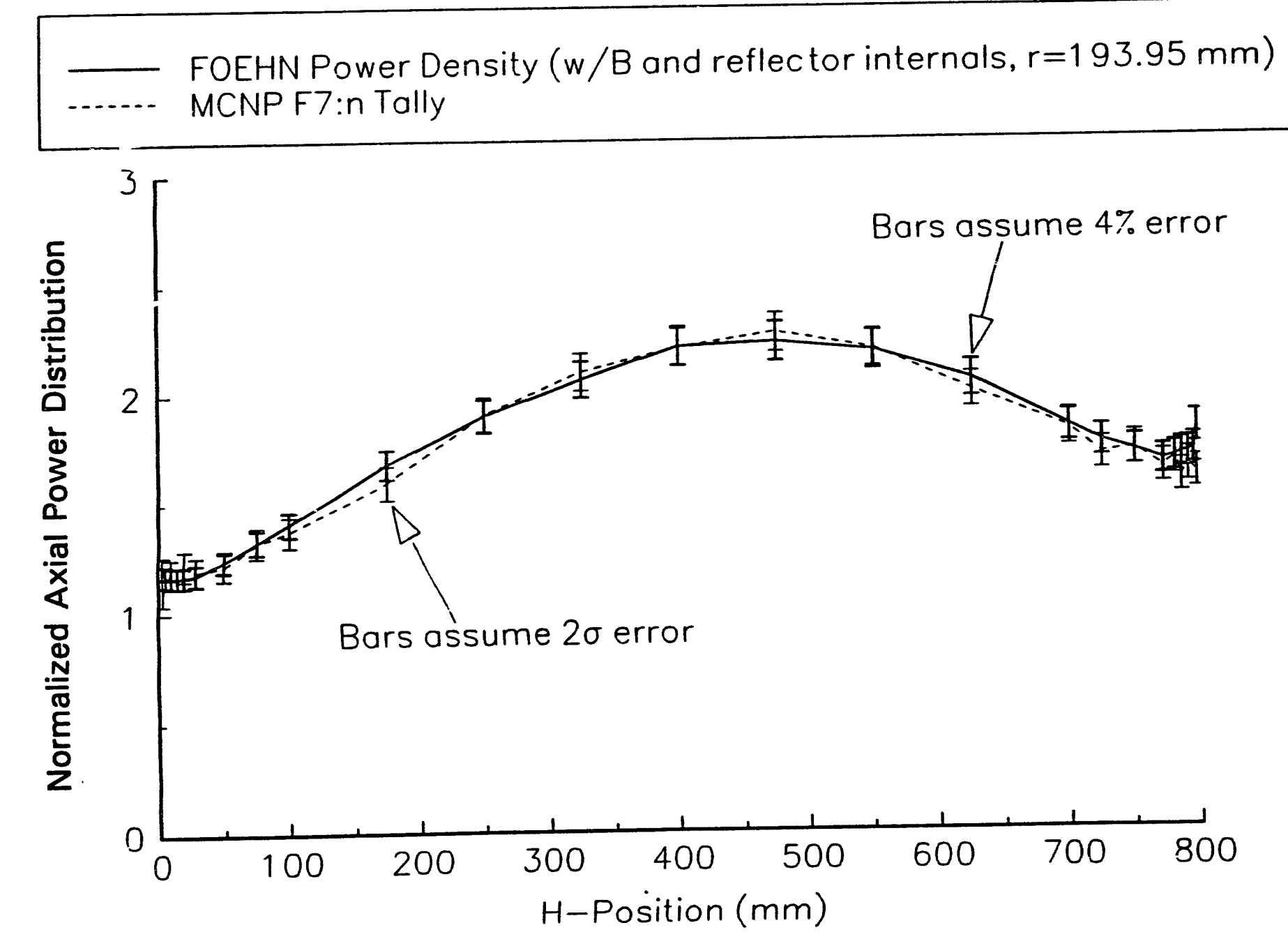

Fig. 4.26. Comparison of normalized experimental and computed axial power distribution in the full-featured FOEHN configuration at $r=193.95 \mathrm{~mm}$. 
Table 4.17. Points of nonmatching power production density in the full complexity reactor configuration ${ }^{a}$

\begin{tabular}{|c|c|c|c|c|c|c|c|c|c|c|c|}
\hline $\begin{array}{c}H / r \\
(\mathrm{~mm})\end{array}$ & 143.5 & 146.5 & 149.5 & 152.5 & 159.0 & 167.5 & 176.0 & 182.5 & 185.5 & 188.5 & 193.95 \\
\hline 2.5 & 0 & 0 & 0 & 0 & 0 & 1 & 1 & 0 & 1 & 1 & 1 \\
\hline 5.0 & & & & & & & & & & & 0 \\
\hline 9.4 & 1 & & & & & & & & & & 0 \\
\hline 14.5 & 0 & & & & & 0 & & & & & 1 \\
\hline 19.4 & 0 & & & & & 0 & & & & & 0 \\
\hline 28.5 & 0 & & & & & 0 & & & & & 0 \\
\hline 50.0 & 0 & 0 & 0 & 0 & 0 & 0 & 0 & 0 & 0 & 0 & 0 \\
\hline 75.0 & 0 & & & & & 0 & & & & & 0 \\
\hline 100.0 & 0 & & & & & 0 & & & & & 0 \\
\hline 175.0 & 0 & 0 & 0 & 0 & 0 & 0 & 0 & 0 & 0 & 0 & 0 \\
\hline 250.0 & 0 & & & & & 0 & & & & & 0 \\
\hline 325.0 & 0 & & & & & 0 & & & & & 0 \\
\hline 400.0 & 0 & 0 & 0 & 0 & 0 & 0 & 0 & 0 & 0 & 0 & 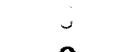 \\
\hline 475.0 & 1 & & & & & 0 & & & & & 0 \\
\hline 550.0 & 1 & & & & & 0 & & & & & 0 \\
\hline 625.0 & 0 & 0 & 0 & 0 & 0 & 0 & 0 & 0 & 0 & 0 & 0 \\
\hline 700.0 & 0 & & & & & 0 & & & & & 0 \\
\hline 725.0 & 0 & . & & & & 0 & & & & & 0 \\
\hline 750.0 & 0 & 0 & 0 & 0 & 0 & 0 & 0 & 0 & 0 & 0 & 0 \\
\hline 771.5 & 0 & & & & & 0 & & & & & 0 \\
\hline 780.6 & 0 & & & & & 0 & & & & & 0 \\
\hline 785.5 & 0 & & & & & 0 & & & & & 0 \\
\hline 790.6 & 0 & & & & & & & & & & 0 \\
\hline 795.0 & & & & & & & & & & & 0 \\
\hline 797.5 & 0 & 0 & 1 & 1 & 1 & 1 & 1 & 1 & 1 & 1 & 1 \\
\hline
\end{tabular}

${ }^{a} 125$ data points, 18 misses $(14.40 \%), 4$ misses excluding top and bottom rows $(3.20 \%)$. 
production (based on gamma activity counting) is expected to be the greatest. The existence of a sharp flux gradient may also imply, for the measurement, a higher error than the $\pm 4 \%$ used for the comparison performed in this work.

\subsection{SUMMARY}

In this chapter, the results of the MCNP simulations of all three FOEHN experiment configurations have been presented and discussed. It has been shown that all three models agree consistently with the experimental results within the limits of interpretation of the statistics inherent to the Monte Carlo approach. It was shown that the computed spatial distribution of the power production in the cores, the thermal flux distribution in the reflector, and the rendement agree very well with the corresponding experimental values. Where discrepancies between the models and the experiment occurred, they were fully correlated to (and explained by) the approximations made, the lack of precise information about the experimental setup, or the limitations of the version of the MCNP code used in this work. 


\section{CONCLUSIONS}

Phase II of the validation of the neutronic design methods of the ANS reactor has been completed and presented in this report. The use of MCNP as a neutronics design code has been benchmarked against the FOEHN critical experiment. Many quantities of interest to the safe and efficient operation of a high-intensity neutron source reactor were computed and compared to their experimental counterparts. It was shown that for all quantities of importance (core power distribution, reflector fluxes, effective multiplication factor, and rendement figure of merit), the computational results reproduced the experimental ones within the error bounds defined by the statistics and the experimental errors. A notable exception pertains to the use of point detector tallies in MCNP for estimating fluxes in small regions. These MCNP tallies have been found to be inadequate for the design estimation of fluxes.

The results presented in this report document a successful benchmarking of the MCNP computer code against the FOEHN critical experiments and a significant, positive contribution to the validation of the neutronics design methodology for the ANS reactor.

In addition to the validation of the neutronics design methodology, the testing of the robustness of the design to small changes in some materials specifications was performed. Specifically, the AG3-NE alloy used as a structural material was replaced entirely by pure aluminum for some runs. It was found that changes in the effective multiplication factor and in some powers were larger than the computed statistical errors. It follows from this study that small changes in materials could have important effects on the neutronics of a reactor sharing some of the design characteristics of the FOEHN experiment. It is therefore recommended that, for a design for which requirements are rigid (such as the ANS reactor), a range of material compositions and of geometric specifications for which the performance remains within the ranges defined by the statistical bands (or by performance specifications) should be identified. Such a sensitivity analysis of the design would be a crucial step in the design effort, both to ensure a safe reactor and to contribute to reducing the cost of the project by identifying acceptable tolerance limits. An example of the type of artifacts that may arise in the design of the ANS reactor can be illustrated by one encountered inadvertently. It was found that small perturbations in some critical parameters significantly affect the performance of the reactor. Specifically, it was found that the mechanical tolerances within the core (i.e., fuel plate sizes, fit of core barrel components) affect the actual borated water content of the core. The improper distribution of this borated water was found to significantly distort the spatial distribution of the power production density. The knowledge of acceptable bounds for the mechanical tolerances may have important consequences on the safe and economical operation of the reactor. For example, the correlation of fuel manufacturing tolerances to power distribution would allow the definition of fuel manufacturing bounds for which the resulting reactor loading and power distribution would remain within the acceptable operational range. This would affect every reload and could result in recurrent savings.

A second issue that must be addressed in the design of the various facilities of the ANS reactor is the use of a version of MCNP capable of treating the $S(\alpha, \beta)$ interactions. It is recommended that for future models, the newest version of MCNP be used after it is quality-assurance certified.

The lack of complete and precise information about the FOEHN experiment caused a number of difficulties, of which many were resolved by experimenting with several plausible options. However, there still remain uncertainties about the positions of certain components in the core. Among the remaining unknowns are the exact location of the borated end caps, the azimuthal positions of the various fuel plates, and the thickness and exact location of the AG3-NE axial portion of the reactor bucket. One of these (the borated end caps location) may be the cause of the larger than average 
discrepancy between experiment and model observed at the axial ends of the core. The use of a homogenized core was dictated by the lack of precise information about the azimuthal position of the fuel plates and the lack of a circular involute geometry option in the MCNP code. The potential error arising from this approximation has been previously quantified in the case of the ANS design for which the core $\mathrm{D}_{2} \mathrm{O}$ is not borated. The effect in the presence of boron is uncertain. A short study aimed at quantifying the difference between a homogenous and an explicit heterogenous model in the presence of borated heavy water is currently under way. 


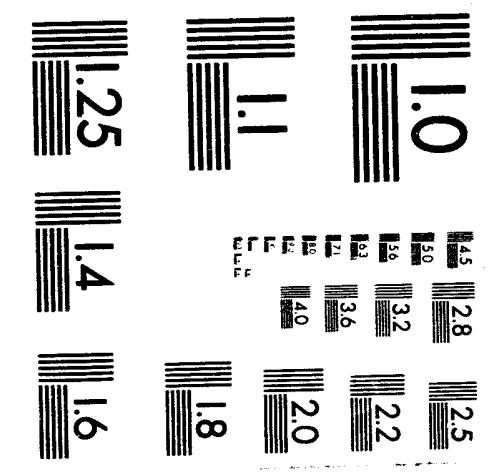



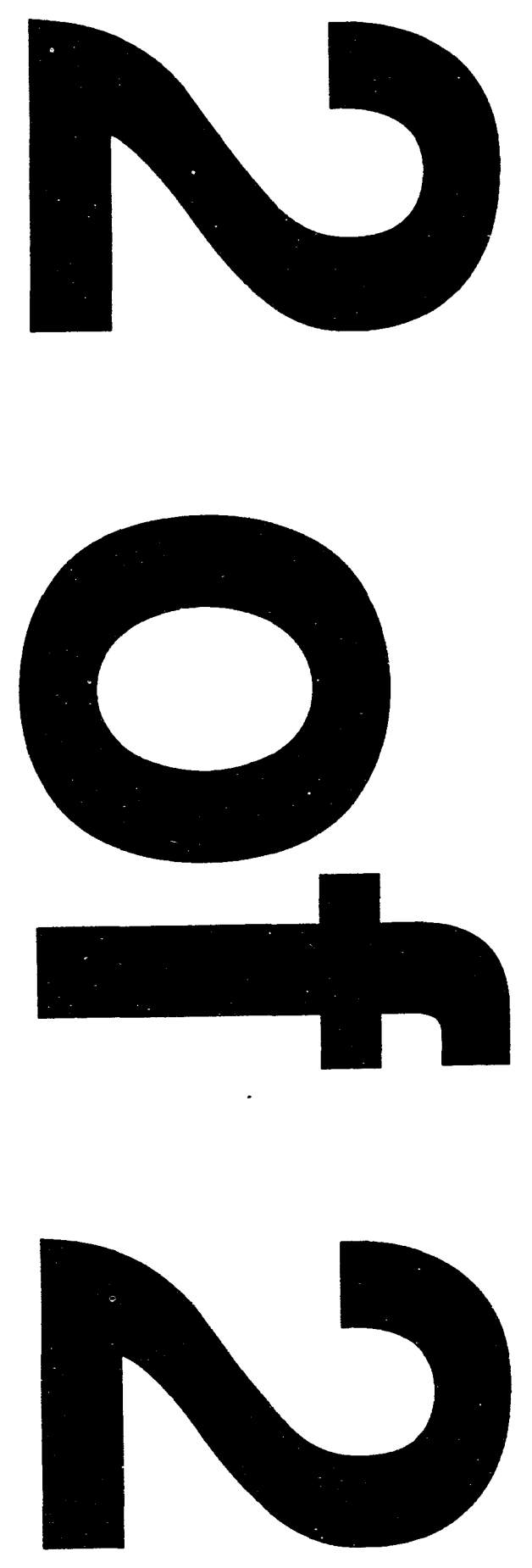


\section{REFERENCES}

1. D. L. Selby et al., The Advanced Neutron Source Research and Development Plan, ORNL/TM-12249, Martin Marietta Energy Systems, Inc., Oak Ridge Natl. Lab., November 1992.

2. K. Scharmer and H. G. Eckert, FOEHN: The Critical Experiment for the Franco-German High Flux Reactor, ORNL/TR-91/23, Martin Marietta Energy Systems Inc., Oak Ridge Natl. Lab., 1991. English translation of K. Scharmer, H. G. Eckert, "FOEHN - Das kritische Experiment fur den Deutsch-Franzosischen Hochflussreaktor," KFK 1064, Dezember 1971. French version: Klaus Scharmer et Hans G. Eckert, "L'experience critique pour le reacteur a Haut-Flux FrancoAllemand," Institut Max von Laue-Paul Langevin, Grenoble, Gesellschaft fur Kernforschung, Commissariat a L'Energie Atomique, et Centre National de la Recherche Scientifique.

3. J. F. Breismeister, MCNP Version 3b, Monte Carlo Neutron and Photon Transport Code System, LA-7396-M, Rev. 2, Los Alamos Natl. Lab., September 1986.

4. J. M. Ryskamp, D. L. Selby, and R. T. Primm III, "Reactor Design of the Advanced Neutron Source," Nucl. Tech. 93, 330-349, March 1991.

5. F. Gallmeier, Verfizierung des dreidimensionalen Rechencodes MORSE-K durch Nachrechen des kritischen Experimentes FOEHN, Technische Universität München, January 16, 1991.

6. A. Rohrmoser, Fakultät für Physik E21, Technische Universität München, private communication to John M. Ryskamp, Idaho Natl. Eng. Lab., December 1991.

7. R. D. Evans, The Atomic Nucleus, McGraw-Hill, New York, 1955.

8. P. J. Davies, Interpolation and Approximation, Dover Publications Inc., New York, 1975.

9. E. L. Redmond II and J. M. Ryskamp, "Monte Carlo Methods, Models, and Applications to the Advanced Neutron Source," Nucl. Tech. 95, 272 (1991). See also E. L. Redmond II, Monte Carlo Methods, Models, and Applications for the Advanced Neutron Source, M.S. Thesis, Massachusetts Institute of Technology, June 1990.

10. A. Rohrmoser, Verification of Data Generation, Two-Dimensional Transport Calculations and Diffusion and Burnup Calculations for the FRM-II Compact Core, ORNL/OLS-92/12, translated from the German (Report No. 00119a issued by the Department of Physics E21, Technische Universität München, July 1991, 35 pages).

11. R. C. Thayer, E. L. Redmond II, and J. M. Ryskamp, "A Monte Carlo Method of Evaluating Heterogeneous Effects in Plate-Fueled Reactors," Trans. Am. Nucl. Soc. 63, 445 (1991).

12. CRC Handbook of Chemistry and Physics, p. F-122, CRC Press, Inc., 62nd Edition, 1981-1982.

13. James T. West III, SABRINA: An Interactive Three-Dimensional Geometry-Modeling Program for MCNP, LA-10688-M, Los Alamos Natl. Lab., October 1986. 
Appendix A. MCNP MODEL INPUT FILE 


\section{APPENDIX A}

\section{MCNP MODEL INPUT FILE}

A full listing of the input for the MCNP model of the full complexity FOEHN configuration is given below.

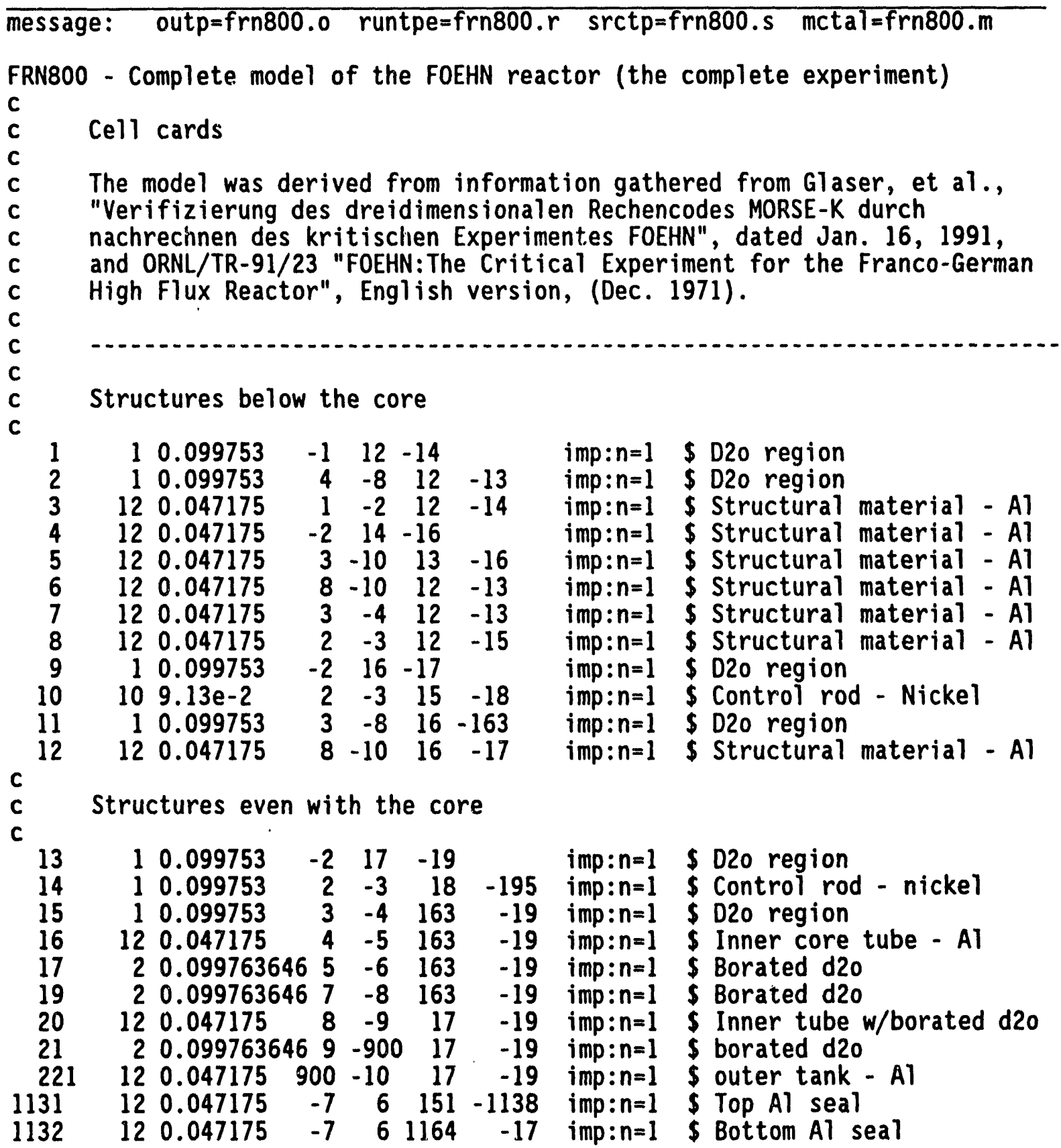




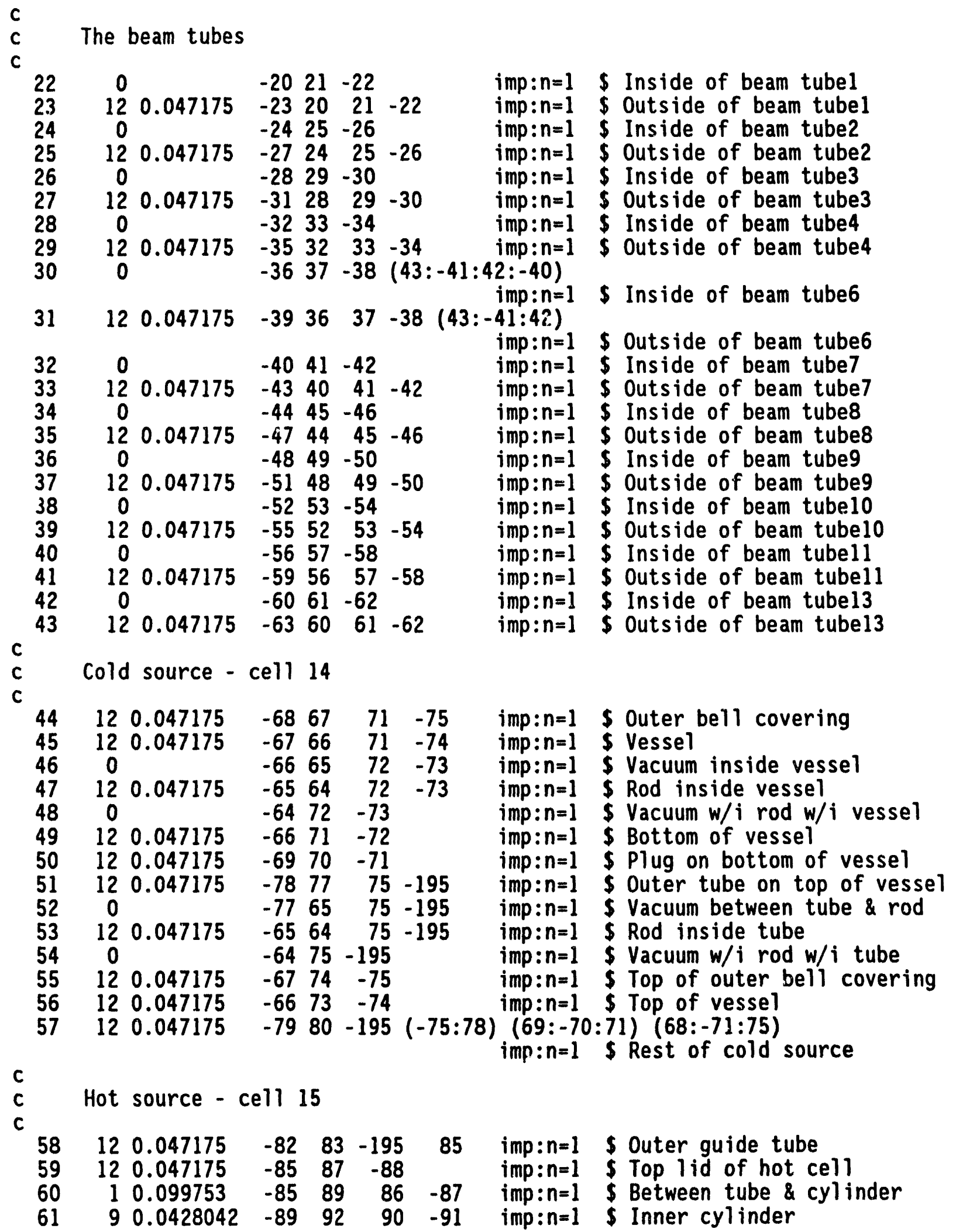




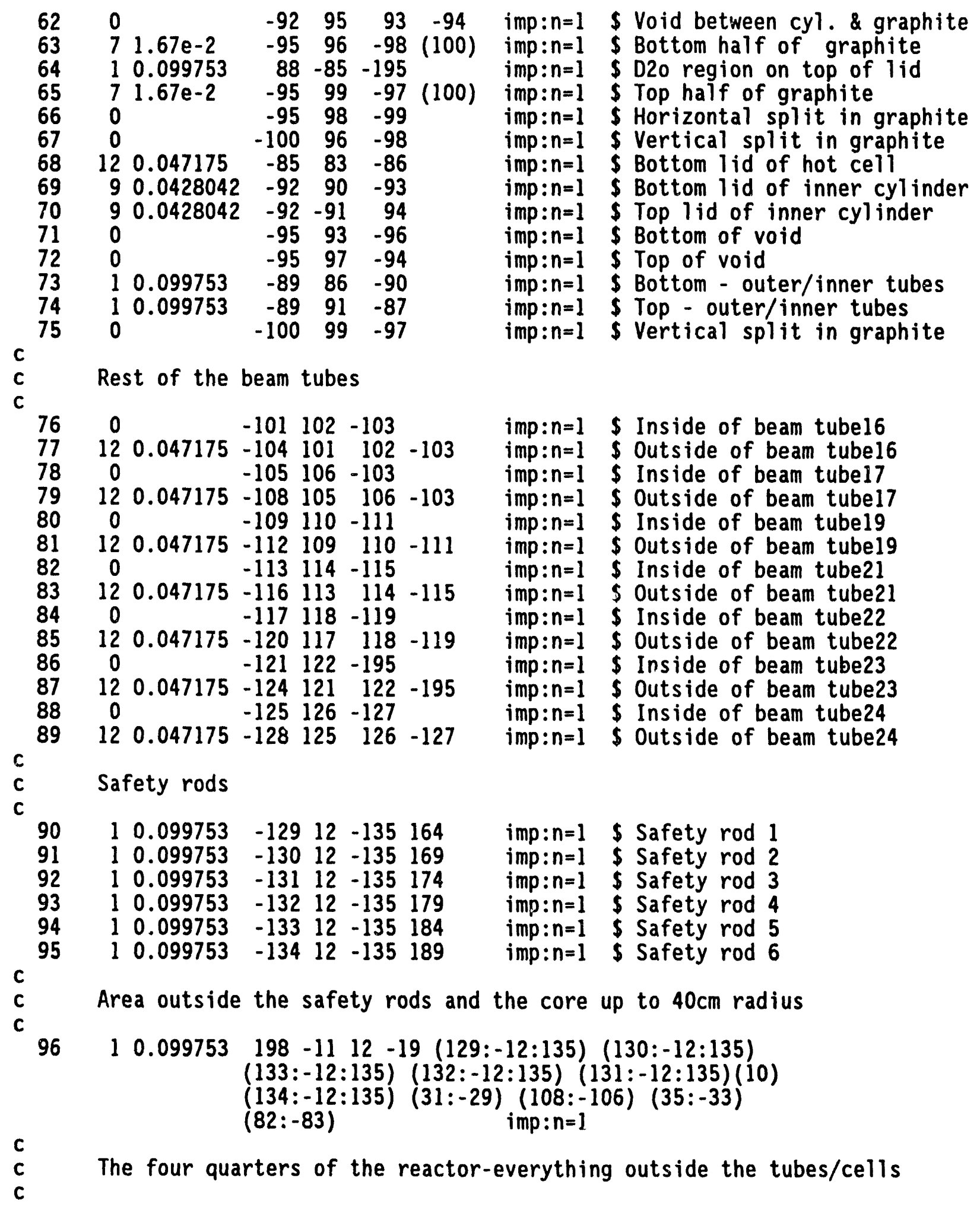




\begin{tabular}{|c|c|c|c|c|}
\hline 97 & \multirow{2}{*}{\multicolumn{2}{|c|}{ 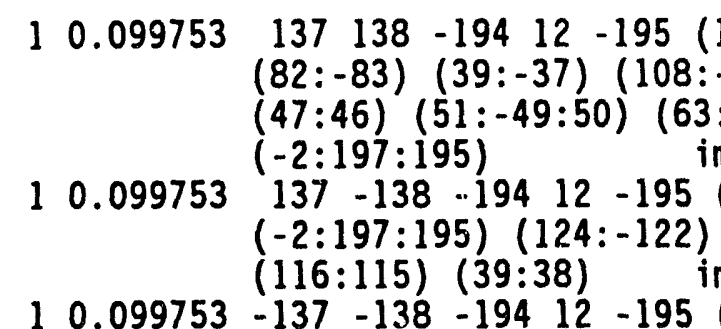 }} & $\begin{array}{l}(11: 19) \\
:-106) \\
3:-62: 62 \\
\text { imp: } n=1\end{array}$ & \multirow{2}{*}{$\begin{array}{l}(120:-118: 119) \\
43:-41)(55:-53: 54) \\
(116:-114)(39:-37) \\
(47:-45)(63: 62) \\
(112: 111)(43: 42)\end{array}$} \\
\hline 98 & & & \multirow{2}{*}{\multicolumn{2}{|c|}{$\begin{array}{l}(11: 19)(47:-45)(63: 62) \\
(35: 34)(112: 111)(43: 42) \\
\text { imp }: n=1 \\
(11: 19)(35:-33: 34)(-2: 197: 195) \\
(27:-25)(31: 30)(112:-110: 111)\end{array}$}} \\
\hline 99 & 10.099753 & $\begin{array}{l}-137-138-194 \quad 12-195 \\
(23:-21: 22)(128: 127) \\
(63:-61)\end{array}$ & & \\
\hline 100 & 10.099753 & $\begin{array}{c}-137 \quad 138-19412-195 \\
(-2: 197: 195)(59:-57: 5 \\
(104:-102)(79:-80)\end{array}$ & $\begin{array}{l}(11: 19) \\
58)(120 \\
\text { imp }: n=1\end{array}$ & $\begin{array}{l}(27: 26)(128:-126) \\
:-118)(31:-29)\end{array}$ \\
\hline 101 & 136 & & imp: $n=0$ & \\
\hline$r$ & \multirow{2}{*}{\multicolumn{4}{|c|}{ Top borated zone }} \\
\hline & & & & \\
\hline $\begin{array}{l}102 \\
103 \\
104 \\
105 \\
106 \\
107 \\
108 \\
109 \\
110 \\
111 \\
112 \\
113 \\
114\end{array}$ & $\begin{array}{ll}14 & 0.0830797 \\
14 & 0.0830797 \\
14 & 0.0830797 \\
14 & 0.0830797 \\
14 & 0.0830797 \\
14 & 0.0830797 \\
14 & 0.0830797 \\
14 & 0.0830797 \\
14 & 0.0830797 \\
14 & 0.0830797 \\
14 & 0.0830797 \\
14 & 0.0830797 \\
14 & 0.0830797\end{array}$ & $\begin{array}{llrl}-7 & 6 & 1138 & -139 \\
-7 & 6 & 139 & -140 \\
-7 & 6 & 140 & -141 \\
-7 & 6 & 141 & -142 \\
-7 & 6 & 142 & -143 \\
-7 & 6 & 143 & -144 \\
-7 & 6 & 144 & -145 \\
-7 & 6 & 145 & -146 \\
-7 & 6 & 146 & -147 \\
-7 & 6 & 147 & -148 \\
-7 & 6 & 148 & -149 \\
-7 & 6 & 149 & -150 \\
-7 & 6 & 150 & -19\end{array}$ & $\begin{array}{l}\operatorname{imp}: n=1 \\
\operatorname{imp}: n=1 \\
\operatorname{imp}: n=1 \\
\operatorname{imp}: n=1 \\
\operatorname{imp}: n=1 \\
\operatorname{imp}: n=1 \\
\operatorname{imp}: n=1 \\
\operatorname{imp}: n=1 \\
\operatorname{imp}: n=1 \\
\operatorname{imp}: n=1 \\
\operatorname{imp}: n=1 \\
\text { imp: } n=1\end{array}$ & $\begin{array}{l}\text { \$ top Aluminum seal } \\
\text { \$ Al plate } \\
\text { \$ Boron plate } \\
\text { \$ Al plate } \\
\text { \$ Al plate } \\
\text { \$ B plate } \\
\text { \$ Al plate } \\
\text { \$ Al plate } \\
\text { \$ B plate } \\
\text { \$ Al plate } \\
\text { \$ Al plate } \\
\text { \$ B plate } \\
\text { \$ Al plate }\end{array}$ \\
\hline C & & & & \\
\hline 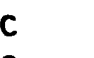 & \multicolumn{4}{|c|}{ Bottom borated zone } \\
\hline $\begin{array}{l}\text { C } 115 \\
116 \\
117 \\
118 \\
119 \\
120 \\
121 \\
122 \\
123 \\
124 \\
125 \\
126\end{array}$ & $\begin{array}{ll}14 & 0.0830797 \\
14 & 0.0830797 \\
14 & 0.0830797 \\
14 & 0.0830797 \\
14 & 0.0830797 \\
14 & 0.0830797 \\
14 & 0.0830797 \\
14 & 0.0830797 \\
14 & 0.0830797 \\
14 & 0.0830797 \\
14 & 0.0830797 \\
14 & 0.0830797\end{array}$ & $\begin{array}{llrl}-7 & 6 & -1164 & 152 \\
-7 & 6 & -152 & 153 \\
-7 & 6 & -153 & 154 \\
-7 & 6 & -154 & 155 \\
-7 & 6 & -155 & 156 \\
-7 & 6 & -156 & 157 \\
-7 & 6 & -157 & 158 \\
-7 & 6 & -158 & 159 \\
-7 & 6 & -159 & 160 \\
-7 & 6 & -160 & 161 \\
-7 & 6 & -161 & 162 \\
-7 & 6 & -162 & 163\end{array}$ & 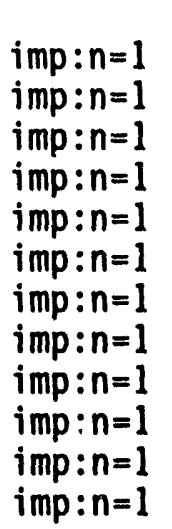 & $\begin{array}{l}\text { \$ Al plate } \\
\text { \$ B plate } \\
\text { \$ Al plate } \\
\text { \$ Al plate } \\
\text { \$ B plate } \\
\text { \$ Al plate } \\
\text { \$ Al plate } \\
\text { \$ B plate } \\
\text { \$ Al plate } \\
\text { \$ Al plate } \\
\text { \$ B plate } \\
\text { \$ Al plate }\end{array}$ \\
\hline 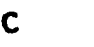 & \multirow{2}{*}{\multicolumn{4}{|c|}{ The inner rings of the safety rods }} \\
\hline c & & & & \\
\hline & \multicolumn{4}{|l|}{ Safety rod 1} \\
\hline $\begin{array}{l}C_{127} \\
128\end{array}$ & $\begin{array}{ll}1 & 0.099753 \\
1 & 0.099753\end{array}$ & $\begin{array}{llll}-164 & 165 & 12 & -135 \\
-165 & 166 & 12 & -135\end{array}$ & $\begin{array}{l}\text { imp: } n=1 \\
\text { imp:n=1 }\end{array}$ & $\begin{array}{l}\text { \$ cadium region } \\
\$ \text { inner cladding }\end{array}$ \\
\hline
\end{tabular}




\begin{tabular}{|c|c|c|c|c|c|c|}
\hline $\begin{array}{l}129 \\
130 \\
131\end{array}$ & $\begin{array}{ll}1 & 0.099753 \\
1 & 0.099753 \\
1 & 0.099753\end{array}$ & $\begin{array}{l}-166 \\
-167 \\
-168\end{array}$ & $\begin{array}{rr}167 & 12 \\
168 & 12 \\
-135 & 12\end{array}$ & $\begin{array}{l}-135 \\
-135\end{array}$ & $\begin{array}{l}\text { imp: } n=1 \\
\text { imp: } n=1 \\
\text { imp: } n=1\end{array}$ & $\begin{array}{l}\$ d 20 \text { channel } \\
\$ \text { Al guide tube } \\
\$ \text { d20 inside guide tube }\end{array}$ \\
\hline $\begin{array}{l}c \\
c\end{array}$ & \multicolumn{6}{|l|}{ Safety rod 2} \\
\hline $\begin{array}{l}\text { c } \\
132 \\
133 \\
134 \\
135 \\
136\end{array}$ & $\begin{array}{ll}1 & 0.099753 \\
1 & 0.099753 \\
1 & 0.099753 \\
1 & 0.099753 \\
1 & 0.099753\end{array}$ & $\begin{array}{l}-169 \\
-170 \\
-171 \\
-172 \\
-173\end{array}$ & $\begin{array}{rr}170 & 12 \\
171 & 12 \\
172 & 12 \\
173 & 12 \\
-135 & 12\end{array}$ & $\begin{array}{l}-135 \\
-135 \\
-135 \\
-135\end{array}$ & $\begin{array}{l}\operatorname{imp}: n=1 \\
\text { imp:n=1 } \\
\text { imp:n=1 } \\
\text { imp: } n=1 \\
\text { imp:n=1 }\end{array}$ & $\begin{array}{l}\text { \$ cadium region } \\
\text { \$ inner cladding } \\
\text { \$ d20 channel } \\
\text { \$ Al guide tube } \\
\text { \$ d20 inside guide tube }\end{array}$ \\
\hline c & & & & & & \\
\hline c & \multicolumn{6}{|l|}{ Safety rod 3} \\
\hline $\begin{array}{l}137 \\
138 \\
139 \\
140 \\
141\end{array}$ & $\begin{array}{ll}1 & 0.099753 \\
1 & 0.099753 \\
1 & 0.099753 \\
1 & 0.099753 \\
1 & 0.099753\end{array}$ & $\begin{array}{l}-174 \\
-175 \\
-176 \\
-177 \\
-178\end{array}$ & $\begin{array}{rr}175 & 12 \\
176 & 12 \\
177 & 12 \\
178 & 12 \\
-135 & 12\end{array}$ & $\begin{array}{l}-135 \\
-135 \\
-135 \\
-135\end{array}$ & $\begin{array}{l}\text { imp: } n=1 \\
\text { imp: } n=1 \\
\text { imp: } n=1 \\
\text { imp: } n=1 \\
\text { imp: } n=1\end{array}$ & $\begin{array}{l}\text { \$ cadium region } \\
\text { \$ inner cladding } \\
\$ \text { d20 channel } \\
\$ \text { Al guide tube } \\
\$ \text { d2o inside guide tube }\end{array}$ \\
\hline c & & & & & & \\
\hline $\begin{array}{l}c \\
c\end{array}$ & \multicolumn{6}{|l|}{ Safety rod 4} \\
\hline $\begin{array}{l}142 \\
143 \\
144 \\
145 \\
146\end{array}$ & $\begin{array}{ll}1 & 0.099753 \\
1 & 0.099753 \\
1 & 0.099753 \\
1 & 0.099753 \\
1 & 0.099753\end{array}$ & $\begin{array}{l}-179 \\
-180 \\
-181 \\
-182 \\
-183\end{array}$ & $\begin{array}{rr}180 & 12 \\
181 & 12 \\
182 & 12 \\
183 & 12 \\
-135 & 12\end{array}$ & $\begin{array}{l}-135 \\
-135 \\
-135 \\
-135\end{array}$ & $\begin{array}{l}\text { imp: } n=1 \\
\text { imp:n=1 } \\
\text { imp: } n=1 \\
\text { imp: } n=1 \\
\text { imp: } n=1\end{array}$ & $\begin{array}{l}\text { \$ cadium region } \\
\$ \text { inner cladding } \\
\$ \text { d20 channel } \\
\$ \text { A1 guide tube } \\
\$ \text { d20 inside guide tube }\end{array}$ \\
\hline C & & & & & & \\
\hline c & \multicolumn{6}{|l|}{ Safety rod 5} \\
\hline $\begin{array}{l}\text { C } \\
147 \\
148 \\
149 \\
150 \\
151\end{array}$ & $\begin{array}{ll}1 & 0.099753 \\
1 & 0.099753 \\
1 & 0.099753 \\
1 & 0.099753 \\
1 & 0.099753\end{array}$ & $\begin{array}{l}-184 \\
-185 \\
-186 \\
-187 \\
-188\end{array}$ & $\begin{array}{rr}185 & 12 \\
186 & 12 \\
187 & 12 \\
188 & 12 \\
-135 & 12\end{array}$ & $\begin{array}{l}-135 \\
-135 \\
-135 \\
-135\end{array}$ & $\begin{array}{l}\text { imp: } n=1 \\
\text { imp: } n=1 \\
\text { imp: } n=1 \\
\text { imp: } n=1 \\
\text { imp: } n=1\end{array}$ & $\begin{array}{l}\text { \$ cadium region } \\
\$ \text { inner cladding } \\
\$ \text { d20 channel } \\
\$ \text { Al guide tube } \\
\$ \text { d20 inside guide tube }\end{array}$ \\
\hline C & & & & & & \\
\hline $\begin{array}{l}\text { C } \\
\text { C }\end{array}$ & \multicolumn{6}{|l|}{ Safety rod 6} \\
\hline $\begin{array}{l}152 \\
153 \\
154 \\
155 \\
156\end{array}$ & $\begin{array}{ll}1 & 0.099753 \\
1 & 0.099753 \\
1 & 0.099753 \\
1 & 0.099753 \\
1 & 0.099753\end{array}$ & $\begin{array}{l}-189 \\
-190 \\
-191 \\
-192 \\
-193\end{array}$ & $\begin{array}{rr}190 & 12 \\
191 & 12 \\
192 & 12 \\
193 & 12 \\
-135 & 12\end{array}$ & $\begin{array}{l}-135 \\
-135 \\
-135 \\
-135\end{array}$ & $\begin{array}{l}\operatorname{imp}: n=1 \\
\operatorname{imp}: n=1 \\
\operatorname{imp}: n=1 \\
\text { imp: } n=1 \\
\text { imp: } n=1\end{array}$ & $\begin{array}{l}\text { \$ cadium region } \\
\text { \$ inner cladding } \\
\$ \text { d20 channel } \\
\$ \text { Al guide tube } \\
\$ \text { d20 inside guide tube }\end{array}$ \\
\hline C & \multirow{2}{*}{\multicolumn{6}{|c|}{ The reflector tank }} \\
\hline $\begin{array}{l}\text { C } \\
\text { C }\end{array}$ & & & & & & \\
\hline 157 & 120.047175 & \multicolumn{5}{|c|}{$\begin{array}{c}-19619412-195(104)(108) \\
(120:-118: 119)(112:-110: 111) \\
(116:-114: 115) \quad \text { imp:n=1 }\end{array}$} \\
\hline $\begin{array}{l}\text { c } \\
\text { c }\end{array}$ & \multirow{2}{*}{\multicolumn{6}{|c|}{ The encompassing sphere - outside the reflector tank }} \\
\hline . & & & & & & \\
\hline
\end{tabular}




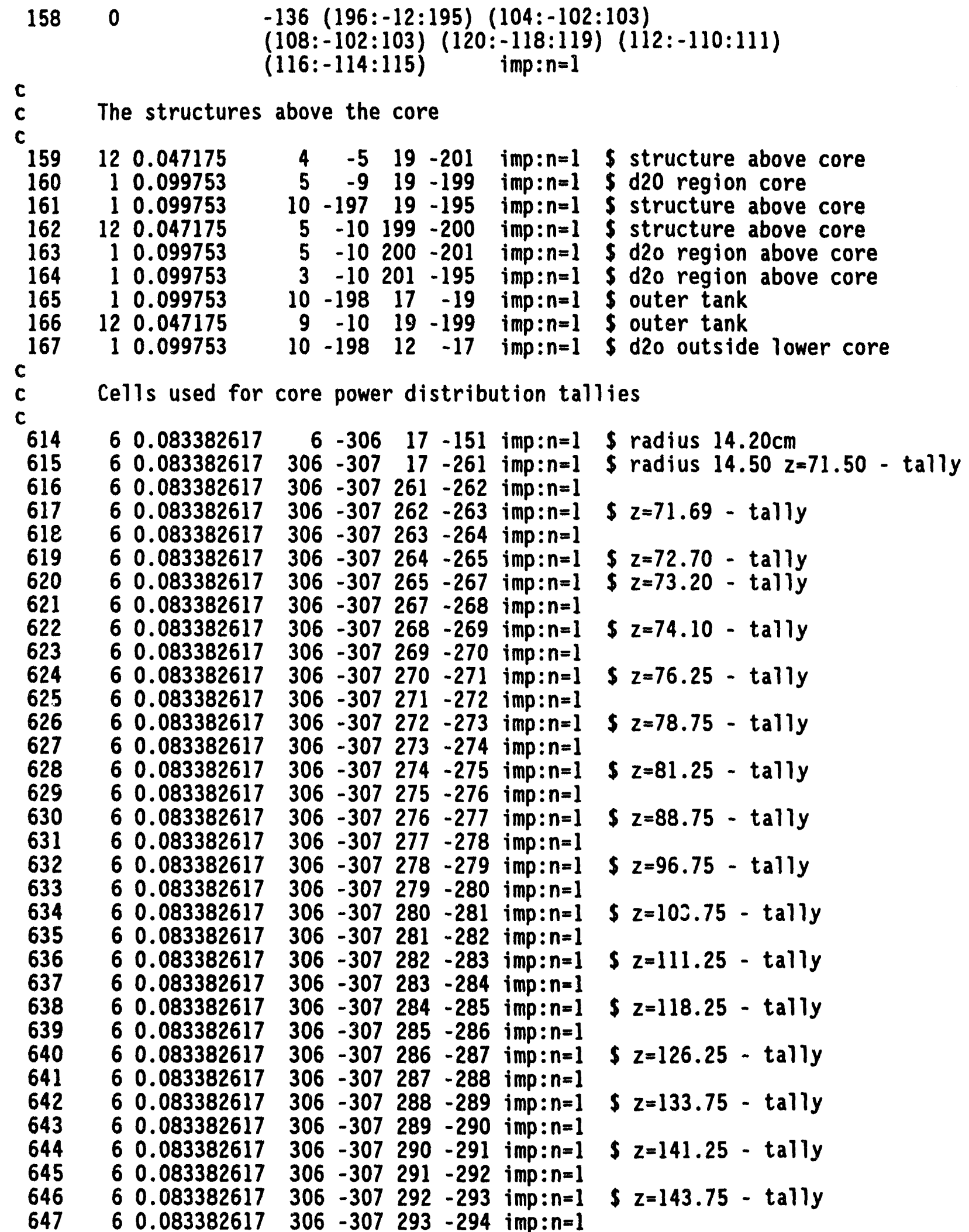




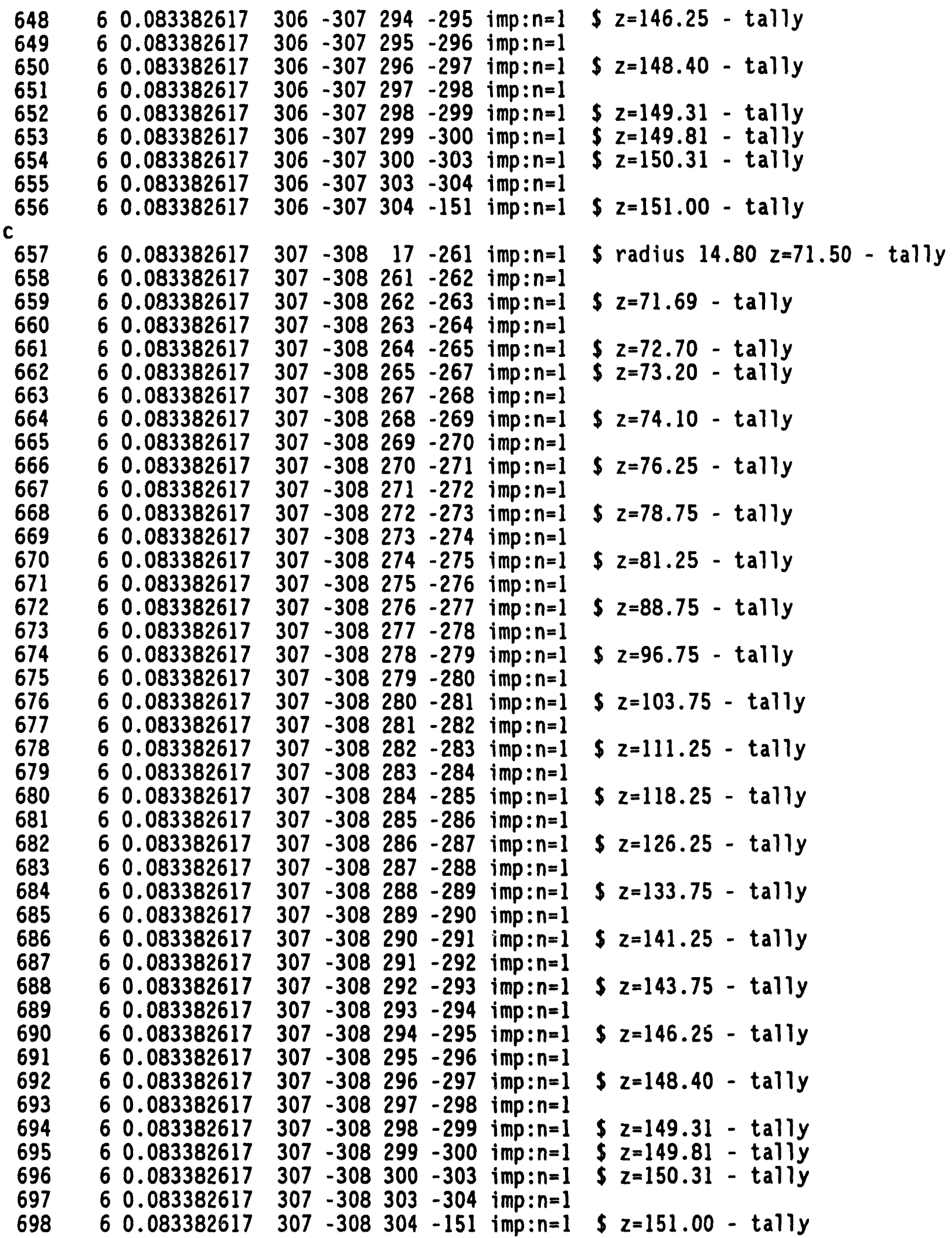


c

699

700

701

702

703

704

705

706

707

708

709

710

711

712

713

714

715

716

717

718

719

720

721

722

723

724

725

726

727

728

729

730

731

732

733

734

735

736

737

738

739

740

C

741

742

743

744

745

746

747

748 $\begin{array}{ll}6 & 0.083382617\end{array}$

$\begin{array}{lll}6 & 0.083382617\end{array}$

$\begin{array}{lll}6 & 0.083382617\end{array}$

$\begin{array}{ll}6 & 0.083382617\end{array}$

$\begin{array}{lll}6 & 0.083382617\end{array}$

$\begin{array}{ll}6 & 0.083382617\end{array}$

$\begin{array}{lll}6 & 0.083382617\end{array}$

$\begin{array}{lll}6 & 0.083382617\end{array}$

$\begin{array}{ll}6 & 0.083382617\end{array}$

$\begin{array}{ll}6 & 0.083382617\end{array}$

$\begin{array}{ll}6 & 0.083382617\end{array}$

$\begin{array}{lll}6 & 0.083382617\end{array}$

$\begin{array}{lll}6 & 0.083382617\end{array}$

$\begin{array}{ll}6 & 0.083382617\end{array}$

$\begin{array}{ll}6 & 0.083382617\end{array}$

$\begin{array}{ll}6 & 0.083382617\end{array}$

$\begin{array}{lll}6 & 0.083382617\end{array}$

$\begin{array}{ll}6 & 0.083382617\end{array}$

$\begin{array}{ll}6 & 0.083382617\end{array}$

$\begin{array}{ll}6 & 0.083382617\end{array}$

60.083382617
6

60.083382617

60.083382617

$\begin{array}{ll}6 & 0.083382617\end{array}$

$\begin{array}{ll}6 & 0.083382617\end{array}$

$\begin{array}{ll}6 & 0.083382617\end{array}$

$\begin{array}{ll}6 & 0.083382617\end{array}$

60.083382617
6

$\begin{array}{ll}6 & 0.083382617\end{array}$

$\begin{array}{ll}6 & 0.083382617\end{array}$

$\begin{array}{ll}6 & 0.083382617\end{array}$

$\begin{array}{ll}6 & 0.083382617\end{array}$

$\begin{array}{ll}6 & 0.083382617\end{array}$

$\begin{array}{ll}6 & 0.083382617\end{array}$

$\begin{array}{ll}6 & 0.083382617\end{array}$

$\begin{array}{ll}6 & 0.083382617\end{array}$

$\begin{array}{ll}6 & 0.083382617\end{array}$

$\begin{array}{lll}6 & 0.083382617\end{array}$

$\begin{array}{ll}6 & 0.083382617\end{array}$

$\begin{array}{ll}6 & 0.083382617\end{array}$

$\begin{array}{ll}6 & 0.083382617\end{array}$

$\begin{array}{ll}6 & 0.083382617\end{array}$

$\begin{array}{ll}6 & 0.083382617\end{array}$

$\begin{array}{lll}6 & 0.083382617\end{array}$

$\begin{array}{ll}6 & 0.083382617\end{array}$

$\begin{array}{lll}6 & 0.083382617\end{array}$

$\begin{array}{lll}6 & 0.083382617\end{array}$

$\begin{array}{lll}6 & 0.083382617\end{array}$

$\begin{array}{lll}6 & 0.083382617\end{array}$

$\begin{array}{lll}6 & 0.083382617\end{array}$
$308-309 \quad 17-261$ imp: $n=1$ $308-309261-262$ imp: $n=1$

$308-309262-263$ imp: $n=1$ $308-309263-264$ imp: $n=1$ $308-309264-265$ imp: $n=1$ $308-309265-267$ imp: $n=1$ $308-309267-268$ imp: $n=1$ $308-309268-269$ imp: $n=1$ $308-309269-270$ imp: $n=1$ $308-309270-271$ imp: $n=1$ $308-309271-272$ imp: $n=1$ $308-309272-273$ imp: $n=1$ $308-309273-274$ imp: $n=1$ $308-309274-275$ imp: $n=1$ $308-309275-276$ imp: $n=1$ $308-309276-277$ imp: $n=1$ $308-309277-278$ imp: $n=1$ $308-309278-279$ imp: $n=1$ $308-309279-280$ imp: $n=1$ $308-309280-281$ imp: $n=1$ $308-309281-282$ imp: $n=1$ $308-309282-283$ imp: $n=1$ $308-309283-284$ imp: $n=1$ $308-309284-285$ imp: $n=1$ $308-309285-286$ imp: $n=1$ $308-309286-287$ imp: $n=1$ $308-309287-288$ imp: $n=1$ $308-309288-289$ imp: $n=1$ $308-309289-290$ imp: $n=1$ $308-309290-291$ imp: $n=1$ $308-309291-292$ imp: $n=1$ $308-309292-293$ imp: $n=1$ $308-309293-294$ imp: $n=1$ $308-309294-295$ imp: $n=1$ $308-309295-296$ imp: $n=1$ $308-309296-297$ imp: $n=1$ $308-309297-298$ imp: $n=1$ $308-309298-299$ imp: $n=1$ $308-309299-300$ imp: $n=1$ $308-309300-303$ imp: $n=1$ $308-309303-304$ imp: $n=1$ $308-309304-151$ imp: $n=1$

$309-313 \quad 17-261$ imp: $n=1$ $309-313261-262$ imp: $n=1$ $309-313262-263$ imp: $n=1$ $309-313263-264$ imp: $n=1$ $309-313264-265$ imp: $n=1$ $309-313265-267$ imp: $n=1$ $309-313267-268$ imp: $n=1$ $309-313268-269$ imp: $n=1$
$\$$ radius $15.10 \quad z=71.50$ - tally

$\$ z=71.69-$ tally

$\$ z=72.70-$ tally

S $z=73.20$ - tally

S $z=74.10-$ tally

S $z=76.25-$ tally

S $z=78.75-$ tally

$\$ z=81.25-$ tally

$\$ z=88.75-$ tally

S $z=96.75-$ tally

$\$ z=103.75-$ tally

$\$ z=111.25-$ tally

$\$ z=118.25$ - tally

$\$ z=126.25-$ tally

S $z=133.75-\operatorname{tally}$

$\$ z=141.25-$ tally

S $z=143.75-\operatorname{tall} y$

$\$ z=146.25-\operatorname{tally}$

$\$ z=148.40-\operatorname{tally}$

$\$ z=149.31$ - tally

$\$ z=149.81-\operatorname{tally}$

\$ $z=150.31$ - tally

$\$ z=151.00-$ tally

$\$$ radius $15.40, z=71.50$ - tally

$\$ z=71.69-$ tally

S $z=72.70-\operatorname{tally}$

\$ $z=73.20$ - tally

$\$ z=74.10-\operatorname{tally}$ 


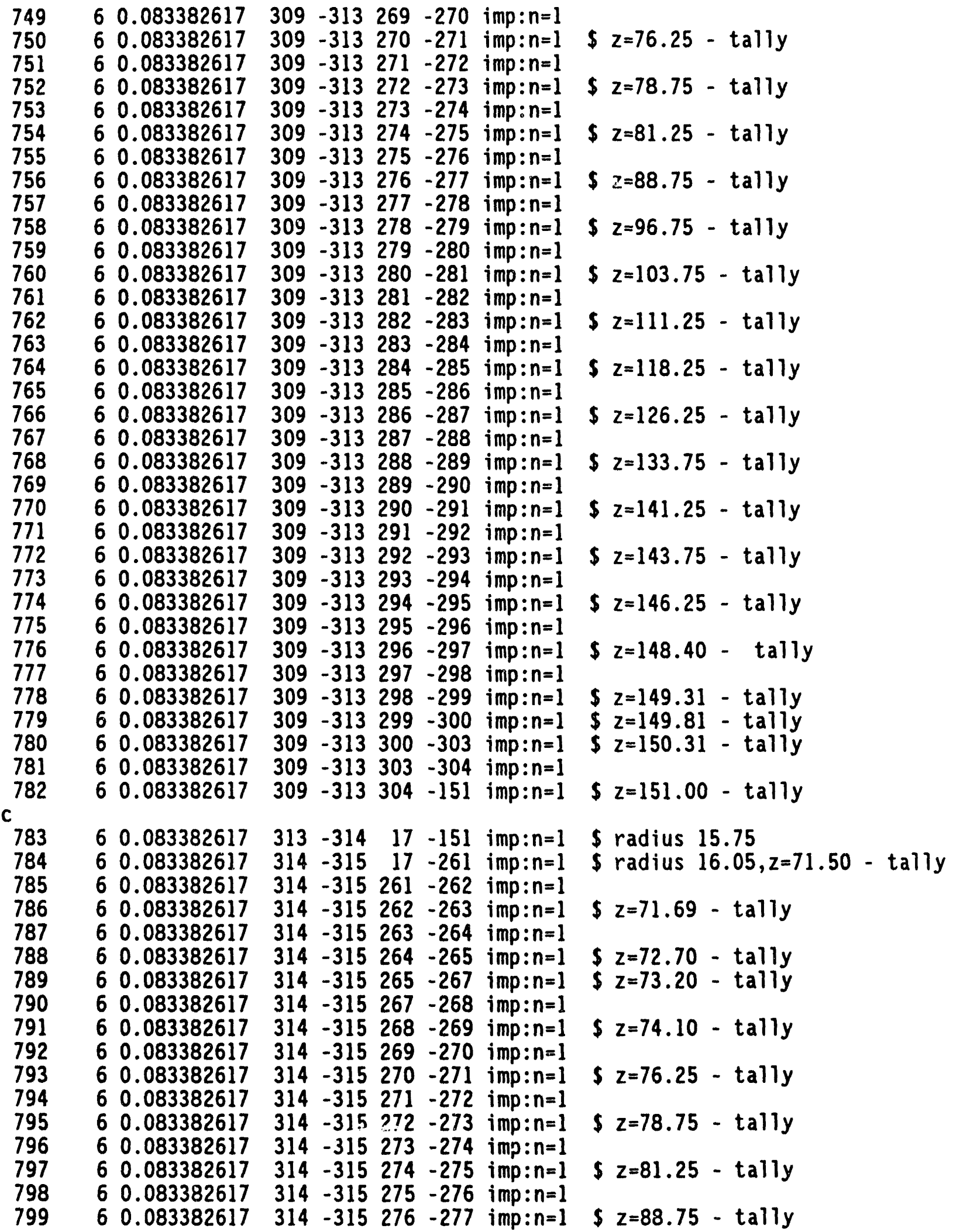




\begin{tabular}{|c|c|c|c|c|c|c|c|}
\hline $\begin{array}{l}800 \\
801 \\
802 \\
803 \\
804 \\
805 \\
806 \\
807 \\
808 \\
809 \\
810 \\
811 \\
812 \\
813 \\
814 \\
815 \\
816 \\
817 \\
818 \\
819 \\
820 \\
821 \\
822 \\
823 \\
824 \\
825\end{array}$ & $\begin{array}{ll}6 & 0.083382617 \\
6 & 0.083382617 \\
6 & 0.083382617 \\
6 & 0.083382617 \\
6 & 0.083382617 \\
6 & 0.083382617 \\
6 & 0.083382617 \\
6 & 0.083382617 \\
6 & 0.083382617 \\
6 & 0.083382617 \\
6 & 0.083382617 \\
6 & 0.083382617 \\
6 & 0.083382617 \\
6 & 0.083382617 \\
6 & 0.083382617 \\
6 & 0.083382617 \\
6 & 0.083382617 \\
6 & 0.083382617 \\
6 & 0.083382617 \\
6 & 0.083382617 \\
6 & 0.083382617 \\
6 & 0.083382617 \\
6 & 0.083382617 \\
6 & 0.083382617 \\
6 & 0.083382617 \\
6 & 0.083382617\end{array}$ & $\begin{array}{l}314 \\
314 \\
314 \\
314 \\
314 \\
314 \\
314 \\
314 \\
314 \\
314 \\
314 \\
314 \\
314 \\
314 \\
314 \\
314 \\
314 \\
314 \\
314 \\
314 \\
314 \\
314 \\
314 \\
314 \\
314 \\
314\end{array}$ & $\begin{array}{l}-315 \\
-315 \\
-315 \\
-315 \\
-315 \\
-315 \\
-315 \\
-315 \\
-315 \\
-315 \\
-315 \\
-315 \\
-315 \\
-315 \\
-315 \\
-315 \\
-315 \\
-315 \\
-315 \\
-315 \\
-315 \\
-315 \\
-315 \\
-315 \\
-315 \\
-315\end{array}$ & $\begin{array}{l}277 \\
278 \\
279 \\
280 \\
281 \\
282 \\
283 \\
284 \\
285 \\
286 \\
287 \\
288 \\
289 \\
290 \\
291 \\
292 \\
293 \\
294 \\
295 \\
296 \\
297 \\
298 \\
299 \\
300 \\
303 \\
304\end{array}$ & $\begin{array}{l}-278 \\
-279 \\
-280 \\
-281 \\
-282 \\
-283 \\
-284 \\
-285 \\
-286 \\
-287 \\
-288 \\
-289 \\
-290 \\
-291 \\
-292 \\
-293 \\
-294 \\
-295 \\
-296 \\
-297 \\
-298 \\
-299 \\
-300 \\
-303 \\
-304 \\
-151\end{array}$ & 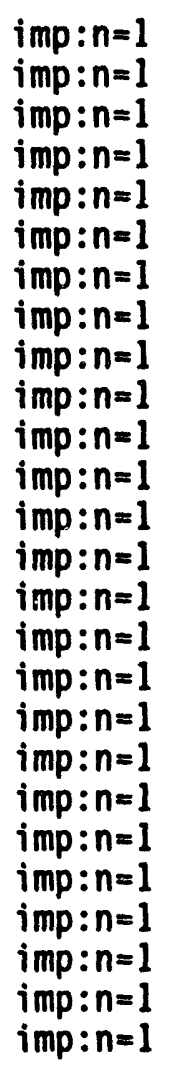 & 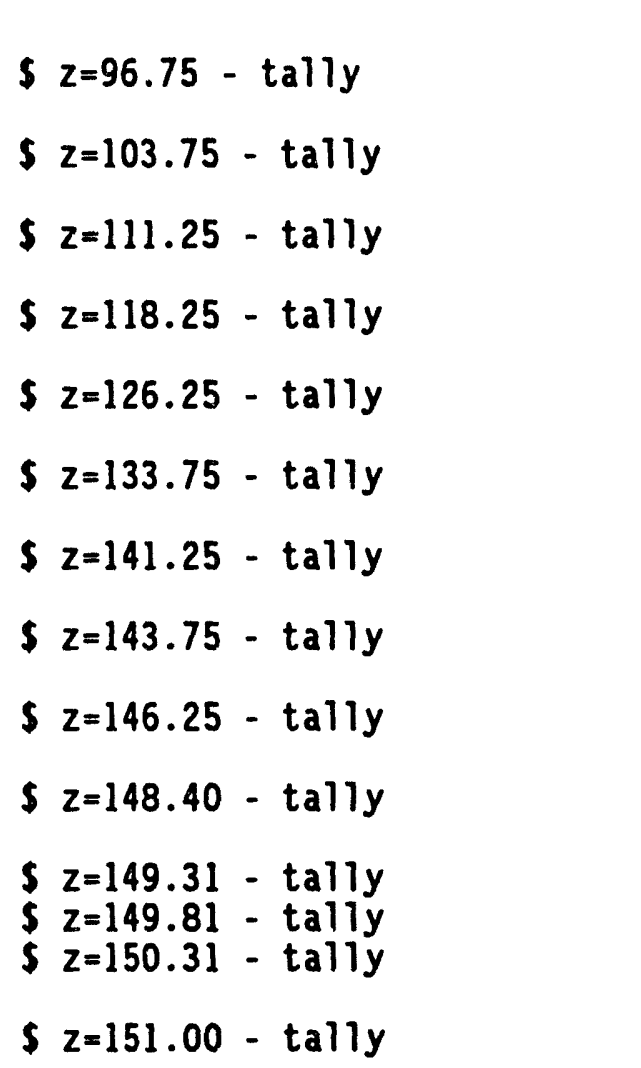 \\
\hline $\begin{array}{l}827 \\
828 \\
829 \\
830 \\
831 \\
832 \\
833 \\
834 \\
835 \\
836 \\
837 \\
838 \\
839 \\
840 \\
841 \\
842 \\
843\end{array}$ & $\begin{array}{ll}6 & 0.08 \\
6 & 0.08 \\
6 & 0.08 \\
6 & 0.08 \\
6 & 0.08 \\
6 & 0.08 \\
6 & 0.08 \\
6 & 0.08 \\
6 & 0.08 \\
6 & 0.08 \\
6 & 0.08 \\
6 & 0.08 \\
6 & 0.08 \\
6 & 0.08 \\
6 & 0.08 \\
6 & 0.08 \\
6 & 0.08 \\
6 & 0.08 \\
6 & 0.08 \\
6 & 0.08 \\
6 & 0.08 \\
6 & 0.08 \\
6 & 0.08 \\
6 & 0.08\end{array}$ & $\begin{array}{l}315 \\
316 \\
316 \\
316 \\
316 \\
316 \\
316 \\
316 \\
316 \\
316 \\
316 \\
316 \\
316 \\
316 \\
316 \\
316 \\
316 \\
316 \\
316 \\
316 \\
316 \\
316 \\
316 \\
316\end{array}$ & $\begin{array}{l}-316 \\
-317 \\
-317 \\
-317 \\
-317 \\
-317 \\
-317 \\
-317 \\
-317 \\
-317 \\
-317 \\
-317 \\
-317 \\
-317 \\
-317 \\
-317 \\
-317 \\
-317 \\
-317 \\
-317 \\
-317 \\
-317 \\
-317 \\
-317 \\
-317\end{array}$ & $\begin{array}{r}17 \\
17 \\
261 \\
262 \\
263 \\
264 \\
265 \\
267 \\
268 \\
269 \\
270 \\
271 \\
272 \\
273 \\
274 \\
275 \\
276 \\
277 \\
278 \\
279 \\
280 \\
281 \\
282\end{array}$ & $\begin{array}{l}-151 \\
-261 \\
-262 \\
-263 \\
-264 \\
-265 \\
-267 \\
-268 \\
-269 \\
-270 \\
-271 \\
-272 \\
-273 \\
-274 \\
-275 \\
-276 \\
-277 \\
-278 \\
-279 \\
-280 \\
-281 \\
-282 \\
-283 \\
-284\end{array}$ & 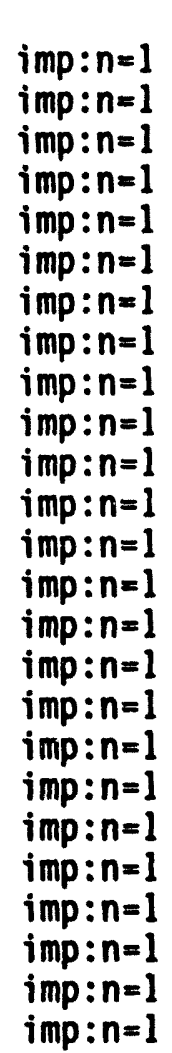 & 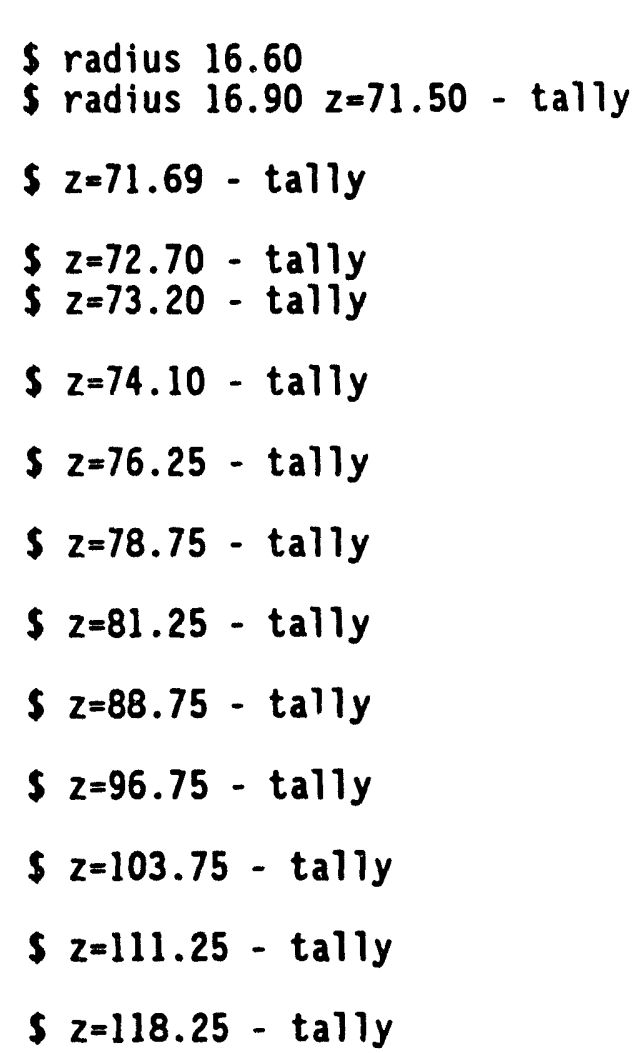 \\
\hline
\end{tabular}




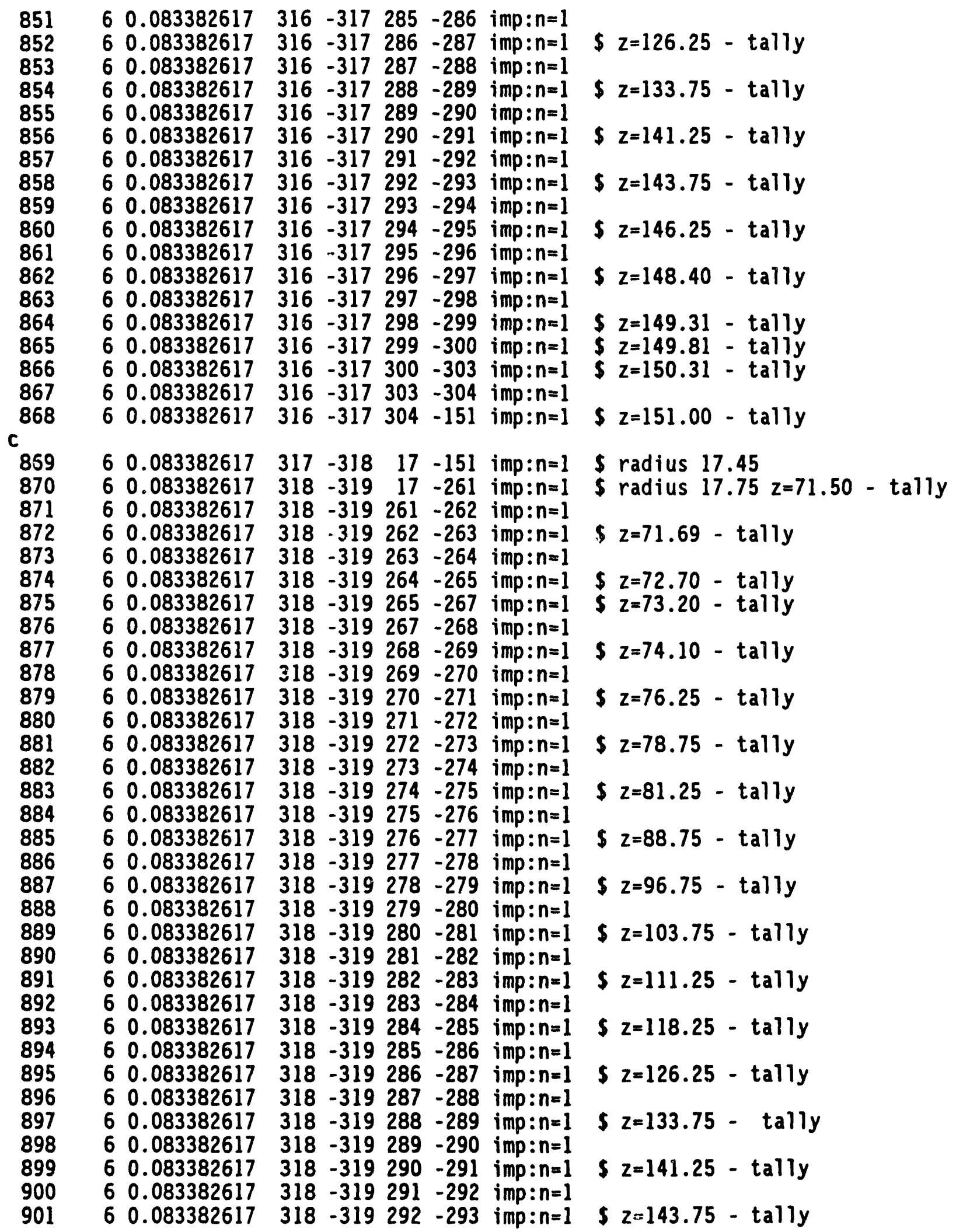




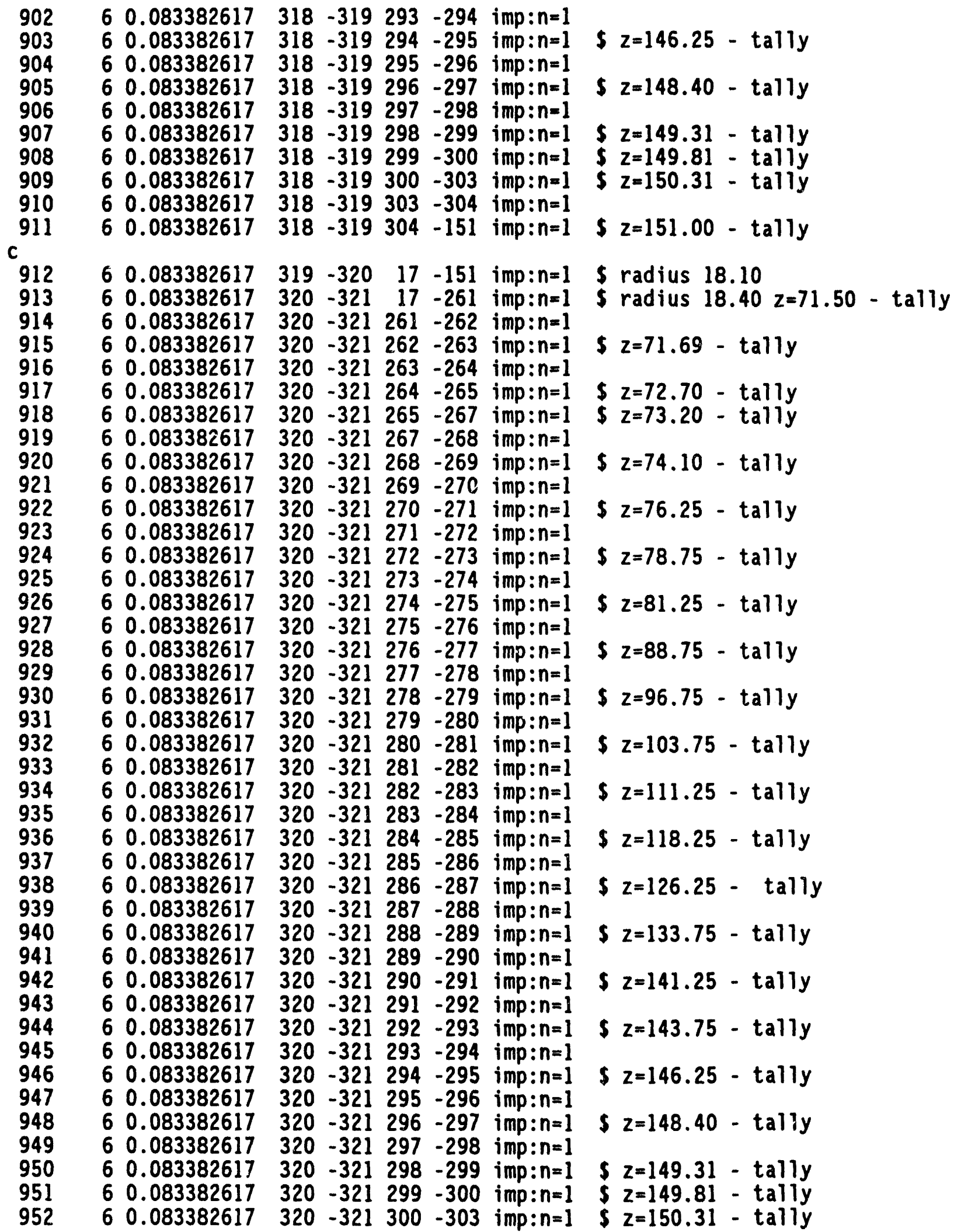




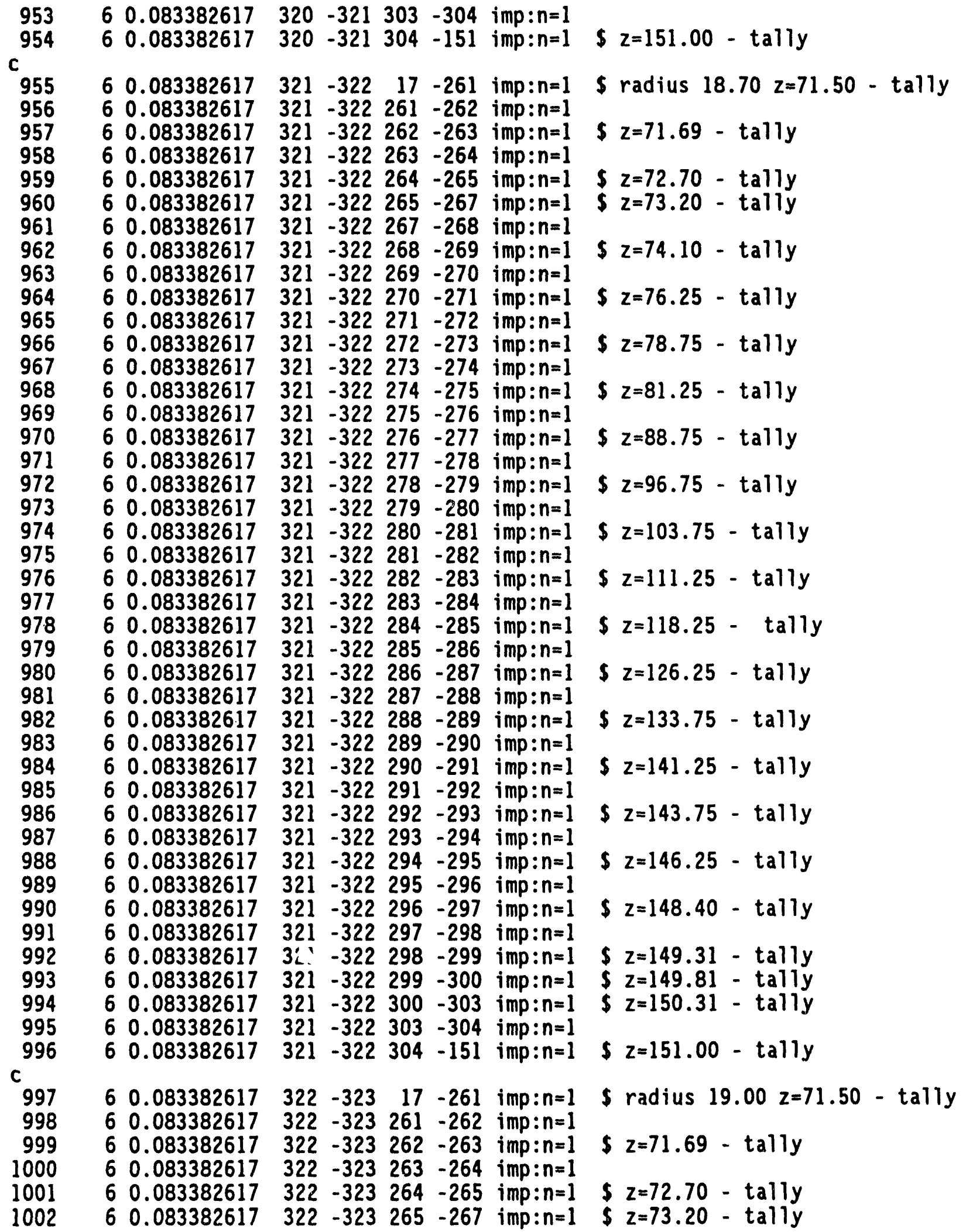


1003

1004

1005

1006

1007

1008

1009

1010

1011

1012

1013

1014

1015

1016

1017

1018

1019

1020

1021

1022

1023

1024

1025

1026

1027

1028

1029

1030

1031

1032

1033

1034

1035

1036

1037

1038 $c$

1039

1040

1041

1042

1043

1044

1045

1046

1047

1048

1049

1050

1051

1052

1053 $\begin{array}{ll}6 & 0.083382617\end{array}$

$\begin{array}{ll}6 & 0.483382617\end{array}$

$\begin{array}{ll}6 & 0.083382617\end{array}$

$\begin{array}{lll}6 & 0.083382617\end{array}$

$\begin{array}{ll}6 & 0.083382617\end{array}$

$\begin{array}{lll}6 & 0.083382617\end{array}$

$\begin{array}{lll}6 & 0.083382617\end{array}$

$\begin{array}{ll}6 & 0.083382617\end{array}$

$\begin{array}{ll}6 & 0.083382617\end{array}$

$\begin{array}{lll}6 & 0.083382617\end{array}$

$\begin{array}{lll}6 & 0.083382617\end{array}$

$\begin{array}{lll}6 & 0.083382617\end{array}$

$\begin{array}{lll}6 & 0.083382617\end{array}$

$\begin{array}{lll}6 & 0.083382617\end{array}$

$\begin{array}{ll}6 & 0.083382617\end{array}$

$\begin{array}{ll}6 & 0.083382617\end{array}$

$\begin{array}{lll}6 & 0.083382617\end{array}$

$\begin{array}{ll}6 & 0.083382617\end{array}$

$\begin{array}{ll}6 & 0.083382617\end{array}$

$\begin{array}{lll}6 & 0.083382617\end{array}$

$\begin{array}{ll}6 & 0.083382617\end{array}$

$\begin{array}{lll}6 & 0.083382617\end{array}$

$\begin{array}{lll}6 & 0.083382617\end{array}$

$\begin{array}{ll}6 & 0.083382617\end{array}$

$\begin{array}{ll}6 & 0.083382617\end{array}$

$\begin{array}{ll}6 & 0.083382617\end{array}$

$\begin{array}{ll}6 & 0.083382617\end{array}$

$\begin{array}{ll}6 & 0.083382617\end{array}$

$\begin{array}{ll}6 & 0.083382617\end{array}$

$\begin{array}{ll}6 & 0.083382617\end{array}$

$\begin{array}{ll}6 & 0.083382617\end{array}$

$\begin{array}{ll}6 & 0.083382617\end{array}$

$\begin{array}{lll}6 & 0.083382617\end{array}$

$\begin{array}{ll}6 & 0.083382617\end{array}$

$\begin{array}{lll}6 & 0.083382617\end{array}$

$\begin{array}{ll}6 & 0.083382617\end{array}$

6 0.C 73382617

$\begin{array}{lll}6 & 0.083382617\end{array}$

$\begin{array}{lll}6 & 0.083382617\end{array}$

$\begin{array}{ll}6 & 0.083382617\end{array}$

$\begin{array}{ll}6 & 0.083382617\end{array}$

$\begin{array}{ll}6 & 0.083382617\end{array}$

$\begin{array}{lll}6 & 0.083382617\end{array}$

$\begin{array}{lll}6 & 0.083382617\end{array}$

$\begin{array}{lll}6 & 0.083382617\end{array}$

$\begin{array}{lll}6 & 0.083382617\end{array}$

$\begin{array}{lll}6 & 0.083382617\end{array}$

$\begin{array}{ll}6 & 0.083382617\end{array}$

$\begin{array}{lll}6 & 0.083382617\end{array}$

$\begin{array}{lll}6 & 0.083382617\end{array}$

$\begin{array}{ll}6 & 0.083382617\end{array}$ $\begin{array}{llll}322 & -323 & 267 & -268 \text { imp : } n=1\end{array}$

$322-323268-269$ imp: $n=1$

$\begin{array}{llll}322 & -323 & 269 & -270 \\ \text { imp: } n=1\end{array}$

$\begin{array}{llll}322 & -323 & 270 & -271 \\ 3 m p: n=1\end{array}$

$\begin{array}{llll}322 & -323 & 271 & -272 \\ 3 m p: n=1\end{array}$

$\begin{array}{llll}322 & -323 & 272 & -273 \\ \text { imp: } n=1\end{array}$

$\begin{array}{llll}322 & -323 & 273 & -274 \\ 3 m p: n=1\end{array}$

$\begin{array}{llll}322 & -323 & 274 & -275 \\ 3 & \text { imp: } n=1\end{array}$

$\begin{array}{lllll}322 & -323 & 275 & -276 & \text { imp: } n=1\end{array}$

$\begin{array}{llll}322 & -323 & 276 & -277 \text { imp: } n=1\end{array}$

$\begin{array}{llll}322 & -323 & 277 & -278 \text { imp: } n=1\end{array}$

$322-323278-279$ imp: $n=1$

$322-323279-280$ imp: $n=1$

$322-323280-281$ imp: $n=1$

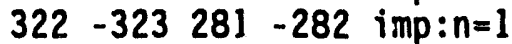

$\begin{array}{llll}322 & -323 & 282 & -283 \\ \text { imp: } n=1\end{array}$

$\begin{array}{llll}322 & -323 & 283 & -284 \\ \text { imp: } n=1\end{array}$

$\begin{array}{llll}322 & -323 & 284 & -285 \\ \text { imp: } n=1\end{array}$

$322-323285-286$ imp: $n=1$

$\begin{array}{llll}322 & -323 & 286 & -287 \\ & \text { imp: } n=1\end{array}$

$\begin{array}{llll}322 & -323 & 287 & -288 \\ & \text { imp: } n=1\end{array}$

$\begin{array}{llll}322 & -323 & 288 & -289 \\ & \text { imp: } n=1\end{array}$

$322-323289-290$ imp: $n=1$

$322-323290-291$ imp: $n=1$

$\begin{array}{llll}322 & -323 & 291 & -292 \\ \text { imp: } n=1\end{array}$

$\begin{array}{llll}322 & -323 & 292 & -293 \\ \text { imp: } n=1\end{array}$

$322-323293-294$ imp: $n=1$

$\begin{array}{llll}322 & -323 & 294 & -295 \\ & \text { imp: } n=1\end{array}$

$322-323295-296$ imp: $n=1$

$\begin{array}{llll}322 & -323 & 296 & -297 \text { imp: } n=1\end{array}$

$\begin{array}{llll}322 & -323 & 297 & -298 \text { imp: } n=1\end{array}$

322. $-323298-299$ imp: $n=1$

$\begin{array}{llll}322 & -323 & 299 & -300 \\ & \text { imp: } n=1\end{array}$

$\begin{array}{llll}322 & -323 & 300 & -303 \text { imp: } n=1\end{array}$

$\begin{array}{llll}322 & -323 & 303 & -304 \\ & \text { imp: } n=1\end{array}$

$\begin{array}{lllll}322 & -323 & 304 & -151 & \text { imp: } n=1\end{array}$

$\begin{array}{lllll}323 & -324 & 17 & -151 & \text { imp: } n=1\end{array}$

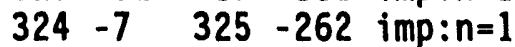

$\begin{array}{lllll}324 & -7 & 17 & -325 & \text { imp: } n=1\end{array}$

$\begin{array}{lllll}324 & -7 & 262 & -263 & \text { imp: } n=1\end{array}$

$\begin{array}{lllll}324 & -7 & 263 & -264 & \text { imp: } n=1\end{array}$

$\begin{array}{llll}324 & -7 & 264 & -265 \\ \text { imp: } n=1\end{array}$

$\begin{array}{llll}324 & -7 & 265 & -267 \\ \text { imp: } n=1\end{array}$

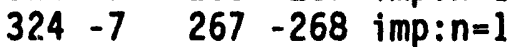

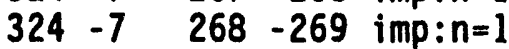

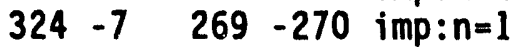

$\begin{array}{llll}324 & -7 & 270 & -271 \\ & \text { imp: } n=1\end{array}$

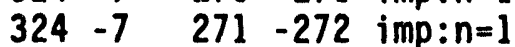

$324-7 \quad 272-273$ imp: $n=1$

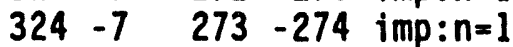

$\begin{array}{llll}324 & -7 & 274 & -275 \\ \text { imp: } n=1\end{array}$
$\$ z=74.10-$ tally

$S z=76.25-t a l l y$

\$ $z=78.75$ - tally

\$ $z=81.25$ - tally

S $z=88.75$ - tally

\$ $z=96.75$ - tally

$\$ z=103.75-t a l l y$

$\$ z=111.25-$ tally

$\$ z=118.25-\operatorname{tally}$

S $z=126.25$ - tally

S $z=133.75-\operatorname{tally}$

$\$ z=141.25-t a 11 y$

$\$ z=143.75-t a l l y$

$\$ z=146.25-t a l l y$

$\$ z=148.40-$ tally

$\$ z=149.31$ - tally

\$ $z=149.81$ - tally

\$ $z=150.31$ - tally

$\$ z=151.00-\operatorname{tally}$

$\$$ radius 19.20

$\$$ radius $19.50 z=71.50$ - tally

$\$ z=71.69-\operatorname{tally}$

$\$ z=72.70$ - tally

$\$ z=73.20$ - tally

$\$ z=74.10-\operatorname{tally}$

$\$ z=76.25$ - tally

\$ $z=78.75-$ tally

$\$ z=81.25-$ tally 


\begin{tabular}{|c|c|c|c|c|c|c|c|}
\hline $\begin{array}{l}1054 \\
1055 \\
1056 \\
1057 \\
1058 \\
1059 \\
1060 \\
1061 \\
1062 \\
1063 \\
1064 \\
1065 \\
1006 \\
1067 \\
1068 \\
1069 \\
1070 \\
1071 \\
1072 \\
1073 \\
1074 \\
1075 \\
1076 \\
1077 \\
1078 \\
1079 \\
1080 \\
1081\end{array}$ & $\begin{array}{l}6 \\
6 \\
6 \\
6 \\
6 \\
6 \\
6 \\
6 \\
6 \\
6\end{array}$ & $\begin{array}{l}0.083382617 \\
0.083382617 \\
0.083382617 \\
0.083382617 \\
0.083382617 \\
0.083382617 \\
0.083382617 \\
0.083382617 \\
0.083382617 \\
0.083382617 \\
0.083382617 \\
0.083382617 \\
0.083382617 \\
0.083382617 \\
0.083382617 \\
0.083382617 \\
0.083382617 \\
0.083382617 \\
0.083382617 \\
0.083382617 \\
0.083382617 \\
0.083382617 \\
0.083382617 \\
0.083382617 \\
0.083382617 \\
0.083382617 \\
0.083382617 \\
0.083382617\end{array}$ & $\begin{array}{ll}324 & -7 \\
324 & -7 \\
324 & -7 \\
324 & -7 \\
324 & -7 \\
324 & -7 \\
324 & -7 \\
324 & -7 \\
324 & -7 \\
324 & -7 \\
324 & -7 \\
324 & -7 \\
324 & -7 \\
324 & -7 \\
324 & -7 \\
324 & -7 \\
324 & -7 \\
324 & -7 \\
324 & -7 \\
324 & -7 \\
324 & -7 \\
324 & -7 \\
324 & -7 \\
324 & -7 \\
324 & -7 \\
324 & -7 \\
324 & -7 \\
324 & -7\end{array}$ & $\begin{array}{l}275 \\
276 \\
277 \\
278 \\
279 \\
280 \\
281 \\
282 \\
283 \\
284 \\
285 \\
286 \\
287 \\
288 \\
289 \\
290 \\
291 \\
292 \\
293 \\
294 \\
295 \\
296 \\
297 \\
298 \\
299 \\
300 \\
326 \\
303\end{array}$ & $\begin{array}{l}-276 \\
-277 \\
-278 \\
-279 \\
-280 \\
-281 \\
-282 \\
-283 \\
-284 \\
-285 \\
-286 \\
-287 \\
-288 \\
-289 \\
-290 \\
-291 \\
-292 \\
-293 \\
-294 \\
-295 \\
-296 \\
-297 \\
-298 \\
-299 \\
-300 \\
-303 \\
-151 \\
-326\end{array}$ & $\begin{array}{l}\operatorname{imp}: n=1 \\
\operatorname{imp}: n=1 \\
\operatorname{imp}: n=1 \\
\operatorname{imp}: n=1 \\
\operatorname{imp}: n=1 \\
\operatorname{imp}: n=1 \\
\operatorname{imp}: n=1 \\
\operatorname{imp}: n=1 \\
\operatorname{imp}: n=1 \\
\operatorname{imp}: n=1 \\
\operatorname{imp}: n=1 \\
\operatorname{imp}: n=1 \\
\operatorname{imp}: n=1 \\
\operatorname{imp}: n=1 \\
\operatorname{imp}: n=1 \\
\operatorname{imp}: n=1 \\
\operatorname{imp}: n=1 \\
\operatorname{imp}: n=1 \\
\operatorname{imp}: n=1 \\
\operatorname{imp}: n=1 \\
\operatorname{imp}: n=1 \\
\operatorname{imp}: n=1 \\
\operatorname{imp}: n=1 \\
\operatorname{imp}: n=1 \\
\operatorname{imp}: n=1 \\
\operatorname{imp}: n=1\end{array}$ & $\begin{array}{l}\$ z=88.75-\text { tally } \\
\$ z=96.75-\text { tally } \\
\$ z=103.75-\text { tally } \\
\$ z=111.25-\text { tally } \\
\$ z=118.25-\text { tally } \\
\$ z=126.25-\text { tally } \\
\$ z=133.75-\text { tally } \\
\text { \$ } z=141.25-\text { tally } \\
\text { \$ } z=143.75-\text { tally } \\
\text { \$ } z=146.25-\text { tally } \\
\text { \$ } z=148.40-\text { tally } \\
\text { \$ } z=149.31-\text { tally } \\
\text { \$ } z=149.81-\text { tally } \\
\text { \& } z=150.31-\text { tally } \\
\text { \$ } z=151.00-\text { tally }\end{array}$ \\
\hline \multicolumn{8}{|c|}{ Surface cells } \\
\hline $\begin{array}{r}1 \\
2 \\
3 \\
4 \\
5 \\
6 \\
7 \\
8 \\
9 \\
900 \\
10 \\
11 \\
12 \\
13 \\
14 \\
15 \\
16 \\
17 \\
18 \\
19\end{array}$ & $\begin{array}{l}\mathrm{cz} \\
\mathrm{cz} \\
\mathrm{cz} \\
\mathrm{cz} \\
\mathrm{cz} \\
\mathrm{cz} \\
\mathrm{cz} \\
\mathrm{cz} \\
\mathrm{cz} \\
\mathrm{cz} \\
\mathrm{cz} \\
\mathrm{cz} \\
\mathrm{pz} \\
\mathrm{pz} \\
\mathrm{pz} \\
\mathrm{pz} \\
\mathrm{pz} \\
\mathrm{pz} \\
\mathrm{pz} \\
\mathrm{pz}\end{array}$ & $\begin{array}{l}9.0 \\
12.1 \\
12.6 \\
13.36 \\
13.97 \\
14.0 \\
19.5 \\
19.61 \\
20.22 \\
20.28 \\
20.78 \\
40.0 \\
0.0 \\
35.0 \\
40.0 \\
13.9 \\
53.0 \\
71.0 \\
113.9 \\
154.629\end{array}$ & & & & & \\
\hline
\end{tabular}


c

C

c

tube 1

20 gq $1.2842759 \mathrm{e}-1 \quad 8.7157241 \mathrm{e}-1 \quad 1.06 .6913061 \mathrm{e}-1 \quad 1.439452 \mathrm{e}-15$ $-3.7499006 \mathrm{e}-153.9392669 \mathrm{el} 1.0262141 \mathrm{e} 2-1.72 \mathrm{e} 21.0360484 \mathrm{e} 4$

21 p $\quad-9.3358043 e-13.5836795 e-1 \quad-2.0083436 e-158.6802007$

$22 \mathrm{p} \quad-9.3358043 \mathrm{e}-1 \quad 3.5836795 \mathrm{e}-1 \quad-2.0083436 \mathrm{e}-15 \quad 9.1680201 \mathrm{el}$

$23 \mathrm{gq} \quad 1.2842759 \mathrm{e}-1 \quad 8.7157241 \mathrm{e}-1 \quad 1.0 \quad 6.6913061 \mathrm{e}-1 \quad 1.439452 \mathrm{e}-15$ $-3.7499006 \mathrm{e}-153.9392669 \mathrm{el} 1.0262141 \mathrm{e} 2-1.72 \mathrm{e} 21.0357444 \mathrm{e} 4$

c

c

C

24 gq $3.126967 e-1 \quad 6.873033 e-1 \quad 1.09 .2718385 e-1 \quad 1.0536957 e-15$ $-1.5621681 \mathrm{e}-15 \quad 5.1328843 \mathrm{el} \quad 7.609814 \mathrm{el}-1.72 \mathrm{e} 29.4773943 \mathrm{e} 3$

25 p $\quad-8.2903757 e-1 \quad 5.591929 e-1 \quad-9.4215763 e-162.4408518 \mathrm{el}$

26 p $\quad-8.2903757 \mathrm{e}-1 \quad 5.591929 \mathrm{e}-1 \quad-9.4215763 \mathrm{e}-16 \quad 1.0090852 \mathrm{e} 2$

27 gq $3.126967 \mathrm{e}-1 \quad 6.873033 \mathrm{e}-1 \quad 1.09 .2718385 \mathrm{e}-1 \quad 1.0536957 \mathrm{e}-15$ $-1.5621681 \mathrm{e}-155.1328843 \mathrm{el} 7.609814 \mathrm{el}-1.72 \mathrm{e} 2 \quad 9.4753543 \mathrm{e} 3$

c

C

C

28 gq $9.9969541 e-1 \quad 3.048649 e-4 \quad 1.0 \quad 3.4899497 e-2 \quad-6.858948 e-15$ $1.1972403 \mathrm{e}-168.5588899 \mathrm{el} 1.4939598-2.72 \mathrm{e} 22.0302923 \mathrm{e} 4$

29 p $\quad 1.7452406 \mathrm{e}-2 \quad-9.998477 \mathrm{e}-1 \quad-3.4300148 \mathrm{e}-15-6.047901$

$30 \mathrm{p} \quad 1.7452406 \mathrm{e}-2 \quad-9.998477 \mathrm{e}-1 \quad-3.4300148 \mathrm{e}-15 \quad 9.5152099 \mathrm{el}$

31 gq $9.9969541 e-13.0458649 e-4 \quad 1.03 .4899497 e-2 \quad-6.8589848 e-15$ $1.1972403 e-168.5588899 \mathrm{el} 1.4939598-2.72 \mathrm{e} 2 \quad 2.0300883 \mathrm{e} 4$

c

c

C

32 gq $7.9389263 e-12.0610737 e-1 \quad 1.08 .0901699 \mathrm{e}-1 \quad-2.7190548 \mathrm{e}-15$ $1.3854276 \mathrm{e}-158.0036531 \mathrm{el} 4.0780649 \mathrm{el}-2.22 \mathrm{e} 21.4313227 \mathrm{e} 4$

33 p $4.539905 \mathrm{e}-1 \quad-8.9100652 \mathrm{e}-1 \quad-1.5258333 \mathrm{e}-151.5821156$

$34 \mathrm{p} \quad 4.539905 \mathrm{e}-1 \quad-8.9100652 \mathrm{e}-1 \quad-1.5258333 \mathrm{e}-15 \quad 9.2582116 \mathrm{el}$

35 gq $7.9389263 \mathrm{e}-12.0610737 \mathrm{e}-1 \quad 1.08 .0901699 \mathrm{e}-1 \quad-2.7190548 \mathrm{e}-15$ $1.3854276 \mathrm{e}-158.0036531 \mathrm{el} 4.0780649 \mathrm{el}-2.22 \mathrm{e} 21.4311187 \mathrm{e} 4$

C

C Beam tube 6

C

36 gq $6.3781868 \mathrm{e}-1 \quad 3.6218132 \mathrm{e}-1 \quad 1.0 \quad 9.612617 \mathrm{e}-1-1.0976368 \mathrm{e}-15$ $8.2712862 \mathrm{e}-16-7.8218928 \mathrm{el}-5.894219 \mathrm{el}-2.42 \mathrm{e} 21.7014096 \mathrm{e} 4$

$37 \mathrm{p} \quad 6.0181502 \mathrm{e}-1-7.986355 \mathrm{le}-1-6.8719506 \mathrm{e}-16 \quad 1.3111231 \mathrm{e}$

$38 \mathrm{p} \quad 6.0181502 \mathrm{e}-1-7.9863551 \mathrm{e}-1 \quad-6.8719506 \mathrm{e}-16 \quad 1.0111123 \mathrm{e} 2$

$39 \mathrm{gq} \quad 6.3781868 \mathrm{e}-1 \quad 3.6218132 \mathrm{e}-1 \quad 1.09 .612617 \mathrm{e}-1-1.0976368 \mathrm{e}-15$ $8.2712862 \mathrm{e}-16-7.8218928 \mathrm{e} 1-5.894219 \mathrm{el}-2.42 \mathrm{e} 21.7012056 \mathrm{e} 4$

C

C Beam tube 7

C

40 gq $9.1451879 \mathrm{e}-1 \quad 8.5481214 \mathrm{e}-2 \quad 1.0 \quad 5.591929 \mathrm{e}-1-4.433639 \mathrm{e}-15$ $1.3554995 \mathrm{e}-15-8.59927 \mathrm{e} 1-2.6290607 \mathrm{el}-2.52 \mathrm{e} 21.7872485 \mathrm{e} 4$

$41 \mathrm{p} \quad 2.923717 \mathrm{e}-1-9.5630476 \mathrm{e}-1 \quad-2.3181099 \mathrm{e}-15 \quad 5.4849705$

42 p $2.923717 \mathrm{e}-1 \quad-9.5630476 \mathrm{e}-1 \quad-2.3181099 \mathrm{e}-15 \quad 1.0298497 \mathrm{e} 2$ 
43 gq $9.1451879 \mathrm{e}-1 \quad 8.5481214 \mathrm{e}-2 \quad 1.0 \quad 5.591929 \mathrm{e}-1 \quad-4.433639 \mathrm{e}-15$ $1.3554995 \mathrm{e}-15-8.59927 \mathrm{e} 1-2.6290607 \mathrm{el}-2.52 \mathrm{e} 2 \quad 1.7870445 \mathrm{e} 4$

c

C Beam tube 8

C

44 gq $4.1317591 \mathrm{e}-1 \quad 5.8682409 \mathrm{e}-1 \quad 1.0-9.8480775 \mathrm{e}-1 \quad-6.3236299 \mathrm{e}-15$

$-7.5362086 \mathrm{e}-15-6.086621 \mathrm{el} 7.2537524 \mathrm{el}-1.72 \mathrm{e} 29.612597 \mathrm{e} 3$

45 p $7.6604444 \mathrm{e}-1 \quad 6.4278761 \mathrm{e}-1 \quad 4.9189108 \mathrm{e}-15$-8.264593e-1

$46 \mathrm{p} \quad 7.6604444 \mathrm{e}-1 \quad 6.4278761 \mathrm{e}-1 \quad 4.9189108 \mathrm{e}-158.747354 \mathrm{e}$

47 gq $4.1317591 \mathrm{e}-1 \quad 5.8682409 \mathrm{e}-1 \quad 1.0-9.8480775 \mathrm{e}-1-6.3236299 \mathrm{e}-15$ $-7.5362086 \mathrm{e}-15-6.086621 \mathrm{el} 7.2537524 \mathrm{el}-1.72 \mathrm{e} 2 \quad 9.610557 \mathrm{e} 3$

C

c Beam tube 9

C

48 gq $2.2040355 e-17.7959645 e-1 \quad 1.0-8.2903757 e-1 \quad-4.433639 e-15$ $-8.3384622 \mathrm{e}-151.0625745 \mathrm{e} 1-1.998412 \mathrm{el}-2.52 \mathrm{e} 21.5979068 \mathrm{e} 4$

49 p $8.8294759 \mathrm{e}-1 \quad 4.6947156 \mathrm{e}-1 \quad 4.7219463 \mathrm{e}-15 \quad 6.4344558 \mathrm{el}$

$50 \mathrm{p} \quad 8.8294759 \mathrm{e}-1 \quad 4.6947156 \mathrm{e}-1 \quad 4.7219463 \mathrm{e}-15 \quad 1.1314456 \mathrm{e} 2$

51 gq $2.2040355 \mathrm{e}-1 \quad 7.7959645 \mathrm{e}-1 \quad 1.0-8.2903757 \mathrm{e}-1 \quad-4.433639 \mathrm{e}-15$ $-8.3384622 \mathrm{e}-151.0625745 \mathrm{e} 1-1.998412 \mathrm{e} 1-2.52 \mathrm{e} 21.5977028 \mathrm{e} 4$

C

C Beam tube 10

C

52 gq $9.9513403 \mathrm{e}-1 \quad 4.8659656 \mathrm{e}-3$ i. $0 \quad 1.391731 \mathrm{e}-1-6.4630636 \mathrm{e}-15$

$4.5194143 \mathrm{e}-16-8.3130253 \mathrm{el}-5.8130336-2.52 \mathrm{e} 21.7587108 \mathrm{e} 4$

53 p $\quad-6.9756474 \mathrm{e}-2 \quad 9.9756405 \mathrm{e}-1 \quad 3.2394228 \mathrm{e}-15 \quad 4.6807504 \mathrm{el}$

$54 \mathrm{p} \quad-6.9756474 \mathrm{e}-2 \quad 9.9756405 \mathrm{e}-13.2394228 \mathrm{e}-151.000075 \mathrm{e} 2$

55 gq $9.9513403 \mathrm{e}-1 \quad 4.8659656 \mathrm{e}-3 \quad 1.0 \quad 1.391731 \mathrm{e}-1 \quad-6.4630636 \mathrm{e}-15$

$4.5194143 \mathrm{e}-16 \quad-8.3130253 \mathrm{e} 1-5.8130336-2.52 \mathrm{e} 2 \quad 1.7585068 \mathrm{e} 4$

C

c Beam tube 11

C

56 gq $7.1658198 \mathrm{e}-12.7414644 \mathrm{e}-1 \quad 1.09 .0712729 \mathrm{e}-1-1.9013903-15$

$1.1881205 \mathrm{e}-15-8.6309466-6.0130121-1.82 \mathrm{e} 28.3011438 \mathrm{e} 3$

$57 \mathrm{p} \quad-5.2991926 \mathrm{e}-18.480481 \mathrm{e}-1 \mathrm{1} 1.1107409 \mathrm{e}-154.9544795 \mathrm{el}$

$58 \mathrm{p} \quad-5.2991926 \mathrm{e}-18.480481 \mathrm{e}-1 \mathrm{1} 1.1107409 \mathrm{e}-151.0834479 \mathrm{e} 2$

59 gq $7.1658198 \mathrm{e}-12.7414644 \mathrm{e}-1 \quad 1.09 .0712729 \mathrm{e}-1-1.9013903 \mathrm{e}-15$

$1.1881205 \mathrm{e}-15-8.6105367-6.0456754-1.82 \mathrm{e} 2 \quad 8.3000121 \mathrm{e} 3$

C

C

Beam tube 13

C

60 gq $2.5 \mathrm{e}-1 \quad 7.5 \mathrm{e}-1 \quad 1.0-8.660254 \mathrm{e}-1 \quad-4.7694522 \mathrm{e}-15$

$-8.2609336 \mathrm{e}-15-5.8232221 \mathrm{el} 1.0086117 \mathrm{e} 2-1.62 \mathrm{e} 2 \quad 9.9269916 \mathrm{e} 3$

$61 \mathrm{p} \quad 8.660254 \mathrm{e}-1 \quad 5.0 \mathrm{e}-1 \quad 4.7694522 \mathrm{e}-15-8.9738835 \mathrm{e} 1$

$62 \mathrm{p} \quad 8.660254 \mathrm{e}-1 \quad 5.0 \mathrm{e}-1 \quad 4.7694522 \mathrm{e}-158.8661165 \mathrm{el}$

63 gq $2.5 \mathrm{e}-17.5 \mathrm{e}-1 \mathrm{1} 1.0-8.660254 \mathrm{e}-1-4.7694522 \mathrm{e}-15$

$-8.2609336 \mathrm{e}-15-5.8232221 \mathrm{el} 1.0086117 \mathrm{e} 2-1.62 \mathrm{e} 29.9249516 \mathrm{e} 3$

C

c Cold source - cell 14

C

$64 \mathrm{c} / \mathrm{z}-6.18 \mathrm{e} 13.28 \mathrm{el} 1.5$

$65 \mathrm{c} / \mathrm{z}-6.18 \mathrm{el} 3.28 \mathrm{el} 1.6$ 


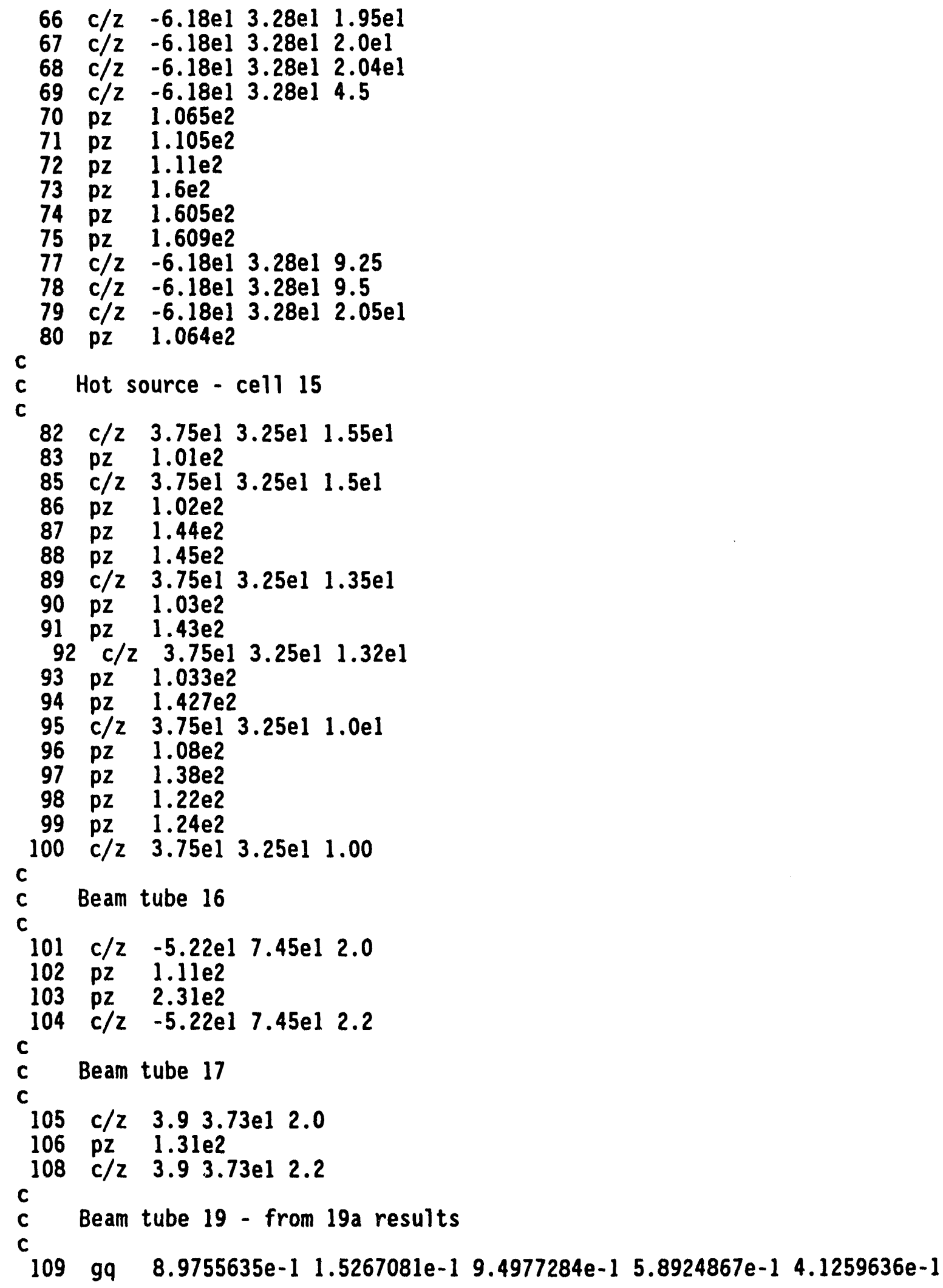




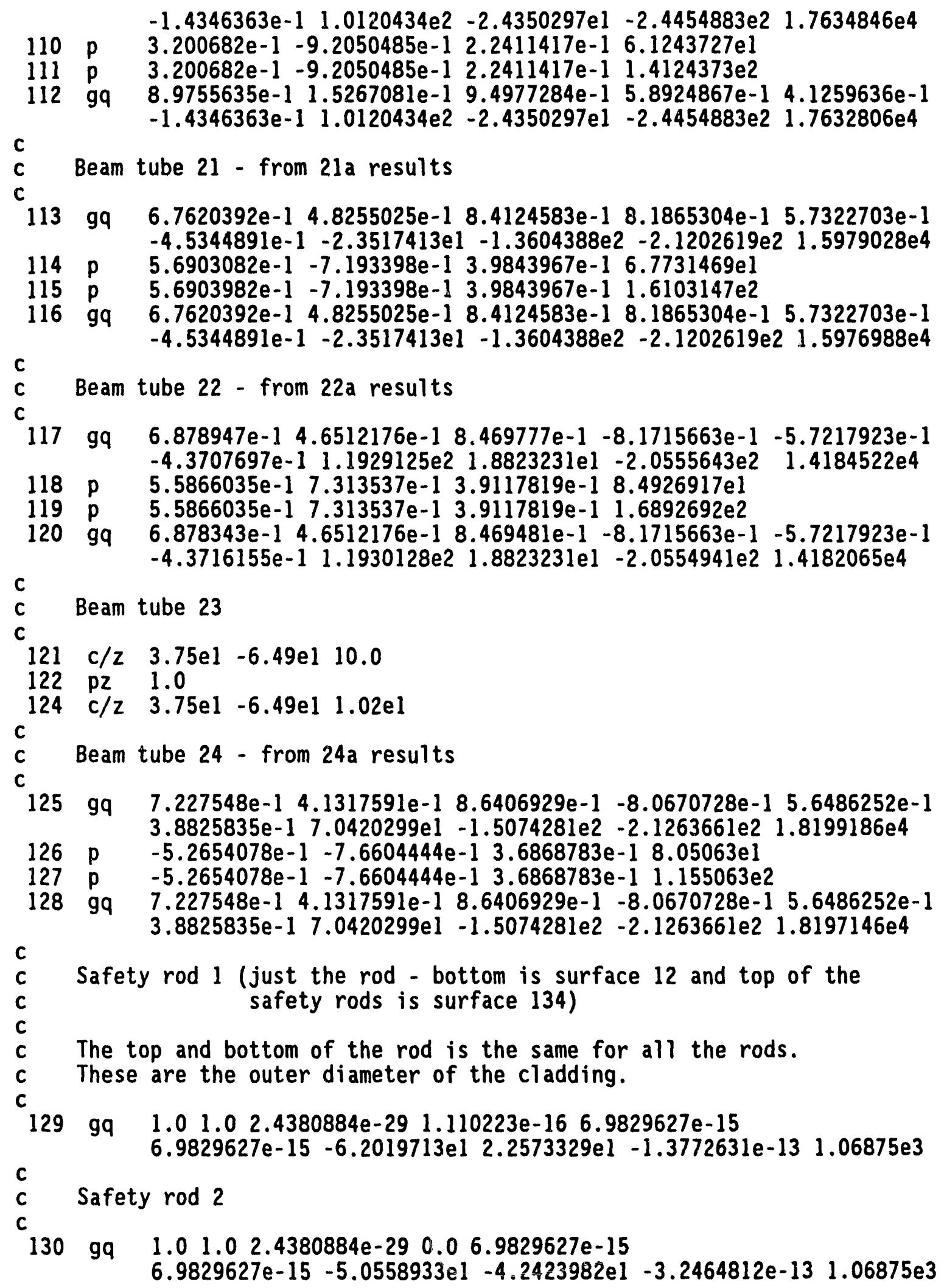


104

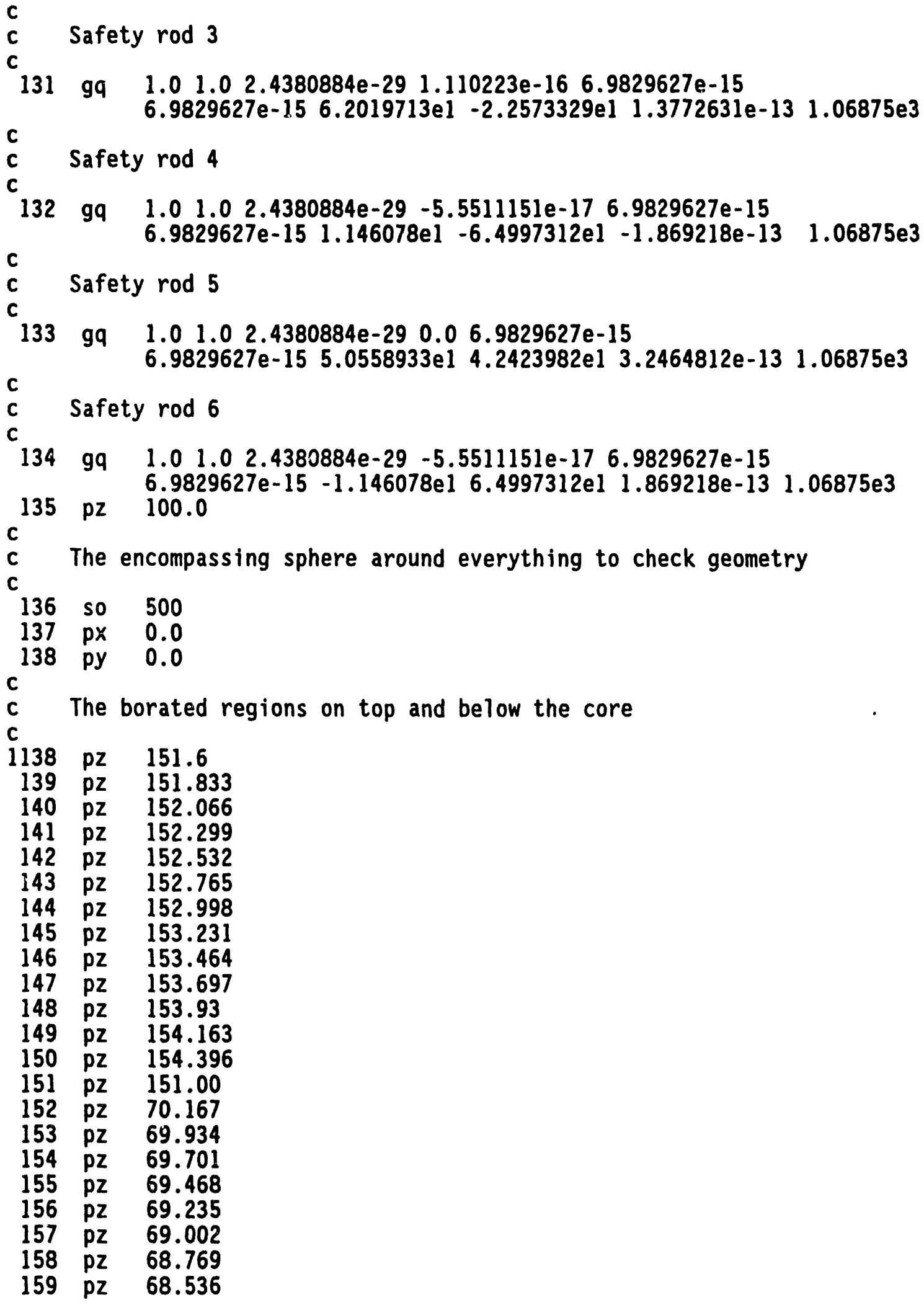




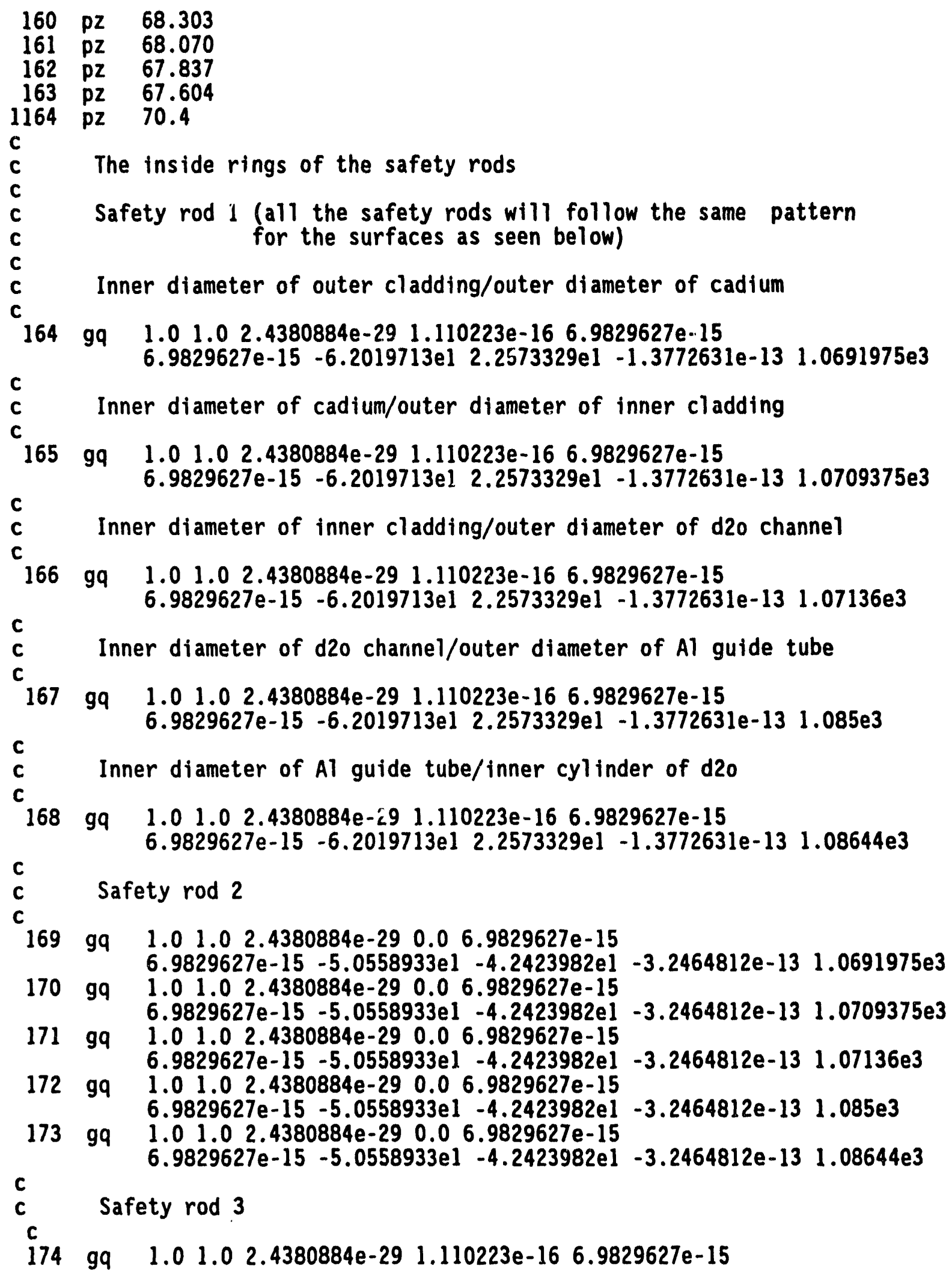


$6.9829627 \mathrm{e}-15 \quad 6.2019713 \mathrm{e} 1-2.2573329 \mathrm{el} \quad 1.3772631 \mathrm{e}-13 \quad 1.0691975 \mathrm{e} 3$

$175 \mathrm{gq} \quad 1.01 .02 .4380884 \mathrm{e}-291.110223 \mathrm{e}-16 \quad 6.9829627 \mathrm{e}-15$

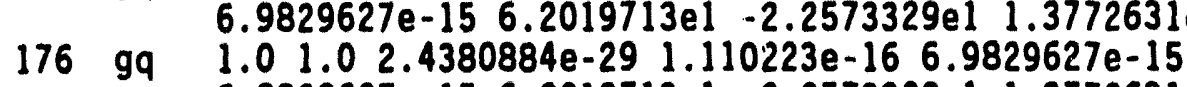

$6.9829627 \mathrm{e}-15 \quad 6.2019713 \mathrm{e} 1-2.2573329 \mathrm{e} 1 \quad 1.3772631 \mathrm{e}-13 \quad 1.07136 \mathrm{e} 3$

177 gq $\quad 1.01 .02 .4380884 \mathrm{e}-29 \quad 1.110223 \mathrm{e}-16 \quad 6.9829627 \mathrm{e}-15$

$6.9829627 \mathrm{e}-15 \quad 6.2019713 \mathrm{e} 1-2.2573329 \mathrm{el} \quad 1.3772631 \mathrm{e}-13 \quad 1.085 \mathrm{e} 3$

$178 \mathrm{gq} \quad 1.01 .02 .4380884 \mathrm{e}-291.110223 \mathrm{e}-16 \quad 6.9829627 \mathrm{e}-15$

$6.9829627 \mathrm{e}-15 \quad 6.2019713 \mathrm{e} 1-2.2573329 \mathrm{el} \quad 1.3772631 \mathrm{e}-13 \quad 1.08644 \mathrm{e} 3$

C

c

c

179 gq $\quad 1.01 .02 .4380884 \mathrm{e}-29-5.5511151 \mathrm{e}-17 \quad 6.9829627 \mathrm{e}-15$

Safety rod 4

$180 \mathrm{gq} \quad 1.01 .02 .4380884 \mathrm{e}-29-5.5511151 \mathrm{e}-176.9829627 \mathrm{e}-15$

$6.9829627 \mathrm{e}-15 \quad 1.146078 \mathrm{e} 1-6.4997312 \mathrm{e} 1-1.869218 \mathrm{e}-13 \quad 1.0691975 \mathrm{e} 3$

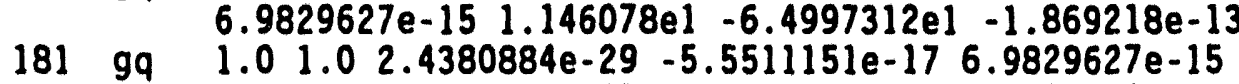

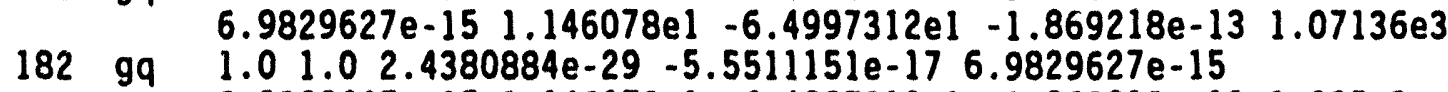

$6.9829627 \mathrm{e}-151.146078 \mathrm{e} 1-6.4997312 \mathrm{el}-1.869218 \mathrm{e}-13 \quad 1.085 \mathrm{e} 3$

$183 \mathrm{gq} \quad 1.01 .02 .4380884 \mathrm{e}-29-5.5511151 \mathrm{e}-17 \quad 6.9829627 \mathrm{e}-15$

$6.9829627 \mathrm{e}-151.146078 \mathrm{e} 1-6.4997312 \mathrm{e} 1-1.869218 \mathrm{e}-13 \quad 1.08644 \mathrm{e} 3$

C

C

C

$184 \mathrm{gq} \quad 1.01 .02 .4380884 \mathrm{e}-290.0 \quad 6.9829627 \mathrm{e}-15$

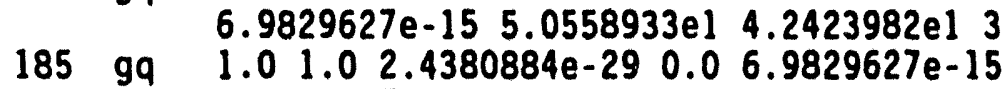

186 gq $\quad \begin{array}{llll}6.9829627 \mathrm{e}-15 & 5.0558933 \mathrm{el} & 4.2423982 \mathrm{el} 3 \\ 1.01 .02 & 2.4380884 \mathrm{e}-29 & 0.0 & 6.9829627 \mathrm{e}-15\end{array}$

$6.9829627 \mathrm{e}-15 \quad 5.0558933 \mathrm{e} 1 \quad 4.2423982 \mathrm{el} 3.2464812 \mathrm{e}-13 \quad 1.07136 \mathrm{e} 3$

$187 \mathrm{gq} \quad 1.01 .02 .4380884 \mathrm{e}-290.06 .9829627 \mathrm{e}-15$

$6.9829627 \mathrm{e}-15 \quad 5.0558933 \mathrm{el} \quad 4.2423982 \mathrm{el} \quad 3.2464812 \mathrm{e}-13 \quad 1.085 \mathrm{e} 3$

188 gq $1.01 .02 .4380884 \mathrm{e}-290.0 \quad 6.9829627 \mathrm{e}-15$

$6.9829627 \mathrm{e}-15 \quad 5.0558933 \mathrm{el} \quad 4.2423982 \mathrm{el} \quad 3.2464812 \mathrm{e}-13 \quad 1.08644 \mathrm{e} 3$

C

c Safety rod 6

C

189 gq $\quad 1.01 .02 .4380884 e-29 \quad-5.5511151 e-17 \quad 6.9829627 e-15$

$6.9829627 \mathrm{e}-15-1.146078 \mathrm{el} \quad 6.4997312 \mathrm{el} 1.869218 \mathrm{e}-13 \quad 1.0691975 \mathrm{e} 3$

$190 \mathrm{gq} \quad 1.01 .02 .4380884 \mathrm{e}-29-5.5511151 \mathrm{e}-17 \quad 6.9829627 \mathrm{e}-15$

$6.9829627 \mathrm{e}-15-1.146078 \mathrm{el} 6.4997312 \mathrm{el} 1.869218 \mathrm{e}-13 \quad 1.0709375 \mathrm{e} 3$

$191 \mathrm{gq} \quad 1.01 .02 .4380884 \mathrm{e}-29-5.5511151 \mathrm{e}-17 \quad 6.9829627 \mathrm{e}-15$

$6.9829627 \mathrm{e}-15-1.146078 \mathrm{el} 6.4997312 \mathrm{el} 1.869218 \mathrm{e}-13 \quad 1.07136 \mathrm{e} 3$

192 gq $1.01 .02 .4380884 \mathrm{e}-29-5.5511151 \mathrm{e}-17 \quad 6.9829627 \mathrm{e}-15$

$6.9829627 \mathrm{e}-15-1.146078 \mathrm{el} \quad 6.4997312 \mathrm{el} 1.869218 \mathrm{e}-13 \quad 1.085 \mathrm{e} 3$

$193 \mathrm{gq} \quad 1.01 .02 .4380884 \mathrm{e}-29-5.5511151 \mathrm{e}-17 \quad 6.9829627 \mathrm{e}-15$

$6.9829627 \mathrm{e}-15-1.146078 \mathrm{el} 6.4997312 \mathrm{el} 1.869218 \mathrm{e}-13 \quad 1.08644 \mathrm{e} 3$

C

C The reflector tank

C

$194 \mathrm{Cz} 115$ S inner diameter 


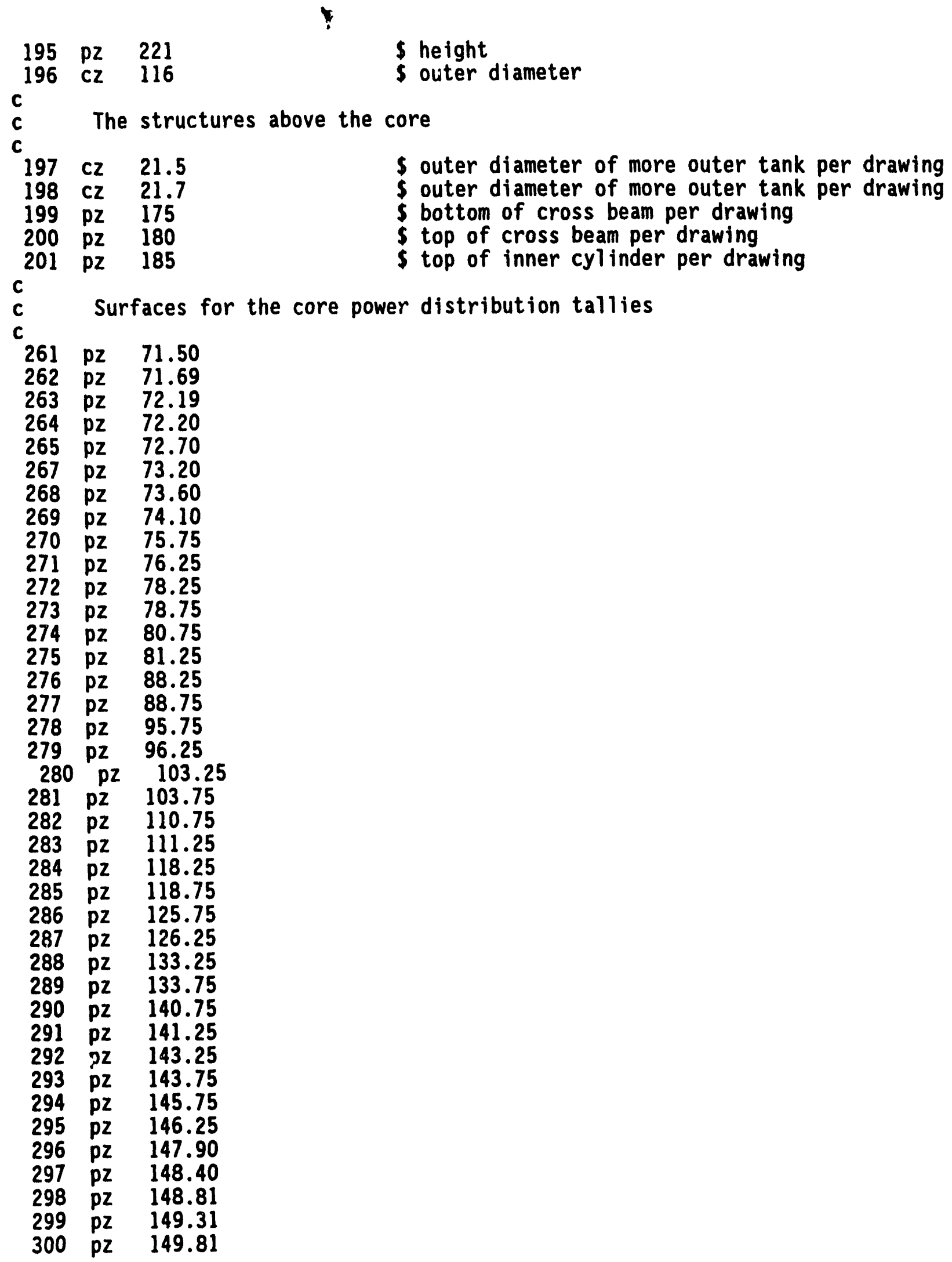




$\begin{array}{lll}303 & \mathrm{pZ} & 150.31 \\ 304 & \mathrm{pZ} & 150.50 \\ 306 & \mathrm{CZ} & 14.20 \\ 307 & \mathrm{CZ} & 14.50 \\ 308 & \mathrm{CZ} & 14.80 \\ 309 & \mathrm{CZ} & 15.10 \\ 313 & \mathrm{CZ} & 15.40 \\ 314 & \mathrm{CZ} & 15.75 \\ 315 & \mathrm{CZ} & 16.05 \\ 316 & \mathrm{CZ} & 16.60 \\ 317 & \mathrm{CZ} & 16.90 \\ 318 & \mathrm{CZ} & 17.45 \\ 319 & \mathrm{CZ} & 17.75 \\ 320 & \mathrm{CZ} & 18.10 \\ 321 & \mathrm{CZ} & 18.40 \\ 322 & \mathrm{CZ} & 18.70 \\ 323 & \mathrm{CZ} & 19.00 \\ 324 & \mathrm{CZ} & 19.20 \\ 325 & \mathrm{pZ} & 71.19 \\ 326 & \mathrm{pZ} & 150.81\end{array}$

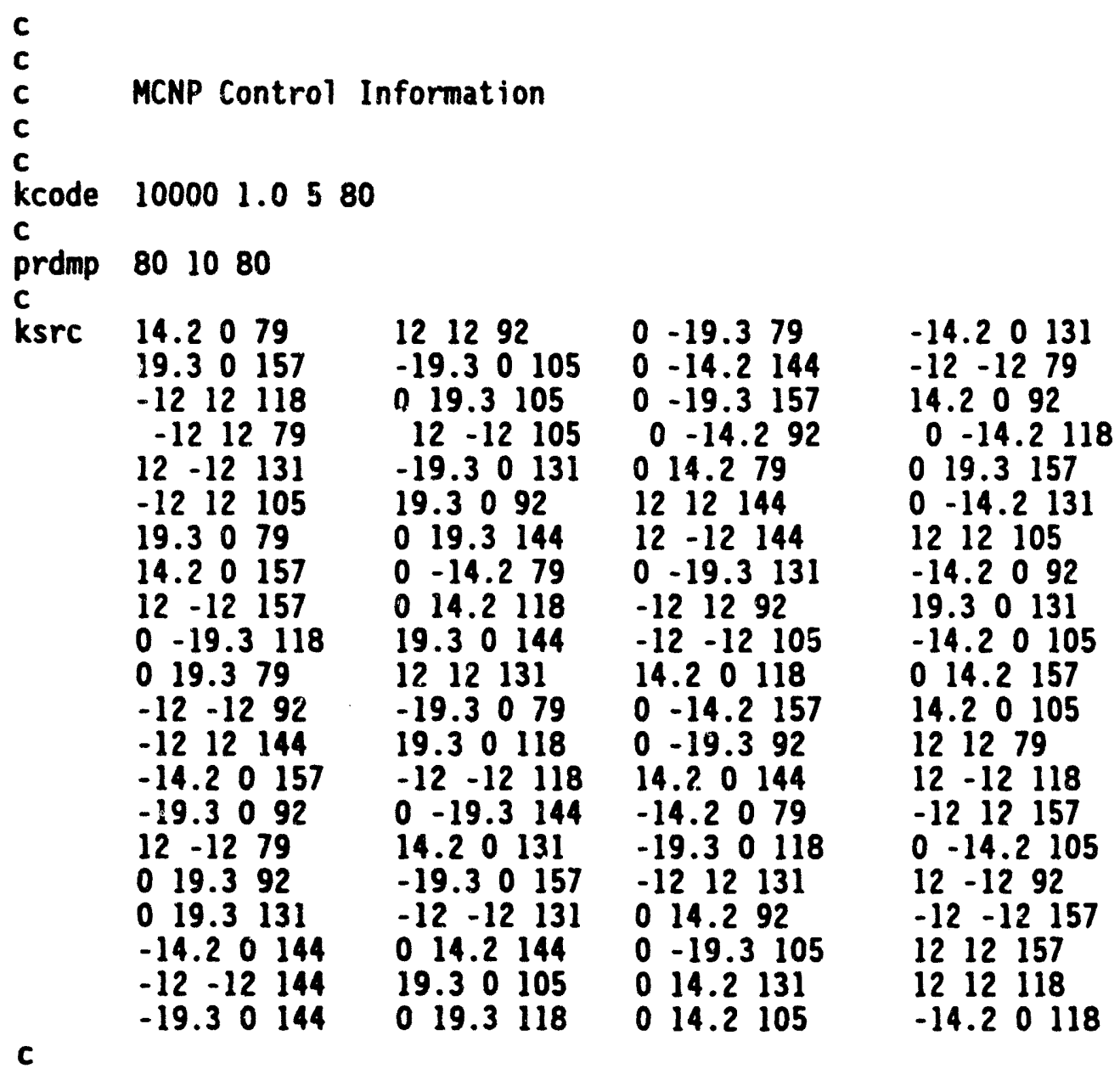




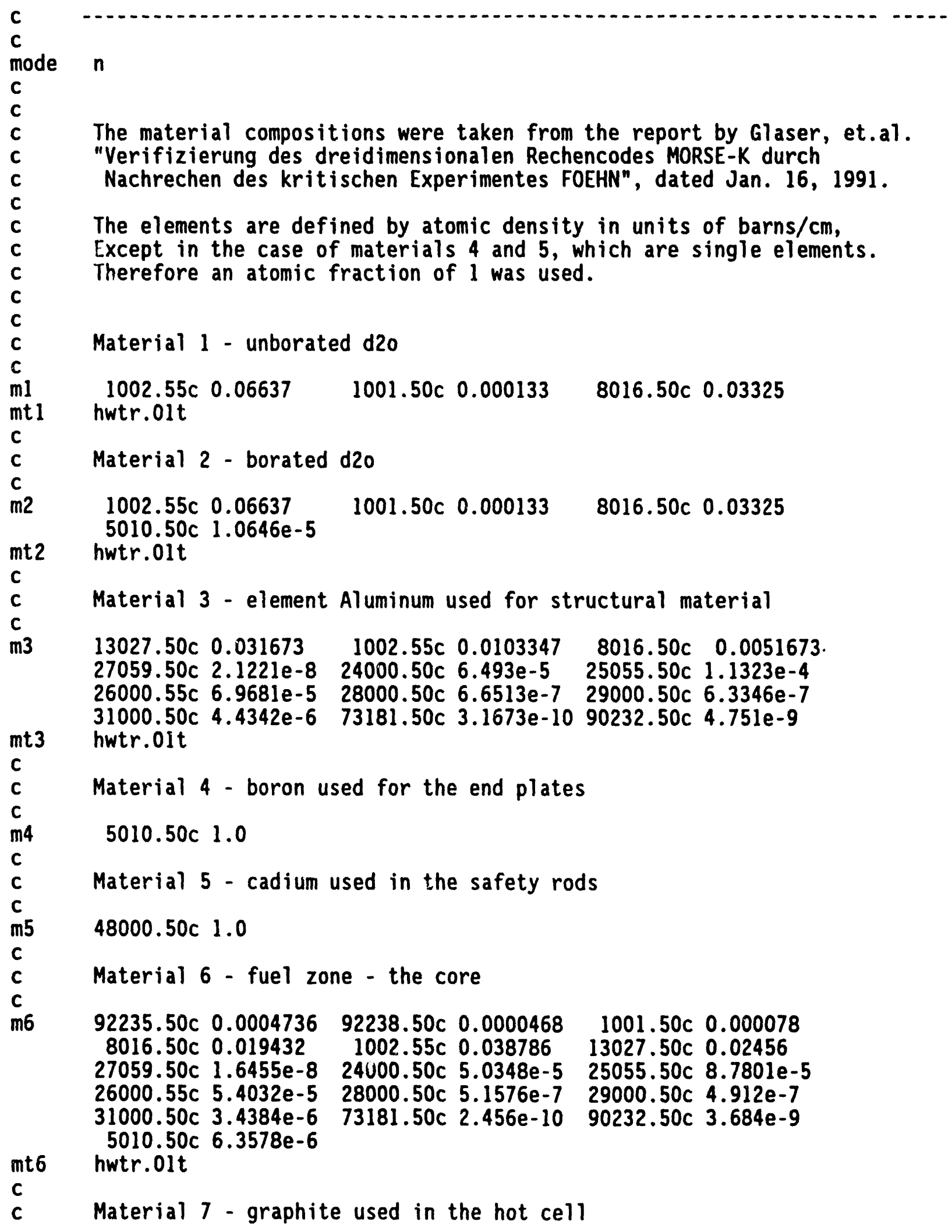




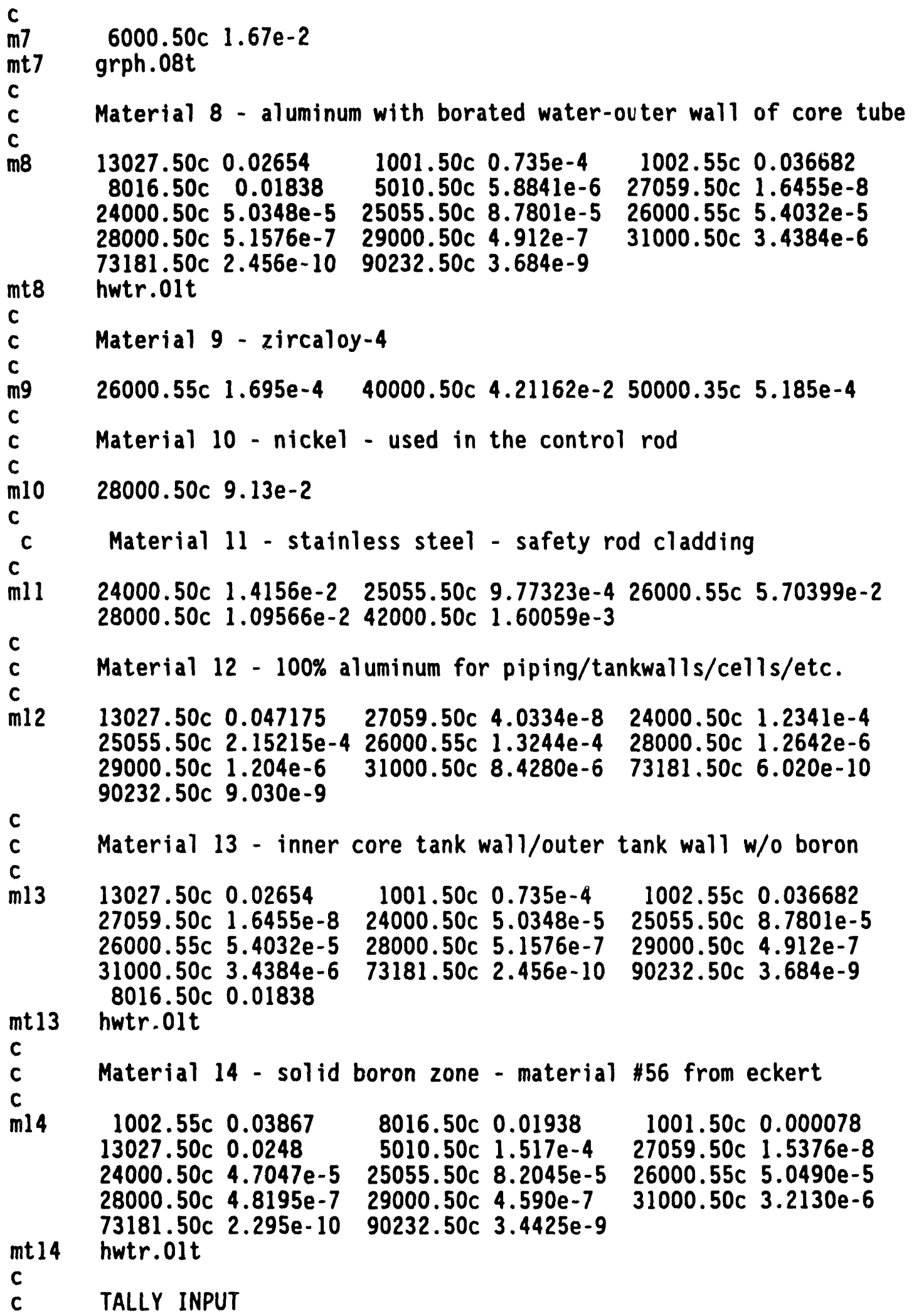


C

C

c Tallies for power at radius $14.50,14.80,15.10 \mathrm{~cm}$ at various heights

C

f7:n $\quad 615617619620622624 \quad 626 \quad 628630632634636 \quad 638640642 \quad 644646$

$\begin{array}{llllllllllllllllll}648 & 650 & 652 & 653 & 654 & 656 & 657 & 659 & 661 & 662 & 664 & 666 & 668 & 670 & 672 & 674 & 676 & 678\end{array}$

$\begin{array}{lllllllllllllllllll}680 & 682 & 684 & 686 & 688 & 690 & 692 & 694 & 695 & 696 & 698 & 699 & 701 & 703 & 704 & 706 & 708 & 710\end{array}$

$\begin{array}{llllllllllll}712 & 714 & 716718720722724726728730732734736737 & 738740\end{array}$

C

C Tallies for power at radius $15.4,16.05,16.6 \mathrm{~cm}$ at various heights

C

f17:n $741743 \quad 745746748 \quad 750752754756758760762764766768770772$

$\begin{array}{lllllllllllllllllllll}774 & 776 & 778 & 779 & 780 & 782 & 784 & 786 & 788 & 789 & 791 & 793 & 795 & 797 & 799 & 801 & 803 & 805\end{array}$

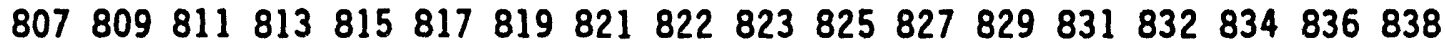

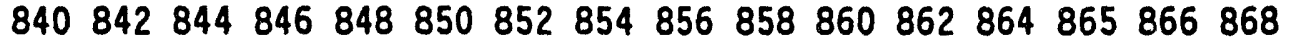

C

C Tallies for power at radius $17.75,18.40,18.70 \mathrm{~cm}$ at various heights

c

f27:n $870 \quad 872 \quad 874 \quad 875 \quad 877879881883885887889891893895897899 \quad 901$

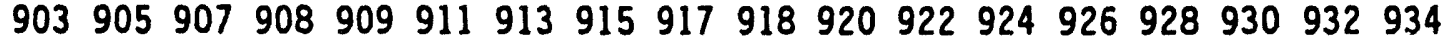

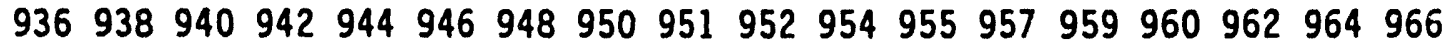
968970972974976978980982984986988990992993994996

C

c Tallies for power at radius $19.0,19.2 \mathrm{~cm}$ at various heights

c

$\begin{array}{llllllllllllll}\text { f37:n } \quad 997 & 999 & 1001 & 1002 & 1004 & 1006 & 1008 & 1010 & 1012 & 1014 & 1016 & 1018 & 1020\end{array}$

$\begin{array}{llllllllllllll}1022 & 1024 & 1026 & 1028 & 1030 & 1032 & 1034 & 1035 & 1036 & 1038 & 1040 & 1042 & 1044 & 1045\end{array}$

$\begin{array}{llllllllllllll}1047 & 1049 & 1051 & 1053 & 1055 & 1057 & 1059 & 1061 & 1063 & 1065 & 1067 & 1069 & 1071 & 1073\end{array}$

10751077107810791081 
ORNL/TM-12466

\section{INTERNAL DISTRIBUTION}

1. J. L. Anderson

2. B. R. Appleton

3. R. S. Booth

4-5. J. H. Campbell

6. R. D. Cheverton

7. H. L. Dodds

8. W. W. Engle

9. G. F. Flanagan

10. F. Gallmeier

11. J. C. Gehin

12-13. M. L. Gildner

14. R. M. Harrington

15. J. B. Hayter

16. D. T. Ingersoll

17-20. R. L. Johnson

21. K. H. King-Jones

22. R. A. Lillie
23. J. A. March-Leuba

24. T. J. McManamy

25. J. T. Mihalczo

26. T. F. Orlin

27. C. C. Queen

28. J. P. Renier

29-33. D. L. Selby

34. P. B. Thompson

35. A. W. Trivelpiece

36. C. D. West

37. G. L. Yoder

38. ORNL Patent Office

39. Central Research Library, Document Reference Section

40. Y-12 Technical Library

4i-42. Laboratory Records

43. Laboratory Records (RC)

\section{EXTERNAL DISTRIBUTION}

44. R. Awan, Division of Energy Research Reactors, Office of Nuclear Energy, Department of Energy, NE-473, Washington, DC 20585

45. P. Ageron, Institut Laue Langevin, 156X 38042, Grenoble Cedex, France

46. K. Böning, Fakultăt für Physik E21, Technische Universităt München, D-8046, Garching, Germany

47. J. Carew, Brookhaven National Laboratory, Building 475-B, Upton, NY 11973

48. J. Hendricks, Los Alamos National Laboratory, Group X6, P.O. Box 1663, Los Alamos, NM 87545

49. A. F. Henry, Professor, Department of Nuclear Engineering, Massachusetts Institute of Technology, 77 Massachusetts Avenue, Cambridge, MA 02139

50. H. C. Honeck, Computer Application Technology, Inc., 621 Colleton Avenue SE, Aiken, SC 29801

51. R. A. Hunter, Director, Office of Facilities, Fuel Cycle/Test Programs, Department of Energy, NE-47, Washington, DC 20585

52. J. A. Lake, Manager, Nuclear Engineering and Reactor Design, Idaho National Engineering Labortory, P.O. Box 1625, Idaho Falls, ID 83415

53. R. F. Lidstone, Atomic Energy of Canada, Ltd., Whiteshell Nuclear Research Establishment, Pinawa, Manitoba, ROE 1LO, Canada 
54. R. C. Little, Los Alamos National Laboratory, Group X6, P.O. Box 1663, Los Alamos, NM 87545

55. T. F. Luera, PhD Manager, Program Development, Reactor Engineering Center, Sandia National Laboratories, Dept. 65006, P.O. Box 5800, Albuquerque, NM 87185

56. M. Milgram, Atomic Energy of Canada, Ltd., Research Company, Chalk River Nuclear Laboratories, Chalk River, Ontario, K0J 1J0, Canada

57. A. M. Ougouag, Idaho National Engineering Laboratory, P.O. Box 1625, Idaho Falls, ID 83415

58. E. Redmond, Department of Nuclear Engineering, Massachusetts Institute of Technology, 77 Massachusetts Avenue, Cambridge, MA 02139

59. A. Rohrmoser, Fakultăt für Physik E21, Technische Universitẵt München, D-8046, Garching, Germany

60. G. A. Rubio, Idaho National Engineering Laboratory, P.O. Box 1625, Idaho Falls, ID 83415

61-95. J. M. Ryskamp, Idaho National Engineering Laboratory, P.O. Box 1625, Idaho Falls, ID 83415

96. E. Shirai, Department of Research Reactor Operations, Japan Atomic Energy Research Institute, Toki-mura, Naka-gun, Ibaraki-ken 319-11, Tokyo, Japan

97. C. A. Wemple, Idaho National Engineering Laboratory, P.O. Box 1625, Idaho Falls, ID 83415

98. J. G. Williams, Engineering Building, Room 104A, University of Arizona, Tucson, AZ 85719

99-103. ANS Project Office, U. S. Department of Energy, Oak Ridge Field Office, FEDC, MS-8218, P. O. Box 2009, Oak Ridge, TN 37831-8218

104. Office of Assistant Manager for Energy Research and Development, U.S. Department of Energy, Oak Ridge Field Office, P.O. Box 2001, Oak Ridge, TN 37831-2001

105. Office of Honors and Awards, P. King, P.O. Box 2008, Building 2518, MS-6324, Oak Ridge, TN $37831-6324$

106-107. Office of Scientific and Technical Information P.O. Box 62, Oak Ridge, TN 37831 

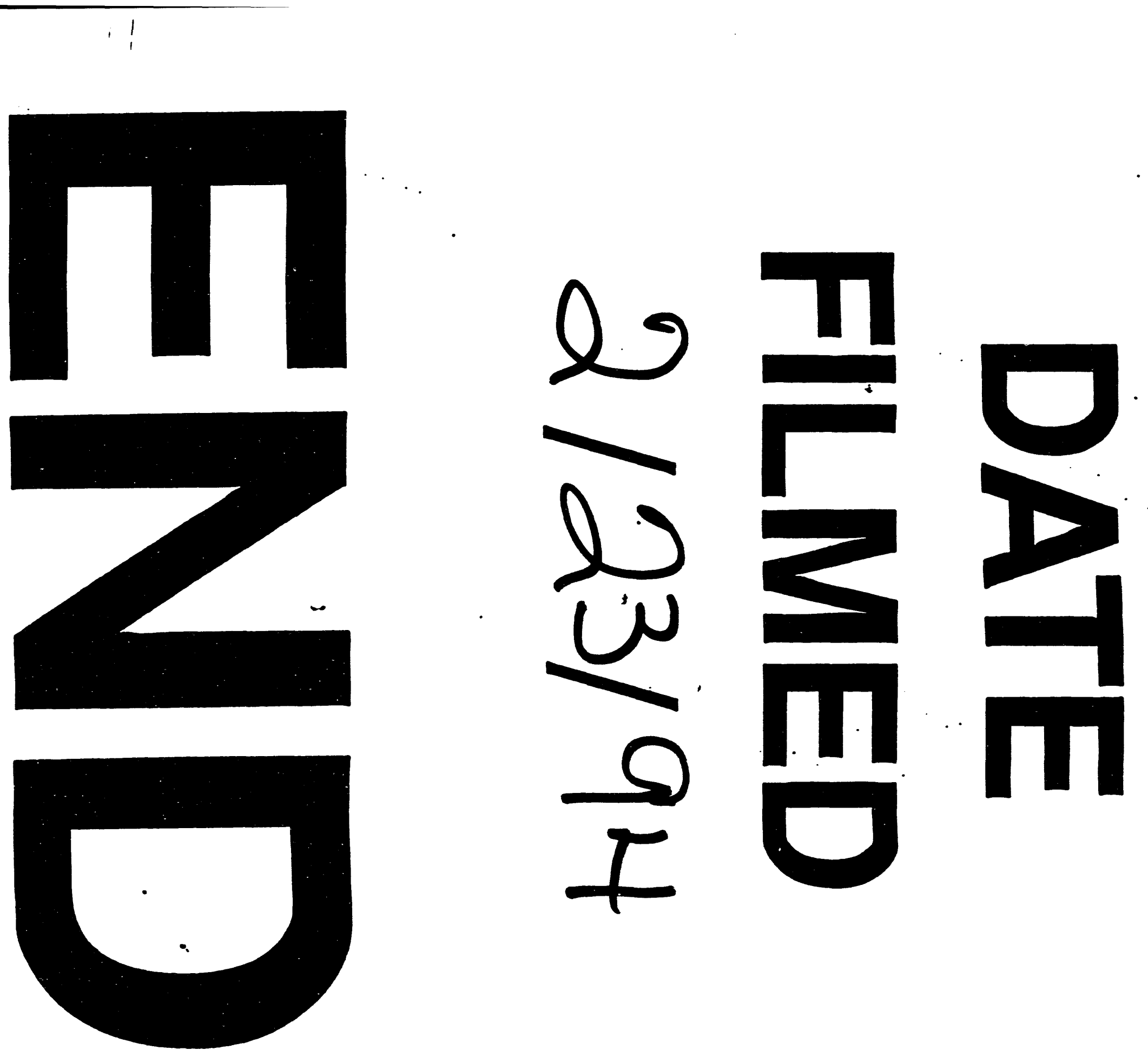


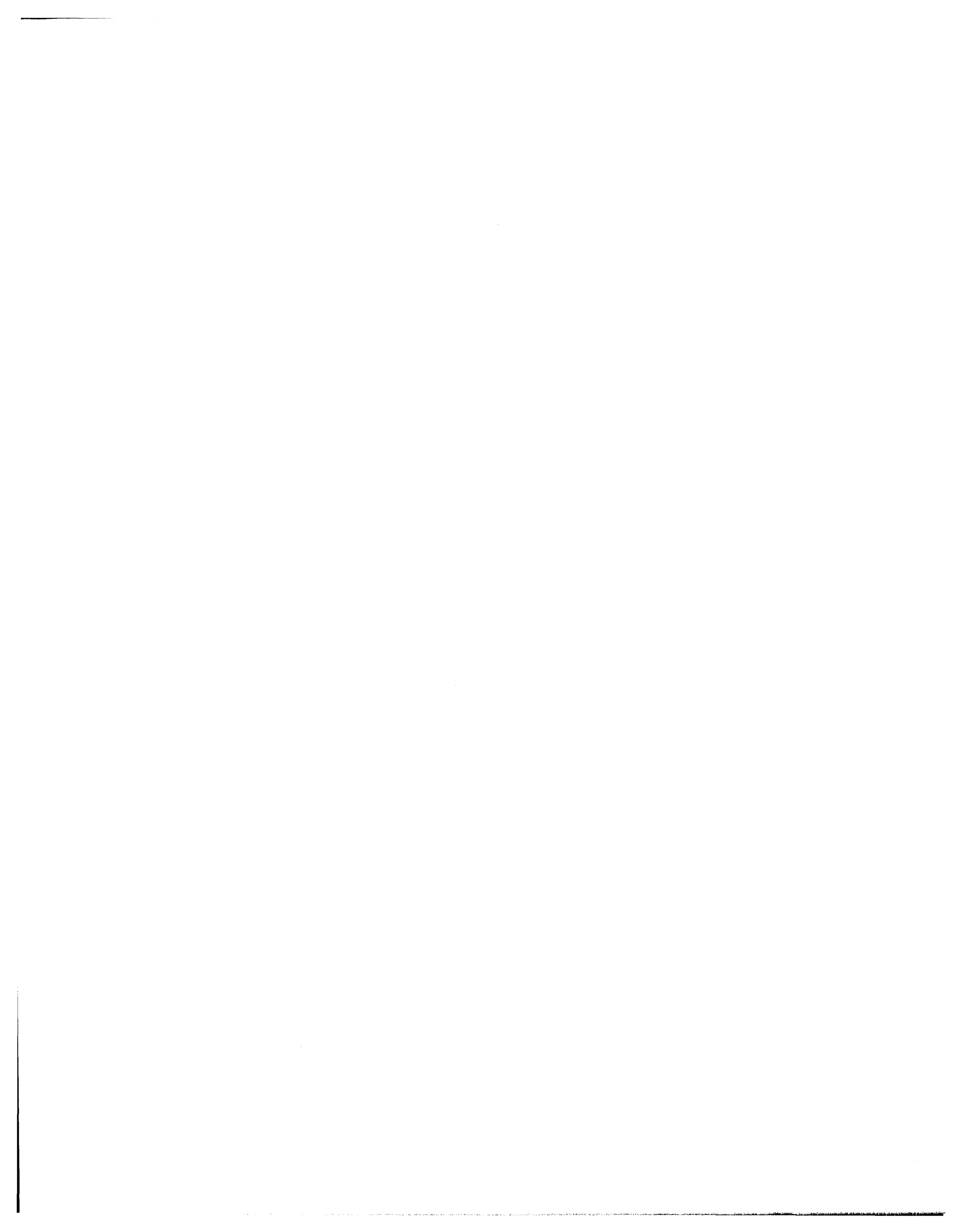

